\title{
Well ER-6-1 Tracer Test Analysis: Yucca Flat, Nevada Test Site, Nye County, Nevada
}

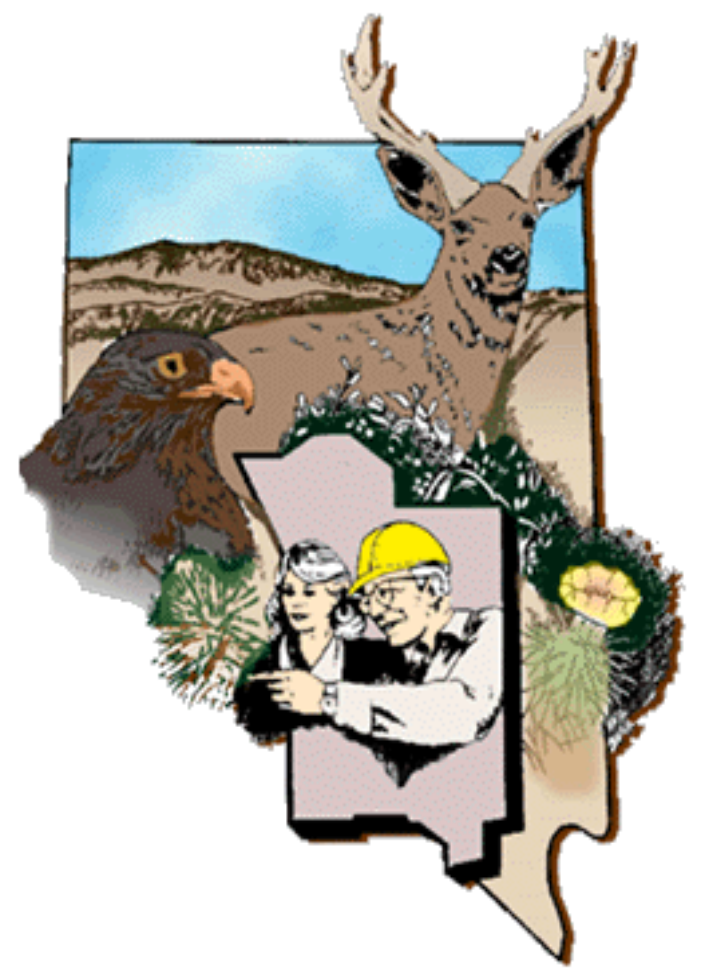

Revision No.: 0 September 2006

Prepared for U.S. Department of Energy under Contract No. DE-AC52-03NA99205.

Approved for public release; further dissemination unlimited. 
Available for public sale, in paper, from:

U.S. Department of Commerce

National Technical Information Service

5285 Port Royal Road

Springfield, VA 22161

Phone: 800.553.6847

Fax: 703.605.6900

Email: orders@ntis.gov

Online ordering: http://www.ntis.gov/ordering.htm

Available electronically at http://www.osti.gov/bridge

Available for a processing fee to U.S. Department of Energy and its contractors, in paper, from:

\author{
U.S. Department of Energy \\ Office of Scientific and Technical Information \\ P.O. Box 62 \\ Oak Ridge, TN 37831-0062 \\ Phone: 865.576.8401 \\ Fax: 865.576.5728 \\ Email: reports@adonis.osti.gov
}

Reference herein to any specific commercial product, process, or service by trade name, trademark, manufacturer, or otherwise, does not necessarily constitute or imply its endorsement, recommendation, or favoring by the United States Government or any agency thereof or its contractors or subcontractors. 


\section{WELL ER-6-1 TRACER TEST ANALYSIS: YUCCA FLAT, NEVADA TEST SITE, NYE COUNTY, NEVADA}

Contributors:

$\underline{\text { Stoller-Navarro Joint Venture }}$

Eric Bhark

Van Kelly

John Pickens

Greg Ruskauff

Los Alamos National Laboratory

Carl Gable

Paul Reimus

Velimir Vesselinov

Revision No.: 0

September 2006

Stoller-Navarro Joint Venture

7710 W. Cheyenne

Las Vegas, NV 89129

Prepared for U.S. Department of Energy under Contract No. DE-AC52-03NA99205.

Approved for public release; further dissemination unlimited. 


\section{WELL ER-6-1 TRACER TEST ANALYSIS: YUCCA FLAT, NEVADA TEST SITE, NYE COUNTY, NEVADA}




\section{TABLE OF CONTENTS}

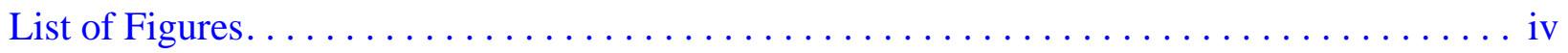

List of Tables $\ldots \ldots \ldots \ldots \ldots \ldots \ldots \ldots \ldots \ldots \ldots \ldots \ldots \ldots \ldots \ldots \ldots \ldots \ldots$ viii

List of Acronyms and Abbreviations $\ldots \ldots \ldots \ldots \ldots \ldots \ldots \ldots \ldots \ldots \ldots \ldots \ldots \ldots \ldots \ldots$

$1.0 \quad$ Introduction. . . . . . . . . . . . . . . . . .

1.1 Purpose and Objectives. . . . . . . . . . . . . . . . . . . .

1.2 Site Layout and Tracer Test Design/Implementation . . . . . . . . . . . . . . 1-2

1.3 Participants . . . . . . . . . . . . . . . . . . . . . . . .

1.4 Supporting Documents . . . . . . . . . . . . . . . . . . . 1-19

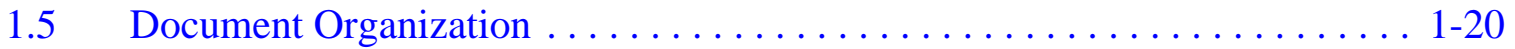

2.0 Conceptual Model of Flow and Transport in the Lower Carbonate Aquifer -

Yucca Flat. . . . . . . . . . . . . . . . . . . . . . . . . . . . . 2-1

$2.1 \quad$ Geology. .................................

2.2 Hydraulic Conceptual Model . . . . . . . . . . . . . . . . . . . . . . . . . 2-4

$2.2 .1 \quad$ Regional . . . . . . . . . . . . . . . . . . . . . . 2-4

2.2.2 Yucca Flat LCA Hydraulic Conceptual Model . . . . . . . . . . . . . . 2-7

2.2.3 Flow Logging Responses at Well Sites ER-6-1 and ER-6-1 \#2. . . . . 2-8

2.3 Fault and Fracture Characterization . . . . . . . . . . . . . . . 2-13

2.4 Transport Conceptual Model . . . . . . . . . . . . . . . . . . . . . 2-16

2.4.1 Regional Framework . . . . . . . . . . . . . . . . . . 2-16

2.4.2 General Transport Behavior and Scoping Calculations . . . . . . . . . 2-16

2.4.3 Estimated Fracture or Effective Porosity . . . . . . . . . . . . . . 2-25

2.4.4 Fluid Electrical Conductivity Analysis . . . . . . . . . . . . . 2 2-28

2.4.4.1 Borehole Peak Velocity Analysis . . . . . . . . . 2-32

2.4.4.2 Mass-Balance Analysis . . . . . . . . . . . . . 2-34

2.4.4.2.1 Zone 1 Mass Balance

(1,890 to $2,350 \mathrm{ft}$ bgs) $\ldots \ldots \ldots \ldots \ldots \ldots$. 2-35

2.4.4.2.2 Zone 2 Mass Balance

(2,350 to 2,950 ft bgs) . . . . . . . . . 2-37

2.4.5 BORE-II Simulation of Fluid Electrical Conductivity Profiles . . . . . 2-39

2.5 Semianalytic Tracer Response Analysis. . . . . . . . . . . . . . . . . 2 2-46

2.5.1 ER-6-1 Lower Zone Analysis. . . . . . . . . . . . . . . . . . . . . . . . . 2-46

2.5.2 ER-6-1 Upper Zone Analysis . . . . . . . . . . . . . . . . . 2-46

2.5.3 ER-6-1 \#1 Analysis . . . . . . . . . . . . . . . . . . 2-51

2.6 Analysis Summary . . . . . . . . . . . . . . . . . . . .

$3.0 \quad$ Numerical Model Analysis . . . . . . . . . . . . . . . . . . . . 3-1

$3.1 \quad$ Introduction. . . . . . . . . 


\section{TABle of Contents (Continued)}

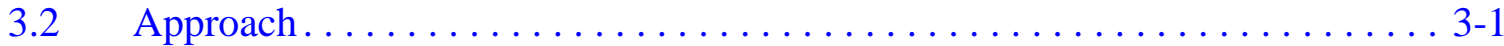

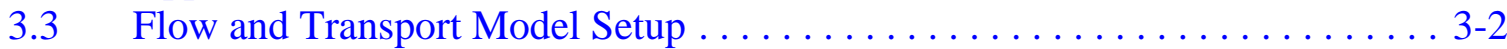

3.3.1 Mesh Generation. . . . . . . . . . . . . . . . . . . . . . . 3-3

3.3.2 Boundary Conditions .......................... 3-5

3.3.3 Initial Conditions . . . . . . . . . . . . . . . . . . 3-6

3.4 Calibration Data . . . . . . . . . . . . . . . . . . . . . . . . . . 3-7

3.4.1 Head, Drawdown, and Flow Sequences . . . . . . . . . . . . . . 3-7

3.4.2 Thermal Flow Meter Data. . . . . . . . . . . . . . . . . . . . . 3-8

3.4.3 Tracer Breakthrough. . . . . . . . . . . . . . . . . . . 3-11

3.5 Hydraulic and Tracer Test Calibration . . . . . . . . . . . . . . . . . . 3-11

3.5.1 Model Run Sequences/Setup . . . . . . . . . . . . . . . . . . . 3-11

3.6 Numerical Tracer Test Model Results . . . . . . . . . . . . . . . . . 3-18

3.6.1 Flow Calibration . . . . . . . . . . . . . . . . . . . 3-18

3.6.2 Transport Analysis . . . . . . . . . . . . . . . . . . . . 3-19

3.7 Subregional Scale Lower Carbonate Aquifer Numerical MWAT Analysis . . 3-30

3.8 Limitations of the Analysis . . . . . . . . . . . . . . . . . .

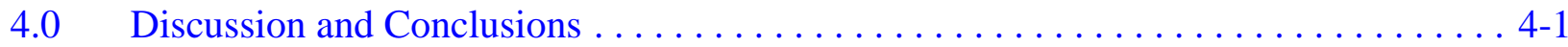

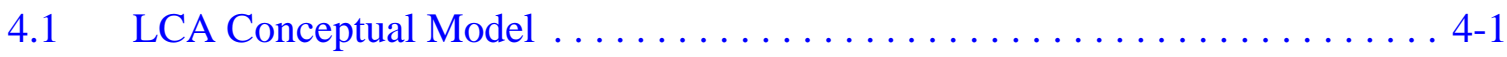

4.2 LCA Transport Parameters Review . . . . . . . . . . . . . . . 4-2

$4.3 \quad$ LCA CAU Scale Processes . . . . . . . . . . . . . . . . . 4-5

$5.0 \quad$ References..................................... . 5-1

\section{Appendix A - Sampling Analysis Review}

A.1.0 Sampling Analysis Review $\ldots \ldots \ldots \ldots \ldots \ldots \ldots \ldots \ldots \ldots \ldots \ldots \ldots \ldots \ldots \ldots$

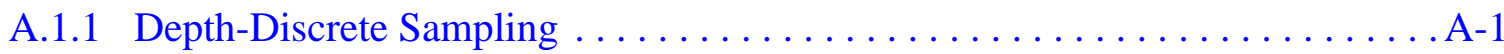

A.1.1.1 2,5-DFBA Well ER-6-1 \#2 ....................... .

A.1.1.2 2,5-DFBA Well ER-6-1 . ...................... A-3

A.1.1.3 2,5-DFBA Well ER-6-1 \#1 .......................

A.1.2 PFBA Well ER-6-1 \#2 .......................... . $\ldots \ldots$

A.1.2.1 PFBA Well ER-6-1.......................

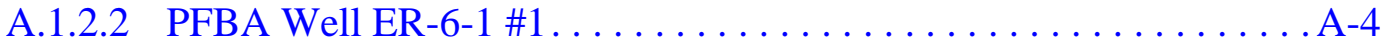

A.1.2.3 2,4,5-TFBA Well ER-6-1 \#2 . . . . . . . . . . . . . . A-4

A.1.2.4 2,4,5-TFBA Well ER-6-1 . . . . . . . . . . . . . . . A-5

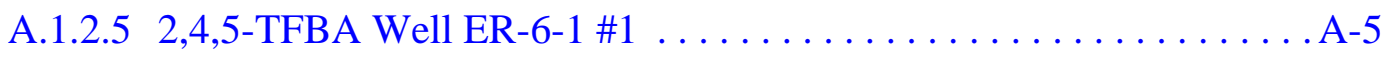

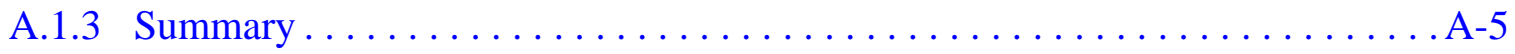

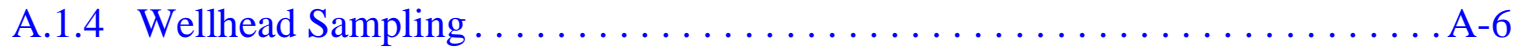

A.2.0 References..................................... A-11 


\section{TABle of Contents (Continued)}

\section{Appendix B - Power-Plane Code}

B.1.0 Description of Power-Plane Technique and the C Code X-Power. . . . . . . . . . B-1

B.2.0 C Code X-Power. . . . . . . . . . . . . . . . . . . . . . . . . . . . . . . B-3

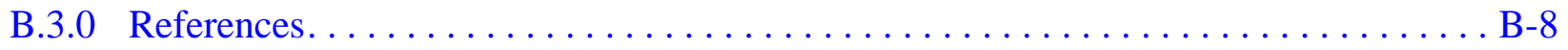




\section{LIST OF FIGURES}

NUMBER

TITLE

PAGE

1-1 Location of Well Cluster ER-6-1 and Underground Nuclear Tests, Yucca Flat . . . . 1-3

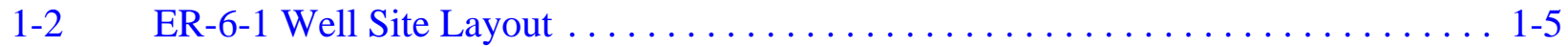

1-3 ER-6-1 Well Construction $\ldots \ldots \ldots \ldots \ldots \ldots \ldots \ldots \ldots \ldots \ldots \ldots \ldots \ldots$

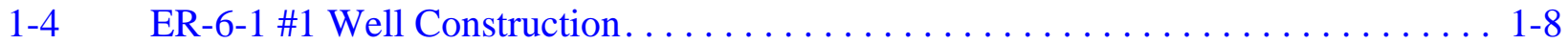

1-5 ER-6-1 \#2 Well Construction. . . . . . . . . . . . . . . . . . . . . . 1-9

1-6 2,6-DFBA Concentration History at ER-6-1 \#2 . . . . . . . . . . . . . . 1-11

1-7 ER-6-1 \#2 Tracer Breakthrough Curves from ER-6-1 Upper Interval Injection . . . 1-14

1-8 ER-6-1 \#2 Tracer Breakthrough Curves from ER-6-1 Lower Interval Injection. . . 1-16

1-9 ER-6-1 \#2 Tracer Breakthrough Curves from ER-6-1 \#1 Injection. . . . . . . . . . . 1-17

2-1 Fault Trace Map at the LCA Surface over the Areal Extent of the Observation-

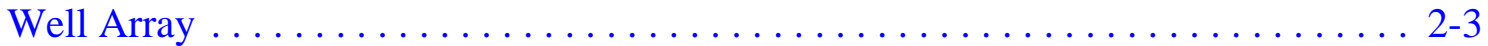

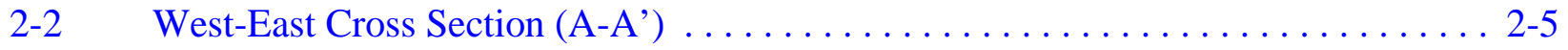

2-3 North-South Geologic Cross Section (B-B') . . . . . . . . . . . . . . . . . 2-6

2-4 Composite SFM Logs for ER-6-1 and ER-6-1 \#2 . . . . . . . . . . . 2-10

2-5 TFM Interval Flow Rates for (a) ER-6-1 and (b) ER-6-1 \#2 . . . . . . . . . . . 2-11

2-6 Composite Logs for (a) ER-6-1 \#2 and (b) ER-6-1 . . . . . . . . . . . . . . 2-14

2-7 2,4,5-TFBA, 2,6-DFBA, and Iodide Injection Mass-Normalized Breakthrough Curves at ER-6-1 \#2 . . . . . . . . . . . . . . . . . . . . . . . . . . . . 2-17

2-8 2,6-DFBA Concentration at ER-6-1 \#2 During the First Day of the Formal Tracer Test . . . . . . . . . . . . . . . . . . . . . . . . . 20

2-9 ER-6-1 \#2 Injection-Mass Normalized Breakthrough Curves for ER-6-1 Upper Zone Chemical Tracers. . . . . . . . . . . . . . . . . . . . . . 2-23

2-10 Fluid EC Logs Measured in ER-6-1 During the Fast-Path Tracer Test . . . . . . . . . 2-29 


\section{LIST OF FIGURES (CONTINUED)}

NUMBER

TITLE

PAGE

2-11 Composite Figure of ER-6-1 SFM-1 and TFM-1 Results with EC Logs

Measured During the Fast-Path Tracer Test . . . . . . . . . . . . . . 2-30

2-12 ER-6-1 In-Borehole Tracing Analysis Using EC Logs . . . . . . . . . . . . . . . 2-33

2-13 BORE-II Simulation of ER-6-1 EC Logs Assuming No Horizontal Flow within the Simulated Interval . . . . . . . . . . . . . . . . . . . 2-42

2-14 BORE-II Simulation of ER-6-1 EC Logs with TFM-1 Horizontal Flows and Best-Fit Vertical Flows . . . . . . . . . . . . . . . . . . . . .

2-15 BORE-II Simulation of ER-6-1 EC Logs with Best-Fit Vertical and Horizontal Flows. . . . . . . . . . . . . . . . . . . . . . . . . . . . . . 2-44

2-16 Comparison of Interval Horizontal Flow Rates for the TFM Analysis and for the Best-Fit BORE-II Analysis of ER-6-1 EC Logs . . . . . . . . . . . . 2-45

2-17 Single- and Dual-Porosity RELAP Fits to Iodide and 2,4,5-TFBA Tracer Breakthrough ........................... 2-47

2-18 RELAP Fit to PFBA Tracer Breakthrough. . . . . . . . . . . . . . . . . . . . 2-50

2-19 RELAP Fit to Microsphere Breakthrough . . . . . . . . . . . . . . . . 2-52

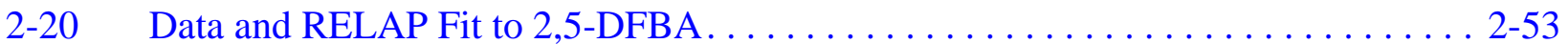

3-1 FEHM Mesh . . . . . . . . . . . . . . . . . . . . . . . .

3-2 Head, Drawdown, and Flow Sequences Defined for Calibration. . . . . . . . . . . . . 3-9

3-3 Borehole Net Interval Flows from Pumping Interference at (a) ER-6-1 and

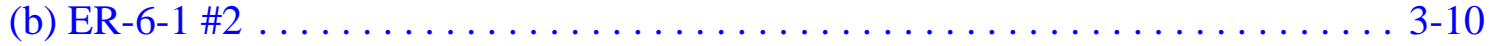

3-4 2,6-DFBA Concentration Data . . . . . . . . . . . . . . . . . . . . 3-12

3-5 Microsphere Concentration Data . . . . . . . . . . . . . . . . . 3-13

3-6 2,5-DFBA Concentration Data . . . . . . . . . . . . . . . . . . . 3-14

3-7 PFBA Concentration Data . . . . . . . . . . . . . . . . . . . . . 3-15

3-8 $\quad 2,4,5-T F B A$ Concentration Data. . . . . . . . . . . . . . . . . 


\section{LIST OF FIGURES (CONTINUED)}

NUMBER

TITLE

PAGE

3-9 Sequence of Model Runs per Single Forward Simulation of Flow and

Transport. . . . . . . . . . . . . . . . . . . . . . . . . . .

3-10 Simulated and Observed ER-6-1 MWAT-TT Drawdown Response . . . . . . . . . . 3-20

3-11 Simulated and Observed ER-6-1 \#2 MWAT-TT Drawdown Response . . . . . . . . 3-21

3-12 Estimated Discrete Feature Permeability and Confidence Limits . . . . . . . . . . . . 3-22

3-13 Discrete Feature and TFM-Calibrated Permeability Field for

(a) All Discrete Features and (b) Two Selected Discrete Features . . . . . . . . . . 3-23

3-14 ER-6-1 \#2 Simulated 2,6-DFBA (Fast-Path Test) Breakthrough Curves . . . . . . . 3-26

3-15 2,5-DFBA (ER-6-1 \#1) Numerical Model Results . . . . . . . . . . . . . . . 3-27

3-16 PFBA (Upper ER-6-1) Numerical Model Results. . . . . . . . . . . . . . . . . . . . 3-28

3-17 2,4,5-TFBA (Lower ER-6-1) Numerical Model Results . . . . . . . . . . . . . . . . . 3-29

3-18 Model Grid and Boundary Conditions for Subregional Analysis . . . . . . . . . . 3-33

3-19 Simulated and Observed ER-3-1 MWAT-TT Drawdown Response . . . . . . . . . 3-37

3-20 Simulated and Observed ER-7-1 MWAT-TT Drawdown Response . . . . . . . . . 3-38

3-21 Simulated and Observed UE-7nS, UE-1h, and U-3cn \#5 MWAT-TT

Drawdown Response . . . . . . . . . . . . . . . . . . . . . . . . 3-39

3-22 Calibrated Model Hydraulic Conductivity Distribution. . . . . . . . . . . . . . . . . . 3-40

3-23 Calibrated Model Storativity Distribution . . . . . . . . . . . . . . . . . . . . . 3-41

3-24 Log-Log Derivative for Simulated ER-7-1 Single-Well Test . . . . . . . . . . . . . 3-43

4-1 2,4,5-TFBA Breakthrough Curve Used To Identify Double Porosity and

Multirate Diffusion. . . . . . . . . . . . . . . . . . . . . . . . 4-4

4-2 Effects of Varying P1 and P2 While Holding P3 Constant . . . . . . . . . . . . 4-9

4-3 Effects of Varying P2 and P3 While Holding P1 Constant . . . . . . . . . . 4-10

A.1-1 $2,4,5-$ TFBA. . . . . . . . . . . . $\ldots \ldots \ldots \ldots \ldots \ldots \ldots \ldots \ldots \ldots \ldots \ldots \ldots \ldots$ 
Well ER-6-1 Tracer Test Analysis

\section{LIST OF FIGURES (CONTINUED)}

NUMBER

TITLE

PAGE

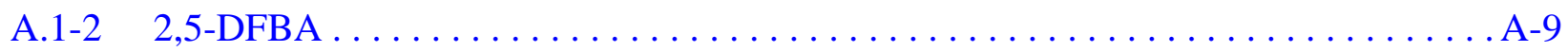

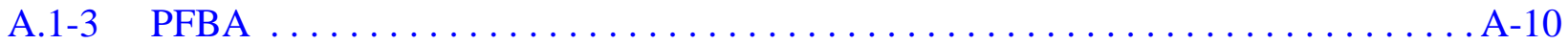




\section{LIST OF TABLES}

NUMBER

TITLE

PAGE

1-1 ER-6-1 Well Locations . . . . . . . . . . . . . . . . . . . . . . 1-4

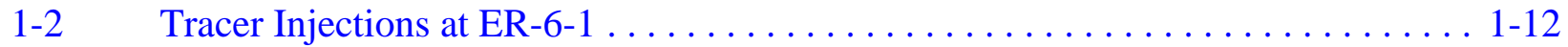

1-3 Tracer Mass Adjustment Factors . . . . . . . . . . . . . . . . . . 1-13

1-4 Estimated Tracer Mass Recoveries . . . . . . . . . . . . . . . . . . . . . 1-18

2-1 Lithologies at ER-6-1 and ER-6-1 \#2 $\ldots \ldots \ldots \ldots \ldots \ldots \ldots \ldots \ldots \ldots \ldots$

2-2 Formation and Completion Intervals at ER-6-1 $\ldots \ldots \ldots \ldots \ldots \ldots \ldots \ldots \ldots$

2-3 Interconnected Interval Determined from TFM Flow Logging. . . . . . . . . . . 2-15

2-4 Tracer Free-Water Diffusion Coefficients . . . . . . . . . . . . . . . . . . . . 2-27

2-5 Simulated Borehole Flow Rate Results of the Zone 1 (1,890 to 2,350 ft bgs)

Material Balance . . . . . . . . . . . . . . . . . . . . . 2-37

2-6 Simulated Interval Flow Rates for Zone 2 (2,350 to 2,850 ft bgs),

Logging Runs at 0 Minutes and 240 Minutes . . . . . . . . . . . . . . . . . . . 2-39

2-7 Single-Porosity Transport Parameters from RELAP for Iodide and 2,4,5-TFBA. . . 2-48

2-8 Dual-Porosity Transport Parameters from RELAP for Iodide and 2,4,5-TFBA . . . 2-48

2-9 Single-Porosity Transport Parameters from RELAP for PFBA . . . . . . . . . . 2-51

2-10 RELAP Estimated Microsphere Filtration and Detachment Rate Constants . . . . 2-51

2-11 Transport Parameters from RELAP Fit for 2,5-DFBA $\ldots \ldots \ldots \ldots \ldots \ldots \ldots .2-54$

3-1 Summary of Transport Parameters $\ldots \ldots \ldots \ldots \ldots \ldots \ldots \ldots \ldots \ldots \ldots$. . . . . . . . . . . . . .

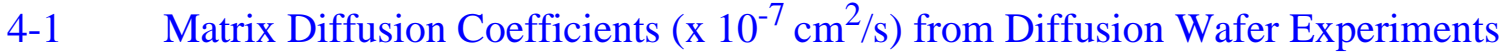
in Core Samples from ER-6-1 . . . . . . . . . . . . . . . . . . . 6 


\section{LIST OF ACRONYMS AND ABBREVIATIONS}

1-D One-dimensional

2-D Two-dimensional

3-D Three-dimensional

bgs Below ground surface

BHTV Borehole televiewer

BN Bechtel Nevada

$\mathrm{Br} \quad$ Bromide

${ }^{\circ} \mathrm{C} \quad$ Degrees Celsius

CAU Corrective Action Unit

CBPT Convolution-based particle tracking

cm Centimeter

$\mathrm{cm}^{2} / \mathrm{s} \quad$ Square centimeters per second

CS Carbon steel

DFBA Difluorobenzoic acid

DOE U.S. Department of Energy

DRI Desert Research Institute

EC Electrical conductivity

EMI Electric Micro-Imager

FBA Fluorinated benzoic acid

FEHM Finite Element Heat-Mass transfer code

FMS Formation micro-scanner

$\mathrm{ft} \quad$ Foot

$\mathrm{ft} / \mathrm{d} \quad$ Feet per day

gpm Gallons per minute

HFM Hydrostratigraphic framework model 


\section{LIST OF ACRONYMS AND ABBREVIATIONS (CONTINUED)}

\begin{tabular}{|c|c|}
\hline HPLC & High-performance liquid chromatograph \\
\hline $\mathrm{hr}$ & Hour \\
\hline HSU & Hydrostratigraphic unit \\
\hline I & Iodide \\
\hline id & Inside diameter \\
\hline in. & Inch \\
\hline JD & Julian day \\
\hline $\mathrm{K}$ & Hydraulic conductivity \\
\hline $\mathrm{kg}$ & Kilogram \\
\hline $\mathrm{kg} / \mathrm{m}^{3}$ & Kilograms per cubic meter \\
\hline $\mathrm{km}$ & Kilometer \\
\hline $\mathrm{L}$ & Liter \\
\hline LANL & Los Alamos National Laboratory \\
\hline LCA & Lower Carbonate Aquifer \\
\hline LCCU & Lower Clastic Confining Unit \\
\hline $\mathrm{Li}$ & Lithium \\
\hline $\mathrm{LiBr}$ & Lithium bromide \\
\hline $\mathrm{LiCl}$ & Lithium chloride \\
\hline $\mathrm{LiOH}$ & Lithium hydroxide \\
\hline $\mathrm{m}$ & Meter \\
\hline m/day & Meters per day \\
\hline $\mathrm{m} / \mathrm{s}$ & Meters per second \\
\hline $\mathrm{m}^{2} / \mathrm{s}$ & Square meters per second \\
\hline $\mathrm{mL}$ & Milliliter \\
\hline $\mathrm{mm}$ & Millimeter \\
\hline
\end{tabular}




\section{LIST OF ACRONYMS AND ABBREVIATIONS (CONTINUED)}

\begin{tabular}{|c|c|}
\hline $\mathrm{MPa}$ & Megapascal \\
\hline MSL & Mean sea level \\
\hline MWAT & Multiple-well aquifer test \\
\hline MWAT-TT & Multiple-well aquifer test-tracer test \\
\hline N/A & Not applicable \\
\hline $\mathrm{Na}$ & Sodium \\
\hline $\mathrm{NaCl}$ & Sodium chloride \\
\hline $\mathrm{NaI}$ & Sodium iodide \\
\hline $\mathrm{NaOH}$ & Sodium hydroxide \\
\hline NAD & North American Datum \\
\hline NNSA/NSO & $\begin{array}{l}\text { U.S. Department of Energy, National Nuclear Security Administration } \\
\text { Nevada Site Office }\end{array}$ \\
\hline NSP & Nevada State Plane \\
\hline NTS & Nevada Test Site \\
\hline od & Outside diameter \\
\hline PEST & Parameter estimation software \\
\hline PFBA & Pentafluorobenzoic acid \\
\hline $\mathrm{ppb}$ & Parts per billion \\
\hline ppm & Parts per million \\
\hline RELAP & Reactive Transport LaPlace Inversion Code \\
\hline SFM & Spinner flow meter \\
\hline SNJV & Stoller-Navarro Joint Venture \\
\hline SPTR & Streamline particle tracking \\
\hline TCU & Tuff Confining Unit \\
\hline $\mathrm{TD}$ & Total depth \\
\hline TFBA & Trifluorobenzoic acid \\
\hline
\end{tabular}


Well ER-6-1 Tracer Test Analysis

\section{LIST OF ACRONYMS AND ABBREVIATIONS (CONTINUED)}

TFM Thermal flow meter

UGTA Underground Test Area

UNLV-HRC University of Nevada Las Vegas - Harry Reid Center

UTM Universal Transverse Mercator

WIPP Waste Isolation Pilot Plant 


\subsection{InTRODUCTION}

\subsection{Purpose and Objectives}

The ER-6-1 multiple-well aquifer test-tracer test (MWAT-TT) investigated groundwater flow and transport processes relevant to the transport of radionuclides from sources on the Nevada Test Site (NTS) through the lower carbonate aquifer (LCA) hydrostratigraphic unit (HSU). The LCA, which is present beneath much of the NTS, is the principal aquifer for much of southern Nevada. This aquifer consists mostly of limestone and dolomite, and is pervasively fractured. Groundwater flow in this aquifer is primarily in the fractures, and the hydraulic properties are primarily related to fracture frequency and fracture characteristics (e.g., mineral coatings, aperture, connectivity).

The objective of the multiple-well aquifer test (MWAT) was to determine flow and hydraulic characteristics for the LCA in Yucca Flat. The data were used to derive representative flow model and parameter values for the LCA. The items of specific interest are:

- Hydraulic conductivity

- Storage parameters

- Dual-porosity behavior

- Fracture flow characteristics

The objective of the tracer transport experiment was to evaluate the transport properties and processes of the LCA and to derive representative transport parameter values for the LCA. The properties of specific interest are:

- Effective porosity

- Matrix diffusion

- Longitudinal dispersivity

- Adsorption characteristics

- Colloid transport characteristics

These properties substantially control the rate of transport of contaminants in the groundwater system and concentration distributions. To best support modeling at the scale of the corrective action 
unit (CAU), these properties must be investigated at the field scale. The processes represented by these parameters are affected by in-situ factors that are either difficult to investigate at the laboratory scale or operate at a much larger scale than can be reproduced in the laboratory. Measurements at the field scale provide a better understanding of the effective average parameter values. The scale of this tracer test is still small compared to the scale of a CAU, but is of sufficient scale to be generally representative of the processes that affect in-situ transport. The scale of the tracer test undertaken is limited by the rate of transport in the formation and the resultant time frame required for completing such a test. The measurements at the field scale will provide information for relating laboratory measurements for transport processes to the larger scale.

This report describes the analysis of the tracer test data and development of a conceptual model of transport in the LCA in Yucca Flat.

\subsection{Site Layout and Tracer Test Design/Implementation}

The ER-6-1 well cluster is located in the northeastern corner of the NTS Area 6 in southeastern Yucca Flat (Figure 1-1). The ground surface is at an elevation of approximately 3,934 feet (ft), and surface drainage in the vicinity is to the southwest into Yucca Lake (playa). The site is almost 1,000 meters $(\mathrm{m})(3,280 \mathrm{ft})$ from the nearest underground nuclear test location. The three underground nuclear tests closest to the ER-6-1 location are PRESIDIO (U-6d), HOREHOUND (U-3gm), and AUSTIN (U-6e). All three tests were conducted above the water table at about $305 \mathrm{~m}$ below ground surface (bgs). The ER-6-1 well location is about 3,250 ft east of the PRESIDIO test location. Figure 1-1 shows the locations of these three tests in relation to the ER-6-1 well location. Radionuclides have not been found in water produced from any of the three emplacement holes during drilling or ER-6-1 during testing. The coordinates of the wells are given in Table 1-1, and the well site layout is shown in Figure 1-2.

The ER-6-1 well site was selected for the tracer test by the Underground Test Area (UGTA) Technical Working Group based on criteria including the availability of existing wells accessing the LCA, suitability of the existing wells, representativeness of the LCA at the location, and expectations for groundwater contaminated with radionuclides. For the ER-6-1 well site, two wells were already located on the site, and a third well was drilled for this tracer test. The three wells are approximately aligned with the dominant local fracture orientation so that flow and transport will take place along 


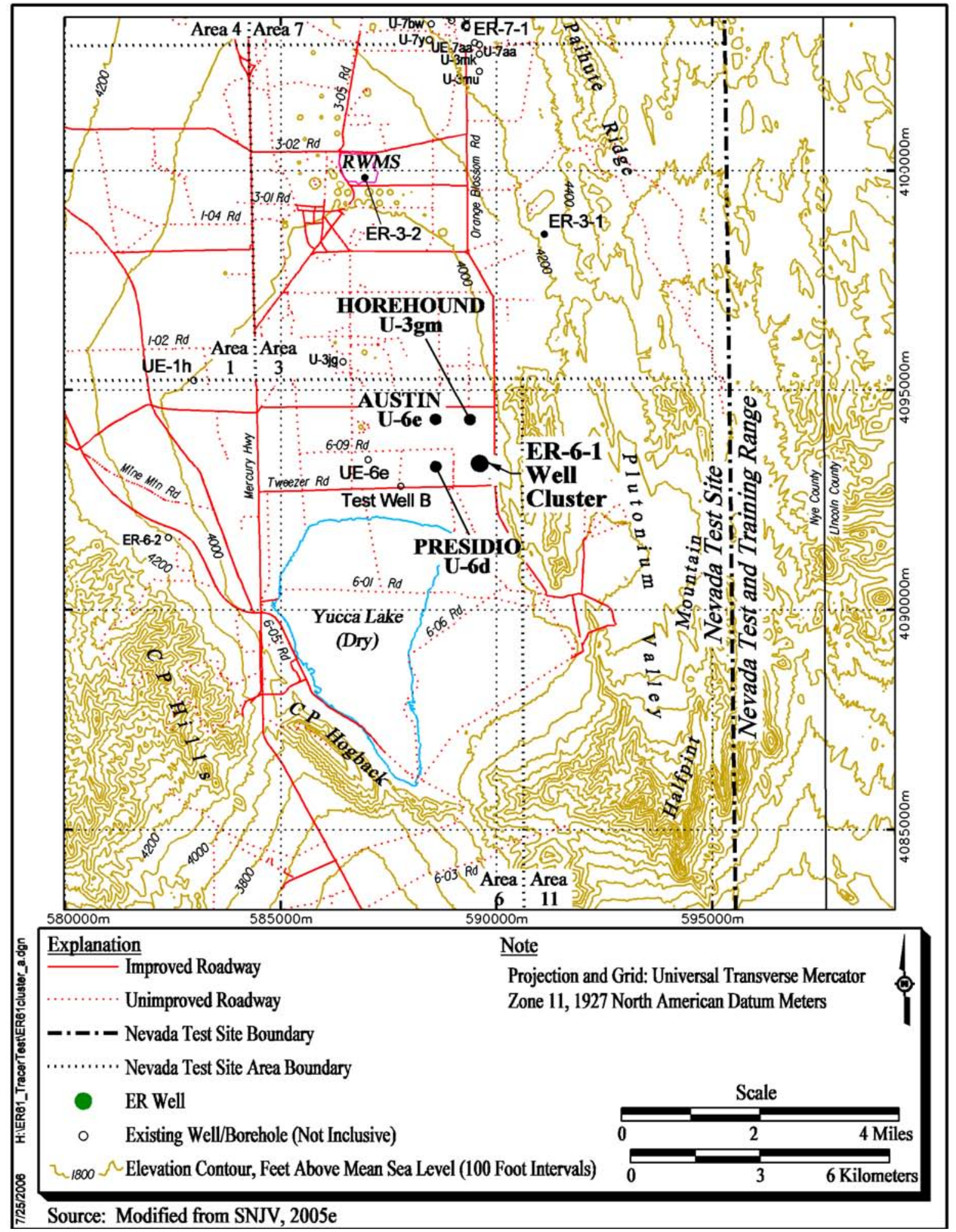

Figure 1-1

Location of Well Cluster ER-6-1 and Underground Nuclear Tests, Yucca Flat 
Table 1-1

ER-6-1 Well Locations

\begin{tabular}{|c|c|c|c|c|}
\hline \multirow{2}{*}{$\begin{array}{c}\text { Nell } \\
\text { Name }\end{array}$} & \multicolumn{2}{|c|}{ NSP, NAD 27 Central Nevada } & \multicolumn{2}{c|}{ UTM, NAD 27, Zone 11 } \\
\cline { 2 - 5 } & Northing (ft) & Easting (ft) & Northing (m) & Easting (m) \\
\hline \hline ER-6-1 \#2 & 813797.17 & 696744.78 & $4,093,356.86$ & $589,616.49$ \\
\hline ER-6-1 \#1 & 813951.08 & 696809.02 & $4,093,403.75$ & $589,635.80$ \\
\hline ER-6-1 & 814000.25 & 696799.26 & $4,093,418.79$ & $589,632.72$ \\
\hline \hline \multicolumn{5}{|c|}{ Source: BN, 2003 } \\
\hline \multicolumn{7}{|c|}{ Relative Locations } & Distance (ft) & \multicolumn{2}{c|}{ Bearing (True North) } \\
\hline \hline \multicolumn{2}{|c|}{ ER-6-1 \#2 to ER-6-1 } & 210.26 & 15.0 & NE \\
\hline ER-6-1 \#2 to ER-6-1 \#1 & 166.78 & 22.7 & NE \\
\hline
\end{tabular}

Source: Modified from SNJV, 2004b

NSP $=$ Nevada State Plane

NAD = North American Datum

UTM = Universal Transverse Mercator

the fracturing rather than across the fracturing (Figure 1-2). The alignment and separation of ER-6-1, the primary injection well, and the recovery well (ER-6-1 \#2) were determined using available data regarding effective porosity and fracture orientations and accommodating existing on-site facilities, and expected operating conditions and operational restrictions such as the maximum pumping rate and the desired length of the test.

Well ER-6-1 was initially drilled using the air-foam rotary method in August 1992 to a depth of 2,129 ft. This well was subsequently deepened to a total depth (TD) of 3,206.4 ft in 1994 by continuous coring; returns during coring were poor. Information on drilling and coring operations can be found in the Completion Report for Well Cluster ER-6-1 (NNSA/NSO, 2004b). After ER-6-1 was deepened, an attempt was made to develop it by airlift pumping. However, very little water was produced and, as such, the core hole could not be considered developed. A formation micro-scanner (FMS) log was run in the upper carbonate section of ER-6-1 after the initial drilling, and an acoustic televiewer log was run in the lower section after coring. Well construction for ER-6-1 is shown in Figure 1-3. This well penetrates carbonate rocks from 1,770 to 3,086 ft bgs, with quartzite below this depth to TD. The well is completed with 13.375-inch (in.) outside diameter (od) casing from the ground surface to 1,795 ft (about $25 \mathrm{ft}$ into the carbonate). Below the 13.375-in. casing, the well is open hole through the carbonate section. The diameter of open hole is $12.25 \mathrm{in}$. to 2,097 ft, $8.75 \mathrm{in}$. to 


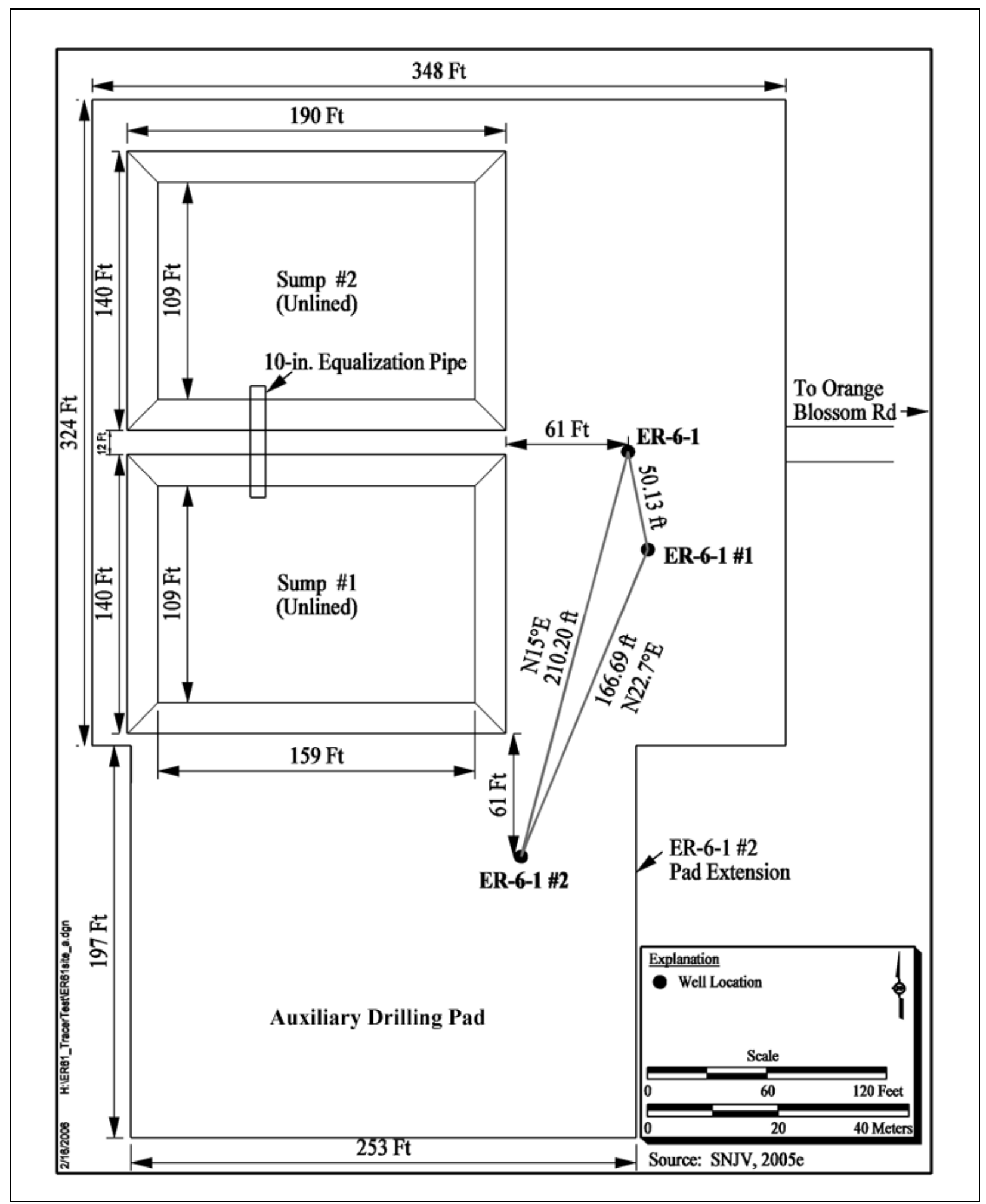

Figure 1-2

ER-6-1 Well Site Layout 


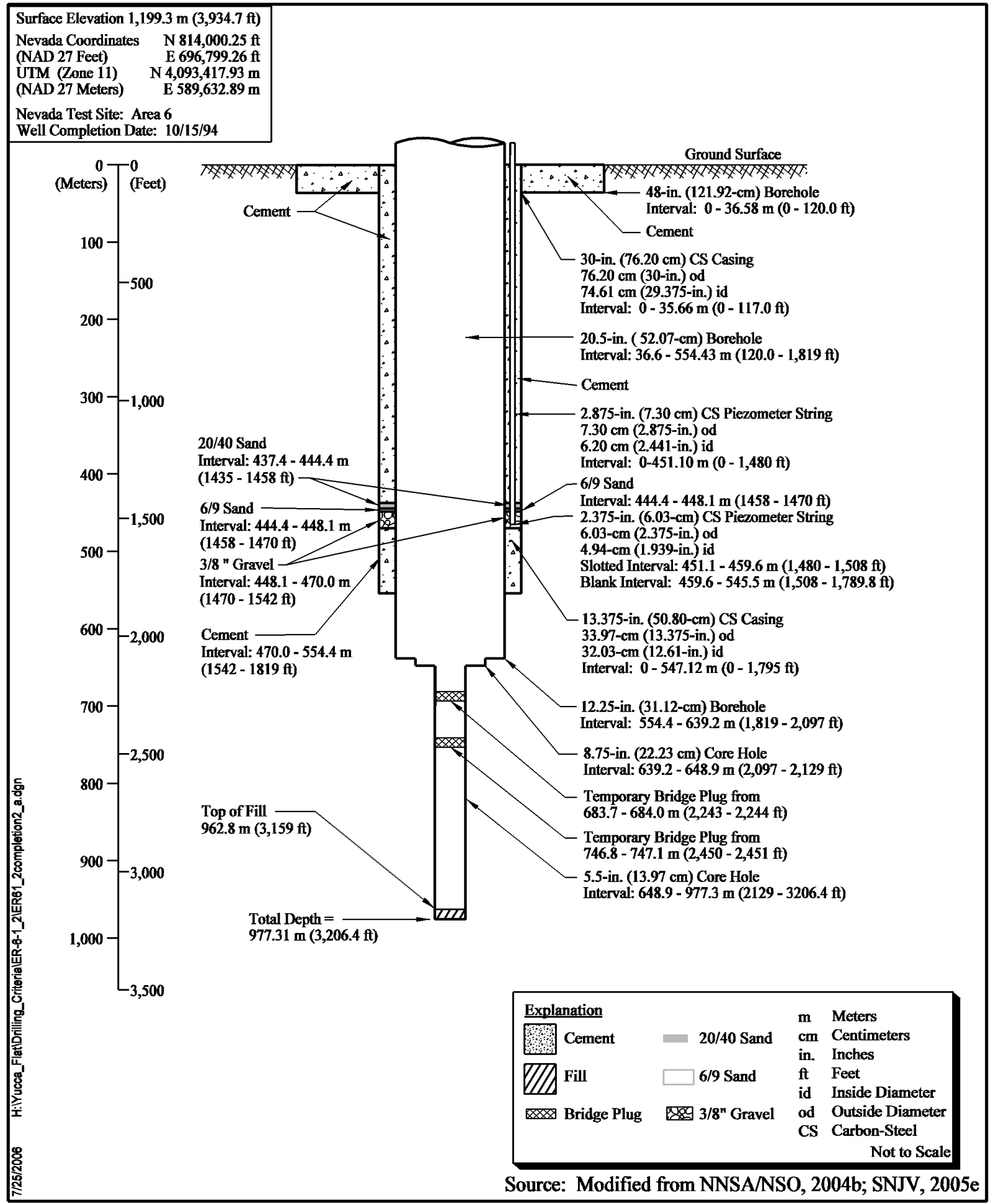

Figure 1-3

ER-6-1 Well Construction 
2,129 ft bgs, and 5.5 in. to TD. A bottom-hole temperature of 40.77 degrees Celsius $\left({ }^{\circ} \mathrm{C}\right)$ was measured at 2,129 ft bgs during geophysical logging. Two bridge plugs were installed in ER-6-1 in 1995 between transmissive zones in the Laketown Dolomite to restrict the natural gradient-driven downward flow of water in the open hole. They were located at depths of 2,239 to 2,247 ft and 2,444.75 to 2,453.25 ft. The locations were determined based on apparent inflow locations from the thermal flow meter (TFM) logs run by Lawrence Livermore National Laboratory after coring.

Well construction for ER-6-1 \#1 is shown in Figure 1-4. Well ER-6-1 \#1 (surface elevation 3,934.5 ft) was drilled in July 1993 to a depth of 2,085 ft (similar to the depth of ER-6-1 at that time) for use as an observation well during future testing of ER-6-1 \#1. This well is completed with slotted 2-7/8-in. tubing across the same carbonate section as ER-6-1. Details of the drilling and completion can be found in the Completion Report for Well Cluster ER-6-1 (NNSA/NSO, 2004b). An acoustic televiewer log was run in ER-6-1 \#1.

Well construction for ER-6-1 \#2 is shown in Figure 1-5. Well ER-6-1 \#2 was completed in October 2002 to a TD of 3,200 ft. This well penetrates carbonate from 1,770 to 3,030 ft, with quartzite below to TD. The well is completed with 13.375-in. od casing from the ground surface to $1,775 \mathrm{ft}$ bgs ( $5 \mathrm{ft}$ into the carbonate), and is cemented from the bottom of casing up to $1,587 \mathrm{ft}$ (just below the carbonate water level) at approximately 1,575 ft bgs. Borehole diameter (completion is open hole) is 12.25 in. through the carbonate section and into the quartzite. The bottom-hole temperature was $44.1^{\circ} \mathrm{C}$. For fracture characterization, an Electric Micro-Imager (EMI) log and an acoustic televiewer log were run in ER-6-1 \#2 for the full depth of the carbonate. However, the televiewer log is unusable due to interferences within the borehole fluid.

Preliminary modeling was conducted to evaluate potential tracer transport between ER-6-1 and ER-6-1 \#2 as the basis for the design of the tracer test. The modeling (using the Reactive Transport LaPlace Inversion Code [RELAP] semianalytic code [Reimus and Haga, 1999]) was updated based on results from the testing program before selection of the final design parameters for the tracer test. The objective was to develop the greatest confidence in completing the tracer test successfully in the allotted time, and was also used to determine required tracer masses. The modeling was conducted to evaluate the range of potential breakthrough times and concentrations for the various tracers under different operational scenarios. Final design parameter values were selected and the test performed. 


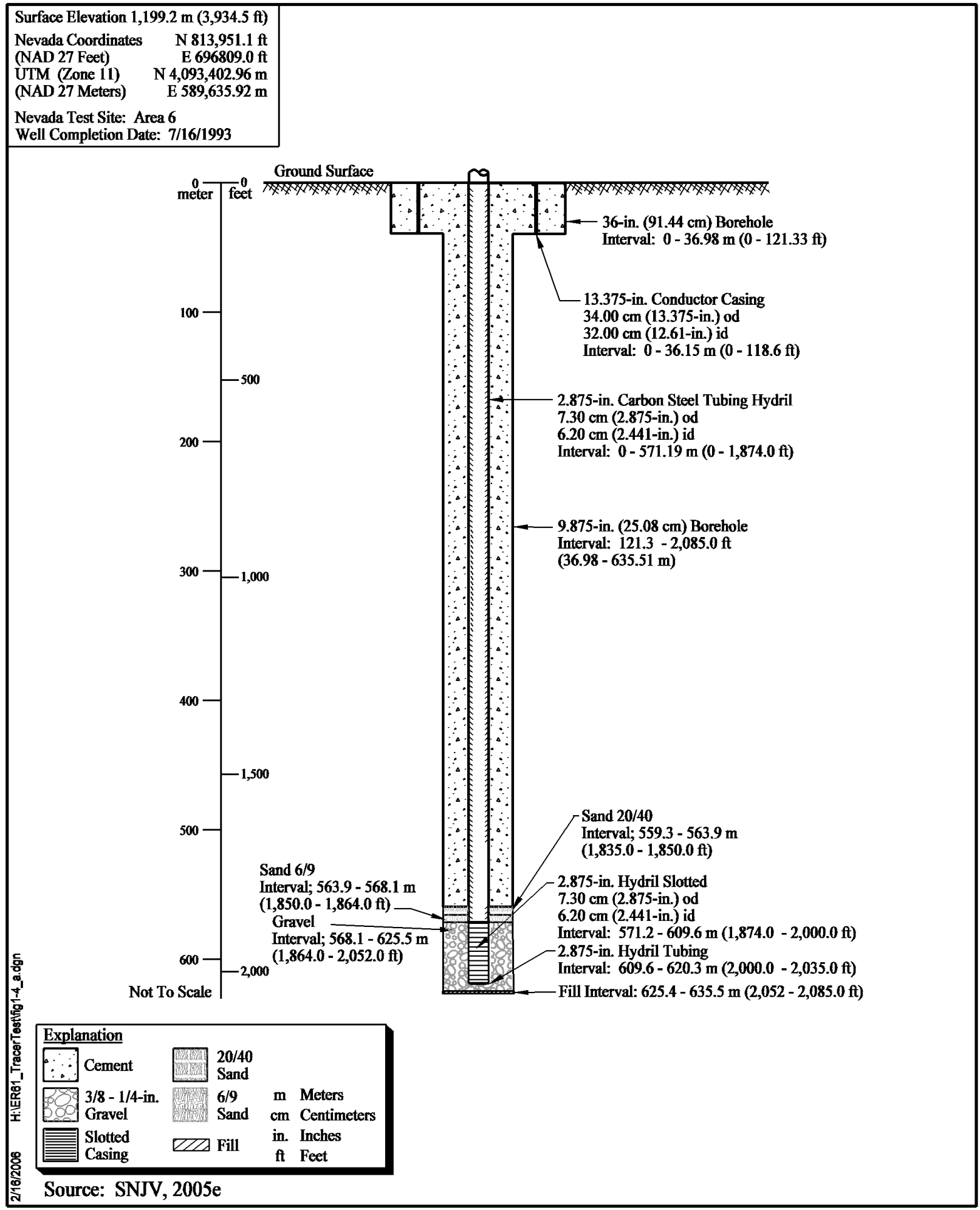

Figure 1-4

ER-6-1 \#1 Well Construction 


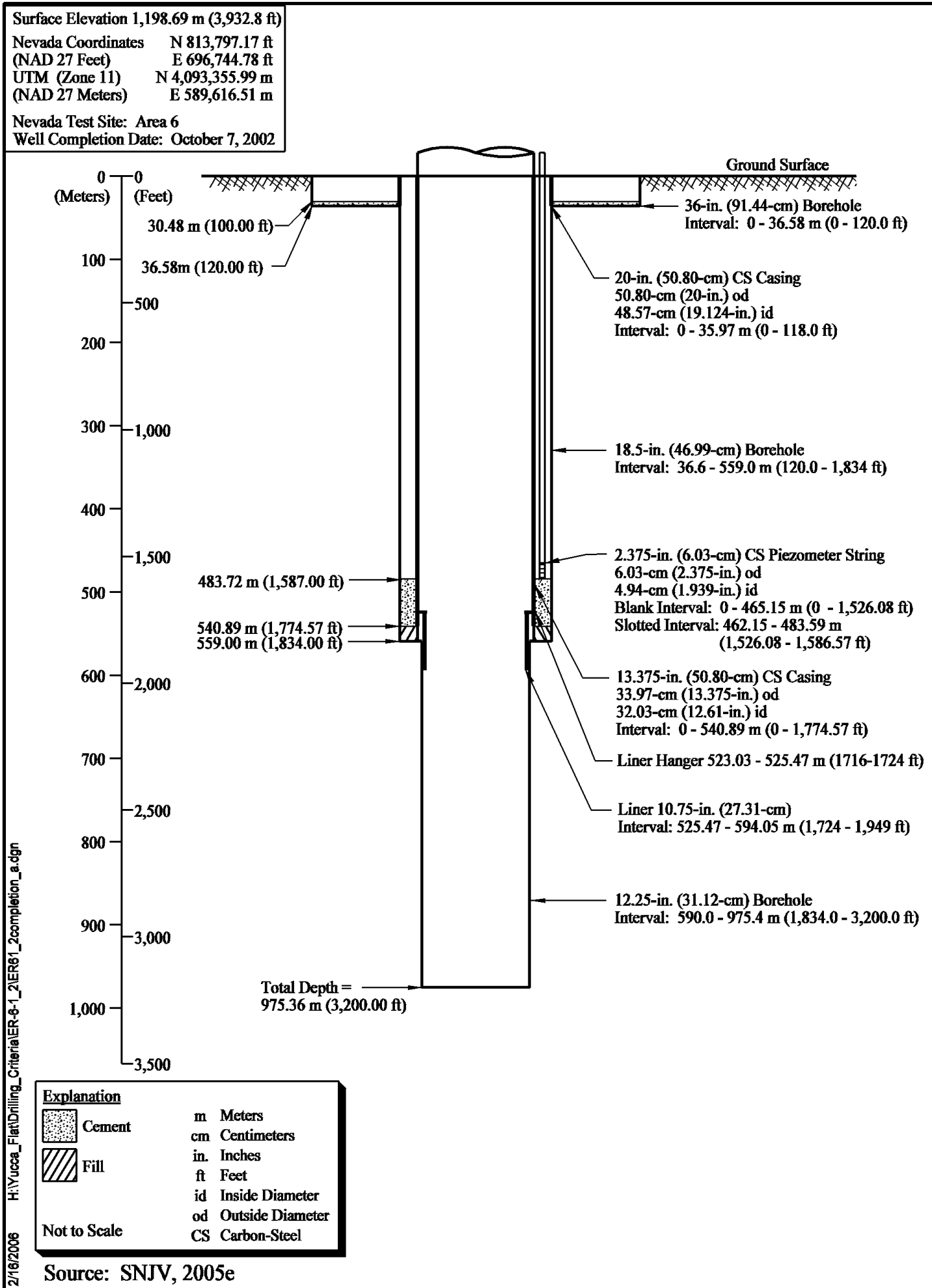

Figure 1-5

ER-6-1 \#2 Well Construction 
A simple tracer test (called the fast-path experiment) was conducted between ER-6-1 and ER-6-1 \#2 concurrent with a constant-rate pumping period from February 12 to 21, 2004. The purpose of the test was to provide information on the transport time for tracer to breakthrough from ER-6-1 to ER-6-1 \#2, provide the rate of tracer concentration change for the fastest breakthrough, and establish expected breakthrough concentrations. This information was used to guide decisions for conducting the MWAT-TT, including the schedule for sampling to monitor tracer breakthrough and the mass of tracer to be injected.

The 10 kilograms (kg) of 2,6-difluorobenzoic acid (2,6-DFBA) was distributed via passive injection into ER-6-1 along the length of the borehole while ER-6-1 \#2 was being pumped. The tracer injectate included $18.6 \mathrm{~kg}$ of sodium chloride $(\mathrm{NaCl})$ to provide a basis for measuring the tracer concentration using a downhole ion-specific electrode for sodium (Na) as well as an electrical conductivity (EC) sensor. The borehole was logged repeatedly after injection of the tracer to observe changes in concentration vertically over time. Samples were collected at the ER-6-1 \#2 well head for analysis of tracer to observe the breakthrough. The test was terminated after 10 days according to the plan.

The 2,6-DFBA was first detected in ER-6-1 \#2 approximately 69 hours (hr) after the start of pulling the injection tubing out of ER-6-1. The initial concentration was 13 parts per billion (ppb) (with a method detection limit of $8.3 \mathrm{ppb}$ ). A continuous rise in tracer concentration occurred, but peak tracer concentration was not realized during the test. The highest concentration during the test was $69 \mathrm{ppb}$, although concentrations appeared to be still increasing (Figure 1-6).

Before the fast-path test, the Desert Research Institute (DRI) conducted spinner flow meter (SFM) and TFM logging during well development. The SFM and TFM were used to aid in determining the depth at which to set a bridge plug in ER-6-1 to allow separate tracer injections into the lower and upper portions of the borehole for the formal tracer test. Lithium (Li), bromide (Br), pentafluorobenzoic acid (PFBA), and two different sizes of microspheres were to be injected into the upper more rapidly responding zone, with iodide (I) and 2,4,5-trifluorobenzoic acid (2,4,5-TFBA) into the lower more slowly responding zone in ER-6-1.

The formal tracer test was conducted with a forced gradient established by pumping 523.8 gallons per minute (gpm) from the recovery well (ER-6-1 \#2), with tracer injected into ER-6-1 \#1 and ER-6-1 upper and lower intervals separated by a bridge plug at 2,600 ft bgs. Paired conservative tracers with 


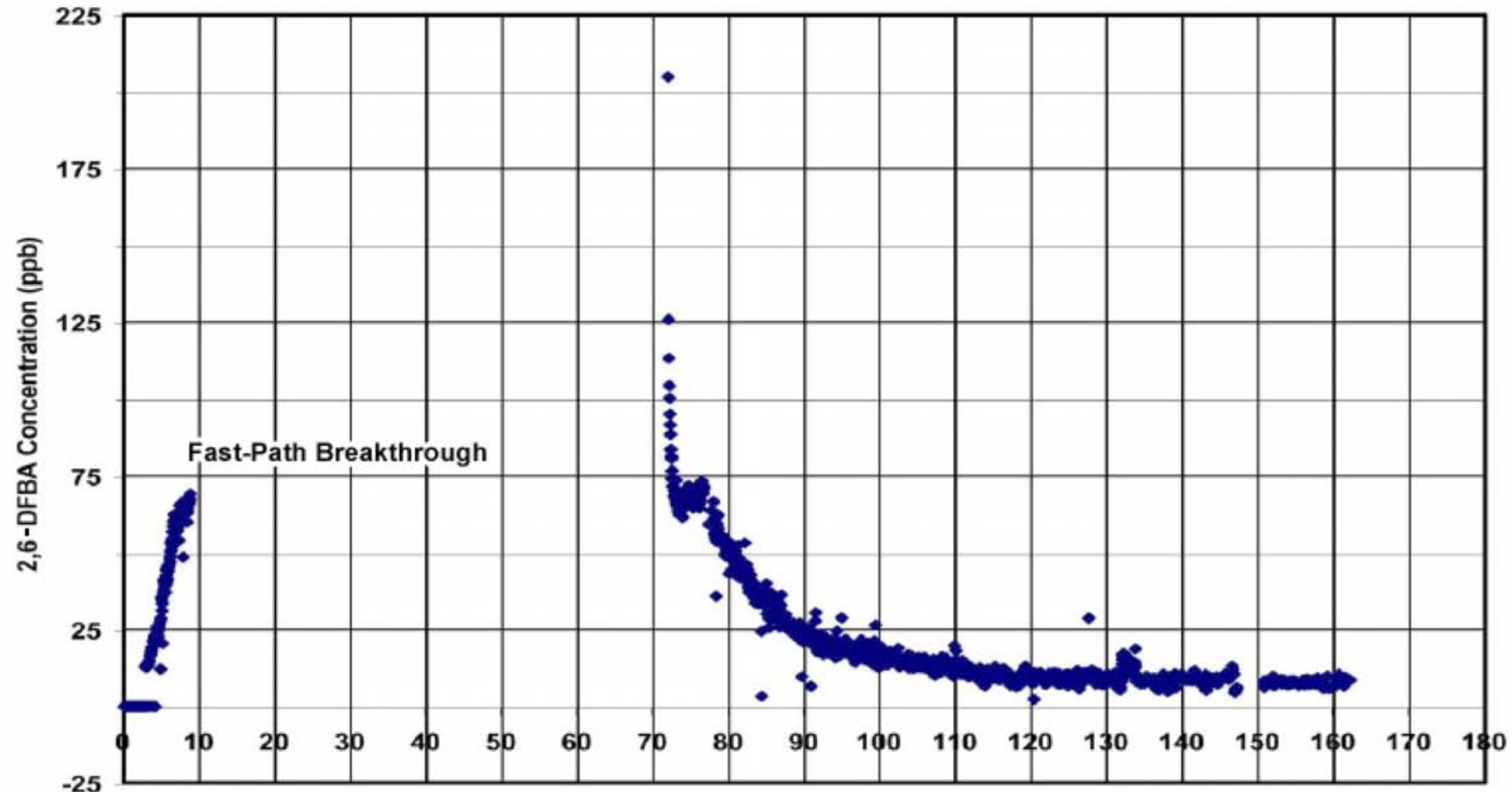

Elapsed Time (Days) From Start of Tracer Injection 
different diffusion coefficients were used to characterize matrix diffusion. The difference in breakthrough between such paired tracers reflects the effect of matrix diffusion. The conservative tracer pairs consisted of an inorganic anionic tracers (Br, injected as lithium bromide [LiBr], and I, injected as sodium iodide [NaI]) with a relatively high diffusion coefficient and an organic tracer (2,6-DFBA, 2,5-DFBA, and 2,4,5-TFBA) with a substantially lower diffusion coefficient. A weakly sorbing tracer ( $\mathrm{Li}$ ion, injected as $\mathrm{LiBr}$, and lithium chloride [ $\mathrm{LiCl}]$ ) was also used to evaluate retardation due to sorption. The weakly sorbing tracer also provides diagnostic information on matrix diffusion and on whether sorption is occurring predominately in the matrix or in fractures.

Microspheres were used as surrogates for colloids. Two different sizes of microspheres were injected to provide information on the effect of size on transport. The tracer injections and masses are shown in Table 1-2.

Table 1-2

Tracer Injections at ER-6-1

\begin{tabular}{||c|c|c|c|c||}
\hline Tracer & Injection Well & $\begin{array}{c}\text { Injection Mass } \\
(\mathrm{kg})\end{array}$ & Injection Date & $\begin{array}{c}\text { Injection/Chase Volumes } \\
(\mathrm{L})\end{array}$ \\
\hline \hline 2,6-DFBA & ER-6-1 (entire) & 10.0 & $2 / 12 / 04$ & $1,160 / 235$ \\
\hline Microspheres (0.2) & ER-6-1 (upper) & $4.8 \times 10^{14}$ spheres & $4 / 27 / 04$ & $22,805 / 11,438$ \\
Microspheres (0.5) & ER-6-1 (upper) & $3.2 \times 10^{14}$ spheres & $4 / 27 / 04$ & $22,805 / 11,438$ \\
\hline 2,5-DFBA & ER-6-1 \#1 & 10.22 & $4 / 29 / 04$ & $6,540 / 11,438$ \\
\hline PFBA & ER-6-1 (upper) & 10.07 & $4 / 30 / 04$ & $23,645 / 11,438$ \\
Lithiuma & ER-6-1 (upper) & 18.95 & $4 / 30 / 04$ & $23,645 / 11,438$ \\
Bromidea & ER-6-1 (upper) & 23.17 & $4 / 30 / 04$ & $23,645 / 11,438$ \\
\hline $2,4,5-T F B A$ & ER-6-1 (lower) & 10.0 & $4 / 30 / 04$ & $6,128 / 11,438$ \\
Iodide $^{a}$ & ER-6-1 (lower) & 20.32 & $4 / 30 / 04$ & $6,128 / 11,438$ \\
\hline
\end{tabular}

aLithium was injected as $100.0 \mathrm{~kg} \mathrm{LiCl}, 25.18 \mathrm{~kg} \mathrm{LiBr}$, and $1.95 \mathrm{~kg}$ lithium hydroxide (LiOH); bromide was injected as $25.18 \mathrm{~kg}$ $\mathrm{LiBr}$; and iodide was injected as $24.0 \mathrm{~kg} \mathrm{Nal}$. All fluorinated benzoic acids (FBAs) were neutralized with sodium hydroxide $(\mathrm{NaOH})$, except for PFBA, which was neutralized with $\mathrm{LiOH} .18 .6 \mathrm{~kg}$ of $\mathrm{NaCl}$ was also injected with 2,6-DFBA to provide the tracer injection solution with a high electrical conductivity contrast for DRI Chemtool logging.

$\mathrm{kg}=$ Kilogram

$\mathrm{L}=$ Liter

Concentration measurements were conducted at the University of Nevada Las Vegas-Harry Reid Center (UNLV-HRC) on samples of the solutions delivered to the ER-6-1 site in carboys. Adjustment factors that represent the ratio of measured tracer injection concentrations to the tracer mass divided 
by injection volume are shown in Table 1-3. Tracer purity was considered in developing these factors. The factors vary from 0.824 to 1.094 .

Table 1-3

Tracer Mass Adjustment Factors

\begin{tabular}{|c|c|}
\hline Tracer & Factor \\
\hline \hline $2,5-D F B A$ & 0.824 \\
\hline PFBA & 1.009 \\
\hline Lithium & 0.924 \\
\hline Bromide & 1.003 \\
\hline $2,4,5-T F B A$ & 0.913 \\
\hline lodide & 1.094 \\
\hline
\end{tabular}

These differences, which are greater than 10 percent in some cases and used in the test interpretation, are significant because test interpretation is based on comparing normalized breakthrough curves of simultaneously injected tracers. Thus, these differences can have a large effect on estimation of matrix diffusion or sorption parameters.

Initially, 2,6-DFBA was observed in the MWAT-TT as a continuation of the fast-path tracer test breakthrough after a drift period of about 63 days. The complete 2,6-DFBA dataset is shown in elapsed time from the start of the injection period in Figure 1-6. The fast-path test was apparently stopped just before the peak concentration would have arrived. The initial concentration values observed after restarting pumping and sampling likely demonstrate the effects of drift (movement of tracer due to ambient groundwater flow). Matrix diffusion is not the cause because the peak concentration had not yet arrived. Mass recovery over the entire test of 53 percent was achieved. Figure 1-7 shows the tracer breakthroughs for the tracers injected into the ER-6-1 upper interval (PFBA, Li, Br, and microspheres field monitoring data) in elapsed time from the start of tracer injection. The field monitoring data for the microspheres are very similar to the final data, but less noisy due to the large steps in resolution associated with the field analysis method. Note that the microspheres were injected more than three days earlier than the chemical tracers. The microspheres show an early, very distinct peak, and the PFBA shows a much slower, broad peak. The Li and Br tracer breakthrough concentrations shown in these graphs have been adjusted by revising the estimates of the background concentrations. The functional background concentrations for $\mathrm{Li}$ and $\mathrm{Br}$ 


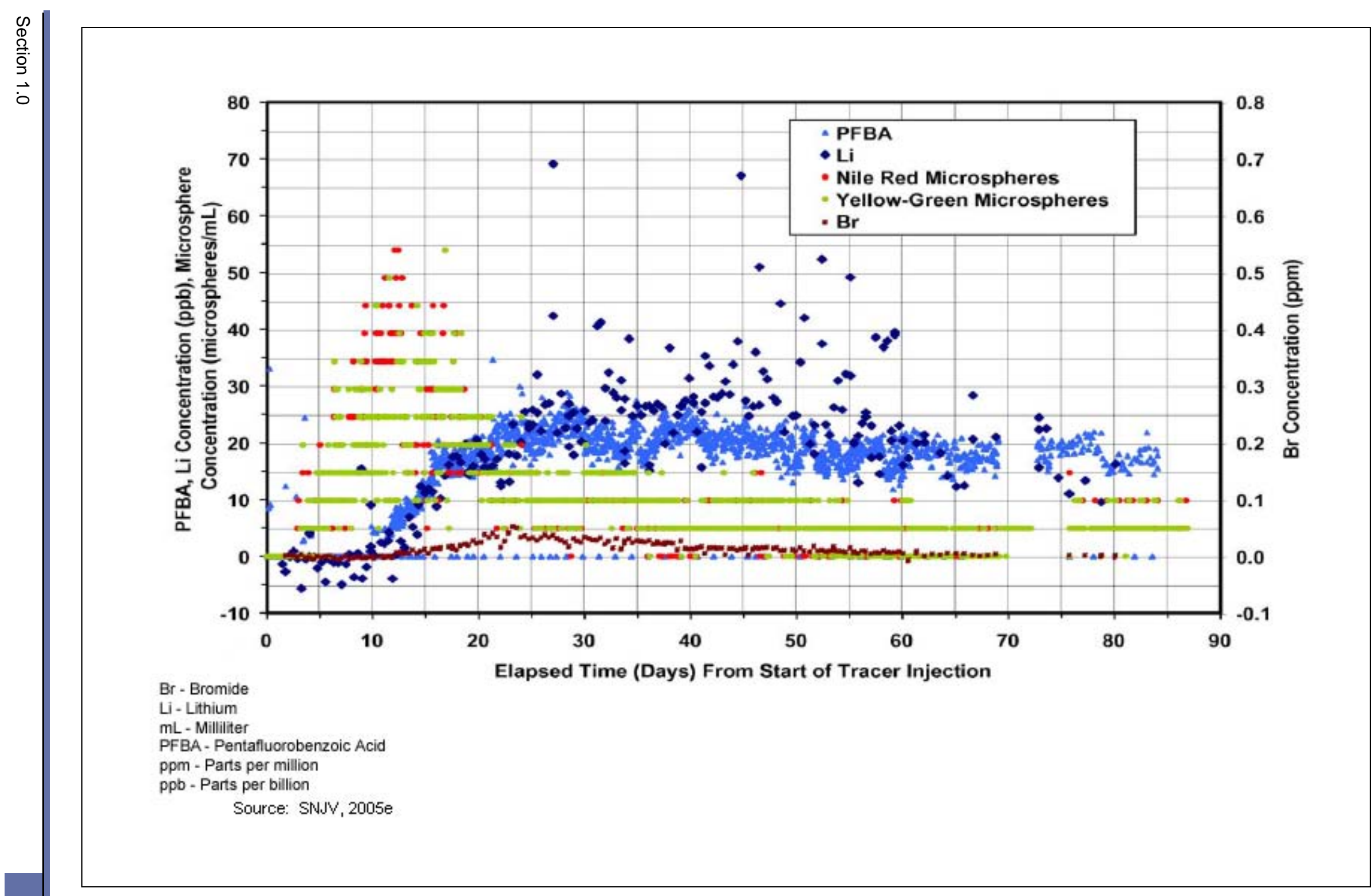

Figure 1-7

ER-6-1 \#2 Tracer Breakthrough Curves from ER-6-1 Upper Interval Injection 
were estimated by averaging the sample concentration values for the early-time samples before the start of concentration increases judged to be the start of breakthrough. Based on the revised breakthrough concentrations, the Li mass recovery was $4.191 \mathrm{~kg}$ (22.1 percent of injected mass), and the $\mathrm{Br}$ mass recovery was $2.825 \mathrm{~kg}$ (12.2 percent of injected mass).

Figure 1-8 shows the paired tracer breakthroughs in ER-6-1 \#2 for ER-6-1 lower interval tracers, 2,4,5-TFBA and I, in elapsed time from the start of tracer injection. The peak concentrations arrived fairly quickly, and the breakthroughs are well-defined and consistent. There may be a small lag of the I tracer behind the 2,4,5-TFBA (although it is difficult to tell), which might reflect matrix diffusion effects. Based on initial interpretations of the flow logging, it was thought that this zone would have slower tracer migration; the formal test results show this was not the case. Mass recoveries of 2,4,5-TFBA and I are estimated at 64 and 63 percent, respectively. This zone has the highest mass recovery.

Figure 1-9 shows the tracer breakthrough data in ER-6-1 \#2 for ER-6-1 \#1 tracer 2,5-DFBA in elapsed time from the start of tracer injection. The initial detection of this tracer took a long time, possibly because the breakthrough concentrations are low and early arrival concentrations were below the quantification level of the analytical equipment. Tracer concentrations were still rising during the remainder of the tracer test, and it is not apparent whether a peak concentration was achieved. This suggests that the flow path from ER-6-1 \#1 to ER-6-1 \#2 may be less directly connected than other paths, possibly because ER-6-1 \#1 is slightly off the estimated strike of the fracture system.

Table 1-4 shows the computed tracer mass recoveries from pumping ER-6-1 \#2. These masses were estimated by using the average pumping rate to determine the volume extracted hourly and using the sample concentration at the end of each hour to estimate the mass recovered during the hour. Recoveries for $\mathrm{Li}$ and $\mathrm{Br}$ are lower than may be expected because of the background value subtraction from analyzed samples. A portion of the analyzed samples had negative values, meaning the $\mathrm{Li}$ or $\mathrm{Br}$ concentration in the sample was less than the original background concentration. The Li and $\mathrm{Br}$ tracer recoveries were recalculated based on an adjusted background concentration, although the total recovery for these tracers remains uncertain because of the lack of a clearly identified stable background concentration. 


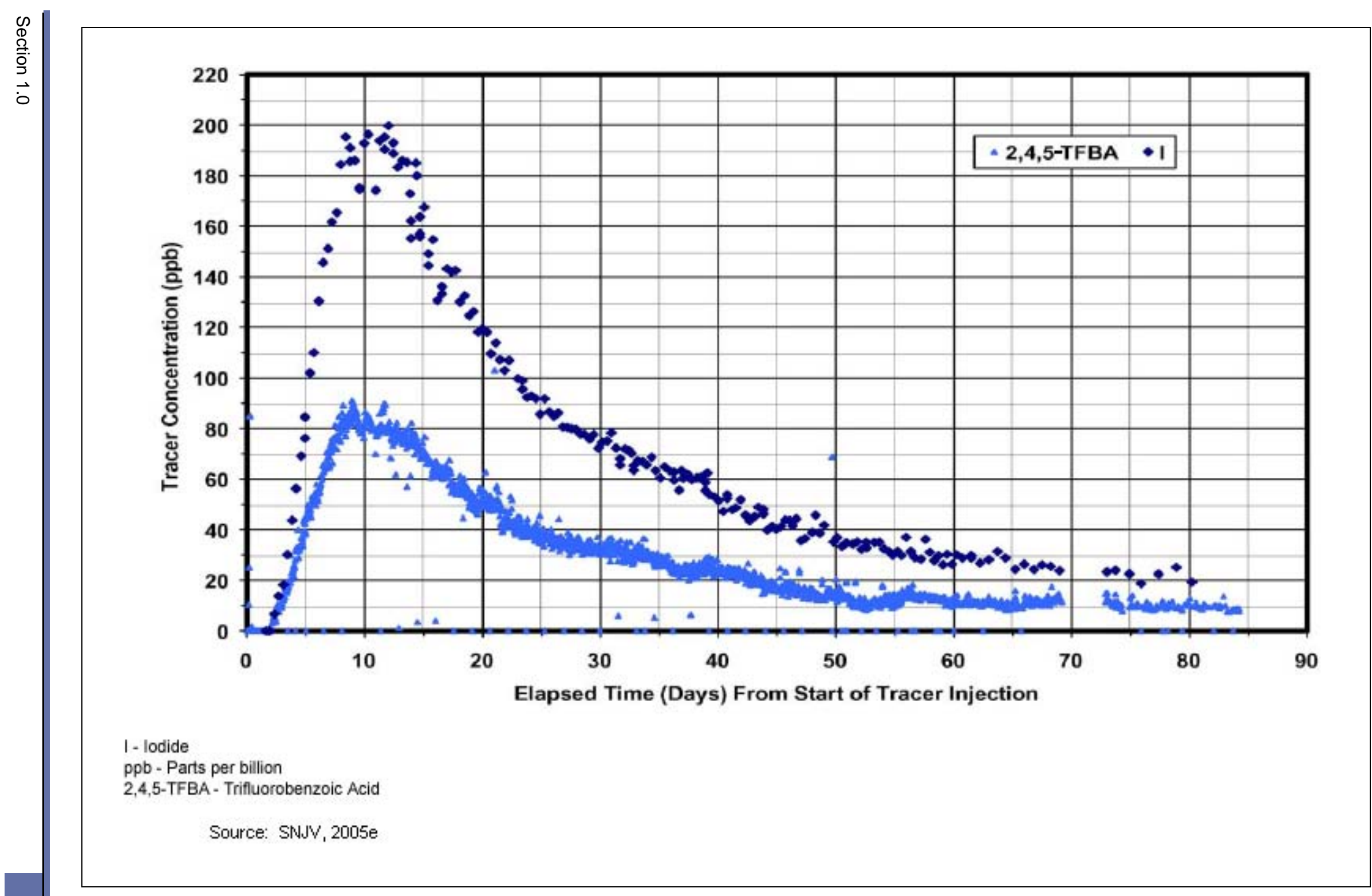

Figure 1-8

ER-6-1 \#2 Tracer Breakthrough Curves from ER-6-1 Lower Interval Injection 


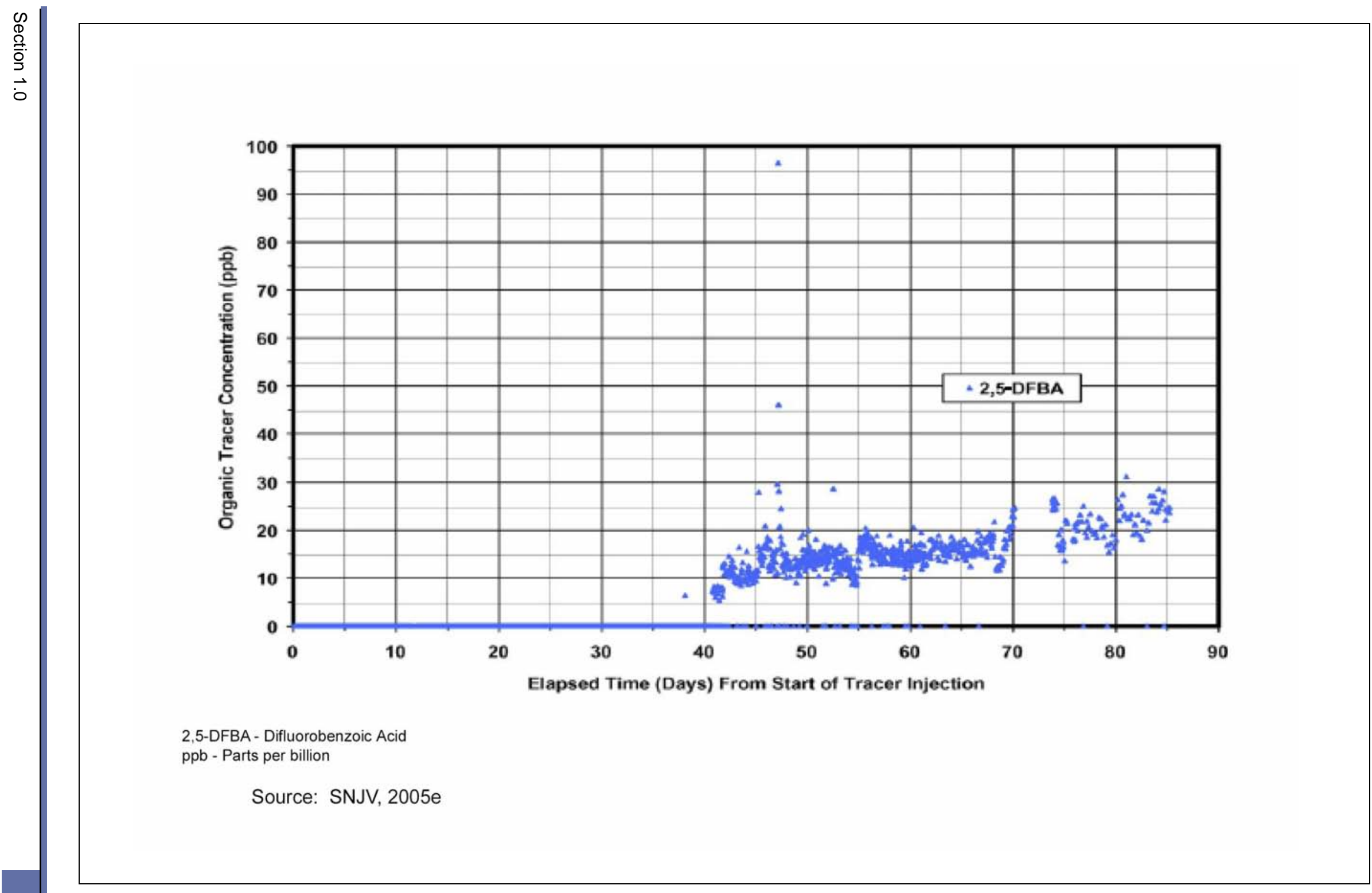

Figure 1-9

ER-6-1 \#2 Tracer Breakthrough Curves from ER-6-1 \#1 Injection 
Table 1-4

Estimated Tracer Mass Recoveries

\begin{tabular}{|c|c|c|c|c||}
\hline Tracer & $\begin{array}{c}\text { Unadjusted } \\
\text { Mass Injected } \\
\mathbf{( k g )}\end{array}$ & $\begin{array}{c}\text { Mass Recovery } \\
\mathbf{( k g )}\end{array}$ & $\begin{array}{c}\text { Percent } \\
\text { Recovery }\end{array}$ & $\begin{array}{c}\text { Injection } \\
\text { Interval }\end{array}$ \\
\hline \hline $2,6-$ DFBA & 10.00 & $5.29^{a}$ & 52.9 & ER-6-1 entire \\
\hline $2,5-$ DFBA & 10.22 & 1.84 & 18.0 & ER-6-1 \#1 \\
\hline $2,4,5-T F B A$ & 10.00 & 6.43 & 64.3 & ER-6-1 lower \\
\hline PFBA & 10.07 & 3.60 & 35.8 & ER-6-1 upper \\
\hline Lithium & 18.95 & 3.75 & 19.8 & ER-6-1 upper \\
\hline Bromide & 23.17 & 0.62 & 2.7 & ER-6-1 upper \\
\hline Iodide & 23.57 & 14.9 & 63.2 & ER-6-1 lower \\
\hline Nile-Red Microspheres & $\begin{array}{c}3.25 \times 10^{14} \\
\text { Microspheres }\end{array}$ & N/A & 3.2 & ER-6-1 upper \\
\hline Yellow-Green Microspheres & $\begin{array}{c}4.82 \times 10^{14} \\
\text { Microspheres }\end{array}$ & N/A & 3.6 & ER-6-1 upper \\
\hline
\end{tabular}

Source: Modified from SNJV, 2005e

aTotal mass recovered since injection; $0.71 \mathrm{~kg}$ recovered during fast-path tracer test; $4.58 \mathrm{~kg}$ recovered during MWAT-TT.

N/A = Not applicable

\subsection{Participants}

The ER-6-1 MWAT-TT was planned and executed by the Stoller-Navarro Joint Venture (SNJV), which is the Environmental Engineering Services Contractor for the UGTA Project of the Environmental Restoration Project of the U.S. Department of Energy (DOE), National Nuclear Security Administration Nevada Site Office (NNSA/NSO).

Participants in the ER-6-1 MWAT-TT included SNJV, Bechtel Nevada (BN), DRI, Los Alamos National Laboratory (LANL), and UNLV-HRC. Stoller-Navarro Joint Venture managed the field implementation of the MWAT-TT, led the data collection effort, conducted tracer sample collection, field analysis, and distribution of samples to off-site laboratories. Bechtel Nevada provided construction and engineering support, conducted well recompletion operations, and maintained site infrastructure. Desert Research Institute provided logging services during development and testing operations. Los Alamos National Laboratory provided the microsphere tracers as well as field equipment for on-site monitoring of microsphere concentrations. The University of Nevada 
Las Vegas-Harry Reid Center conducted laboratory analyses for tracers, in addition to preparing all concentrated chemical tracers used in the testing.

The analyses in this document were conducted jointly between SNJV and LANL. Stoller-Navarro Joint Venture provided basic analysis, infrastructure programming and Finite Element Heat-Mass (FEHM) transfer code setup, and data-specific products. Los Alamos National Laboratory provided mesh construction; specific utility codes for use with FEHM; the convolution approach to transport; general FEHM expertise; and semianalytic analyses, drift velocity estimates, and much thought-provoking discussion.

\subsection{Supporting Documents}

The UGTA Project and other investigators have conducted a variety of data collection and analysis tasks in Yucca Flat. Documents relating to the ER-6-1 tracer test and the LCA in Yucca Flat include the following:

- Wells ER-6-1 and ER-6-2 Core Fracture Analyses and Geophysical Log Comparisons (IT, 1996b)

- Summary of Hydrogeologic Controls on Ground-Water Flow at the Nevada Test Site, Nye County, Nevada (Laczniak et al., 1996)

- Laboratory Experiments to Evaluate Diffusion of ${ }^{14} \mathrm{C}$ into Nevada Test Site Carbonate Aquifer Matrix (Hershey et al., 2003)

- Analysis of Well ER-7-1 Testing, Yucca Flat FY 2003 Testing Program, Nevada Test Site, Nevada (SNJV, 2004a)

- Completion Report for Well ER-7-1 (NNSA/NSO, 2004a)

- Completion Report for Well Cluster ER-6-1 (NNSA/NSO, 2004b)

- Underground Test Area Fracture Analysis Report for Yucca Flat Wells ER-2-1, ER-6-1 \#2, ER-7-1, and ER-12-2 Nevada Test Site (SNJV, 2005d)

- Analysis of Hydraulic Responses from the ER-6-1 Multiple-Well Aquifer Test, Yucca Flat FY 2004 Testing Program, Nevada Test Site, Nye County, Nevada (SNJV, 2005a)

- Analysis of Well ER-6-2 Testing, Yucca Flat FY 2004 Testing Program, Nevada Test Site, Nye County, Nevada (SNJV, 2005b) 
- ER-6-1 Well Cluster Multiple Well Aquifer Test - Tracer Test Data Report, Volumes I, II, and III (SNJV, 2005e)

- A Hydrostratigraphic Model and Alternatives for the Groundwater Flow and Contaminant Transport Model of Corrective Action Unit 97: Yucca Flat-Climax Mine, Lincoln and Nye Counties, Nevada (BN, 2006)

- Tracer Transport Properties in the Lower Carbonate Aquifer of Yucca Flat (Reimus et al., 2006)

Laczniak et al. (1996) set the regional framework with the remaining documents describing activities and data specific to the LCA in Yucca Flat and flow and transport processes.

\subsection{Document Organization}

Section 1.0 is the introduction, and also contains information on the test design, participants, and supporting documents.

Section 2.0 describes the hydraulic and transport conceptual model derived from regional observations, geologic analysis, hydraulic test responses (constant-rate pumping and flow logging) at LCA wells in Yucca Flat, fluid EC-profile analysis with BORE-II, fracture analysis from image logs, scoping calculations, and semi-analytical interpretations of test response.

Section 3.0 describes the setup, implementation, and analysis of a FEHM model of the tracer test. Hydraulic head, drawdown, TFM flow logging, fast-path tracer breakthrough, and main test breakthrough data were used in this analysis. Also included is an analysis of semi-regional response to pumping.

Section 4.0 discusses the results of the suite of analyses.

Section 5.0 provides a list of references.

Appendix A and Appendix B provide additional supporting material as discussed in Section 3.0. 


\subsection{Conceptual Model of Flow AND TRANSPORT IN THE LOWER CARBonate AQUIFER - YUCCA FLAT}

This section summarizes preliminary findings in the development of an appropriate conceptual model for the interpretation of the multiple-well, convergent-flow tracer test performed in the LCA at the ER-6-1 well site in southern Yucca Flat. The interpretation methodology utilized both the monitored hydraulic and tracer responses. The discussion below includes evaluation of information regarding regional and local geology, fracture characterization studies in ER-6-1 and ER-6-1 \#2, flow logging in ER-6-1 and ER-6-1 \#2, the MWAT hydraulic response data, tracer breakthrough responses at ER-6-1 \#1 and ER-6-1 \#2, and tracer free-water diffusion and sorption data.

\subsection{Geology}

The LCA in Yucca Flat has a highly heterogeneous permeability distribution due to variations in fracturing, both laterally and vertically across the well cluster, and also across the larger general kilometer (km)-scale section of the LCA that spans the observation-well array for the ER-6-1 \#2 MWAT. Flow through the LCA is primarily controlled by fracture permeability resulting from brittle deformation of the carbonates. Laczniak et al. (1996), Gonzales et al. (1998), Gonzales and Drellack (1999), and most recently BN (2006), all of whom developed a hydrogeologic framework for Yucca Flat, report that the LCA hydraulic conductivity is highly spatially variable and reflects the observed differences in fracturing and fault density.

Yucca Flat is a topographically closed basin bounded on all sides by volcanic and sedimentary ranges which have, through erosion, deposited thick sheets of alluvium on the underlying sedimentary and volcanic units. The general stratigraphy, from oldest to youngest, is comprised of thick Paleozoic carbonate and silicic units representative of sedimentation near the continental margin, overlain by Tertiary volcanics deposited from multiple eruptive events of the southwestern Nevada volcanic field (Gonzales et al., 1998). The overlying sedimentary units are Quaternary and Tertiary in age, with minor components of Tertiary volcanics, and primarily include alluvium and playa deposits. 
The LCA HSU is the primary component of the pre-Tertiary sedimentary units within Yucca Flat. It is the principal aquifer for much of southern Nevada. The LCA is confined above and below, respectively, by zeolitized tuffs within the tuff confining unit (TCU) HSU and by the lower clastic confining unit (LCCU) HSU, projected to be deep and below the depth of interest. The top of the LCA is an erosional surface that is highly fractured and, based upon observations at UE-10j, potentially karstified near the top, although the extent of any karstification is unknown (SNJV, 2004a). A thin (tens-of-feet-thick) layer of paleocolluvium is found at the contact of the LCA and the overlying volcanics. Some of this overlying material may penetrate the fractured surface of the LCA. In general, the LCA is composed of multiple formations including shale, quartzite, and siltstone that may create semi-independent flow systems within the LCA in the horizontal plane (Laczniak et al., 1996). The lowest unit penetrated in the ER-6-1 well cluster is the Eureka Quartzite, which is conceived, but in fact may not be, a lower confining unit for the section of LCA penetrated at the cluster.

The northern and western limits of the LCA are likely truncated, respectively, by intrusive contacts and fault contacts with confining units. A steep hydraulic gradient across confining units that bound the basin to the north, northeast, west and above provide evidence of the hydraulic isolation of the LCA from adjacent units (Laczniak et al., 1996). Relative to the MWAT observation well array shown in Figure 2-1, the LCA is laterally continuous, and possibly hydraulically connected, with the possible exception of the Carpetbag and Tippinip fault systems in western Yucca Flat where the LCA juxtaposes confining units as a result of normal faulting (Laczniak et al., 1996). The large permeability contrast between the units may create a barrier to lateral flow. A fault trace map at the projected LCA surface from the Yucca Flat hydrostratigraphic framework model (HFM) (SNJV, 2005a, and BN, 2006), presented in Figure 2-1, shows the ubiquitous north-south-trending faults beneath Yucca Flat, including those mentioned above. These faults are predominantly high-angle normal faults related to Basin and Range extension (Byers et al., 1976). The majority of the observation wells, relative to the long-term pumping of ER-6-1 \#2, are oriented along the direction of fault continuity with the exception of UE-1h and ER-3-1. Well UE-1h is located west of the pumping well in the overthrust LCA3 across the Topgallant and Yucca Faults, which may act as flow barriers. Well ER-3-1 is located northeast of the pumping well across at least three major faults. 


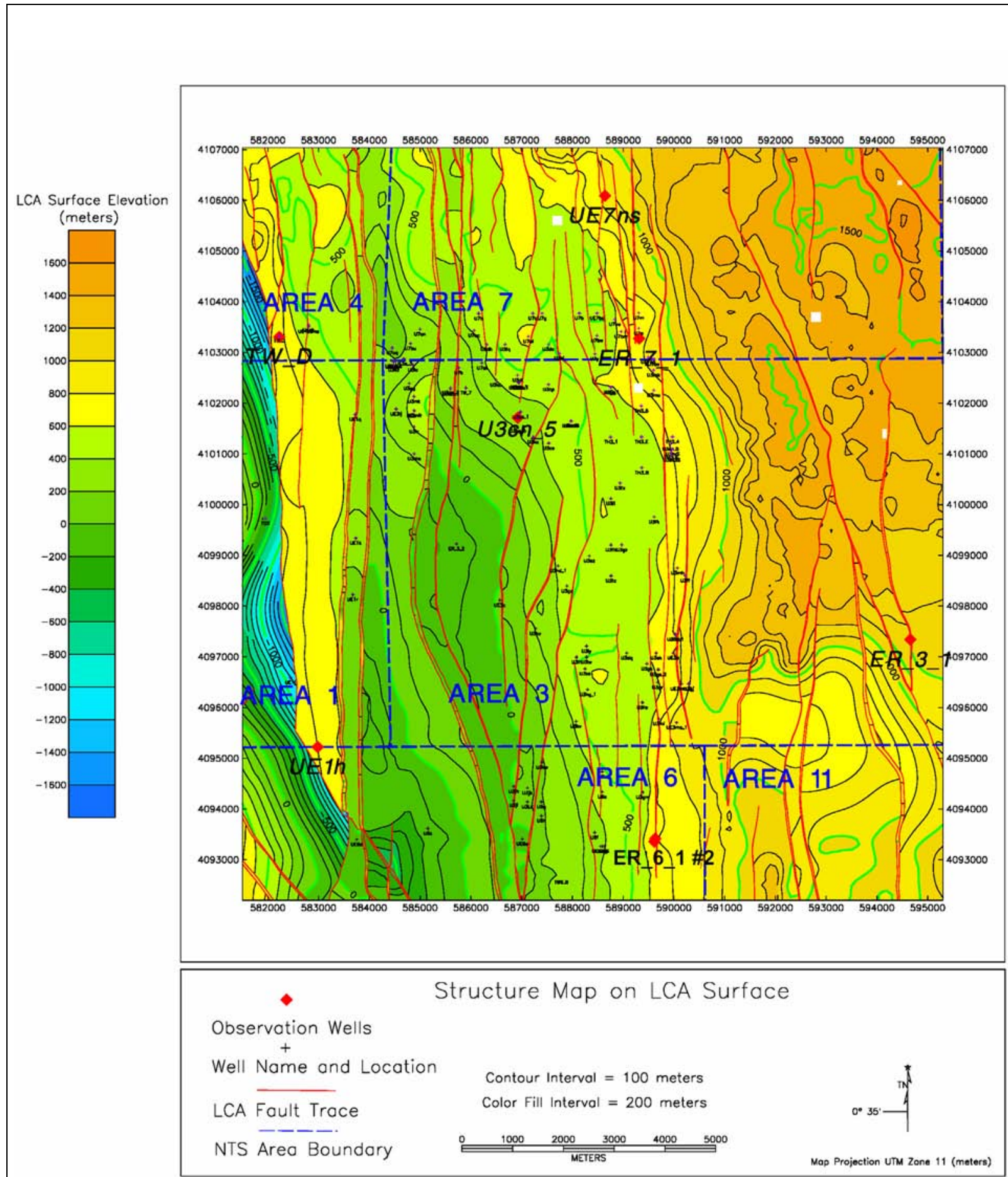

Source: SNJV, 2005a, and BN, 2006

Figure 2-1

Fault Trace Map at the LCA Surface over the Areal Extent of the Observation-Well Array 
The ER-6-1 well site is located on a minor structural block bounded by two north-south trending faults (NNSA/NSO, 2004b; BN, 2006). Both faults dip steeply to the west and have stratigraphic displacement down to the west, with less stratigraphic throw than the valley-forming faults. The westernmost fault is inferred from gravity and seismic data (see Figures 23 and 24 in Drellack et al., 1992), while the east-bounding fault was penetrated in the TCU by ER-6-1 and ER-6-1 \#1 at a depth of approximately 1,714 ft bgs during drilling operations (NNSA/NSO, 2004b). West-to-east and north-to-south trending cross sections that intersect the well site are presented in Figures 2-2 and 2-3, respectively, and show the hydrostratigraphy of the minor fault block. The cross sections also show the approximate water-table depth located in the volcanics above the LCA.

Table 2-1 presents the lithologies discussed in the Completion Report for Well Cluster ER-6-1 (NNSA/NSO, 2004b) and the well data report for ER-6-1 \#2 (IT, 2003). The borehole intervals located below the LCA in ER-6-1 and ER-6-1 \#2 are open to the Eureka Quartzite. Table 2-2 shows the borehole test intervals.

\subsection{Hydraulic Conceptual Model}

\subsubsection{Regional}

Laczniak et al. (1996) indicated that most of the groundwater flowing beneath Yucca Flat passes through the LCA and is the only subsurface pathway by which groundwater leaves the basin. As previously mentioned, Laczniak et al. (1996), Gonzales et al. (1998), Gonzales and Drellack (1999), and BN (2006) developed a hydrogeologic framework model for Yucca Flat that conceptualizes LCA hydraulic conductivity as a highly spatially variable reflecting differences in fracturing and fault density, which is one of the major controls on groundwater flow in the LCA. This conceptual model is supported by the analysis of Rojstaczer (1987), who saw effects of groundwater pumpage in Ash Meadows clearly influenced by large-scale fracture and conduit features. Garber and Thordarson (1962) provided a similar conceptual flow model from pumping the LCA at Water Well C (south of ER-6-1 in Yucca Flat) where they were not able to pump at a rate sufficiently high to produce a drawdown response distinct from barometric and earth-tide effects. 


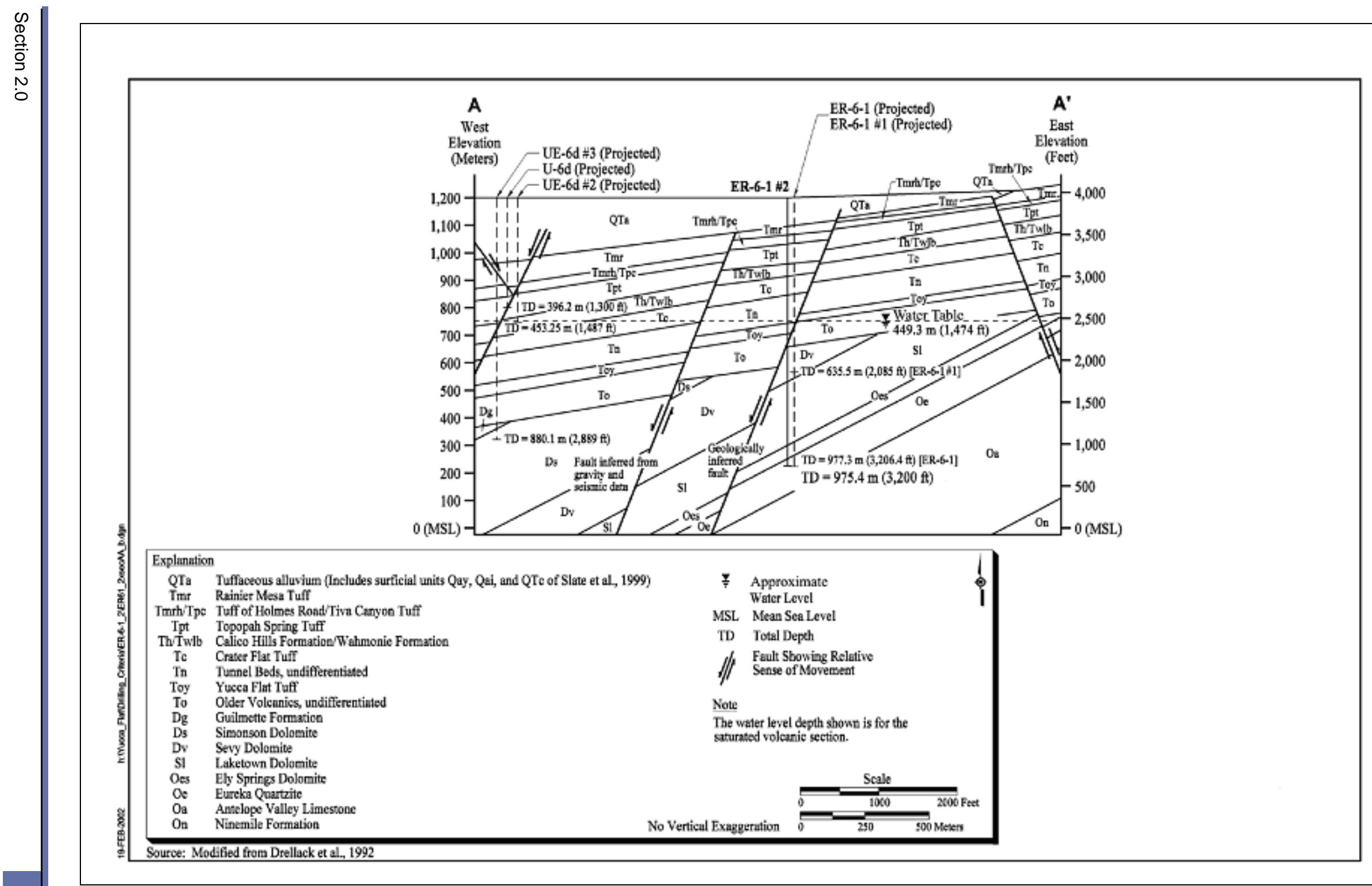

Figure 2-2

West-East Cross Section (A-A') 


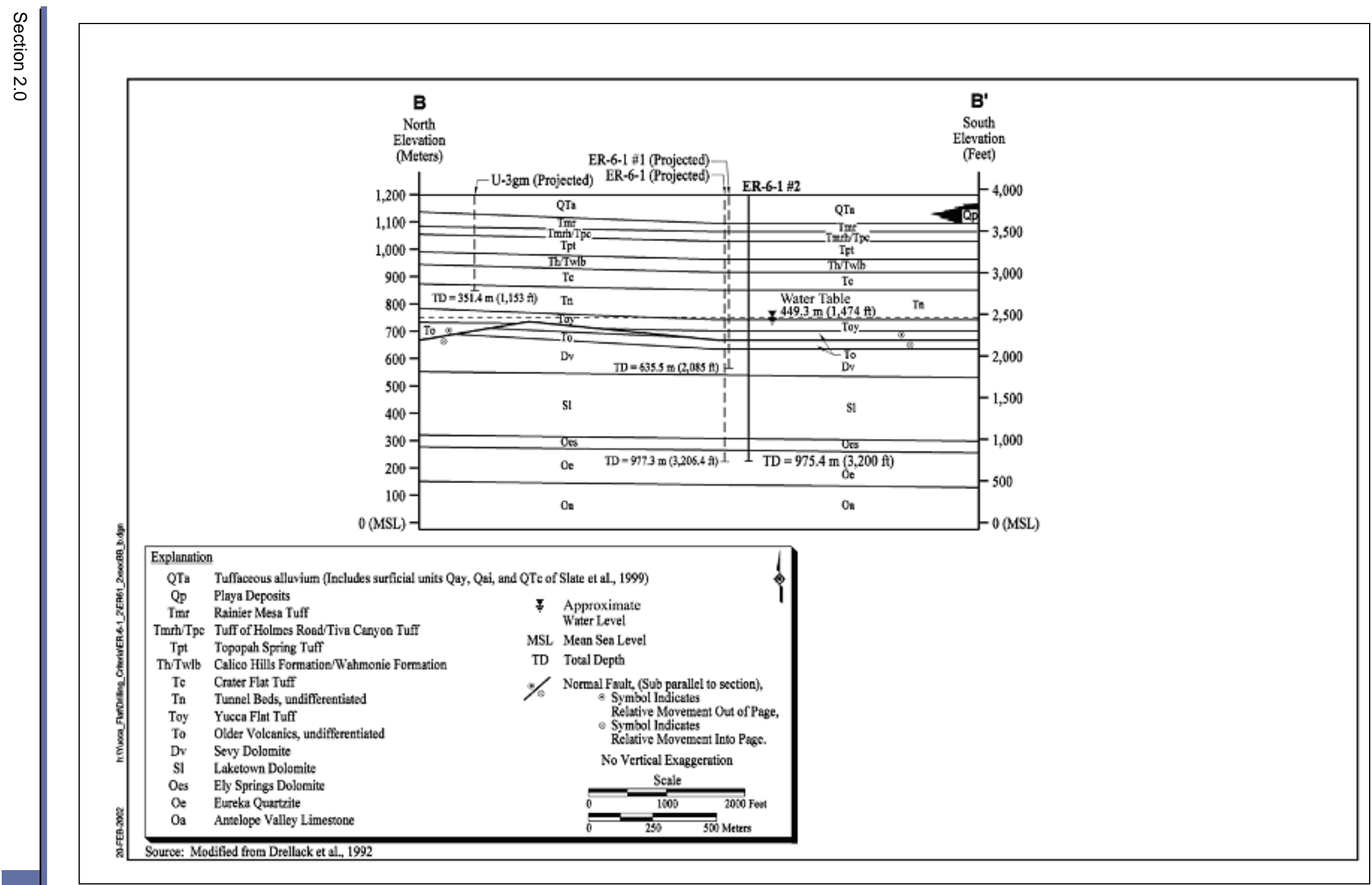

Figure 2-3 
Table 2-1

Lithologies at ER-6-1 and ER-6-1 \#2

\begin{tabular}{|c|c|c|}
\hline Lithologies & $\begin{array}{c}\text { ER-6-1 } \\
\text { (ft bgs) }\end{array}$ & $\begin{array}{c}\text { ER-6-1 \#2 } \\
\text { (ft bgs) }\end{array}$ \\
\hline \hline Paleocolluvium & 1,765 to 1,770 & 1,170 to 1,775 \\
\hline Dolostone (Sevy Dolomite) & 1,770 to 2,234 & N/A \\
\hline Dolostone (Laketown Dolomite) & 2,234 to 2,920 & 1,775 to 2,930 \\
\hline Dolostone (Ely Springs Dolomite) & 2,920 to 3,086 & 2,930 to 3,090 \\
\hline Sandstone (Eureka Quartzite) & 3,086 to 3,124 & N/A \\
\hline Quartzite (Eureka Quartzite) & 3,124 to 3,206 & 3,090 to 3,200 \\
\hline
\end{tabular}

Source: IT, 2003, and NNSA/NSO, 2004b

Table 2-2

Formation and Completion Intervals at ER-6-1

\begin{tabular}{|c|c|c|c|c|}
\hline $\begin{array}{c}\text { Well } \\
\text { Name }\end{array}$ & $\begin{array}{c}\text { LCA Formation } \\
\text { Interval } \\
\text { (ft bgs) }\end{array}$ & $\begin{array}{c}\text { LCA Formation } \\
\text { Interval Thickness } \\
\text { (ft) }\end{array}$ & $\begin{array}{c}\text { LCA Completion or } \\
\text { Open Interval } \\
\text { (ft bgs) }\end{array}$ & $\begin{array}{c}\text { LCA Completion or Open } \\
\text { Interval Thickness } \\
\text { (ft) }\end{array}$ \\
\hline \hline $\begin{array}{c}\text { ER-6-1 } \\
\text { Upper }\end{array}$ & 1,770 to 2,599 & 829 & 1,819 to 2,599 & 780 \\
\hline $\begin{array}{c}\text { ER-6-1 } \\
\text { Lower }\end{array}$ & 2,600 to 3,086 & 486 & 2,600 to 3,086 & 486 \\
\hline ER-6-1 \#1 & 1,770 to 2,085 & 315 & 1,835 to 2,085 & 250 \\
\hline ER-6-1 \#2 & 1,775 to 3,090 & 1,315 & 1,774 to $3,090^{\mathrm{a}}$ & 1,315 \\
\hline
\end{tabular}

aNote: Well ER-6-1 \#2 had a liner hanger and liner from 1,716 to 1,949 ft bgs during the ER-6-1 MWAT-TT. During pumping of ER-6-1 \#2, groundwater may have entered the borehole behind the liner and exited above the liner. Flow logging and depth-discrete sampling were not performed above the liner and, therefore, the importance of flow and tracer entering behind the liner cannot be fully quantified. During drilling, an increase in production was noted between 1,860 to $1,890 \mathrm{ft}$ bgs indicating the possible presence of a fractured or faulted zone.

\subsubsection{Yucca Flat LCA Hydraulic Conceptual Model}

The ER-6-1 MWAT hydraulic interpretive model indicates a discrete fracture or high-permeability channel flow (e.g., non-radial flow) regime without apparent hydraulic double-porosity effects (SNJV, 2005a). At the Yucca Flat CAU-scale, MWAT-TT results suggest that extensive faults, or fault zones, channel flow north to south. This is evident because of the lack of a response at UE-1h, west of the ER-6-1 site across the Yucca and Topgallant Fault systems (Figure 2-1), and from the unusual response at ER-3-1, northeast of the site across at least three major faults. The ER-3-1 response showed both a 10-day lag to pumping at ER-6-1 \#2 and the response of a constant-head 
(or high-permeability) feature. This behavior can be explained as fault-related, although it is also likely that the LCA is unconfined near ER-3-1, which could at least account for the phase lag in response to pumping. Just over $10 \mathrm{~km}$ north of the well site (the second farthest observation well), ER-7-1 showed a nearly immediate response to pumping with a lag on the order of hours, and so too at the start of the recovery period. The single-well and MWAT-TT estimates of the LCA hydraulic conductivity at ER-7-1 are 397 feet per day (ft/d) and $4 \mathrm{ft} / \mathrm{d}$, respectively, with the single-well test also showing a constant-head, or high-permeability, feature nearby that is presumably related to the large-scale feature that connects ER-6-1 to ER-7-1. Each test sampled a different portion of the LCA, the single-well test stressing a volume centered at the well and the MWAT-TT (in relation to the ER-7-1 location) stressing the LCA along a north-south trending fault from ER-6-1 \#2, and then the fault blocks normal to the fault (Figure 2-1). Well ER-7-1 appears to be situated along the same fault system as well cluster ER-6-1 (Figure 2-1), strongly suggesting that the fault system acts as a high-permeability conduit through which a pressure response readily propagates. The directional variation in observation well responses indicates that CAU-scale, north-south trending faults impact flow through the LCA at the basin scale.

Desert Research Institute used a TFM to conduct cross-borehole flow logging at ER-6-1 and ER-6-1 \#2 while each was pumping in turn. Borehole interval flow rates measured under pumping conditions, in addition to supplementary borehole measurements (e.g., temperature profiles), were analyzed to determine borehole interval hydraulic conductivities (SNJV, 2005a; Oberlander and Russell, 2004). These data permit the identification of discrete fault- or fracture-dominated flow features, consistent with the inferred interpretative flow model local to the well site. Borehole flow logging did not access lower intervals because of fill. In-borehole in ER-6-1 flows during the MWAT-TT are different than during the SFM and TFM logging because of the presence of the packer in ER-6-1 (from 2,599 to 2,600 ft bgs) during the MWAT-TT.

\subsubsection{Flow Logging Responses at Well Sites ER-6-1 and ER-6-1 \#2}

\section{Spinner Flow Meter Results}

This section briefly recaps the flow-logging analysis from SNJV (2005a). Well ER-6-1 was logged in January 2004 with the SFM at several pumping rates varying from 1,041 to 275 to 565 gpm.

Figure 2-4 plots the composite normalized flow log for ER-6-1 along with calculated interval flow 
rates (expressed as a percent of the total) and a representative temperature log from the SFM tool (log MOV 02). From a review of Figure 2-4, one can see that the dominant flow feature in the logged interval occurs between 2,351 and 2,381 ft bgs, with the second most productive horizon between 2,861 and 2,946 ft bgs. Note that a full 24 percent of the borehole flow originates below a depth of 2,861 ft bgs.

Well ER-6-1 \#2 was logged in February 2004 with the SFM at several pumping rates varying from 275 to 545 gpm. Figure 2-4 plots the composite normalized flow log for ER-6-1 \#2 along with calculated interval flow rates (expressed as a percent of the total) and a representative temperature log from the SFM tool (log MOV 23; 275 gpm). From a review of Figure 2-4, it appears that the dominant flow feature in the logged interval occurs between 2,151 and 2,226 ft bgs (36 percent), with the second most productive horizon between 2,851 and 2,951 ft bgs (25 percent). Approximately 36 percent of the borehole flow originates at a depth below 2,816 ft bgs in an interval comprising 12 percent of the open-hole interval. In fact, 61 percent of the interval flow originates from 19 percent of the open interval length.

While SFM flow logging in ER-6-1 and ER-6-2 \#2 suggests higher hydraulic conductivity or transmissivity in the upper zone (above 2,600 ft bgs), more rapid arrival of tracer occurs through the lower zone. The potential causes are lower fracture porosity in the lower zone or more direct connection in the lower zone (i.e., hydraulic anisotropy directions are different in upper and lower zones). Oberlander and Russell (2004) noticed systematically higher hydraulic conductivities in the lower part of both wells, which also suggests that a more direct connection is possible.

\section{Thermal Flow Meter Results}

The TFM was run in ER-6-1 on March 30, 2004, over the interval from 1,825 to 2,900 ft bgs (campaign TFM-2). The TFM was also run in ER-6-1 when ER-6-1 \#2 was pumped. This log was run on February 2, 2004, over an interval from 1,825 to 2,900 ft bgs (campaign TFM-1).

Figure 2-5(a) plots the successive difference between interval flow rates measured by the TFM. Under ambient conditions (TFM-2), formation water flows into the borehole at depths above 2,170 ft bgs and water flows back out of the borehole below that depth, with the strongest outflow between 2,350 and 2,540 ft bgs. When the TFM is run in ER-6-1 during ER-6-1 \#2 pumping, flow enters the borehole over an interval that extends deeper than in the ambient case. 


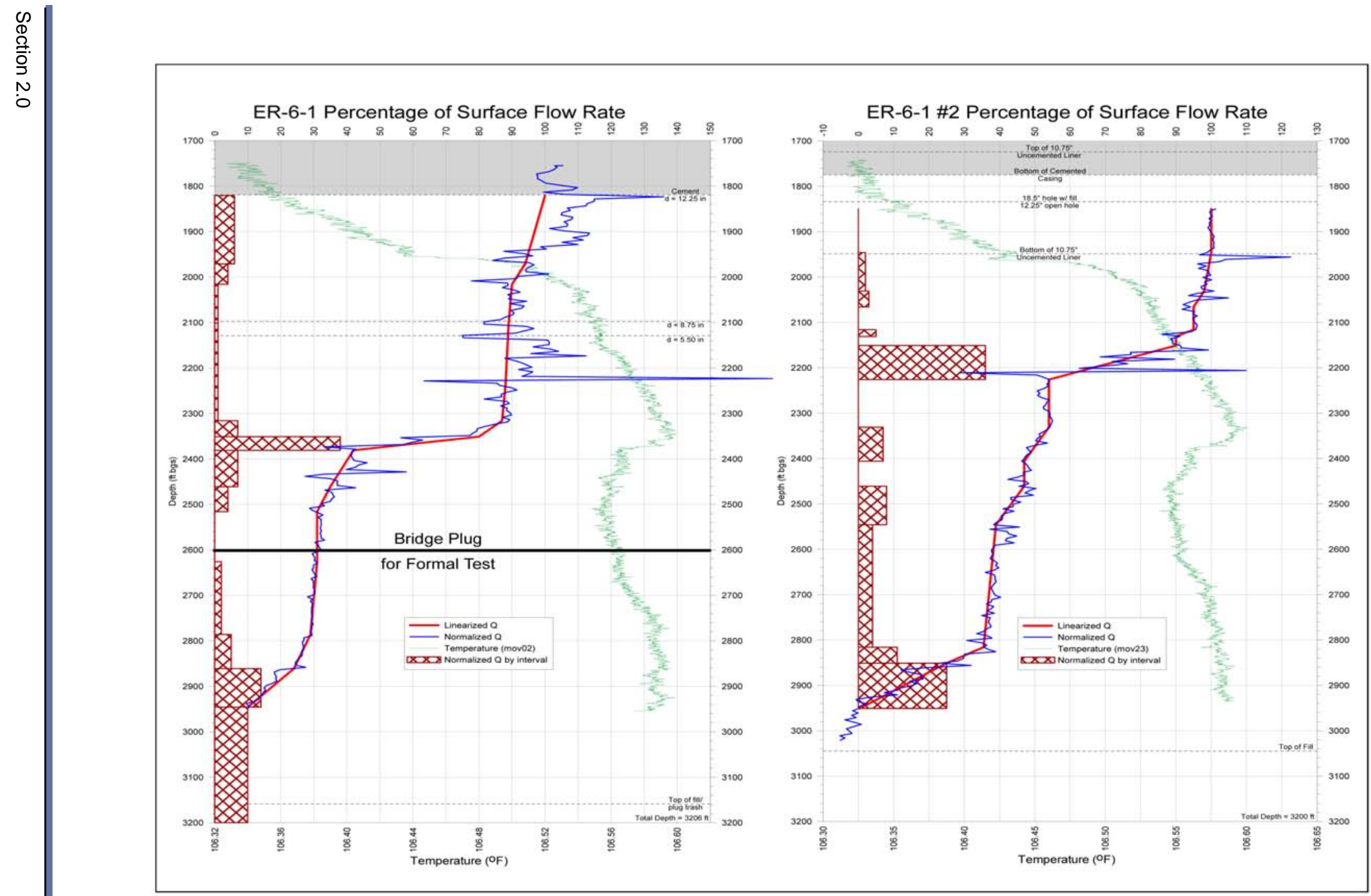

Source: Modified from SNJV, 2005a

Figure 2-4

Composite SFM Logs for ER-6-1 and ER-6-1 \#2 
으
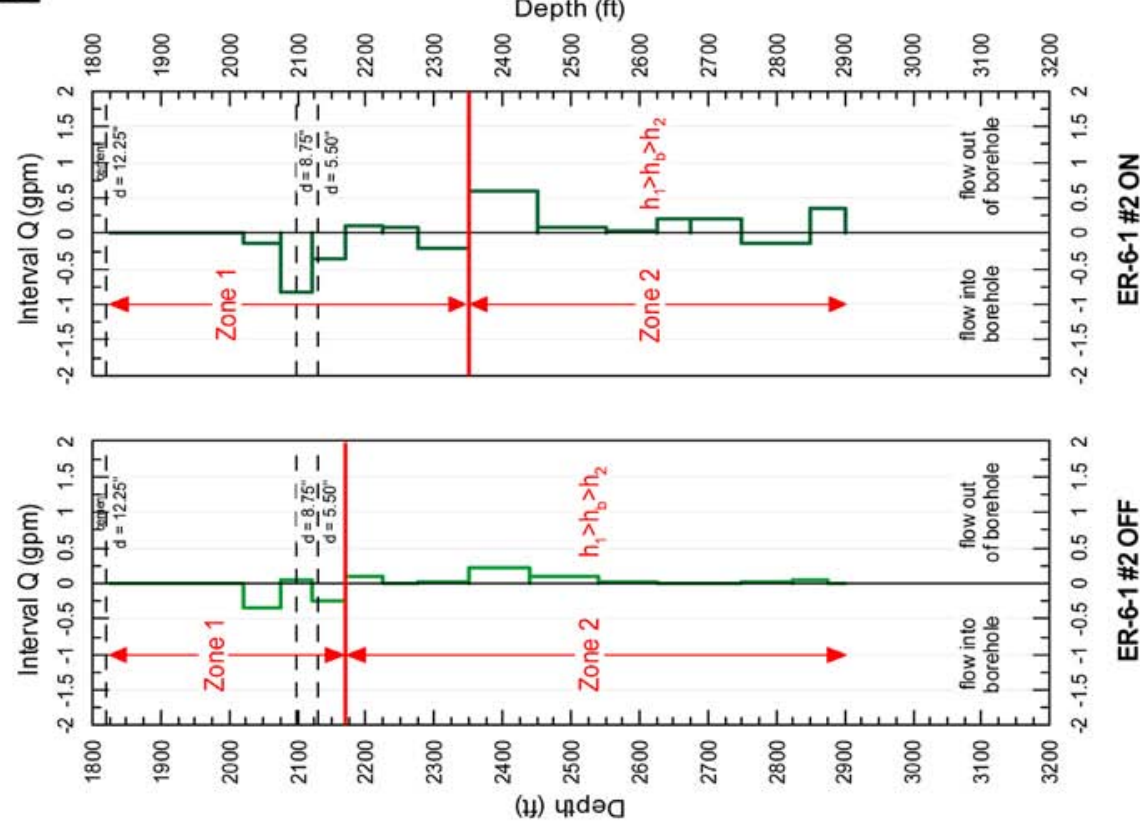

চ
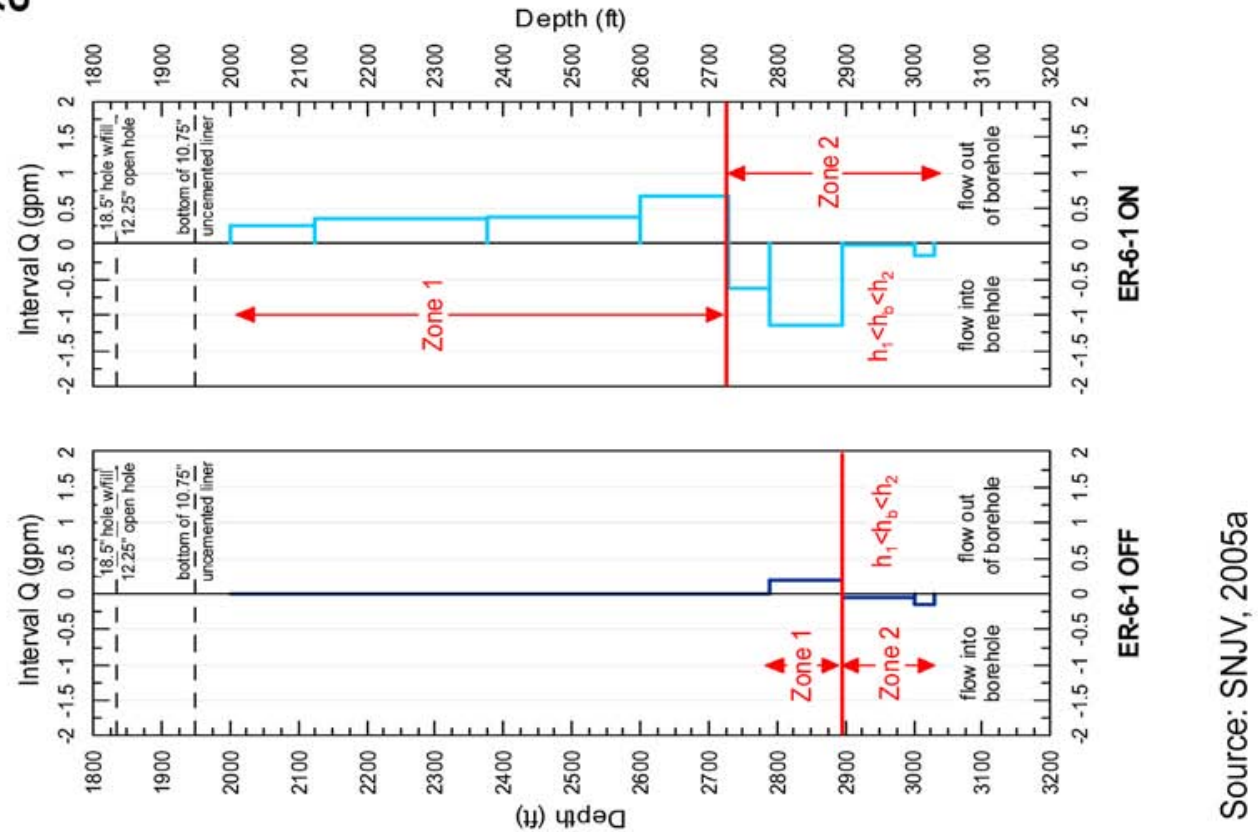

Figure 2-5

TFM Interval Flow Rates for (a) ER-6-1 and (b) ER-6-1 \#2 
From the SFM results for ER-6-1, it appears that a major transmissive feature exists between 2,351 and 2,381 ft bgs. This coincides with the interval where most flow exits the borehole under ambient and ER-6-1 \#2 pumping conditions, and which is also associated with washouts. From these logs, it can also be concluded that when ER-6-1 \#2 is pumped, it lowers the head in the ER-6-1 zone(s) connected to borehole ER-6-1 \#2 sufficiently to create a stronger downward flow cell in the borehole and also enough to lower the zone of borehole inflow to a depth of 2,350 ft bgs. It appears that ER-6-1 is better connected to ER-6-1 \#2 in the lower zone (Zone 2) located between 2,350 ft bgs and the bottom of the borehole under conditions of pumping in ER-6-1 \#2.

The TFM was run in ER-6-1 \#2 on December 3, 2003, over the interval from 2,000 to 3,031 ft bgs (campaign TFM-1 \#2). The TFM was also run in ER-6-1 \#2 when ER-6-1 was pumped. This log was run on January 28, 2004, over an interval from 2,000 to 3,031 ft bgs (campaign TFM-2 \#2). Figure 2-5(b) plots the difference between borehole flow rates (i.e., interval flow rates) measured by the TFM. Under ambient conditions (TFM-1 \#2), formation water flows into the borehole at depths below 2,900 ft bgs, and water flows back out of the borehole between a depth of 2,900 and 2,800 ft bgs. Interval flows are very low. Under ambient conditions, borehole interflow is negligible in ER-6-1 \#2.

Conditions change significantly in ER-6-1 \#2 when ER-6-1 is pumped. Figure 2-5(b) shows the interval flow rates for logging campaign TFM-2 \#2. When ER-6-1 is pumping, flow into ER-6-1 \#2 occurs in the interval from 2,725 to 3,040 ft bgs. Flow rates into the borehole exceed $1 \mathrm{gpm}$ in the brecciated interval from approximately 2,800 to 2,900 ft bgs. This zone coincides with a relatively transmissive zone from 2,816 to 2,951 ft bgs (apparently associated with several washouts) as determined from the SFM logs run in ER-6-1 \#2 (see Figure 2-4). Above a depth of 2,725 ft bgs, the borehole fluid exits the borehole over a zone from 2,000 to 2,750 ft bgs. The largest borehole flow rate change centers on a depth of 2,725 ft bgs. From a review of Figure 2-5(b), the borehole can be divided into two zones depending on whether flow is directed into or out of the borehole.

From the SFM results for ER-6-1 \#2, a major transmissive feature appears to exist between 2,151 and 2,226 ft bgs (a zone of many washouts and breakouts with 36 percent normalized transmissivity) and 2,816 and 2,951 ft bgs (a zone of minor breakouts with 25 percent normalized transmissivity).

Oberlander and Russell (2004) noticed similar patterns. From these results, it can be concluded that 
when ER-6-1 is pumped, it lowers the head in ER-6-1 \#2 borehole zones(s) well connected to ER-6-1 sufficiently to create a stronger upward flow cell in the borehole. It appears that ER-6-1 \#2 is better connected to ER-6-1 in the upper zone (Zone 1) located between depths 2,000 and 2,725 ft bgs under conditions of pumping in ER-6-1.

\section{Interconnectedness Evaluated from Flow Logging}

Figure 2-6(a) and (b) plots the borehole TFM interval flow rates when the opposing borehole is being pumped, the normalized interval transmissivities as determined from the SFM logging, and documented washouts, fracture zones, and breccia zones. Flow between ER-6-1 and ER-6-1 \#2 is controlled by discrete intervals dominated by fractured and brecciated carbonates. The TFM logs analyzed for conditions when the opposing well is pumped provide direct evidence for borehole connection intervals.

The SFM logging results delineate the locally most transmissive interval at the borehole being logged. The TFM flow logging results delineate what intervals are the best connected while the other borehole is being pumped. Thus, the TFM logging results are the most relevant and valuable in determining the intervals of interconnectedness for transport of tracer introduced in ER-6-1 while ER-6-1 \#2 is being pumped. The interpreted connection between ER-6-1 \#2 and ER-6-1 from TFM analysis is summarized in Table 2-3.

\subsection{Fault and Fracture Characterization}

Core fracture analyses and geophysical log comparisons were performed for ER-6-1 after well completion in 1994. Caliper and borehole televiewer (BHTV) logging were performed. Fracture analysis was difficult due to shattering over much of the core. Consequently, confidence in observations and interpretations was reported as lower. The ER-6-1 core fracture analyses report (IT, 1996b) summarizes the fracture information for ER-6-1 as follows:

- In-situ brecciation is more important than individual fracture sets.

- The majority of fractures in core were filled with reddish-brown, iron-oxide-stained clay. The thickness of clay in some fractures exceeds 1 to 2 millimeter (mm). Many of the tight, hairline cracks in highly fractured intervals were coated with a red iron-oxide stain. 

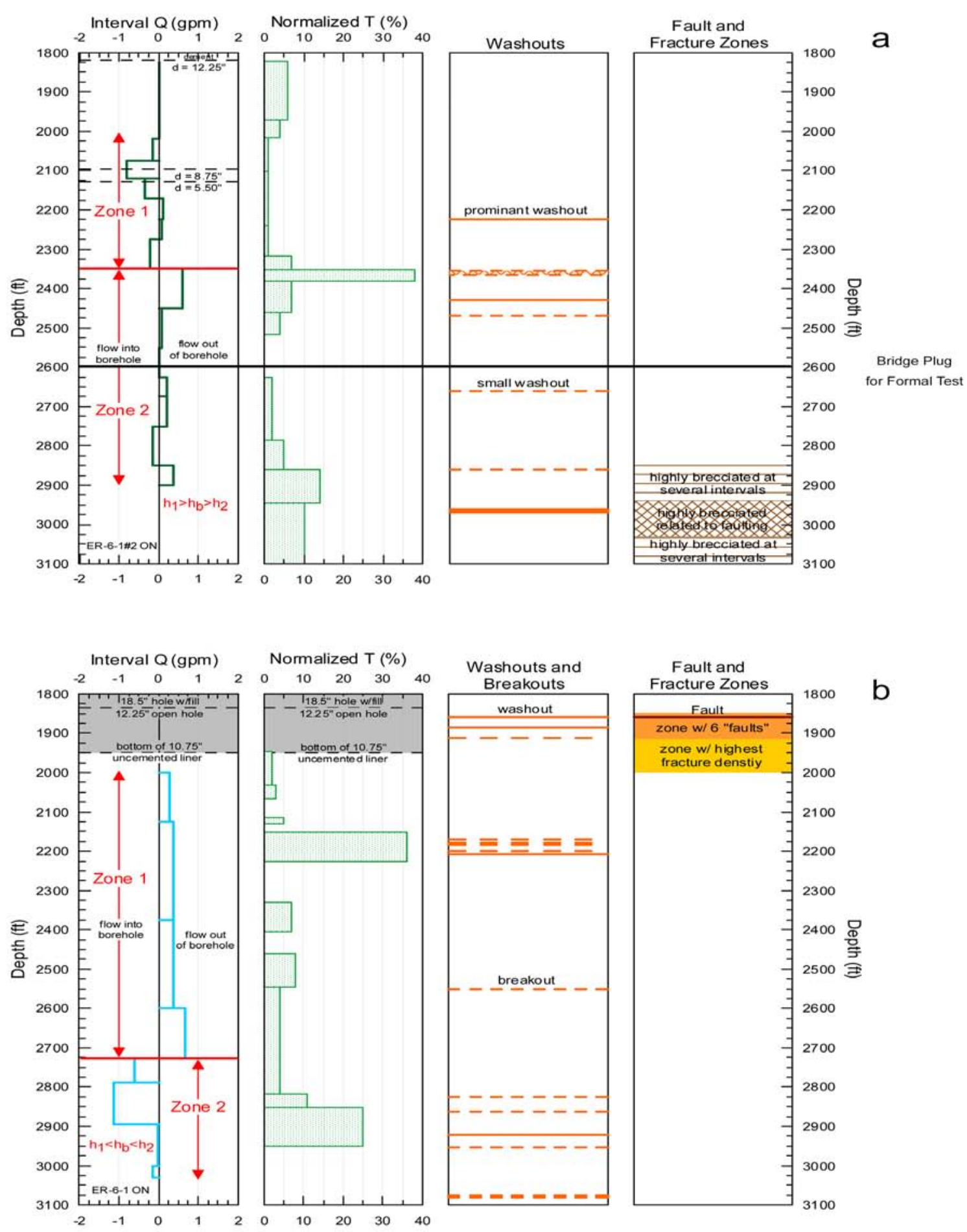

Source: SNJV, 2005a

Figure 2-6

Composite Logs for (a) ER-6-1 \#2 and (b) ER-6-1 
Table 2-3

Interconnected Interval Determined from TFM Flow Logging

\begin{tabular}{|c|c|c|}
\hline $\begin{array}{c}\text { Zones } \\
\text { (ft bgs) }\end{array}$ & $\begin{array}{c}\text { Depth Interval in ER-6-1 } \\
\text { (ft bgs) }\end{array}$ & $\begin{array}{c}\text { Depth Interval in ER-6-1 \#2 } \\
\text { (ft bgs) }\end{array}$ \\
\hline \hline $\begin{array}{c}\text { Upper } \\
\text { (above 2,600) }\end{array}$ & 2,350 to 2,600 & 2,000 to 2,600 \\
\hline $\begin{array}{c}\text { Lower } \\
\text { (below 2,600) }\end{array}$ & 2,600 to 3,086 a & 2,600 to 2,725 \\
\hline
\end{tabular}

aNote: Maximum TFM logged depth in ER-6-1 was 2,900 ft bgs. The ER-6-1 SFM log showed that 10 percent of the inflow was coming from below 2,946 ft bgs. The ambient TFM log in ER-6-1 performed in 1995 showed inflow at 2,240 to $2,440 \mathrm{ft}$ bgs and then downward flow with outflow from 2,950 to 3,100 ft bgs and no flow below 3,100 ft bgs. Therefore, it is concluded that the LCA/Eureka Quartzite contact at 3,086 ft bgs is a reasonable base for flow in and out of the lower zone of ER-6-1.

- $\quad$ Older, randomly oriented, completely healed fractures were common.

- Highly brecciated zones were especially important below 2,850 ft bgs.

- There was not a strong association between fracture intervals with measurable aperture and borehole washouts.

- Extension fractures: 17 fractures were orientable with the BHTV with high-dip angle, and have a mean strike azimuth of 31.6 degrees.

- Breccia zones or faults: six narrowly defined zones or faults were identified in core and interpreted on the BHTV as planar features. The mean strike of these faults is 13.7 degrees, but there is a wide interval.

- Caliper logging revealed prominent washouts at 2,225, 2,430, and 2,960 to 2,970 ft bgs and smaller washouts at 2,355 to 2,365, 2,470, 2,660, and 2,860 ft bgs. Most of the washouts do not correlate with zones of observed aperture. Correlation between washouts and breccia zones is generally strong.

The ER-6-1 \#2 fracture analysis (SNJV, 2005d) summarizes the fracture information as follows:

- Water production during drilling increased by 50 gpm between 1,860 and 1,890 ft bgs, indicating the possible presence of a fractured or faulted zone. (However, this zone was not accessible during flow logging.)

- The EMI logging was conducted from 1,790 to 3,202 ft bgs. Three fracture orientations are visible on the stereonet plots.

- Most of the fracture features are characterized as irregular, mineral-filled joints or bedding fractures. 
- Bedding planes and fractures comprise more than half of the fractures identified and strike 169 degrees south and dip 27 degrees west.

- Joint fractures dip approximately perpendicular to bedding, strike north 355 degrees, and dip 41 degrees east.

- $\quad$ Faults (defined as apertures greater than $100 \mathrm{~mm}$ ) are rare and occur between depths of 1,848 and 1,914 ft bgs. They strike north-northwest 338 degrees and dip 51 degrees east (opposite the westward-dipping geologically inferred fault).

\subsection{Transport Conceptual Model}

\subsubsection{Regional Framework}

Winograd and Thordarson (1975) describe the general conceptual model of the LCA hydrogeology and hydrochemistry. This conceptual model includes negligible intercrystalline and vugular porosity and associated permeability with water moving along solution-modified fractures and brecciated zones, and fracture porosity of 0.01 or less with higher porosity in the brecciated zones. Winograd and Pearson (1976) use groundwater isotope data to argue for large-scale (at least 11-km scale) flow channeling, or concentrated flow along fast preferential paths in the LCA, along eastern Frenchman Flat to Ash Meadows. Interestingly, Winograd and Pearson (1976) did not reason that channeling was a particularly satisfying explanation for the observed chemistry, but this conceptual model still appears plausible in light of the speedy response at ER-7-1, $10 \mathrm{~km}$ north of ER-6-1 \#2, and the linear flow regime encountered.

\subsubsection{General Transport Behavior and Scoping Calculations}

\section{Lower Zone Response}

The estimated peak tracer concentration arrival time for the ER-6-1 fast-path tracer test and the ER-6-1 MWAT-TT are both about nine days. This suggests that fracture-dominated transport in the lower zone resulted in the most rapid arrival of tracer at ER-6-1 \#2 from tracer injection in ER-6-1. Figure 2-7 shows the injection-mass normalized breakthrough curves for 2,6-DFBA (with main tracer test data path time shifted to end of the fast-path test), I, and TFBA. Note that the I and TFBA curves show very little qualitative difference in behavior (although the noise in I concentration makes the peak arrival identification unclear); if double-porosity effects were strong, the I peak should arrive 


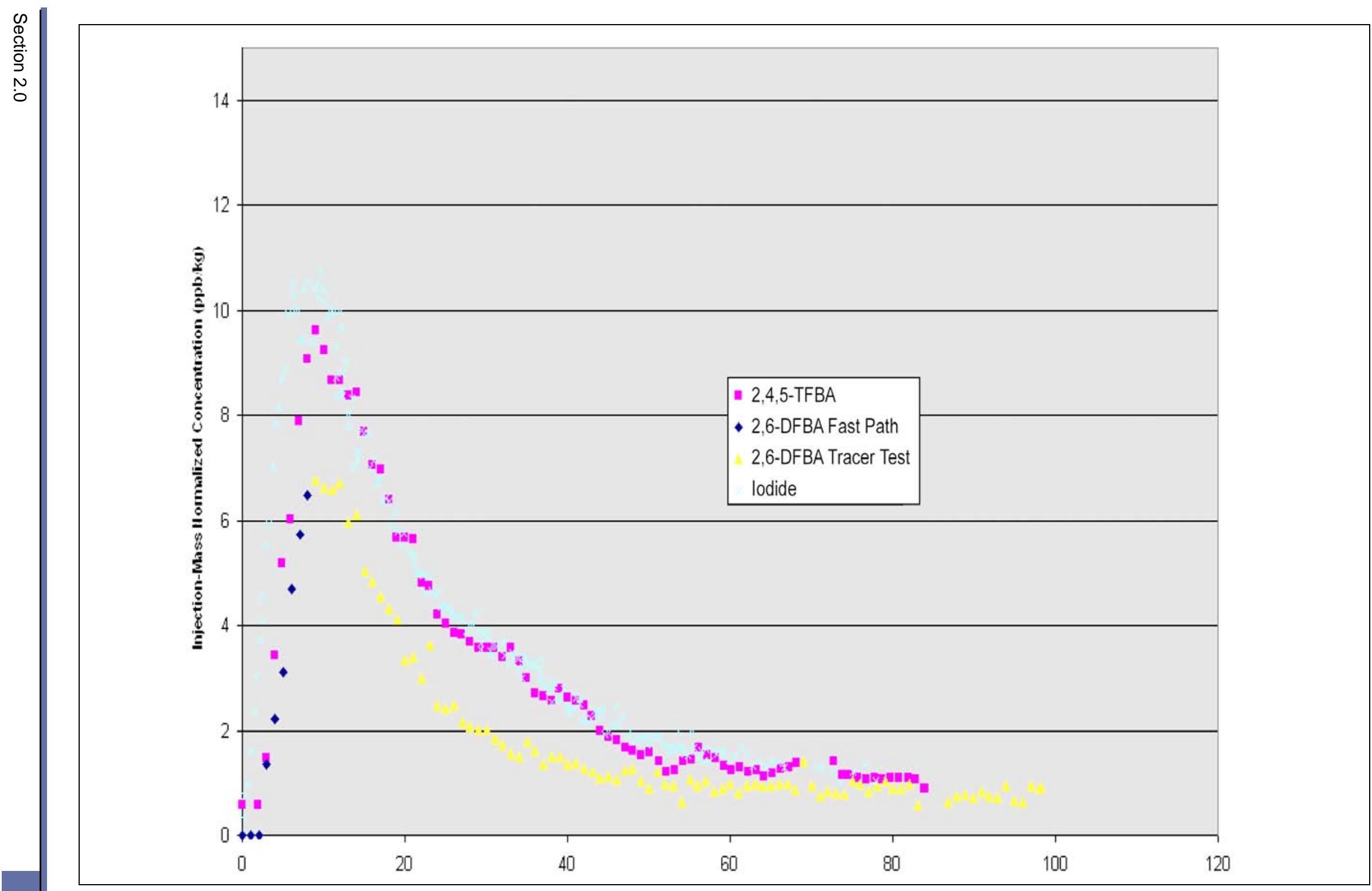

Figure 2-7

2,4,5-TFBA, 2,6-DFBA, and lodide Injection Mass-Normalized Breakthrough Curves at ER-6-1 \#2 
clearly later (it does not) than the TFBA. The 2,6-DFBA curves are also similar to the TFBA data, suggesting that the fast-path and formal tracer test involved the same pathways.

At the start of the MWAT-TT pumping, the 2,6-DFBA tracer concentration (used in the fast-path test) at ER-6-1 \#2 was 205 ppb as compared with the maximum tracer concentration of $69 \mathrm{ppb}$ at the end of the 8.8-day pumping period for the fast-path tracer test (Figure 1-6). This rebound in tracer concentration in the fractures after a period of nonpumping is a classic response for transport in a double-porosity system. However, matrix diffusion is likely not the cause of this concentration spike because the concentrations were still increasing when the flow interruption occurred. Under these conditions, matrix diffusion would be expected to reduce concentrations after resumption of flow (concentrations would have been higher in the fractures than the matrix at the time of the flow interruption, so there would have been net diffusion into the matrix during the interruption), and matrix diffusion is not clearly indicated in the responses of the TFBA and I. The increase in concentration can also be interpreted to be the result of the fast-path 2,6-DFBA plume drifting toward ER-6-1 \#2 during the time the pump was off before the start of the ER-6-1 MWAT-TT.

These breakthrough concentrations for tracers injected in the lower zone of ER-6-1 were well above the detection limit as compared to the tracer breakthrough curves for the organic acid tracers injected in the upper zone of ER-6-1 and in ER-6-1 \#1. The amount of I injected = I-formula weight/NaI-formula weight x $24 \mathrm{~kg}$ of injected $\mathrm{NaI}=20.3 \mathrm{~kg}$. The ratio of I injected to 2,4,5-TFBA injected is (20.3/10) 2.0. The ratio of the peak I concentration to the peak 2,4,5-TFBA concentration is (195 ppb/88 ppb) 2.2 (because the purity of the organic tracer is likely less than 100 percent, the ratio may even be higher). Because the diffusion coefficient of I (about $3 \times 10^{-9}$ square meters per second $\left[\mathrm{m}^{2} / \mathrm{s}\right]$ ) is higher than for 2,4,5-TFBA (about $1 \times 10^{-9} \mathrm{~m}^{2} / \mathrm{s}$ ) the $\mathrm{I} / 2,4,5$-TFBA peak concentration ratio should have been lower, not greater, than the mass injected ratio. This behavior is unexpected unless other processes are impacting transport, or there are errors or uncertainties in the injectate concentrations and masses.

The overall 2,6-DFBA breakthrough curve was not quantitatively analyzed because of the long flow interruption. However, the 2,6-DFBA concentration spike after resumption of pumping does suggest that the natural gradient flow at the ER-6-1 well complex is oriented more in the direction from ER-6-1 to ER-6-1 \#2 than vice versa (as interpreted from Yucca Flat LCA water levels), as the latter 
situation would result in a lower initial concentration upon resumption of pumping. Unfortunately, it is not possible to obtain a well-constrained estimate of the groundwater drift velocity during the flow interruption because the distribution of the tracer plume around ER-6-1 \#2 at the time of the flow stoppage was unknown. However, a rough estimate of the drift velocity can be made as follows:

- Upon resumption of pumping for the main tracer test, it took about $20 \mathrm{hr}$ (Figure 2-8) for the 2,6-DFBA concentrations to decline to the same level (about $69 \mathrm{ppb}$ ) as before the pump stoppage. It seems reasonable to assume that during this 20-hr period, the water being drawn into ER-6-1 \#2 included at least some traced water that had drifted into the volume of water produced during this first $20 \mathrm{hr}$ of pumping for the formal tracer test.

- The $20 \mathrm{hr}$ that it took for the 2,6-DFBA concentrations to decline to the end of the fast-path concentrations represent about $1 / 12^{\text {th }}$ of the time it took for peak tracer concentrations to arrive from the lower zone of ER-6-1 (about $240 \mathrm{hr}$ ). Assuming that the time to reach peak concentrations represents the approximate time it takes to sweep out a cylindrical volume of the aquifer with a radius equal to the distance between ER-6-1 and ER-6-1 \#2 (about $64 \mathrm{~m}$ ), then the radial distance swept out in $1 / 12^{\text {th }}$ the time (i.e., 20/240) would be about $1 / \sqrt{12}$ of the distance between ER-6-1 to ER-6-1 \#2, or about 18 m (assuming radial flow).

- By integrating the area under the 2,6-DFBA breakthrough curve, it is estimated that about 37.5 percent additional tracer mass was recovered during the initial $20 \mathrm{hr}$ of pumping after the flow stoppage than would have been recovered if concentrations had remained at what they were before the pump was stopped.

- This additional 37.5 percent of tracer mass is equivalent to about $7.5 \mathrm{hr}$ ( 37.5 percent of $20 \mathrm{hr}$ ) of additional pumping of water containing 2,6-DFBA at pre-pump-stoppage concentrations (about $69 \mathrm{ppb}$ ). Assuming radial flow, the radial distance "swept out" in $7.5 \mathrm{hr}$ would be about $11 \mathrm{~m}(=\sqrt{7.5 /(240)} \times 64 \mathrm{~m})$. This radial distance could be considered an upper bound for the distance that tracers drifted under ambient flow conditions during the pump stoppage. However, it is more reasonable to assume that all of the extra tracer mass produced during the $20 \mathrm{hr}$ of pumping would have moved from outside to inside the 18-m swept-out radial distance from ER-6-1 \#2 during the flow stoppage (all the mass that was already inside the 26-m radial distance would have either moved closer to the production well or a little bit past the production well). In this case, it is more appropriate to assume that the production of the additional tracer mass occurred during the last $7.5 \mathrm{hr}$ of the 20 -hr production period, not at the beginning of the period. The inner and outer radial distances associated with the last $7.5 \mathrm{hr}$ of the first $20 \mathrm{hr}$ of pumping may be calculated by solving the following equation for $x$ (which equates the areas being swept out in the first and last $7.5 \mathrm{hr}): 11=\left(18^{2}-x^{2}\right)$. An implicit assumption in this analysis is that the water moving into the sweep-out zone during the flow interruption had about the same tracer concentrations as the water that was just entering the swept-out zone at the time of the flow stoppage (which was approximately the maximum concentration before or after the flow stoppage, not counting the first $20 \mathrm{hr}$ after flow resumption). 


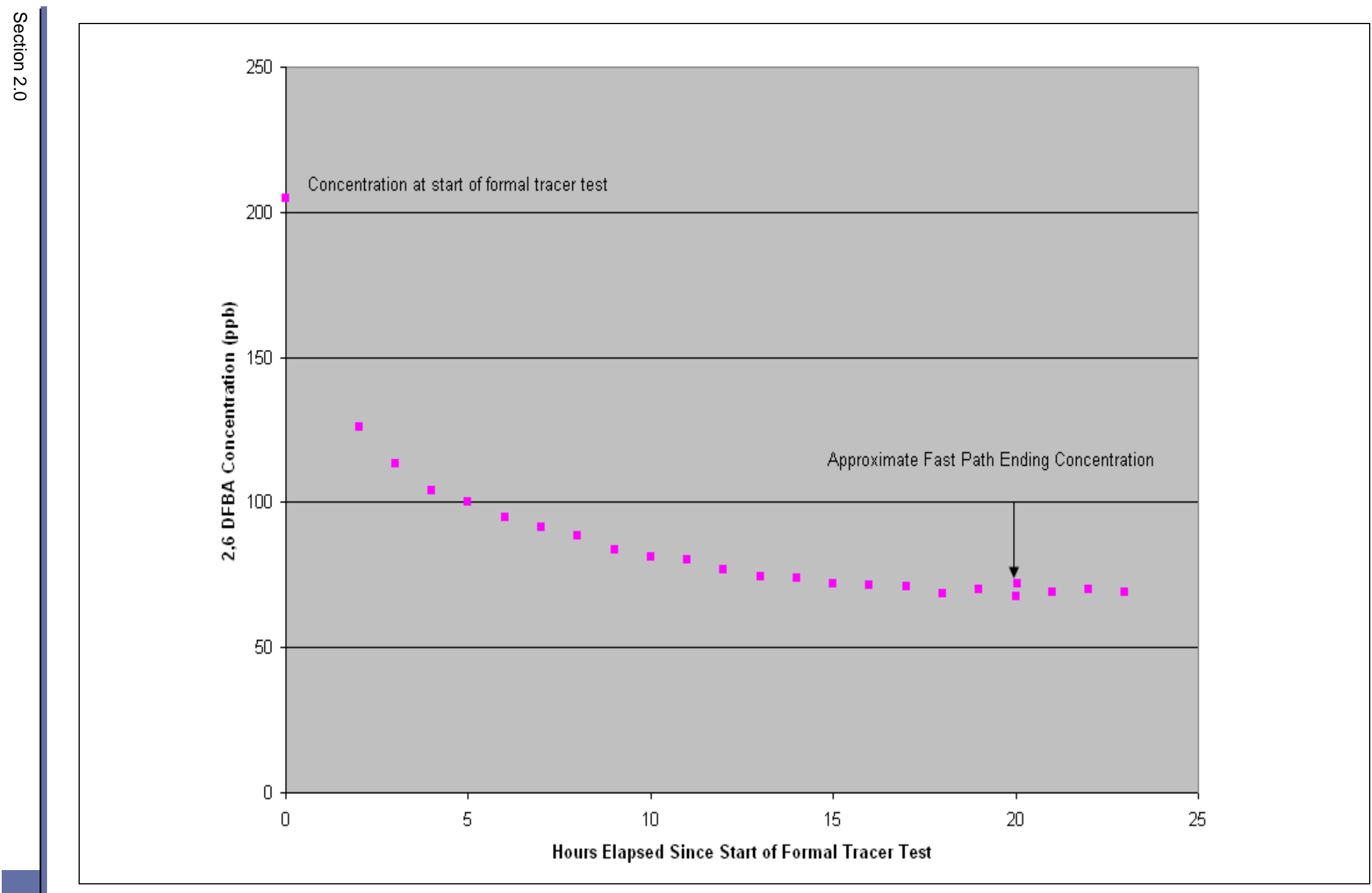

Figure 2-8

2,6-DFBA Concentration at ER-6-1 \#2 During the First Day of the Formal Tracer Test 
- Solving the equation for the inner and outer radial distances presented in the previous paragraph results in an inner radial distance of $14 \mathrm{~m}$. Thus, the distance that tracer-bearing water moved with the natural gradient during the 61-day flow stoppage is estimated to be $18-14=4 \mathrm{~m}$, yielding an estimated ambient flow velocity in the direction from ER-6-1 to ER-6-1 \#2 of 4/61 = 0.066 meters per day (m/day). This analysis assumes that the natural gradient is oriented directly from ER-6-1 to ER-6-1 \#2 - if the orientation is at some acute angle to this direction, then the actual drift velocity would be somewhat greater $(0.066 \mathrm{~m} / \mathrm{day}$ divided by the cosine of the angle).

- A qualitative reality check on this estimate of $4 \mathrm{~m}$ of drift during the flow stoppage can be obtained by considering that some of the tracer mass that was very close to the production well at the time of the flow stoppage should have drifted up to $4 \mathrm{~m}$ past the well during the stoppage. In this case, relatively high concentrations upon resumption of pumping could be expected to persist for as long as it takes to sweep out at least a 4-m radial zone around ER-6-1 \#2. Assuming radial flow, the time necessary to sweep out a 4-m radial zone should have been about $1 \mathrm{hr}\left(=4^{2} / 64^{2} \times 240 \mathrm{hr}\right)$; the highest concentrations were encountered during the first hour or two of pumping.

- If the mean arrival time of the tracer mass injected into the lower zone of ER-6-1 (approximately $800 \mathrm{hr}$ ) is used as the time it takes to sweep out a cylindrical volume of aquifer with a radius of $64 \mathrm{~m}$ (instead of the peak arrival time), then the estimate of the tracer drift distance during the flow stoppage decreases to $3 \mathrm{~m}$ and the drift velocity estimate decreases to $0.049 \mathrm{~m} /$ day. That is, the radial distance swept during the first $20 \mathrm{hr}$ of pumping is $\sqrt{(20 / 800)} \times 64 \mathrm{~m}=10 \mathrm{~m}$, and the radial distance swept in $7.5 \mathrm{hr}$ is $\sqrt{7.5 / 800} \times 64 \mathrm{~m}=6 \mathrm{~m}$, so the equivalent radial distance swept in the last $7.5 \mathrm{hr}$ of the first $20 \mathrm{hr}$ of pumping becomes $\sqrt{10^{2}-6^{2}}=8 \mathrm{~m}$, and the drift distance is $10-8=2 \mathrm{~m}$.

In summary, the 2,6-DFBA response immediately after resumption of pumping suggests a natural gradient direction that is oriented from ER-6-1 toward ER-6-1 \#2 and an average flow velocity estimate (note that this is an actual pore velocity, not a specific discharge) of 0.049 to $0.066 \mathrm{~m} /$ day. This flow velocity estimate involves no direct assumptions about flow porosity, but it does assume radial or quasi-radial flow during pumping (velocities varying as the inverse of distance from ER-6-1 \#2) and an ambient flow direction oriented directly from ER-6-1 to ER-6-1 \#2 rather than at some acute angle to an imaginary line intersecting the two wells.

The 2,4,5-TFBA tracer was injected into the lower zone of ER-6-1. Depth-discrete sampling was generally performed on a 100 -ft depth frequency. Using the discrete-depth sampler, this tracer was detected in ER-6-1 \#2 from the lowest sampling depth at 2,900 ft bgs, but higher concentrations were observed in the more shallow zones (2,850 ft bgs and shallower). Therefore, the most active 
connection zone from ER-6-1 to ER-6-1 \#2 is at and above 2,850 ft bgs but with some connection as deep as 2,900 ft bgs in ER-6-1 \#2.

Examination of the TFM log for ER-6-1 while pumping ER-6-1 \#2 shows the most active connection for the lower zone in ER-6-1 is below about 2,625 ft bgs, which is very similar to the top of the lower zone at 2,600 ft bgs. Examination of the DRI TFM log for ER-6-1 \#2 while pumping ER-6-1 shows the most active connection for the lower zone in ER-6-1 \#2 is above 2,725 ft bgs (because pumping stress is in the opposite direction compared to the tracer test, the connection is not entirely analogous).

The ambient TFM in ER-6-1 performed during 1995 showed inflow at 2,240 to 2,440 ft bgs, and then downward flow with outflow from 2,950 to 3,100 ft bgs and no flow below 3,100 ft bgs. The ambient 2004 TFM log is much different with little outflow below 2,550 ft bgs. During 1995, the TFM log suggests the presence of a transmissive feature below 2,900 ft bgs that was not logged in 2004. The bottom of the active tracer outflow interval in ER-6-1 may be the base of the LCA above the Eureka Quarzite at 3,086 ft bgs.

In summary, the most active tracer outflow from ER-6-1 is estimated to be between 2,650 and 3,086 ft bgs, and the most active tracer inflow in ER-6-1 \#2 is below 2,600 ft bgs and above 2,850 ft bgs.

\section{Upper Zone Connection}

The PFBA tracer was injected into the upper zone of ER-6-1 above 2,599 ft bgs. It was not detected below 2,550 ft bgs in ER-6-1 \#2 (SNJV, 2005e, Figure 6-4). This observation shows that tracer from the ER-6-1 upper zone did not move deeper to ER-6-1 \#2 and also that tracer injected in the lower zone below 2,600 ft bgs likely did not enter ER-6-1 \#2 above 2,550 ft bgs. Discrete-depth sampling for ER-6-1 \#2 on May 18 and 19, 2004, shows highest PFBA concentrations from 2,300 ft bgs and higher, suggesting better connection above 2,300 ft bgs.

Figure 2-9 shows injection-mass normalized breakthrough curves for PFBA, Li, and Br. The tracers show similar behavior with no clear double-porosity effects. However, the interpretation is complicated by the use of $\mathrm{Li}$ and $\mathrm{Br}$ as a drilling fluid tracer and the presence of both above some nominal background concentration in the groundwater at the start of the test. The too-rapid decline of $\mathrm{Br}$ in Figure 2-9 suggests that the Br background concentration is changing over the test. Because 


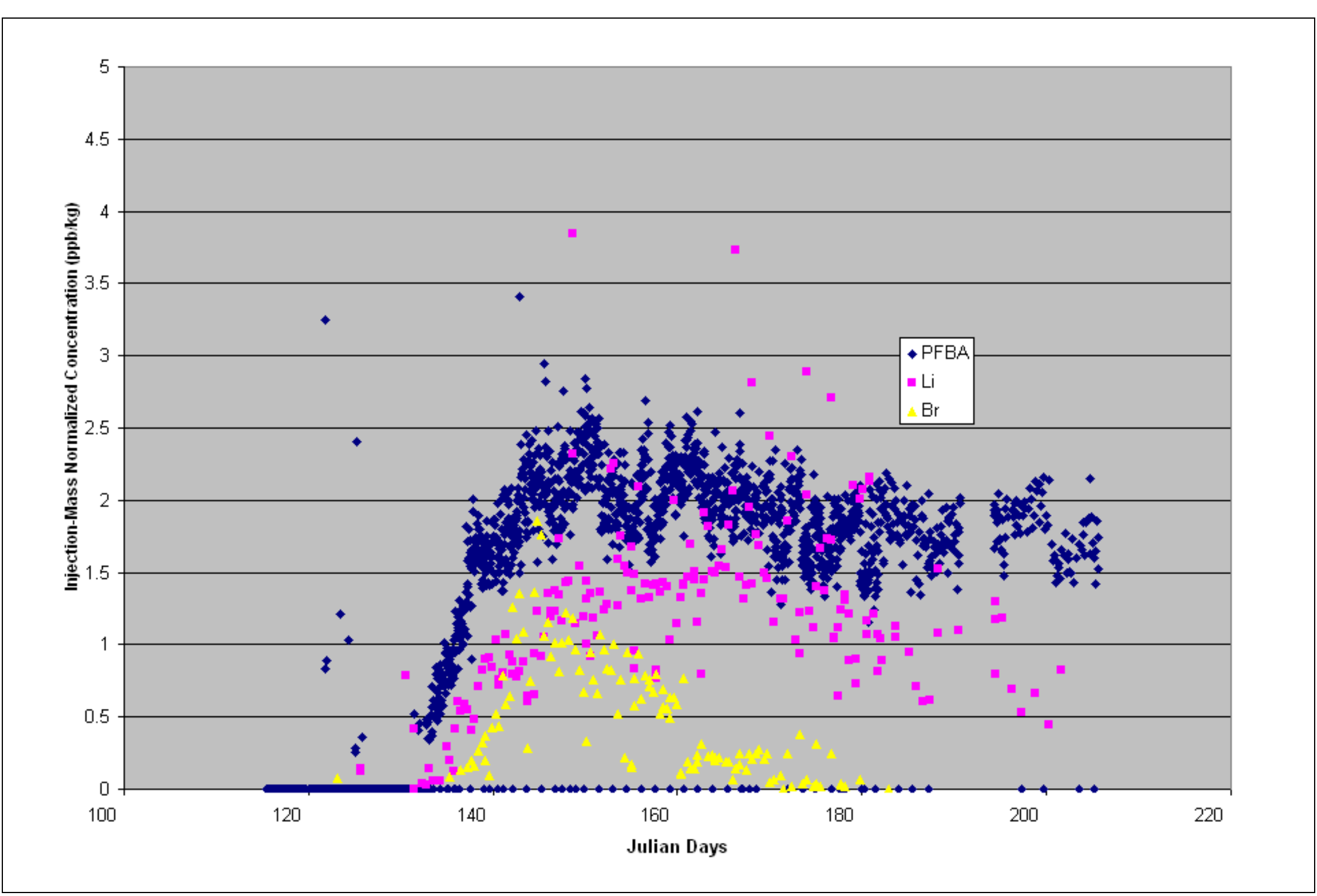

Figure 2-9

ER-6-1 \#2 Injection-Mass Normalized Breakthrough Curves for ER-6-1 Upper Zone Chemical Tracers 
double-porosity effects are interpreted through the differences in tracer curves, these effects make such interpretations problematic.

Examination of the TFM log for ER-6-1 while pumping ER-6-1 \#2 shows outflow only from below 2,350 ft bgs, with the most active outflow at 2,350 to 2,450 ft bgs in ER-6-1. Examination of the TFM log for ER-6-1 \#2 while pumping ER-6-1 shows an outflow zone from 2,000 to 2,725 ft bgs depth (higher elevations are covered by the liner) in ER-6-1 \#2.

The SFM logs show the most transmissive intervals between 2,352 and 2,381 ft bgs in ER-6-1 and between 2,151 and 2,226 ft bgs in ER-6-1 \#2. This corresponds to an average elevation rise in this zone of inferred connection of $177 \mathrm{ft}$ between ER-6-1 and ER-6-1 \#2.

In ER-6-1 under conditions of ER-6-1 \#2 pumping, heads are highest in the interval from 2,025 to approximately 2,350 ft bgs and lowest in the interval from 2,350 to 2,900 ft bgs. In ER-6-1 \#2 under conditions of ER-6-1 pumping, heads are highest at the bottom of the borehole from 2,725 to 3,025 ft bgs and lowest in the interval from 2,000 to 2,725 ft bgs. Therefore, under interference pumping conditions, the relative higher and lower head zones are reversed. This suggests an angled transmissive connection between the two boreholes which is lower in ER-6-1 than in ER-6-1 \#2.

In summary, the most active tracer outflow from the upper zone of ER-6-1 is between 2,350 and 2,450 ft bgs (with some outflow from 2,450 to 2,550 ft bgs), and the corresponding most active tracer inflow in ER-6-1 \#2 is below 2,600 ft bgs and above 2,850 ft bgs (or 2,950 ft bgs).

\section{Apparent Tracer Analytical Anomalies}

A number of the tracer detections identified from the depth-discrete samples are unexpected and are unlikely to be representative of actual transport behavior. Some of the positive hits may be the result of interference between the various organic tracers during high-performance liquid chromatograph (HPLC) analysis. The data report also lists other potential causes as contamination of the samples during HPLC analysis and cross-contamination of samples due to residual contamination of the discrete bailer.

Tracer 2,5-DFBA was injected into ER-6-1 \#1. Tracer is detected from depth-discrete samples along the full depth of ER-6-1 \#2 either during or after the tracer test, which is not expected. For samples 
collected after the tracer test pumping stopped, tracer detection in samples collected deep in the borehole could result from flow within the borehole.

Organic tracers injected in the upper and lower zones of ER-6-1 are reported from depth-discrete samples taken in ER-6-1 \#1 either during or after the tracer test. Tracer detection in ER-6-1 \#1 is not expected from tracers I and 2,4,5-TFBA that were injected in the lower zone of ER-6-1. Appendix A reviews these anomalies further.

\subsubsection{Estimated Fracture or Effective Porosity}

Based on the theoretical plug-flow travel time between the tracer-addition and the production well in a radially convergent-flow tracer test, an initial estimate of fracture or effective porosity can be calculated using the relationship:

$$
\phi=\frac{Q t_{p}}{\pi r^{2} b}
$$

where $\phi$ is the fracture porosity, $Q$ is the production rate, $t_{p}$ is the time to reach the peak concentration at the production well after injection of the pulse at the tracer-addition well, $r$ is the distance between the tracer-addition and production wells, and $b$ is the aquifer thickness. The time to reach the peak concentration is considered representative of the average transport rate between the tracer-addition and production wells under the assumption that diffusive losses to the matrix are minimal along a flow path that exhibits rapid transport through the fractures. Jones et al. (1992) successfully used this relationship to provide initial estimates of fracture or effective porosity for flow paths that exhibited rapid fracture-dominated transport in a fractured dolomite aquifer at the DOE Waste Isolation Pilot Plant (WIPP) site.

The transport behavior for the lower zone shows that the fracture system has a low porosity and good connection, exhibiting a relatively rapid tracer breakthrough at the production well. The time of peak tracer arrival at the production well is about nine days for the tracers injected in the lower zone of ER-6-1. The average production rate for ER-6-1 \#2 during the tracer test was 523.8 gpm. From SFM logging, it appears that about 31 percent of the flow is from below 2,600 ft bgs in ER-6-1, and about 39 percent of the flow is from below 2,600 ft bgs in ER-6-1 \#2. Taking an average of 35 percent, the estimated flow below 2,600 ft bgs corresponding to the lower transport zone is $183 \mathrm{gpm}(0.35 \mathrm{x} 523.8$ 
gpm). The transport distance between wells of $296 \mathrm{ft}$ and the lower zone thickness is $486 \mathrm{ft}$ (2,600 to $3,086 \mathrm{ft}$ bgs). The calculated fracture porosity for the lower zone using the above relation is 0.0024 .

The transport behavior for the upper zone suggests that the fracture system is less well connected, exhibiting a much slower breakthrough compared to the lower zone. The time of peak tracer arrival at the production well is about 29 days for the tracers injected in the upper zone of ER-6-1. From SFM logging, it appears that about 69 percent of the flow is from above 2,600 ft bgs in ER-6-1, and about 61 percent of the flow is from above 2,600 ft bgs in ER-6-1 \#2. Taking an average of 65 percent, the estimated flow below 2,600 ft corresponding to the upper transport zone is 340 gpm ( 0.65 $\mathrm{x} 523.8 \mathrm{gpm}$ ). The transport distance between wells is $296 \mathrm{ft}$ and the upper zone thickness is $829 \mathrm{ft}$ (1,770 to 2,599 ft bgs). The calculated fracture porosity for the upper zone using the above relation is 0.0083 (which is a factor of 3.5 larger than that calculated for the lower zone). The larger apparent effective porosity (based on a later time of peak tracer concentration) may be the result of anisotropy and orientation of the principal transmissivity direction. Both of these factors can result in a much larger impact of matrix diffusion, thus preventing time of peak tracer concentration as a reliable approach to estimate fracture porosity.

\section{Longitudinal Dispersivity}

A theoretical analysis of convergent-flow tracer tests with a pulse input at a tracer-addition well was presented by Welty and Gelhar (1989). Using the assumption that longitudinal dispersivity divided by the distance between the production- and tracer-addition wells is much less than unity, they developed the following relation to estimate longitudinal dispersivity:

$$
\alpha=\frac{3 r\left(\Delta t / t_{m}\right)^{2}}{64}
$$

where $\alpha$ is longitudinal dispersivity, $r$ is distance between tracer-addition and production wells, $t_{m}$ is arrival time of the peak concentration at the production well, $\Delta t$ is equal to twice the time period from concentration $e^{-1} C_{m}$ to concentration $C_{m}$, and $C_{m}$ is the peak concentration. Jones et al. (1992) used this relation to estimate longitudinal dispersivities for three tracer test sites where flow paths exhibited rapid fracture-dominated transport in a fractured dolomite aquifer at the WIPP site. The final calibrated longitudinal dispersivities were consistent with the estimates using the above relation. 
Using equation 2-2, a longitudinal dispersivity of about $15 \mathrm{ft}$ was calculated based on analysis of the I and 2,4,5-TFBA breakthrough curves for transport from the ER-6-1 lower zone to ER-6-1 \#2. A value of $15 \mathrm{ft}$ is about 5 percent of the travel distance between wells and is consistent with the longitudinal dispersivity versus transport scale reported in Gelhar et al. (1985) and Neuman (1990).

\section{Matrix Porosity}

The most recent database developed for the NTS LCA matrix porosities is contained in the Frenchman Flat contaminant transport data document (SNJV, 2005c); the mean LCA matrix porosity is 0.068. Data from Reimus et al. (2006) give matrix porosities from ER-6-1 core ranging from 0.009 to 0.06, with distinct groupings at around 0.01, 0.03, and 0.06. Hershey et al. (2003) reported LCA matrix porosities from three UE-7nS core samples as 0.017, 0.0174, and 0.025.

\section{Free-Water Diffusion Coefficients}

Aqueous diffusion coefficients were calculated at a temperature representative of formation conditions using the Hayduck and Laudie method reported in Tucker and Nelken (1982). Using this method, the diffusion coefficient is calculated as a function of the reciprocal of water viscosity to the power 1.14. The temperature dependence is incorporated in the water viscosity term. Table 2-4 summarizes the free-water diffusion coefficients. The anionic tracer diffusivities were extrapolated from 25 to $41.4^{\circ} \mathrm{C}$ based on temperature and viscosity data using an approach from Lerman (1979).

\section{Table 2-4}

Tracer Free-Water Diffusion Coefficients

\begin{tabular}{|c|c|}
\hline Tracer & $\begin{array}{c}\text { Diffusion Coefficient } \\
\text { Calculated at } \mathbf{4 1} \mathbf{}^{\circ} \mathbf{C} \\
\left(\mathbf{c m}^{2} / \mathbf{s}\right)\end{array}$ \\
\hline \hline $2,4,5-T F B A$ & $1.16 \times 10^{-5}$ \\
\hline PFBA & $1.12 \times 10^{-5}$ \\
\hline $2,5-D F B A$ & $1.19 \times 10^{-5}$ \\
\hline $\begin{array}{c}2,6-D F B A \\
\text { (Fast-Path Test) }\end{array}$ & $1.19 \times 10^{-5}$ \\
\hline Iodide & $2.95 \times 10^{-5}$ \\
\hline Bromide & $2.97 \times 10^{-5}$ \\
\hline
\end{tabular}

$\mathrm{cm}^{2} / \mathrm{s}=$ Square centimeters per second 


\subsubsection{Fluid Electrical Conductivity Analysis}

This section presents an analysis of the EC logs recorded in ER-6-1 during the injection phase of the fast-path tracer test. The fast-path tracer test was conducted concurrent with the nine-day, constant-rate pumping of ER-6-1 \#2 (February 12 to February 21, 2004) before the MWAT-TT. A $\mathrm{NaCl}$ tracer was introduced with the fast-path tracers to provide an in-well tracer that could be monitored in ER-6-1 for dilution over time and provide insight into the location of tracer exit intervals. Electrical conductivity, sodium ion, $\mathrm{pH}$, and temperature logs were collected in ER-6-1 over a two-day period after tracer addition. This section provides a semiquantitative assessment of the EC logs with an interpretation of internal borehole flow during tracer injection.

The tracer was placed into borehole ER-6-1 by first pumping the tracer solution into 2-7/8-in. tubing that was installed in the well to a depth of 3,104 ft bgs (almost full depth). The tubing was then removed from the borehole, releasing the solution along the length of the borehole. The solution concentration was varied within the injection tubing to compensate for differences in borehole diameter at multiple intervals in an attempt to achieve a constant concentration along the entire borehole. Upon complete removal of the injection tubing, a 3.25-hr process, nine fluid EC logs were collected over the following $48 \mathrm{hr}$. A final background EC log was collected on March 30, 2004, before the MWAT-TT and after the $\mathrm{NaCl}$ tracer was completely flushed from the ER-6-1 borehole. The complete suite of EC logs is shown in Figure 2-10 along with the borehole diameter. The initial EC log was measured approximately $4 \mathrm{hr}$ after tracer injection, with the last EC log being measured $48.5 \mathrm{hr}$ after tracer injection. The time history of the first four EC logs measured after tracer addition are complex and exhibit what appears as a down-borehole migration pattern below a depth of 2,000 ft bgs.

Figure 2-11 plots the ER-6-1 EC logs along with the normalized transmissivity distribution determined from SFM-1 logging and also with the interpreted results from the TFM log measured when ER-6-1 \#2 was being pumped (TFM-1). Analysis of the SFM-1 logs and the TFM-1 logs for ER-6-1 is provided in Oberlander and Russell (2004) and in the MWAT-TT data report (SNJV, 2005e).

The MWAT-TT (SNJV, 2005e) interpretation of the SFM logs measured in ER-6-1 is that the borehole is dominated by discrete flow zones that are related to fractures and brecciated zones within the LCA 


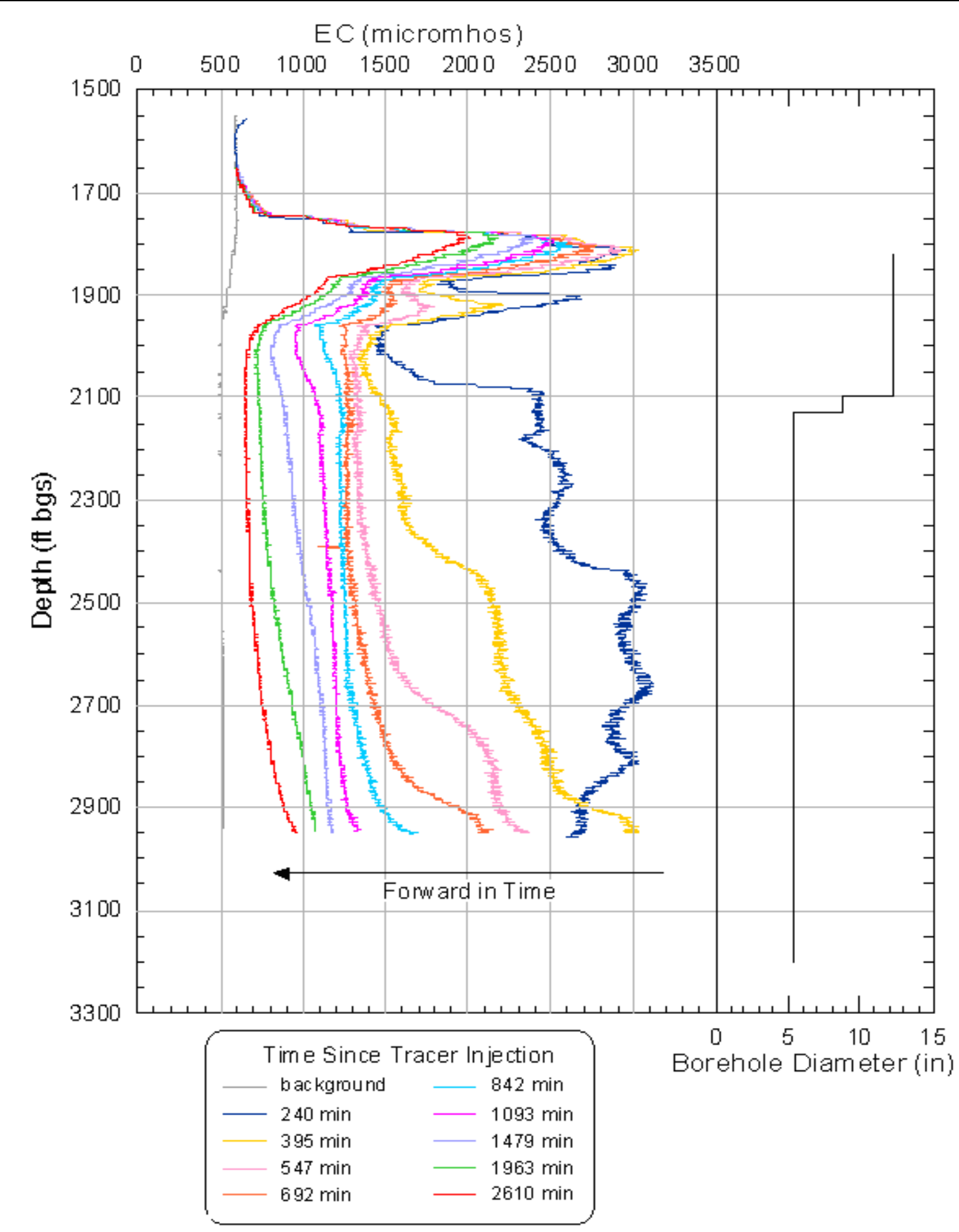

Figure 2-10

Fluid EC Logs Measured in ER-6-1 During the Fast-Path Tracer Test 


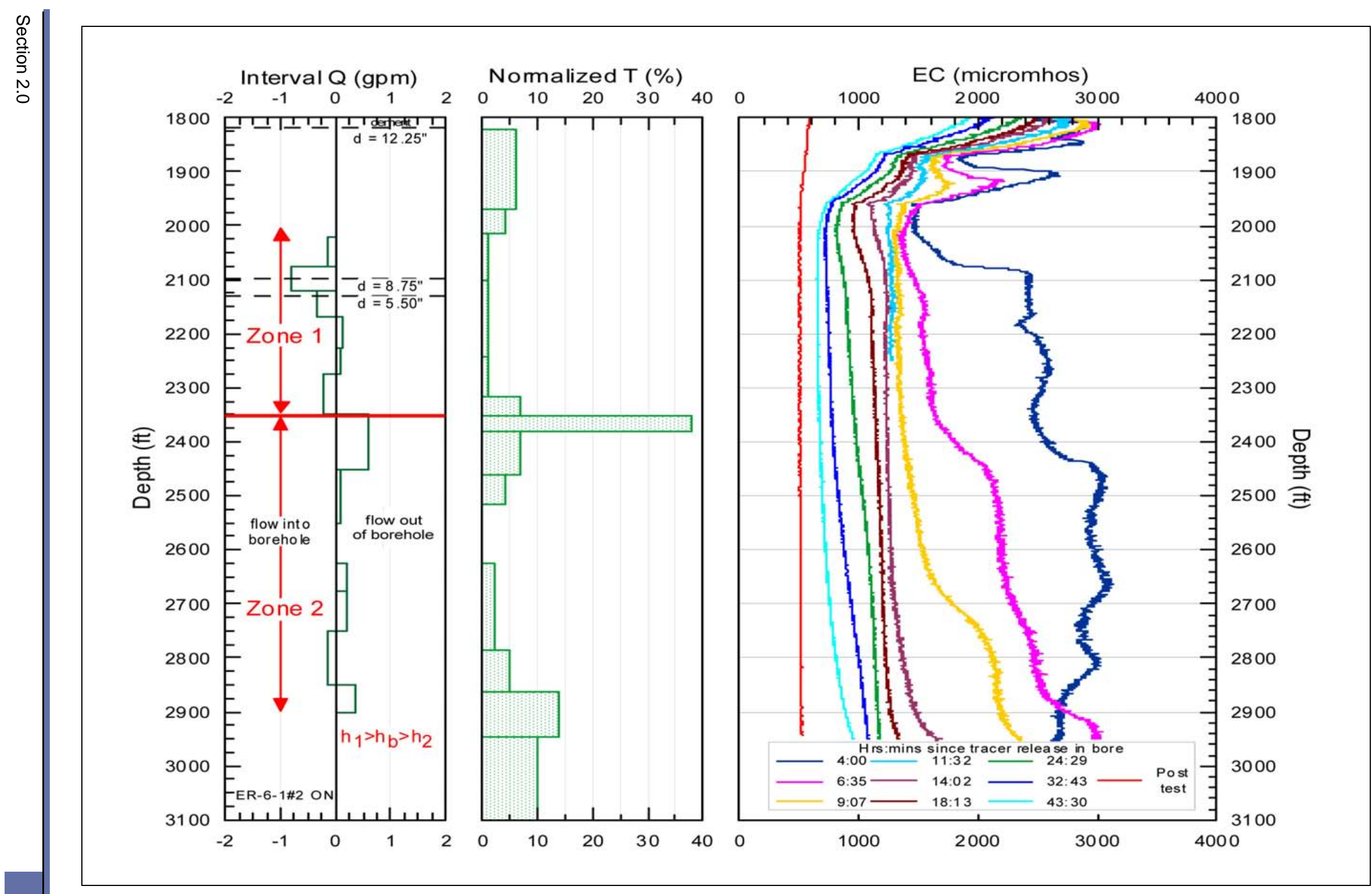

Figure 2-11

Composite Figure of ER-6-1 SFM-1 and TFM-1 Results with EC Logs Measured During the Fast-Path Tracer Test

\section{Uncontrolled When Printed}


and also the underlying Eureka Quartzite. In both boreholes, ER-6-1 and ER-6-1 \#2, there is significant transmissivity in the lower portion with a transmissive interval farther up in the section. In ER-6-1 the most transmissive interval resides between 2,351 and 2,381 ft bgs. In Figure 2-11 (second panel), the normalized transmissivity is greatest around a depth of 2,350 ft bgs, and significant transmissivity exists in the lower one third of the borehole.

The MWAT-TT (SNJV, 2005e) interpretation of the TFM-1 log is that the flow was into the borehole above a depth of 2,350 ft bgs and was dominantly out of the borehole below that depth.

Within-borehole flow rates reached approximately $1.5 \mathrm{gpm}$. Again, this analysis was also performed under pumping conditions at ER-6-1 \#2. The borehole is a fixed diameter (5.5 in.) below a depth of 2,129 ft bgs.

The analysis of transient EC tracer-dilution logs at injection ER-6-1 (fast-path tracer test) has been analyzed through a series of methodologies to augment the TFM analysis presented in the MWAT-TT data report (SNJV, 2005e) and to estimate where tracers are exiting the tracer addition well. This information is useful for developing a conceptual understanding of the tracer injection process and developing conceptual and physical constraints on tracer test interpretation.

Several analysis methodologies have been employed to analyze the EC tracer dilution logs that progress from simple to complex. The methods employed include: (1) in-borehole peak concentration tracing, (2) interval mass-balance analyses, (3) and numerical simulations of EC log development using BORE-II (Doughty and Tsang, 2000). Information determined from the previous TFM-1 analysis presented in the MWAT-TT data report (SNJV, 2005e) is used as a conceptual framework for interpreting the EC logs and to provide constraints for the mass-balance and BORE-II simulations.

The mass-balance techniques including the BORE-II analysis require that EC be converted to an actual concentration (mass/volume). The conversion of measured EC to mass requires three steps: (1) correction of the measured EC to actual EC accounting for fluid temperature (Doughty and Tsang, 2000) at each measurement point (approximately 3-ft interval); (2) conversion of the corrected EC profiles to fluid/tracer-concentration profiles using an empirical relationship provided by LANL (Reimus, 2005); and (3) conversion of concentration to mass at each measurement point, incorporating the variable borehole diameter. 


\subsubsection{Borehole Peak Velocity Analysis}

A simple methodology for the analysis of tracer logs measured in a borehole through time is the measurement of peak migration velocity within the borehole. For this method to work, one needs to have multiple logs that exhibit a definable peak concentration profile and vertical flow within the borehole. The analysis approach simply tries to track the center of mass of the peak as it migrates within the borehole. The velocity of the center of mass is equivalent to the first moment of the tracer peak. By calculating the distance traveled between peaks one gets an average borehole velocity across that borehole interval. Because velocity is equal to volumetric flow rate (length/time $\left[L^{3} / T\right]$ ) divided by area $\left(L^{2}\right)$, the diameter of the borehole can be used to calculate borehole volumetric flow rate. This analysis methodology has many assumptions that would generally not be met in a borehole environment as complex as ER-6-1, including horizontal inflow or outflow within the analysis interval, poor borehole diameter knowledge, and significant diffusion or non-Taylor dispersion (i.e., turbulence).

Inspection of the EC logs shows a distinct concentration peak located at a depth of approximately 2,074 ft bgs in the first log measured $4 \mathrm{hr}$ after tracer addition. The next two EC logs appear to show a downward migration of this concentration peak over the next $5.1 \mathrm{hr}$. Figure 2-12 plots the first three EC logs measured in ER-6-1 after tracer addition. In this figure, an EC value of 1,850 micromhos reflects the approximate 50 percent concentration of the peak as it migrates down the borehole. For each of the three logs, the vertical depth of this concentration has been determined along with the time between logging measurements. Assuming an average borehole diameter of 5.5 in. provides an estimate of borehole volumetric flow rate.

The estimated borehole velocity between the first and second EC log is -0.0111 meters per second $(\mathrm{m} / \mathrm{s})$, which is equivalent to a volumetric flow rate of $-2.7 \mathrm{gpm}$. The negative signs reflect that the velocity is directed down the borehole. The borehole diameter changes from 8.75 in. to $5.5 \mathrm{in}$. within this depth interval. Therefore, the estimated volumetric flow rate is biased low. The estimated borehole velocity between the second and third EC $\log$ is $-0.01006 \mathrm{~m} / \mathrm{s}$, which is equivalent to a volumetric flow rate of $-2.4 \mathrm{gpm}$.

It is useful to compare these results to the results from the TFM results reported in the MWAT-TT (SNJV, 2005e) and depicted in Figure 2-11. In the analysis of the TFM results when ER-6-1 \#2 was 


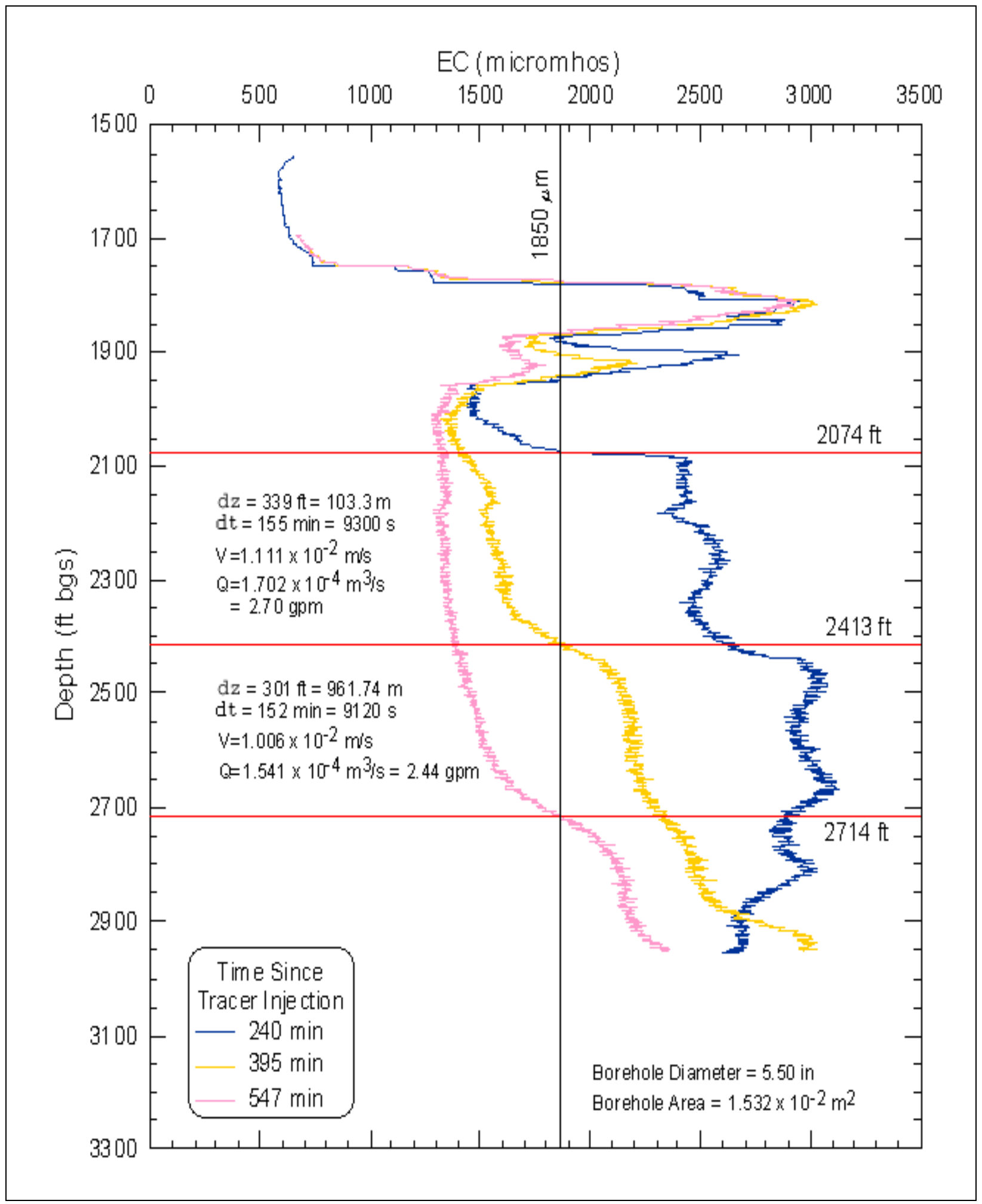

Figure 2-12

ER-6-1 In-Borehole Tracing Analysis Using EC Logs 
pumping (a condition similar to the condition under which the EC logs were measured), it was found that the borehole could broadly be split into an upper zone above a depth of 2,350 ft bgs where flow was dominantly into the borehole and a lower zone where flow was out of the borehole. Likewise, the dominant inflowing feature occurred at a depth of approximately 2,100 ft bgs. If the TFM-1 borehole flow model is used to interpret the simple analysis of in-borehole peak tracing, the results are both consistent and inconsistent in some aspects.

Both analyses consistently find downward internal borehole flow. The in-borehole peak tracing method also demonstrates that the borehole volumetric flow from a depth of approximately 2,100 ft bgs to a depth of 2,714 ft bgs is decreasing, which is consistent with the TFM-1 results. What is inconsistent is the magnitude of vertical flow. The TFM-1 analysis estimated that when ER-6-1 \#2 was pumping, the maximum ER-6-1 borehole flow rate was approximately 1.5 gpm. The peak tracing method yields a value in excess of $2.7 \mathrm{gpm}$. The in-borehole peak tracing method also estimates a downward borehole flow rate of $2.4 \mathrm{gpm}$ between a depth of 2,400 and 2,700 ft bgs. This is more than two times greater than measured in the TFM-1 analysis.

Although there is a good deal of uncertainty in the peak tracing method under the conditions encountered in ER-6-1, the results do indicate downward borehole flow and also suggest that flow is continuing down the borehole past a depth of 2,700 ft bgs, where the SFM located significant transmissivity. The TFM-1 analysis and interpretation (SNJV, 2005e) did not characterize any significant borehole flow below a depth of 2,700 ft bgs when ER-6-1 \#2 was being pumped.

\subsubsection{Mass-Balance Analysis}

Another basic model of analysis for in-borehole concentration logs or EC logs is through some form of a mass-balance analysis. The rate of change of tracer mass in a borehole is related to the mass flux in and out where the mass flux (mass/time) is simply the product of concentration and volumetric flow rate. One generally assumes continuity in volumetric flow rate, that is the volume of water inflowing into the borehole interval is equal to the amount flowing out of the interval over a given time interval.

The simplest and most widely applied method of borehole mass-balance techniques is the borehole dilution method (Freeze and Cherry, 1979), which is a method for estimating groundwater velocity 
through the monitoring of the decay of a tracer mass. In preparation for tracer test analyses, LANL (Reimus, 2005) performed a borehole dilution analysis on the ER-6-1 EC logs and found that the concentration decay for the EC logs estimated a total borehole flushing flow rate of approximately 2.6 gpm. This value is closer in magnitude to the results of the peak velocity analysis presented above rather than the TFM results.

The analysis presented in this section uses mass-balance concepts coupled with a conceptual model for borehole flow developed from the TFM results. From a review of the TFM profiles under ambient conditions, the ER-6-1 borehole can be divided into two zones based on the average formation head in the zone relative to the composite borehole head. In Zone 1 (above a depth of 2,350 ft bgs), the formation head is greater than the borehole head and flow is directed into the borehole. In Zone 2 (below a depth of 2,350 ft bgs), the formation head is less than the borehole head and flow is directed out of the borehole.

In the tracer mass-balance method presented herein, the analysis is split between tracer in Zone 1 and Zone 2. In Zone 1 (above 2,350 ft bgs), the tracer data are highly spatially variable and are uncertain due to two factors: the mixing of different tracer concentrations near intervals of borehole diameter change, and a transient upper-tracer boundary condition at a depth of approximately 1,820 ft bgs (tracer was injected into the blank casing above the open completion interval). Therefore, tracer mass balance is investigated in Zone 1 as a single interval (mixing volume) from 1,890 to 2,350 ft bgs. Recall that TFM detected no borehole flow above a depth of 2,000 ft bgs in ER-6-1.

Zone 2 extends from a depth of 2,350 to 2,900 ft bgs. Again, TFM results did not detect significant borehole flow below a depth of 2,900 ft bgs. Because the upper concentration boundary condition on Zone 2 was well characterized and the interval immediately above and across all of Zone 2 is a constant diameter, the Zone 2 tracer mass balance was broken into multiple intervals (mixing volumes) based on the TFM results.

\subsection{Zone 1 Mass Balance (1,890 to 2,350 ft bgs)}

Tracer mass balance is tested for the complete Zone 1 interval 1,890 to 2,350 ft bgs at each time step defined as the time between successive EC profiles (Figure 2-10). Zone 1 mass was determined for each profile as the summation of mass at each measurement point over the entire interval. With the 
mass in the interval estimated for each measured log, the change in mass between successive logs could also be estimated. The time between EC logs defines the time steps over which the analysis can be performed.

The Zone 1 mass balance must account for the initial mass in place, the amount of mass flowing in and out of Zone 1 over a given time period. The change in mass in Zone 1 can be written as:

$$
\Delta M\left(t_{n}-t_{n-1}\right)=M\left(t_{n-1}\right)+Q_{\text {in }} C_{\text {formation }}\left(t_{n}-t_{n-1}\right)-Q_{\text {out }} C_{\text {out }}\left(t_{n}-t_{n-1}\right)
$$

where $\Delta M$ is equal to the change in mass in Zone 1 between EC logs measured at $t_{n}$ and $t_{n-1}, Q_{i n}$ is assumed to be the horizontal flow rate into the interval from the formation, $C_{\text {formation }}$ is the background groundwater concentration obtained from the background EC log (see Figure 2-10 background log), $Q_{\text {out }}$ is the volumetric flow rate flowing out of Zone 1 (in this case, assumed to be flowing down the borehole past a depth of 2,350 ft bgs), and $C_{\text {out }}$ is the average out-flowing concentration from Zone 1 to Zone 2. For the first EC log after tracer addition, $\left(t_{n}-t_{n-1}\right)$ is equal to the elapsed time from tracer addition to measurement of the first log. For simplicity, $\left(t_{n}-t_{n-1}\right)$ is generally referred to as $d t$ or a time step in the text.

Of the parameters defined above, only $\mathrm{Q}_{\text {in }}$ and $\mathrm{Q}_{\text {out }}$ are unknown. Therefore, $\mathrm{Q}_{\text {in }}$ and $\mathrm{Q}_{\text {out }}$ are iteratively adjusted to minimize the error between the estimated and measured change in mass between logs $\left(\Delta \mathrm{M}_{1}\right)$. As a constraint, it is assumed that $\mathrm{Q}_{\text {in }}$ and $\mathrm{Q}_{\text {out }}$ are equal. A potentially important assumption of this simple Zone 1 analysis is that the top boundary of Zone 1, defined at a depth of 1,890 ft bgs, is treated as a no-flow, no mass diffusive flux boundary.

The Zone 1 mass-balance results are shown in Table 2-5. For each of the eight time steps available (i.e., eight EC logs in addition to a background log), Table 2-5 reports the observed mass and simulated mass, and the optimal borehole flow rate $\left(Q_{i n}=Q_{\text {out }}\right)$ for Zone 1 . The mass-balance error, the difference in mass estimated and calculated between logging runs, is less than 0.1 percent for each logging-time interval. The "best-fit" flow rate, optimized to reduce the estimated mass-balance error at each time step over Zone 1, has a time average of $1.57 \mathrm{gpm}$. Because this analysis treats the entire interval within Zone 1 as a single mixing volume, the borehole flow rate is comparable to the borehole flow rate measured in the TFM campaign at a depth of approximately 2,350 ft bgs. The flow rate measured in the TFM analysis at 2,350 ft bgs was approximately 1.5 gpm down borehole, 
which agrees very well with the mass-balance estimate. It is also interesting to note the transient simulated flow rate ranging from $2.42 \mathrm{gpm}$ for the first log pair to approximately $1.4 \mathrm{gpm}$ in the last three analysis pairs. This could be hydraulic transience and/or a time varying inflowing background concentration that is impacted by the tracer injection at early times and approaches background with later EC logs.

Table 2-5

Simulated Borehole Flow Rate Results of the Zone 1

(1,890 to 2,350 ft bgs) Material Balance

\begin{tabular}{|c|c|c|c|c|}
\hline EC Logs & $\begin{array}{l}\text { Time Step } \\
\text { (sec) }\end{array}$ & $\begin{array}{l}\text { Observed } \\
\text { Mass } \\
\text { (kg) }\end{array}$ & $\begin{array}{l}\text { Simulated } \\
\text { Mass } \\
(\mathrm{kg})\end{array}$ & $\begin{array}{c}\text { Optimal } \\
Q \\
\text { (gpm) }\end{array}$ \\
\hline t0 - t1 & 9,600 & 0.0331 & $\mathrm{~N} / \mathrm{A}$ & 2.42 \\
\hline $\mathrm{t} 1-\mathrm{t} 2$ & 9,300 & 0.0256 & 0.0256 & 1.57 \\
\hline $\mathrm{t} 2-\mathrm{t} 3$ & 8,100 & 0.0223 & 0.0223 & 1.51 \\
\hline t3 - t4 & 9,000 & 0.0199 & 0.0199 & 1.56 \\
\hline $\mathrm{t} 4-\mathrm{t} 5$ & 15,600 & 0.0175 & 0.0175 & 1.30 \\
\hline t5 - t6 & 21,600 & 0.0146 & 0.0146 & 1.45 \\
\hline t6 - t7 & 29,400 & 0.0111 & 0.0111 & 1.42 \\
\hline t7 - t8 & 39,600 & 0.0083 & 0.0083 & 1.35 \\
\hline t8 & $\mathrm{N} / \mathrm{A}$ & 0.0063 & 0.0063 & $\mathrm{~N} / \mathrm{A}$ \\
\hline
\end{tabular}

An important assumption of this analysis is that horizontal outflows to the formation within Zone 1 are minimal. This may be incorrect and this could be significant because the TFM only detects net inflows and outflows that occur between the coarsely spaced TFM measurement stations. For example, cross-borehole horizontal inflow and outflow through a high transmissivity feature intersecting the borehole would go undetected by the TFM measurement.

\subsection{Zone 2 Mass Balance (2,350 to 2,950 ft bgs)}

In Zone 2, the analysis was extended to discrete depth intervals chosen based on the results from the TFM. The approach is similar to that applied for Zone 1, with the primary difference being that the $Q_{\text {in }}$ and $Q_{\text {out }}$ components are now subdivided into lateral and vertical components such that $Q_{\text {in }}$ equals vertical flow in from the interval above $\left(Q_{\text {top }}\right)$ plus lateral inflow/outflow $\left(Q_{\text {lat }}\right)$ from the formation, and $Q_{b o t}$ equals vertical flow down to the interval below. The tracer solution concentrations for the 
interval boundaries can be based on measurements as can an average out flowing interval concentration. Again it is assumed that inflowing formation water is characterized by the background $\log$ and is constant for a given depth.

For the Zone 2 mass-balance calculations, the difference between the estimated and measured change in mass is minimized on an interval-by-interval basis, and stepping forward in time. That is, mass conservation is assessed at each borehole interval sequentially, beginning at the top interval and working downward for each successive EC profile. The following equation describes the change in mass in interval (i):

$$
\begin{aligned}
& \Delta M_{i}\left(t_{n}-t_{n-1}\right)=M_{i}\left(t_{n-1}\right)+\left[Q_{\text {top }} C_{\text {top }}\left(t_{n}-t_{n-1}\right)\right]_{i} \\
& +\left[Q_{\text {lat }} C_{\text {lat }}\left(t_{n}-t_{n-1}\right)\right]_{i}-\left[Q_{b o t} C_{b o t}\left(t_{n}-t_{n-1}\right)\right]_{i}
\end{aligned}
$$

For each interval ( $i$ ) there are now two, rather than one, unknown flow rates to iteratively solve for. Two constraints are imposed to make the problem tractable and reduce the number of unknowns to one $\left(Q_{b o t}\right)$. The constraints are: (1) $Q_{\text {top }}$ equals $Q_{b o t}$ from the interval above the one being analyzed, and (2) $Q_{\text {lat }}$ equals the value measured during TFM. Again the objective is to minimize the difference between the estimated and simulated change in mass, per interval and per time step, by adjusting $Q_{b o t}$ subject to the constraints listed above.

An example of Zone 2 mass-balance results is shown in Table 2-6 for the first time step (between the first two EC logs, see Figure 2-10). Mass is preserved in all Zone 2 intervals to within 0.2 percent. While $Q_{\text {lat }}$ for each interval is fixed (i.e., set equal to the measured TFM data), $Q_{\text {top }}$ and $Q_{b o t}$ appear reasonable and within the measurement accuracy range. However, using $Q_{b o t}$ as the only fitting parameter introduces some error because $Q_{\text {in }} \neq Q_{\text {out }}$. That is, $Q_{\text {top }}+Q_{\text {lat }} \neq Q_{\text {bot }}$ because the optimization of $Q_{b o t}$ is not constrained by this equality. When SNJV (2005e) attempted to add this constraint in conjunction with that of minimizing mass-balance error, the estimated flow-rate parameters were unrealistic. In other words, there is a component of error associated with one of the datasets that prevents interval mass from being conserved while at the same time honoring measured TFM flow rates. The error is most likely associated with the poor spatial discretization of TFM measurement locations, as discussed above. Despite the error, the optimized inflow/outflow rates are in general agreement with those observed. The point worth noting regarding the Zone 2 analysis is 
Table 2-6

Simulated Interval Flow Rates for Zone 2 (2,350 to 2,850 ft bgs), Logging Runs at 0 Minutes and 240 Minutes

\begin{tabular}{|c|c|c|c|c|c|c|c|c||}
\hline $\begin{array}{c}\text { Top } \\
\text { (ft bgs) }\end{array}$ & $\begin{array}{c}\text { Bottom } \\
\text { (ft bgs) }\end{array}$ & $\begin{array}{c}\text { Simulated } \\
\boldsymbol{Q}_{\text {lat }}(\mathbf{g p m})\end{array}$ & $\begin{array}{c}\text { Simulated } \\
\boldsymbol{Q}_{\text {bot }}(\mathbf{g p m})\end{array}$ & $\begin{array}{c}\text { Simulated } \\
\boldsymbol{Q}_{\text {top }}(\mathbf{g p m})\end{array}$ & $\begin{array}{c}\text { Simulated } \\
\boldsymbol{Q}_{\text {error }} \\
\mathbf{( g p m})\end{array}$ & $\begin{array}{c}\Delta \boldsymbol{M} \mathbf{( k g )} \\
\text { Measured }\end{array}$ & $\begin{array}{c}\Delta \boldsymbol{M} \mathbf{( k g )} \\
\text { Simulated }\end{array}$ & $\begin{array}{c}\text { Percent } \\
\text { Mass } \\
\text { Error }\end{array}$ \\
\hline \hline 2,350 & 2,450 & 0.600 & 1.43 & 1.35 & 0.52 & $5.52 \times 10^{-4}$ & $5.52 \times 10^{-4}$ & 0.072 \\
\hline 2,450 & 2,550 & 0.085 & 1.25 & 1.43 & 0.27 & $8.59 \times 10^{-4}$ & $8.59 \times 10^{-4}$ & 0.023 \\
\hline 2,550 & 2,625 & 0.025 & 1.27 & 1.25 & 0.00 & $6.23 \times 10^{-4}$ & $6.23 \times 10^{-4}$ & 0.045 \\
\hline 2,625 & 2,675 & 0.210 & 1.28 & 1.27 & 0.20 & $3.71 \times 10^{-4}$ & $3.71 \times 10^{-4}$ & 0.039 \\
\hline 2,675 & 2,750 & 0.200 & 1.33 & 1.28 & 0.15 & $4.44 \times 10^{-4}$ & $4.44 \times 10^{-4}$ & 0.035 \\
\hline 2,750 & 2,850 & -0.135 & 1.31 & 1.33 & 0.11 & $4.55 \times 10^{-4}$ & $4.56 \times 10^{-4}$ & 0.169 \\
\hline 2,850 & 2,900 & 0.365 & 1.29 & 1.31 & 0.39 & $2.55 \times 10^{-4}$ & $2.55 \times 10^{-4}$ & 0.031 \\
\hline 2,850 & 2,900 & 0.365 & 1.29 & 1.31 & 0.39 & $2.55 \times 10^{-4}$ & $2.55 \times 10^{-4}$ & 0.031 \\
\hline
\end{tabular}

that the method predicts that there is significant borehole flow down the interval past a depth of 2,900 ft bgs.

\subsubsection{BORE-II Simulation of Fluid Electrical Conductivity Profiles}

The final tool used to investigate the EC logs at ER-6-1 is BORE-II (Doughty and Tsang, 2000). The purpose of BORE-II is to reproduce, through a one-dimensional (1-D) finite-difference formulation, the tracer profiles as they evolve in the borehole. BORE-II is used to perform the 1-D simulation considering advection and disperion (but not density effects) of EC profiles that are parameterized by horizontal inflow/outflow intervals, interval rates, interval concentrations, and lower/upper borehole boundary conditions. Through calibration of the borehole hydraulic model by fitting the simulated to measured EC profiles, a general set of parameters is defined that provides an indication of the outflows and inflows within the borehole.

As for any case of inverse modeling, some parameters will be held constant or considered priors, and others will be varied to calibrate to the observed tracer profiles. For an initial simulation scenario, horizontal inflow/outflow zones are defined as nonfitting parameters and are considered known. In this case the intervals identified from the TFM logging of ER-6-1 while ER-6-1 \#2 was pumped (at a 475-gpm rate similar to that for the fast-path tracer test) are used. The TFM-derived intervals and interval rates are shown in Figure 2-11. Without these logging data, the definition of lateral flow 
zones would be completely arbitrary. The direction of flow as identified from the TFM log analysis (i.e., flow into or out of the borehole) is also preserved for the BORE-II simulation. For inflow zones, the formation concentration (or EC) is defined from the background EC log. The remaining model parameters, the horizontal and vertical flow rates, are defined as the fitting parameters. Horizontal flow rates correspond to the fixed inflow/outflow zones. The rate is assumed uniform across each zone. Vertical flow rates are assigned only at the top and bottom nodes of the borehole and provide transient-boundary conditions.

Electrical conductivity log evolution in ER-6-1 is modeled within the 5.5-in. constant-diameter section of the borehole from 2,129 to 3,206 ft bgs ( $820 \mathrm{ft}$ borehole model). This was necessary because BORE-II does not incorporate variable borehole areas. The nine EC profiles were logged from about 1,650 to 2,950 ft bgs. Although the upper $500 \mathrm{ft}$ of the logs are not considered for the analysis, they are not considered to be significant zones of horizontal flow in this interval. To account for the truncation of the profiles, the upper boundary concentration (at 2,129 ft bgs) is specified at each time step for the simulation.

The $820-\mathrm{ft}$ simulation interval is discretized into 180 equidistant nodes, the number of nodes being equal to the maximum number of horizontal inflow/outflow points, or "feed" points, that may be defined in BORE-II. Each node (and likewise feed point) is assigned to an interval defined from the TFM logs, and is assigned a corresponding inflow/outflow rate. During model calibration, the initial horizontal flow condition is defined from the TFM results (Figure 2-11). To be consistent with BORE-II convention, positive and negative flow rates correspond to horizontal flow into and out of the borehole, respectively, and to vertical flow upward and downward, respectively.

Before model calibration, the general influence of vertical flow on borehole tracer dilution was assessed. All horizontal flow rates were set to no flow. The vertical flow rate, representing inflow from the top and outflow below the tracer-measurement interval, was adjusted for each simulation until a qualitative best fit to the measured data was achieved. Figure 2-13 shows the measured and simulated profiles for this initial simulation. This simulation suggests that the observed EC logs are dominated by vertical flow from above with little impact from lateral inflow/outflows. The best-fit vertical rate is $2.5 \mathrm{gpm}$, a value in relative agreement with that derived from the analysis of borehole 
dilution results of Reimus (2005) of 2.6 gpm. This result suggests that horizontal inflow/outflow has a minor role in tracer dilution through this borehole interval.

To better match the transient EC profiles, the horizontal interval flow rates as determined from the TFM data were included in the simulation, in conjunction with vertical flow specified at both the top and bottom (nodes) of the borehole. The following sequence of steps was followed to determine the best-fit flow parameters:

- Horizontal flow rates alone were first considered, setting vertical flow equal to no flow. In this case, net horizontal flow is out of the borehole such that a vertical inflow rate (in from above the borehole measurement interval) of $3.77 \mathrm{gpm}$ must be specified to conserve fluid mass. This scenario is considered unlikely.

- Vertical flow rates into and out of the borehole were adjusted to match the tracer-curve propagation down the borehole. The measured and simulated profiles are shown in Figure 2-14.

- Horizontal flow rates were adjusted within intervals in an attempt to match both the tracer-curve propagation rate and tracer-profile shape. The measured and simulated profiles are shown in Figure 2-15.

As previously discussed, the analysis is not unique; therefore, only general characteristics of the borehole flow regime are determined through the analysis. Figure 2-16 plots the BORE-II best fit interval flow rates versus the borehole interval flow rates determined in the TFM-1 analysis. The agreement in horizontal flow rates is generally good. However, the vertical flow rate imposed at the top of the modeled section is much higher than suggested by the TFM analysis as is the flow rate at the bottom of the interval. Density effects could explain this discrepancy, although field operations tried to achieve an average density of 1.002 (SNJV, 2005e).

The primary conclusion from the BORE-II simulations is that the EC log evolution appears to require a significant borehole flow circuit between the depths of 2,129 and 2,950 ft bgs. This conclusion is at odds with the results from the TFM analysis (Figure 2-11), which suggests that inflow in ER-6-1 is near the top of the interval with ubiquitous outflow below 2,350 ft bgs. 


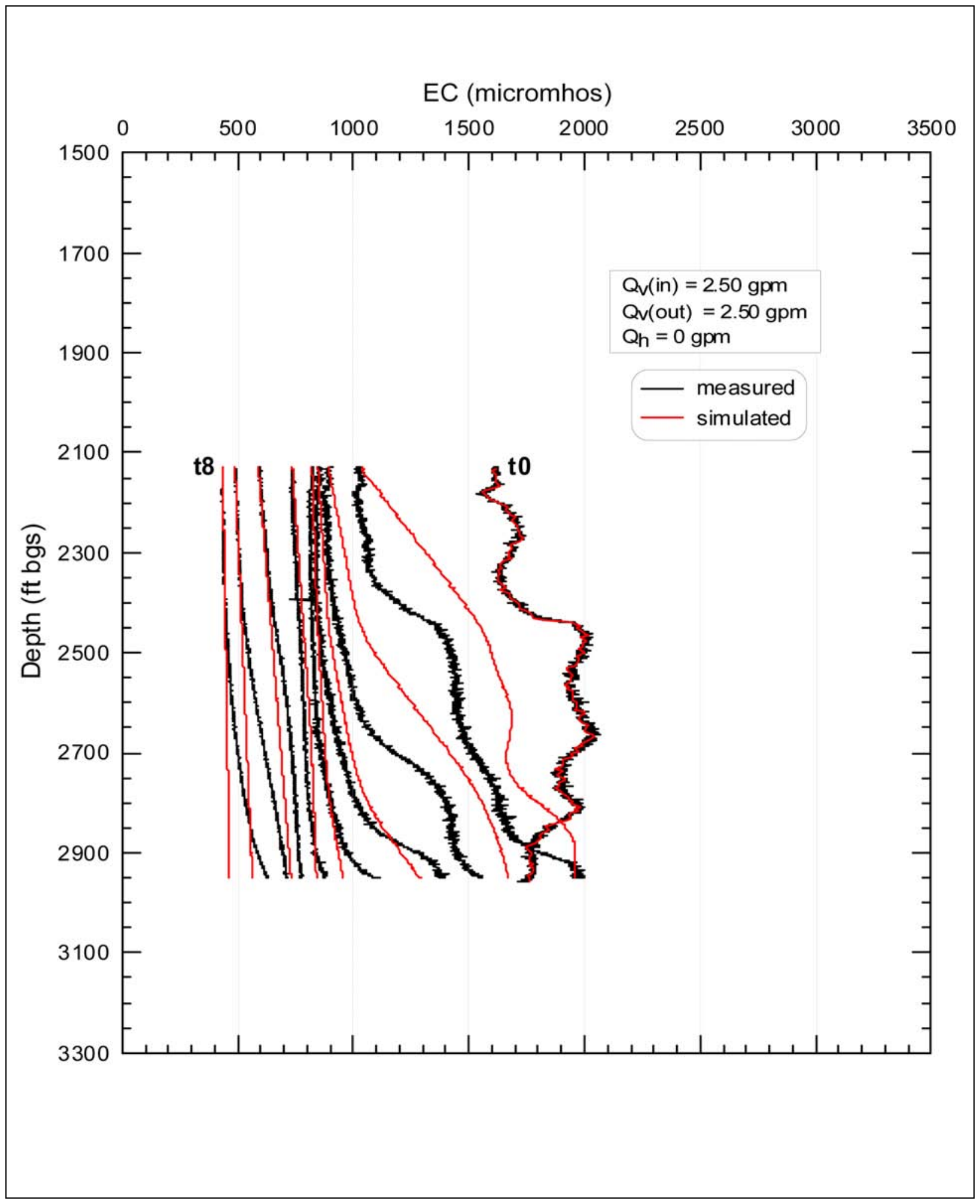

Figure 2-13

BORE-II Simulation of ER-6-1 EC Logs Assuming No Horizontal Flow within the Simulated Interval 


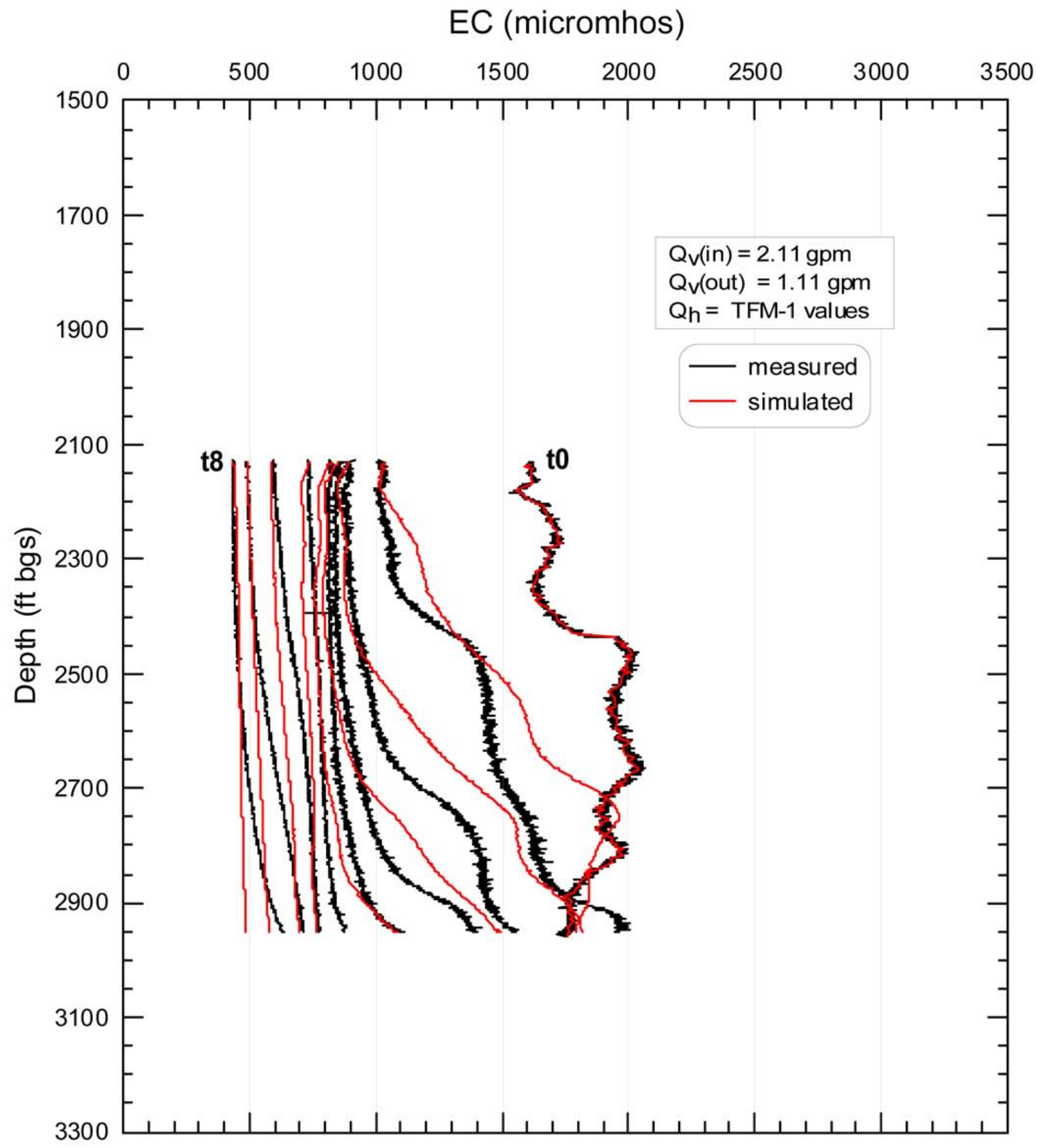

Figure 2-14

BORE-II Simulation of ER-6-1 EC Logs with TFM-1 Horizontal Flows and Best-Fit Vertical Flows 


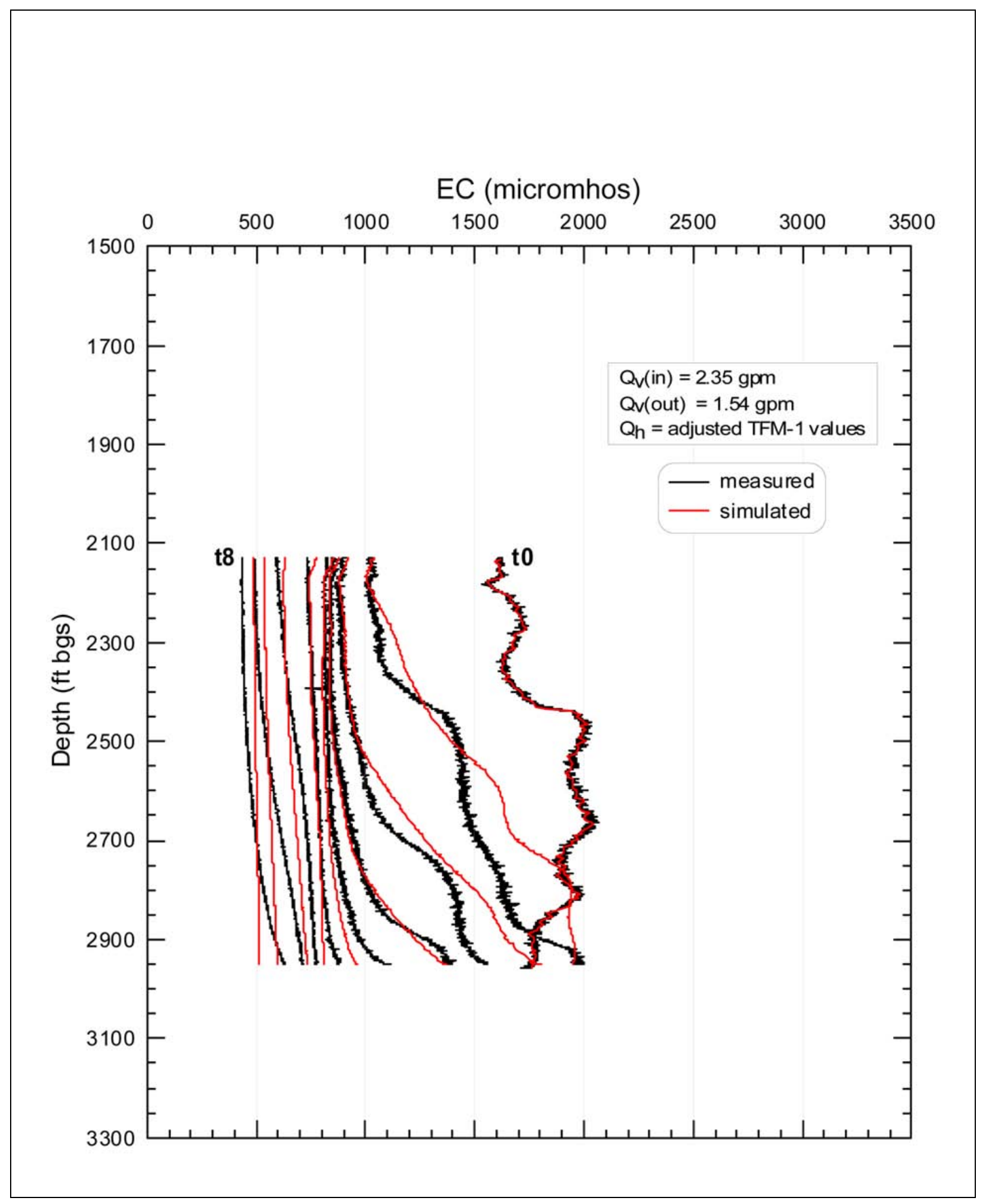

Figure 2-15

BORE-II Simulation of ER-6-1 EC Logs with Best-Fit Vertical and Horizontal Flows 


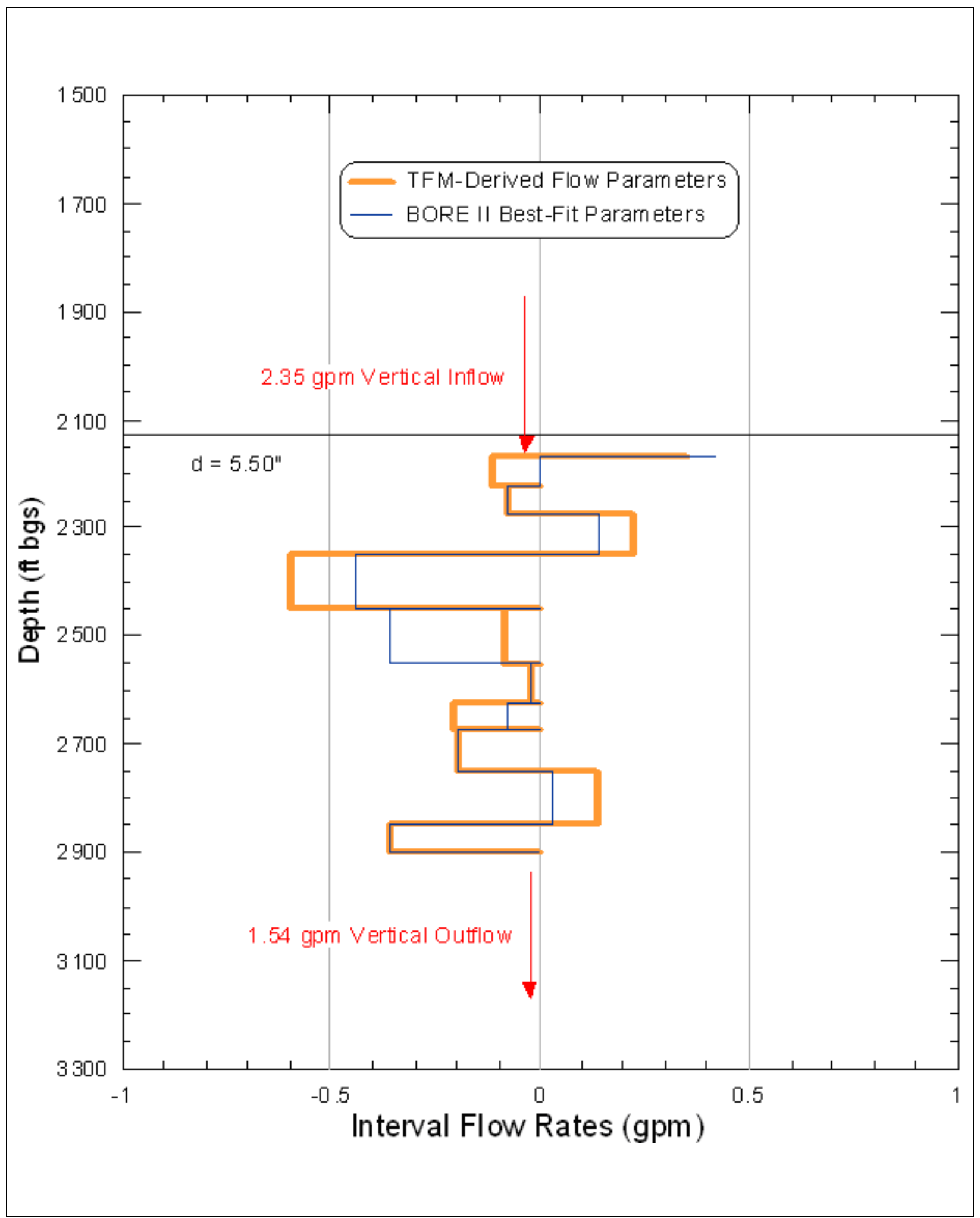

Figure 2-16

Comparison of Interval Horizontal Flow Rates for the TFM Analysis and for the Best-Fit BORE-II Analysis of ER-6-1 EC Logs 


\subsection{Semianalytic Tracer Response Analysis}

The normalized tracer breakthrough curves from the ER-6-1 tracer test were interpreted using the semianalytical model RELAP (Reimus and Haga, 1999) to obtain estimates of transport parameters that can be used as starting points for subsequent, more detailed test interpretations. The RELAP model assumes 1-D transport through fractures with 1-D diffusion into the matrix perpendicular to fractures. Additionally, fast or slow first-order sorption or filtration reactions can be accounted for either in the fractures, the matrix, or both. The RELAP code was used previously for interpreting the BULLION forced-gradient experiment conducted at the ER-20-6 location on Pahute Mesa in 1997 (Reimus and Haga, 1999).

\subsubsection{ER-6-1 Lower Zone Analysis}

Figure 2-17 shows RELAP fits, both single and dual porosity, to the I and 2,4,5-TFBA abstracted breakthrough curves using a linear flow (e.g., not radially converging with constant velocity away from the pumping well) regime as suggested by the MWAT hydraulic interpretation. A matrix porosity of 0.03 was assumed for this analysis as being the central tendency, and is consistent with the values of Reimus et al. (2006) and Hershey et al. (2003). Tables 2-7 and 2-8 list the transport parameters corresponding to these fits. Note that the single- and dual-porosity curves shown in Figure 2-17 are very similar because the tracer responses exhibit negligible separation, indicating little or no discernable matrix diffusion. Thus, a single curve represents both tracers equally well. The lack of apparent matrix diffusion over the time and distance scales of the tracer responses is an important result with significant implications for modeling of radionuclide transport in the LCA in Yucca Flat.

\subsubsection{ER-6-1 Upper Zone Analysis}

The upper zone of ER-6-1 was preliminarily interpreted to be connected to the faster transport path to ER-6-1 \#2, and consequently had a broader suite of tracers injected, including PFBA, Li, Br, and two sizes (200 and 500 nanometers) of microspheres.

Figure 2-9 shows the breakthrough of the chemical tracers injected into the ER-6-1 upper zone. The $\mathrm{Li}$ and $\mathrm{Br}$ data have had the preliminary background correction developed by SNJV (2005e) applied. However, the Br tail data still appear to decline too rapidly with respect to the other tracers, implying 


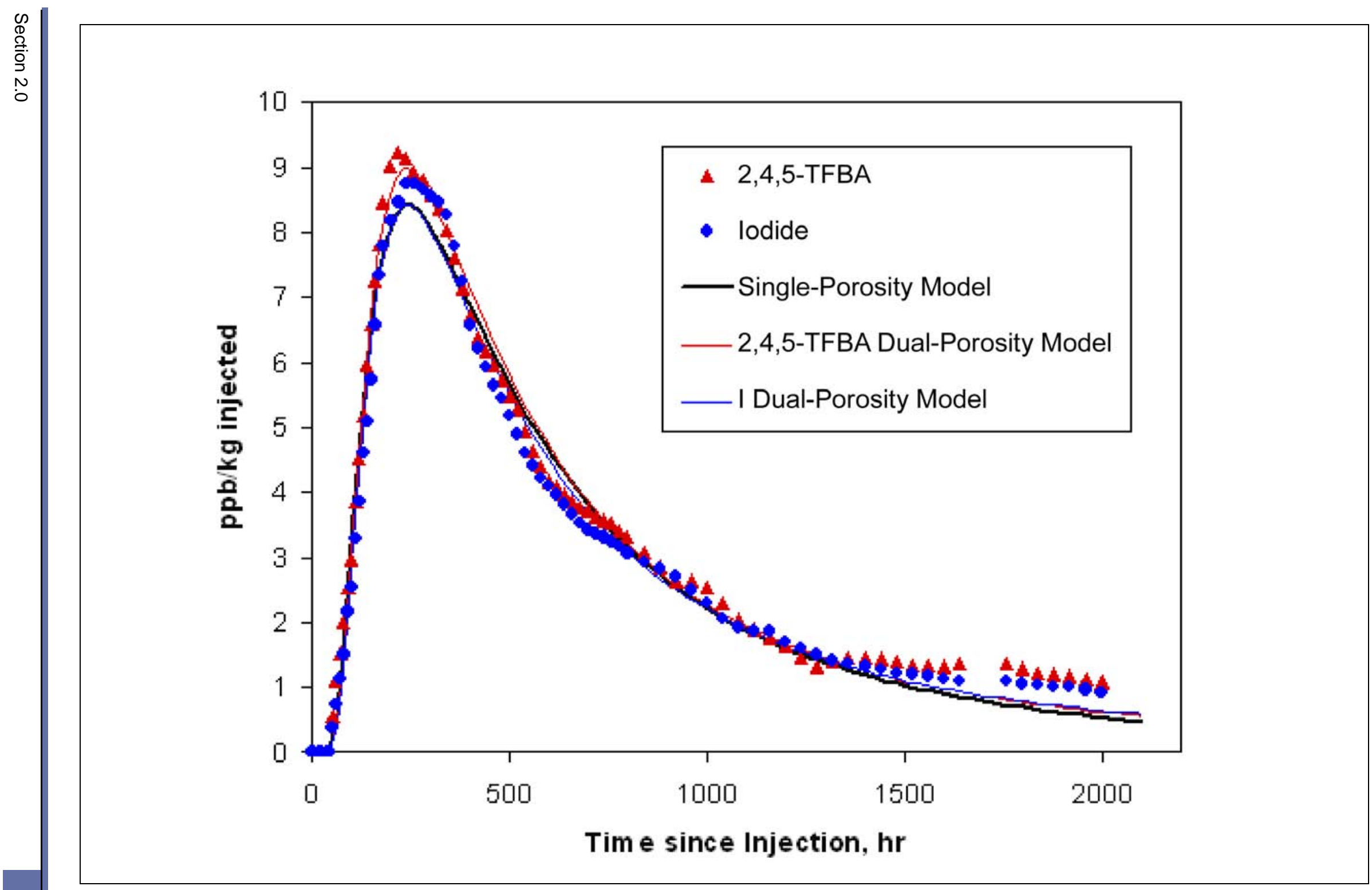

Figure 2-17

Single- and Dual-Porosity RELAP Fits to lodide and 2,4,5-TFBA Tracer Breakthrough 
Table 2-7

\section{Single-Porosity Transport Parameters from RELAP for lodide and 2,4,5-TFBA}

\begin{tabular}{|c|c|}
\hline Transport Parameter & Value \\
\hline Tracer Mass Fraction $^{a}$ & 0.76 \\
\hline Mean residence time, $\mathrm{hr}$ & 825 \\
\hline Peclet number & 1.9 \\
\hline$\frac{\phi}{b} \sqrt{D_{m}}, \sec ^{-1 / 2} \mathrm{~b}$ & 0 \\
\hline Flow Porosity ${ }^{c}$ & 0.01 \\
\hline Longitudinal Dispersivity, m & 34 \\
\hline
\end{tabular}

aMass fraction is the fraction of tracer mass participating in the test yielding best fit to the breakthrough curves. If a mass fraction of 1.0 is assumed (all tracer mass participating), the mean residence time increases to 1,600 hr, the Peclet number decreases to 0.9 , and the sum of squares differences between the data and model increases by about 70 percent.

b $\frac{\phi}{b} \sqrt{D_{m}}$ is a mass transfer coefficient for matrix diffusion, where $\phi=$ matrix porosity, $b=$ fracture half-aperture, and $D_{m}=$ diffusion

${ }^{\mathrm{c}}$ Flow porosity is calculated from $Q \tau / \pi r^{2} h$, where $Q=40$ percent of production flow rate (based on flow logs), $\tau=$ mean residence time, $r=$ distance between wells, and $h=$ interval thickness (125 $\mathrm{m}$ for lower zone).

Table 2-8

Dual-Porosity Transport Parameters from RELAP for lodide and 2,4,5-TFBA

\begin{tabular}{|c|c|}
\hline Transport Parameter & Value \\
\hline$\overline{\text { Tracer Mass Fraction }}^{a}$ & 0.85 \\
\hline Mean residence time, $\mathrm{hr}$ & 780 \\
\hline Peclet number & 1.8 \\
\hline$\frac{\phi}{b} \sqrt{D_{m}}, \sec ^{-1 / 2 \mathrm{~b}}$ (lodide) & $1.1 \times 10^{-4}$ \\
\hline Flow Porosity ${ }^{c}$ & 0.009 \\
\hline Longitudinal Dispersivity, m & 36 \\
\hline
\end{tabular}

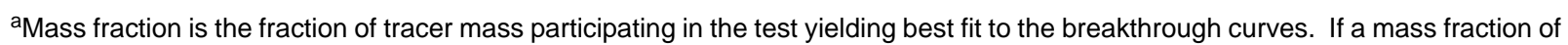
1.0 is assumed (all tracer mass participating), the mean residence time increases to $1,600 \mathrm{hr}$, the Peclet number decreases to 0.9 , and the sum of squares differences between the data and model increases by about 70 percent. b $\frac{\phi}{b} \sqrt{D_{m}}$ is a mass transfer coefficient for matrix diffusion, where $\phi=$ matrix porosity, $b=$ fracture half-aperture, and $D_{m}=$ diffusion

${ }^{c}$ Flow porosity is calculated from $Q \tau / \pi r^{2} h$, where $Q=40$ percent of production flow rate (based on flow logs), $\tau=$ mean residence time, $r=$ distance between wells, and $h=$ interval thickness (125 $\mathrm{m}$ for lower zone). 
that some type of non-constant temporal trend of unknown form is observed. Both Li and Br have significant background concentrations in Yucca Flat groundwater, and both are also used as drilling fluid tracers. Thus, any estimated transport parameters using these two tracers are likely to be very uncertain, and therefore are not considered further. Flow logging (Figure 2-4) shows multiple inflow points, one between 2,150 and 2,250 ft and another between 2,500 and 2,600 ft, into the ER-6-1 \#2 borehole, and these two pathways were used to analyze the upper zone breakthrough. The flow pathway conducting tracers into ER-6-1 \#2 just below 2,500 ft would appear to be associated with a minor flow zone conducting less than 10 percent of the overall production flow based on the spinner flow log of Figure 2-4. Figure 2-18 shows the single-porosity RELAP fit to the PFBA data, and Table 2-9 shows the associated parameters.

Two alternative approaches were used to interpret the microsphere breakthrough curves. In the first approach, all filtration was assumed to be slow and irreversible, so the microsphere breakthrough at ER-6-1 \#2 was effectively fitted by adjusting the filtration rate constant so that a small fraction (matching the breakthrough curve) was not filtered at all during the travel time in the flow system. In this approach, the tail of the simulated microsphere breakthrough curve rapidly decays to zero because the microspheres are not allowed to detach. In this case, the microsphere breakthrough curve(s) can be explained entirely using the faster flow pathway, and the slower pathway is predicted to make no contribution at all when using the same filtration and detachment rate constants as in the faster pathway. In reality, there is probably some combination of reversible and irreversible filtration (or fast and slow detachment rates) occurring, and there is probably also some contribution of microspheres from both flow pathways. Discrete bailer data would have helped constrain this interpretation, but the microspheres were not analyzed in the bailer samples.

The best-fitting filtration and detachment rate constants for the two interpretive approaches described above are listed in Table 2-10, with fits shown in Figure 2-19 along with the abstracted PFBA data for reference. Clearly both sizes of microspheres were significantly filtered, although some of them arrived sooner than the chemical tracers. These fits were obtained using the same model parameters that provided the best fits to the solute breakthrough curves, except that the matrix diffusion coefficients were always set to zero (no matrix diffusion), and rate-limited sorption in fractures was assumed to account for filtration and detachment of the microspheres. The breakthrough curves of the two microspheres were similar enough that they were not analyzed separately. 


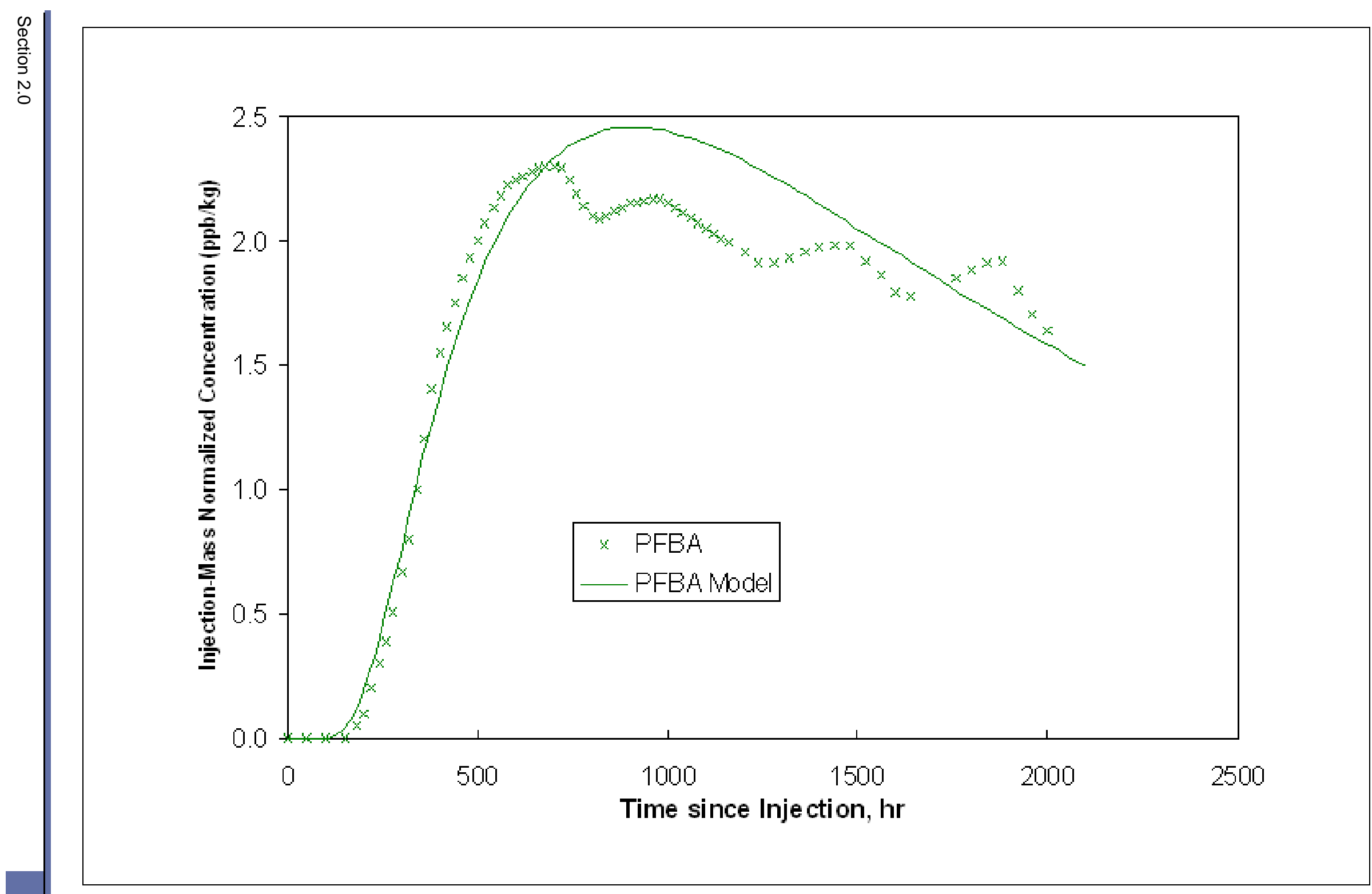

Figure 2-18

RELAP Fit to PFBA Tracer Breakthrough 
Table 2-9

Single-Porosity Transport Parameters from RELAP for PFBA

\begin{tabular}{|c|c|c|}
\hline Transport Parameter & Pathway 1 & Pathway 2 \\
\hline Tracer Mass Fraction $^{a}$ & 0.35 & 0.45 \\
\hline Mean residence time, $\mathrm{hr}$ & 1,600 & 3,500 \\
\hline Peclet number & 3 & 3 \\
\hline$\frac{\phi}{b} \sqrt{D_{m}}, \mathrm{sec}^{-1 / 2 \mathrm{~b}}$ & 0 & 0 \\
\hline Flow Porosity ${ }^{c}$ & 0.009 & 0.006 \\
\hline Longitudinal Dispersivity, m & 22 & 22 \\
\hline
\end{tabular}

${ }^{a}$ Mass fraction is the fraction of tracer mass participating in the test yielding best fit to the breakthrough curves. b $\frac{\phi}{b} \sqrt{D_{m}}$ is a mass transfer coefficient for matrix diffusion, where $\phi=$ matrix porosity, $b=$ fracture half-aperture, and $D_{m}=\operatorname{diffusion}$

${ }^{\mathrm{c}}$ Flow porosity is calculated from $Q \tau / \pi r^{2} h$, where $Q=40$ percent of production flow rate for pathway 1 and 10 percent for pathway $2, \tau=$ mean residence time, $r=$ distance between wells, and $h=$ interval thickness $(300 \mathrm{~m})$.

Table 2-10

RELAP Estimated Microsphere Filtration and Detachment Rate Constants

\begin{tabular}{|c|c|c|}
\hline Transport Parameter & Pathway 1 & Pathway 2 \\
\hline \hline Mass Fraction $^{\mathrm{a}}$ & 0.35 & 0.45 \\
\hline Irreversible Filtration Rate Constant, 1/hr $^{\text {Reversible Filtration Rate Constant, 1/hr }}$ & 0.004 & 0.002 \\
\hline $\begin{array}{c}\text { Reversible Detachment Rate Constant times Fracture } \\
\text { Aperture, 1/hr }\end{array}$ & 0.0035 & $0.0035^{\mathrm{b}}$ \\
\hline
\end{tabular}

aMass fractions, mean residence time, and Peclet number are the same as in Table 2-9 (single-porosity RELAP fit to PFBA breakthrough curve).

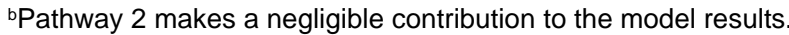

\subsubsection{ER-6-1 \#1 Analysis}

The 2,5-DFBA normalized breakthrough curve from ER-6-1 \#1 is shown in Figure 2-20 along with the subset of the data used for the analysis and a RELAP interpretive match to the data. Because there was no simultaneously introduced tracer that could be compared with the 2,5-DFBA to determine whether matrix diffusion was occurring, and because matrix diffusion was not conclusively observed in the other tracer responses where such tracer pairs were used, the 2,5-DFBA breakthrough curve was interpreted assuming a single-porosity system (no matrix diffusion). The transport parameters 


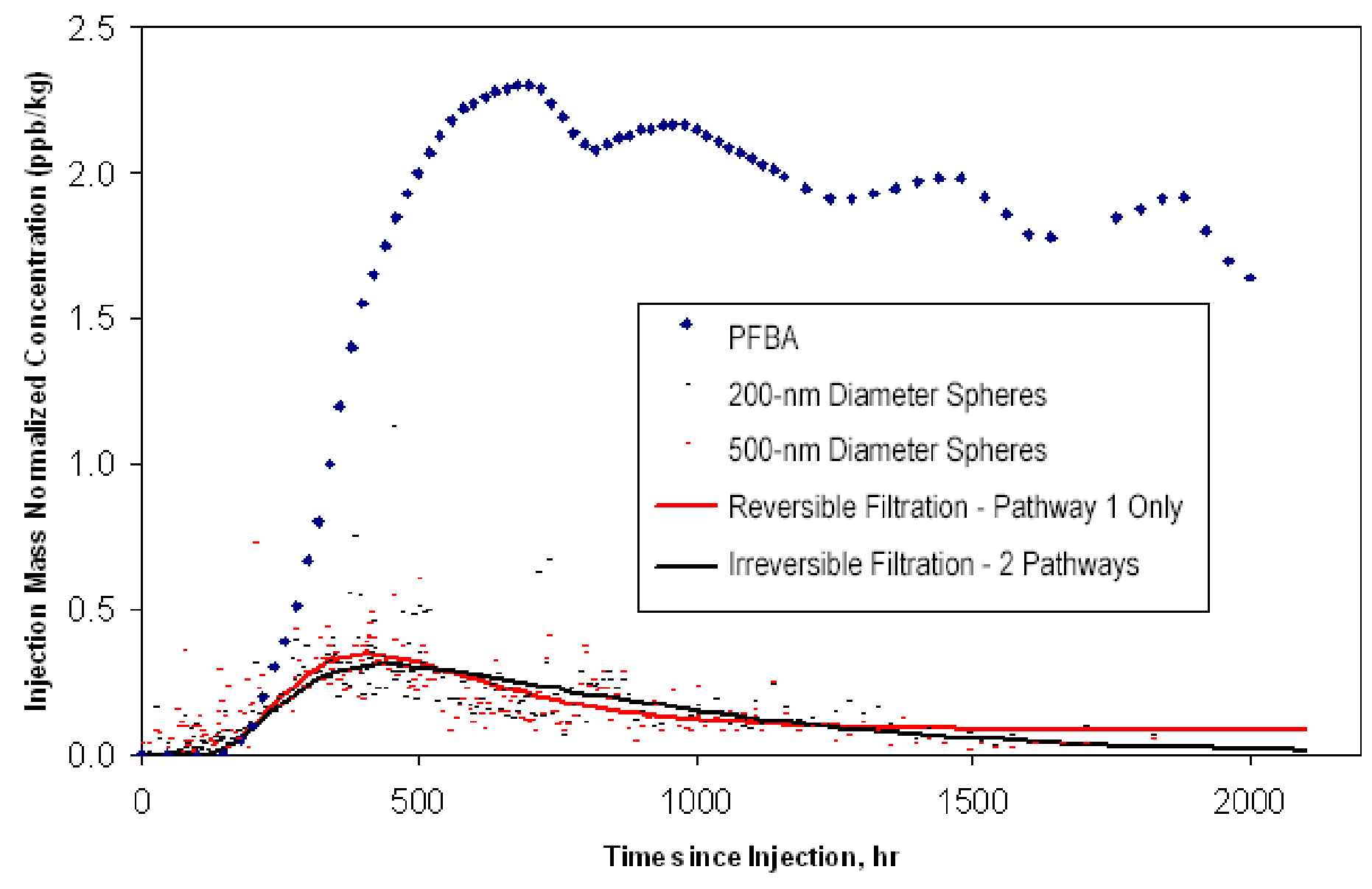

Figure 2-19

RELAP Fit to Microsphere Breakthrough 


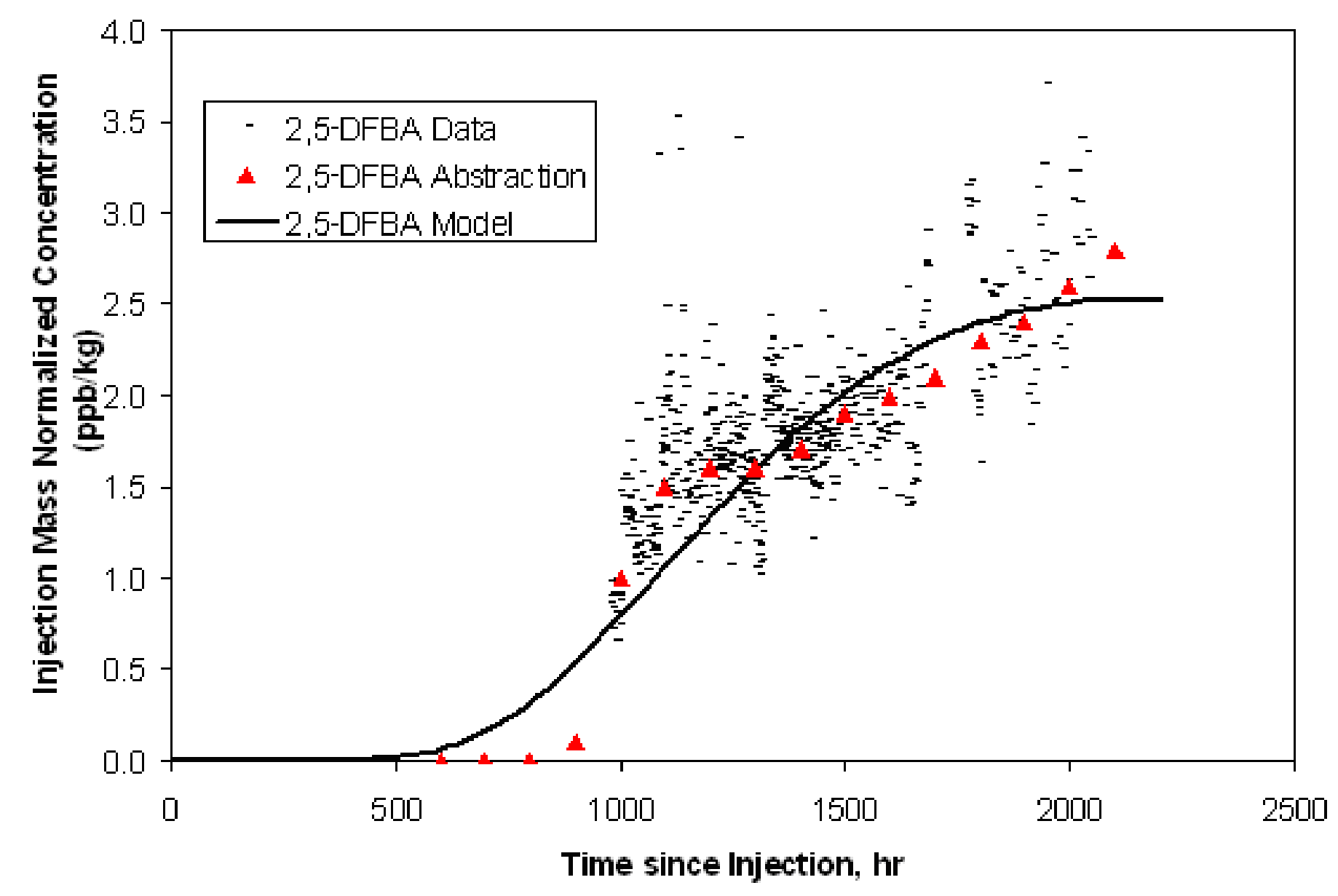

Figure 2-20

Data and RELAP Fit to 2,5-DFBA 
associated with the RELAP curve shown in Figure 2-20 are listed in Table 2-11. The discrete bailer data clearly indicated that almost all the 2,5-DFBA was entering ER-6-1 \#2 at or above the fault zone at 2,200 ft depth. This result is not surprising given that the bottom of ER-6-1 \#1 is just barely over $2,000 \mathrm{ft}$ bgs.

Table 2-11

Transport Parameters from RELAP Fit for 2,5-DFBA

\begin{tabular}{|c|c|}
\hline Transport Parameter & Value \\
\hline Tracer Mass Fraction $^{a}$ & 0.98 \\
\hline Mean residence time, $\mathrm{hr}$ & 3,300 \\
\hline Peclet number & 6.5 \\
\hline$\frac{\phi}{b} \sqrt{D_{m}}, \sec ^{-1 / 2 \mathrm{~b}}$ & 0 \\
\hline Flow Porosity ${ }^{c}$ & 0.020 \\
\hline Longitudinal Dispersivity, m & 14 \\
\hline
\end{tabular}

aMass fraction is the fraction of tracer mass participating in the test yielding best fit to the breakthrough curves.

b $\frac{\phi}{b} \sqrt{D_{m}}$ is a mass transfer coefficient for matrix diffusion, where $\phi=$ matrix porosity, $b=$ fracture half-aperture, and $D_{m}=$ diffusion

${ }^{\mathrm{c}}$ Flow porosity is calculated from $Q \tau / \pi r^{2} h$, where $Q=40$ percent of production flow rate (based on flow logs), $\tau=$ mean residence time, $r=$ distance between wells $(92 \mathrm{~m})$, and $h=$ interval thickness $(300 \mathrm{~m})$.

\subsection{Analysis Summary}

Basic analysis of the normalized tracer responses failed to reveal measurable dual-porosity behavior. Given the relatively low (0.01 to 0.06 percent) laboratory measurements (Hershey et al., 2003; Reimus et al., 2006) of matrix porosity, the relatively quick breakthrough, and conceptual model of linear flow, dual-porosity effects would be expected to be subtle, but the effects are further obscured by tracer injection mass uncertainty, changing background concentrations of the inorganic tracers Li and $\mathrm{Br}$, and tracer breakthrough concentrations near the analytical detection limit.

Effective porosities and longitudinal dispersivities estimated from scoping calculations and semianalytic methods are generally within the range that might be expected for the type of rock and scale of the tracer test. The effective porosity is not especially low, with the order of magnitude range between roughly 0.003 and 0.01 . This is not unreasonable given that the permeable zones of the LCA encountered in ER-6-1 cluster wells are fracture zones, rather than single features, that have a 
brecciated or shattered appearance. The longitudinal dispersivity ranges from about 5 to 30 percent of the test scale.

Information determined from the previous TFM-1 analysis presented in the MWAT-TT data document (SNJV, 2005e) is used as a conceptual framework for interpreting the EC logs and to provide constraints for the mass-balance and BORE-II simulations. Three different analysis methodologies suggest that there is significant downward flow within the borehole from above a depth of 2,074 ft bgs that passes below a depth of 2,900 ft bgs. Horizontal flow in and out of the borehole occurs within this depth interval. It appears that when ER-6-1 \#2 is pumped, it connects hydraulically to the bottom (below 2,900 ft bgs) of ER-6-1, creating a hydraulic head significantly lower than in the borehole above 2,350 ft bgs depth and even above 2,074 ft bgs depth. This results in a significant flow circuit (greater than 2 gpm) within ER-6-1 from top to bottom.

The in-borehole peak tracing technique only provided estimates of borehole velocity and volumetric flow rate across two intervals. This method confirmed downward flow from a depth of 2,074 and 2,714 ft bgs, with the vertical downward flow rate decreasing with depth. The TFM-1 results (SNJV, 2005e) estimated that when ER-6-1 \#2 was pumping, the maximum ER-6-1 borehole flow rate was approximately $1.5 \mathrm{gpm}$. The peak tracing method yields a value in excess of $2.7 \mathrm{gpm}$. The in-borehole peak tracing method also estimates a downward borehole flow rate of 2.4 gpm between a depth of 2,400 and 2,700 ft bgs, implying a significant amount of flow below 2,700 ft bgs.

The mass-balance technique yielded contradictory results. A simple borehole dilution analysis performed by Reimus (2005) yielded a borehole volumetric flushing rate of $2.7 \mathrm{gpm}$ for the borehole interval from 1,800 and 2,900 ft bgs. This rate is inconsistent with the TFM-1 results but compares well with the in-borehole tracing results. A mass-balance analysis was performed for the interval from 1,890 to 2,350 ft bgs. The "best-fit" flow rate, optimized to reduce the estimated mass-balance error at each time step over Zone 1, was a time average for all logs of $1.57 \mathrm{gpm}$. Because this analysis treats the entire interval within Zone 1 as a single mixing volume, the borehole flow rate is comparable to the borehole flow rate measured in the TFM-1 campaign at a depth of approximately 2,350 ft bgs. The flow rate measured in the TFM-1 analysis at 2,350 ft bgs was approximately 1.5 gpm. 
A mass-balance analysis was also performed across the borehole interval from 2,350 to 2,950 ft bgs (termed Zone 2). For the Zone 2 mass-balance calculations, the difference between the estimated and measured change in mass was minimized on an interval-by-interval basis stepping forward in time. The intervals were based on the results of the TFM-2 analysis. The estimated flow rates were unrealistic when TFM derived flow rates and tracer mass migration were considered jointly. However, the analysis did yield general agreement with the flow rates, and did require a significant borehole flow rate down the borehole and below a depth of 2,900 ft bgs.

Several observations can be made based on the BORE-II forward model simulations. Definition of a vertical flow profile alone is insufficient to capture the time-varying attributes (i.e., amplitude, frequency) of the evolving EC logs; zones of inflow and outflow are required. A relatively high (2.3 gpm) vertical borehole flow rate must be defined as the upper-boundary condition to match the rapidly decreasing tracer mass at the upper boundary. The curvature of the profiles is extremely sensitive to horizontal flow rates. This high relative sensitivity allows for better definition of these parameters. The smoothness of the profiles (with the exception of the initial condition), in conjunction with the high horizontal flow-rate sensitivity, indicates that vertical flow is controlling the speed of tracer dilution. A significant outflow zone beneath the deepest EC measurement 2,930 ft bgs point is required to fit the data and satisfy the above-listed flow characteristics.

It is evident that multiple spatial arrangements of flow rates down the borehole may provide equivalent simulated EC profiles. It is difficult to assess parameter correlation through forward calibration, with the level of difficulty increasing as the number of parameters increases; therefore, the BORE-II simulation must be viewed as a semi-quantitative application in this case providing general characteristics of ER-6-1 borehole flow while ER-6-1 \#2 was pumped. Because the EC logs evolve quickly, there is very little transient log evolution that can be used to calibrate horizontal flows within the logged interval. 


\subsection{Numerical Model analysis}

\subsection{Introduction}

This section describes the construction of a tracer test-scale numerical model and its use for estimation of formation hydraulic and transport properties. The general approach to model calibration and parameter estimation is presented in Section 3.2. Section 3.3 describes the numerical model setup including a description of the numerical code applied for the analysis and a description of the numerical flow and transport mesh. Sections 3.4 and 3.5 describe the setup and procedure for the calibration process, with a focus on definition of the target data and their simulation. Section 3.6 presents the analysis results. Section 3.7 presents a subregional scale analysis of flow in the Yucca Flat LCA, using a two-dimensional (2-D) flow model, based upon the hydraulic response data from distant observation wells during the MWAT-TT. Finally, Section 3.8 discusses limitations of the analysis.

\subsection{Approach}

Model calibration (also called "parameter estimation," "solving the inverse problem," and "inversion") entails estimating formation hydraulic and transport parameters such that simulated flow and transport responses match those measured in the field to within some acceptable range. Other uses of models are for testing hypotheses and conceptual understanding (Krabbenhoft and Anderson, 1986) and for estimating physical parameters (Finsterle and Persoff, 1997). This analysis was done to explore possible models of flow and transport of the ER-6-1 tracer test by attempting to synthesize geologic data, borehole flows and heads, and tracer breakthrough in a quantitative framework. The resultant information will ultimately be used to support assessment of underground-test related radionuclide migration.

For this analysis, the parameter estimation software (PEST) (Watermark, 2004) is used, which automates the iteration through model sensitivity and parameter adjustment. The PEST code systematically identifies and evaluates the more important parameters that improve calibration. The 
PEST code begins by changing each parameter to be considered by a certain amount and records the absolute and relative degree to which the model calibration, or simulated versus observed data fits, change. The Levenberg-Marquardt procedure is used to compute parameters that improve the model agreement with the target data. The basic algorithm used by PEST has a long history of successful use in solving groundwater problems. The reader is referred to the PEST manual (Watermark, 2004). The LCA is a fractured rock, and flow log data suggest that there are discrete zones through which flow and transport occurs. The approach used in this analysis is the mixed discrete continuum, where dominant fractures (or breccia zones in the case of the ER-6-1 well cluster) are explicitly represented as relatively 2-D features (via the power plane method described in Appendix B) embedded in the three dimensional domain that represents the remaining fracture network (Carrera and Martinez-Landa, 2000).

\subsection{Flow and Transport Model Setup}

The flow and transport simulator used in the analysis is FEHM (Zyvoloski et al., 1997a and b), developed by LANL. The FEHM code simulates three-dimensional (3-D), time-dependent, multiphase, nonisothermal flow, and multicomponent reactive groundwater transport through porous and fractured media. The FEHM code finite-element formulation allows for representation of complex 3-D geologic media and structures and their effects on subsurface flow and transport. The hydrologic source/sink term, lateral boundary conditions, and parameter values are inputs to FEHM. The FEHM code output consists of the spatial distribution of transient head and concentration through specified boundaries, planes, and or groups of mesh nodes. The transport processes of interest in this analysis include advection, dispersion, sorption, matrix diffusion, and colloid-facilitated transport. Tracer transport is simulated using the streamline particle tracking (SPTR) algorithm, a number of documents supporting the FEHM code are readily available from LANL. In addition to the user's manual (Zyvoloski et al., 1997b), these documents include a description of the mathematical models and numerical methods used by FEHM (Zyvoloski et al., 1997a), documentation of the functional and performance requirements for FEHM, description of the FEHM software, the verification and validation plan, and description of the verification and validation activities (Dash et al., 1997; Dash, 2000 and 2001). 


\subsubsection{Mesh Generation}

A finite-element mesh was constructed for simulation of the geologic area that impacted flow and transport during the MWAT-TT. The FEHM mesh was constructed to satisfy the following requirements:

- Encompass only the ER-6-1 cluster scale, well hydraulic, and tracer responses

- Capable of simulating hydrogeologic features inherent to the conceptual model at a realistic spatial scale

- Capable of realistically simulating borehole hydraulic conditions

- Minimize the node count for minimization of model computational time

The numerical model boundaries were defined to represent a refined section of the LCA that fully captures the hydraulic and transport responses measured at the three cluster wells, ER-6-1,

ER-6-1 \#1, and ER-6-1 \#2. The model domain is centered laterally at the pumping well (ER-6-1 \#2) and extends vertically along the complete extent of the ER-6-1 \#2 completion within the LCA. There is no stratigraphy or structure built into the mesh; geologic features are defined by their hydraulic properties rather than by mesh geometry. The only irregular geometry defined in the mesh is the location of the three wells (Figure 3-1). The mesh was constructed with a high-resolution octree mesh around the wells that telescopes to larger mesh spacing as distance from the well increases. The mesh remains finer extending to the edges to obey mesh expansion metrics and for simplicity in avoiding an unstructured mesh.

The east-to-west, north-to-south, and vertical dimensions of the numerical model are 1,040, 1,112, and $400 \mathrm{~m}$, with the ER-6-1 \#2 location at point $(0,0) \mathrm{m}$. The plan coordinates of point (easting, northing $)=(0,0) \mathrm{m}$ are 589,609.04 and 4,093,330.92 $\mathrm{m}$ Universal Transverse Mercator (UTM) (UTM Zone 11). The mesh is aligned north to south, with a 15.329 degrees counterclockwise rotation, such that ER-6-1 \#2 and ER-6-1 have the same easting coordinate. The boreholes are defined as the vertical line of nodes along each of the three octree-mesh-refined zones, which effectively define each borehole as the central four elements (along each vertical plane) at the refined mesh zones. The borehole vertical node spacing is $0.3125 \mathrm{~m}$, and the four-element centroids have planar dimensions of $0.0625 \mathrm{~m}$. From the refined zones, the elements telescope out to the area of 
a) Entire Mesh
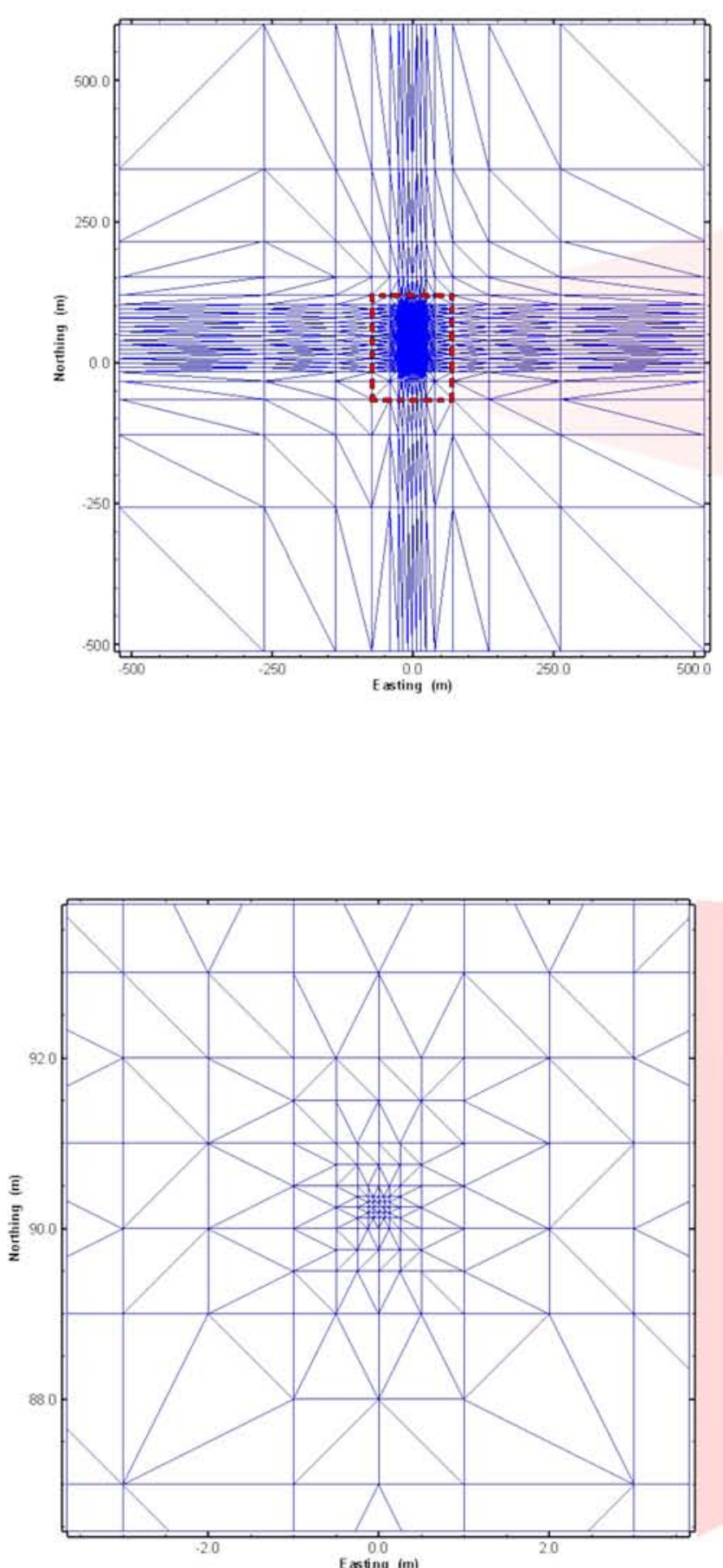

d) Mesh Around ER-6-1 b) View of Refined Area
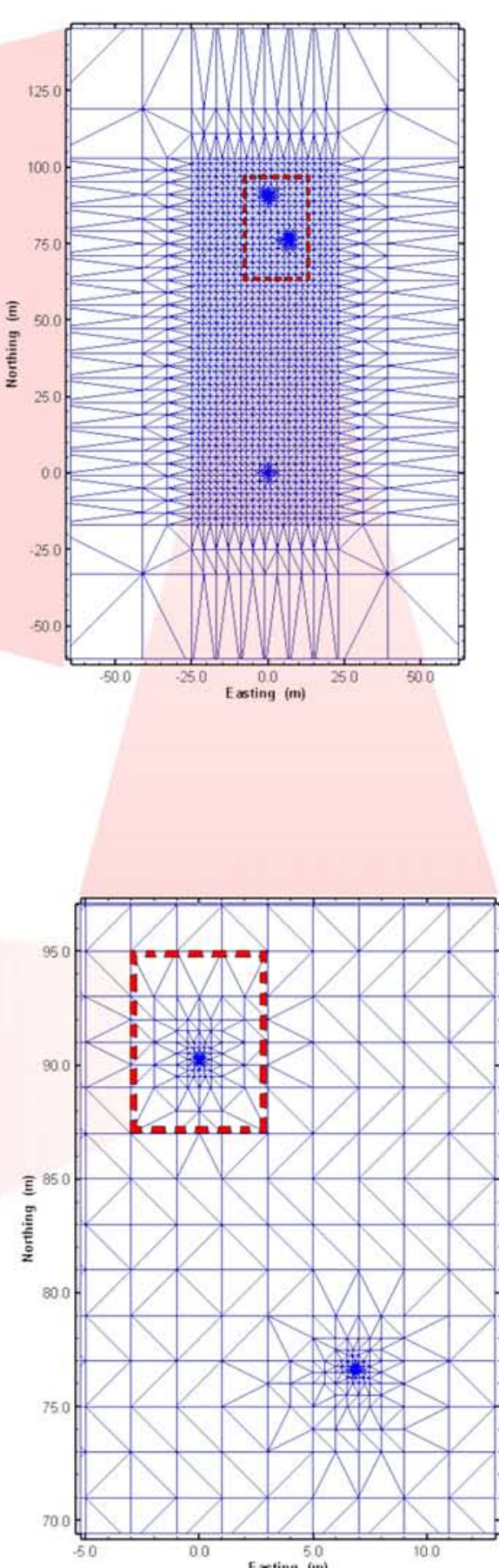

c) Mesh Near ER-6-1 \#1 and ER-6-1

Figure 3-1

Figure 3-1
FEHM Mesh 
interest, defined as the subvolume of the complete mesh that fully captures the three wells at high spatial resolution. It is within the area of interest that geologic features (e.g., faults, bedding planes) connecting the wells must be spatially defined. Beyond the area of interest (in the planar orientation), the mesh continues to get coarser until the domain boundaries are reached.

The decision to define the mesh at a small spatial scale, relative to the full planar extent of the MWAT-TT across a larger area of Yucca Flat, was motivated by analysis of the MWAT-TT hydraulic and transport responses. Regarding the former, hydraulic responses at the ER-6-1 well cluster indicated that pseudo-steady-state conditions were achieved within approximately $2.5 \mathrm{hr}$ of pumping. The rapid onset of pseudo-steady-state, together with the understanding that the response diagnostics are dependent primarily on the flow geometry between the pumping and observation well (Butler, 1990), suggests the basic hydraulics can be reasonably captured in a smaller scale model. Pumping in ER-6-1 \#2 and ER-6-1 was simulated by setting a specified rate boundary condition at the approximate pump intake location in the model. This approach is similar to that of Jones et al. (1992), which provided satisfactory results.

\subsubsection{Boundary Conditions}

For the tracer test analysis, the solution of the groundwater flow equations requires the specification of pressure at the mesh edges and flow at internal discharge nodes (i.e., a pumping well). The (lateral and planar) mesh borders are specified as steady (constant-in-time) pressure boundaries; flows at these boundaries are unknown. The spatial variation of pressure at the boundaries is discussed below. Discharge nodes that correspond to pumping wells are specified by transient flow, with the flow rate (or flux) known from field measurement.

Specified pressures at the mesh edges control the steady-state, ambient flux through the model domain. The LCA hydraulic gradient across both the ER-6-1 well cluster and the model domain has not been determined with certainty. The spatial variations between LCA head measurements at/near the well cluster, both historically and during the MWAT-TT, are within the range of measurement uncertainty such that a definitive gradient calculation is prevented (SNJV, 2005e). However, analysis of tracer breakthrough curves, before and following a period of ambient flow during the MWAT-TT, suggests that drift velocity is a significant transport mechanism. Conceptually, the hydraulic gradient is directed approximately north to south across the domain. 
In order to define the steady-state pressure at lateral boundaries, the north-to-south hydraulic head change is defined along with the head at the northern boundary, as a fitting parameter during model calibration. The northern boundary is defined as a constant pressure boundary, and the change across the model is specified in order to define the constant pressure at the southern boundary. Pressure at the east and west lateral boundaries is fixed for individual model runs, but not throughout the entire calibration process as they are also dependent on the domain hydraulic properties. The method by which the east and west boundary pressures were defined through calibration is described in Section 3.3.3.

Pressure at the top and bottom domain boundaries were not specified; these boundaries were considered to have a no-flow condition.

Pumping in ER-6-1 \#2 and ER-6-1 was simulated by setting a specified-rate boundary condition at the node closest to the pump intake location in the model. The permeability of the borehole under laminar flow was estimated as described by Chen and Jiao (1999) at $2 \times 10^{-7} \mathrm{~m}^{2}$.

\subsubsection{Initial Conditions}

Initial head conditions corresponding to the time at which each simulation of the MWAT-TT are required as described further in Section 3.5.1. The initial conditions are dependent on three general hydraulic features: (1) the constant head datum defined for the northern lateral boundary, (2) the north-to-south head change, and (3) spatial distribution of node hydraulic properties. The latter two features are in most cases defined as fitting parameters during model calibration; therefore, initial conditions vary from transient model run to run. To account for this before any transient simulation of the MWAT-TT, the model is run with the input parameters to steady-state conditions over the domain used in the transient analysis, thus ensuring a physically consistent representation of groundwater flow. This is the means by which the east and west lateral boundary pressures are held constant through a sequence of model runs (described in Section 3.5.1), yet are permitted to vary during model calibration. 


\subsection{Calibration Data}

Data used for flow model calibration included observation well head, observation well drawdown/recovery, and TFM-derived borehole interval flux from cross-borehole pumping. The SFM data were used only for conceptual model development, not model calibration, because the TFM data directly addresses cross-borehole connectivity. Although formation head and drawdown are derived from the same field measurement, it is important to differentiate the two during the calibration process. Drawdown is independent of the magnitude of head; therefore, while head measurement may be uncertain, drawdown is not. All hydraulic response data are defined as drawdown with the exception of the first datum in each sequence, at each well, which is defined as head. The transport targets include tracer breakthrough curves at the pumping well (ER-6-1 \#2) from the fast-path and MWAT-TT.

The variation in calibration data types requires that their weighting in parameter estimation be adjusted. This is primarily for two reasons: (1) because of the many different measurement units, the magnitude of the data varies by several orders of magnitude between datasets; the data with larger magnitudes naturally have greater impact on the objective function and, therefore, are given greater consideration when updating fitting parameters during optimization, and (2) because of greater uncertainty, from any number of sources, in select sets the uncertainty in the observed data may need to be considered by decreasing their influence on the objective function. Weights can be determined from data measurement error, if known, or empirically based on qualitative considerations of the relative importance of each data type. The latter procedure was used in this analysis.

\subsubsection{Head, Drawdown, and Flow Sequences}

The fast-path and MWAT-TT were divided into six sequences, each defined as a period of either drawdown due to pumping at ER-6-1 \#2 or recovery. Because of the approximately logarithmic relationship between pressure response and time beginning at a step change in pumping rate, head and drawdown calibration data were selected from the reverse logarithmic-time sampling of the data within each sequence in order effectively capture the transient response. Accordingly, this sampling scheme required that each change in pumping conditions be defined as an individual sequence. The scheme is beneficial not only for appropriate sampling of the measured hydraulic response data for calibration data, but it also permits the simple exclusion (or weight adjustment) of one or more 
sequences in the analysis in the case that these calibration data are uncertain. The six flow sequences correspond to the periods of: (1) the fast-path tracer test pumping at ER-6-1 \#2, (2) recovery, (3) MWAT-TT pumping at ER-6-1 \#2, (4) 4-day planned recovery, (5) MWATT-TT drawdown, and (6) 40-day MWAT-TT recovery (Figure 3-2).

\subsubsection{Thermal Flow Meter Data}

The TFM-derived borehole interval flow rates from cross-borehole pumping are also used as flow calibration targets. These data and their contribution relative to the conceptual flow model were presented in Section 2.2.2, and are also presented in SNJV (2005e). To summarize, the TFM data are point measurements of (assumed steady-state) vertical borehole flow collected under constant pumping conditions at a remote well. A single measurement campaign was performed at ER-6-1 \#2 while pumping at ER-6-1 on Julian Day (JD) 28, and at ER-6-1 while pumping ER-6-1 \#2 on JD 41. The former sampling period was before the fast-path tracer test. Sufficient time was allowed between pumping at ER-6-1 and the start of the fast-path tracer test (pumping at ER-6-1 \#2) that the LCA head returned to static conditions. The latter TFM-sampling period was conducted during the fast-path tracer test.

The TFM data provide estimates of net interval flow between the borehole and formation. Because the TFM measurement locations are sparse, with the distance between measurements on the order of hundreds of feet, the calculated flows may be biased low because they cannot detect mid-interval inflow and outflow (e.g., cross-borehole flow). Regardless, the TFM logs provide evidence for defining borehole connections between ER-6-1 and ER-6-1 \#2.

The borehole net interval flows from interference pumping are presented in Figure 3-3. Each interval flow is used as a target datum for model calibration. As discussed, the vertical mesh resolution along boreholes is $0.3125 \mathrm{~m}$, providing sufficient resolution for the cumulative addition of flow at each interval. The TFM calibration targets are directly related to the flow component of the model and related hydrogeologic features, and are conceptually associated to transport. 


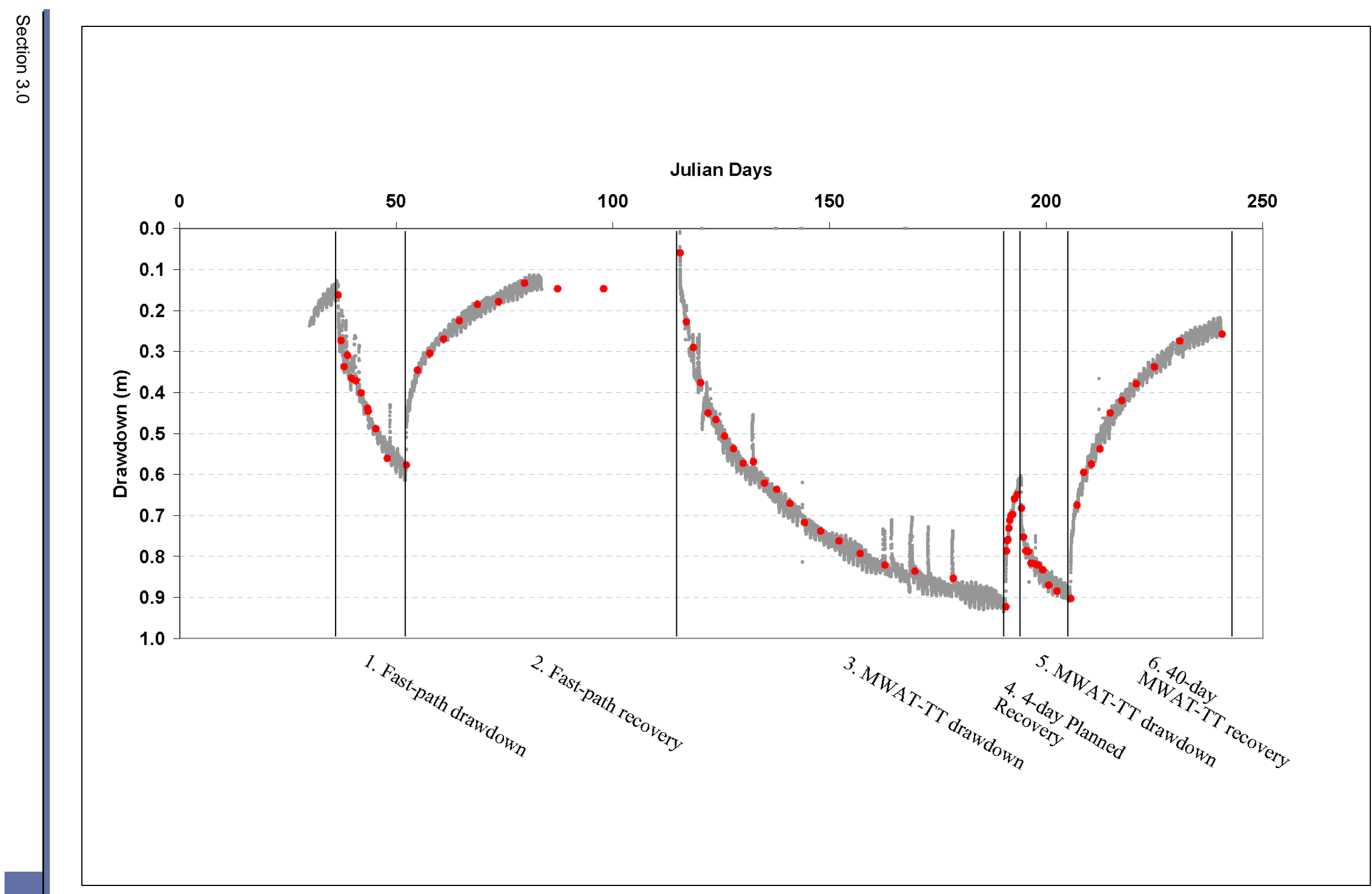

Figure 3-2

Head, Drawdown, and Flow Sequences Defined for Calibration

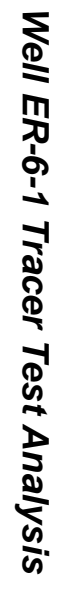




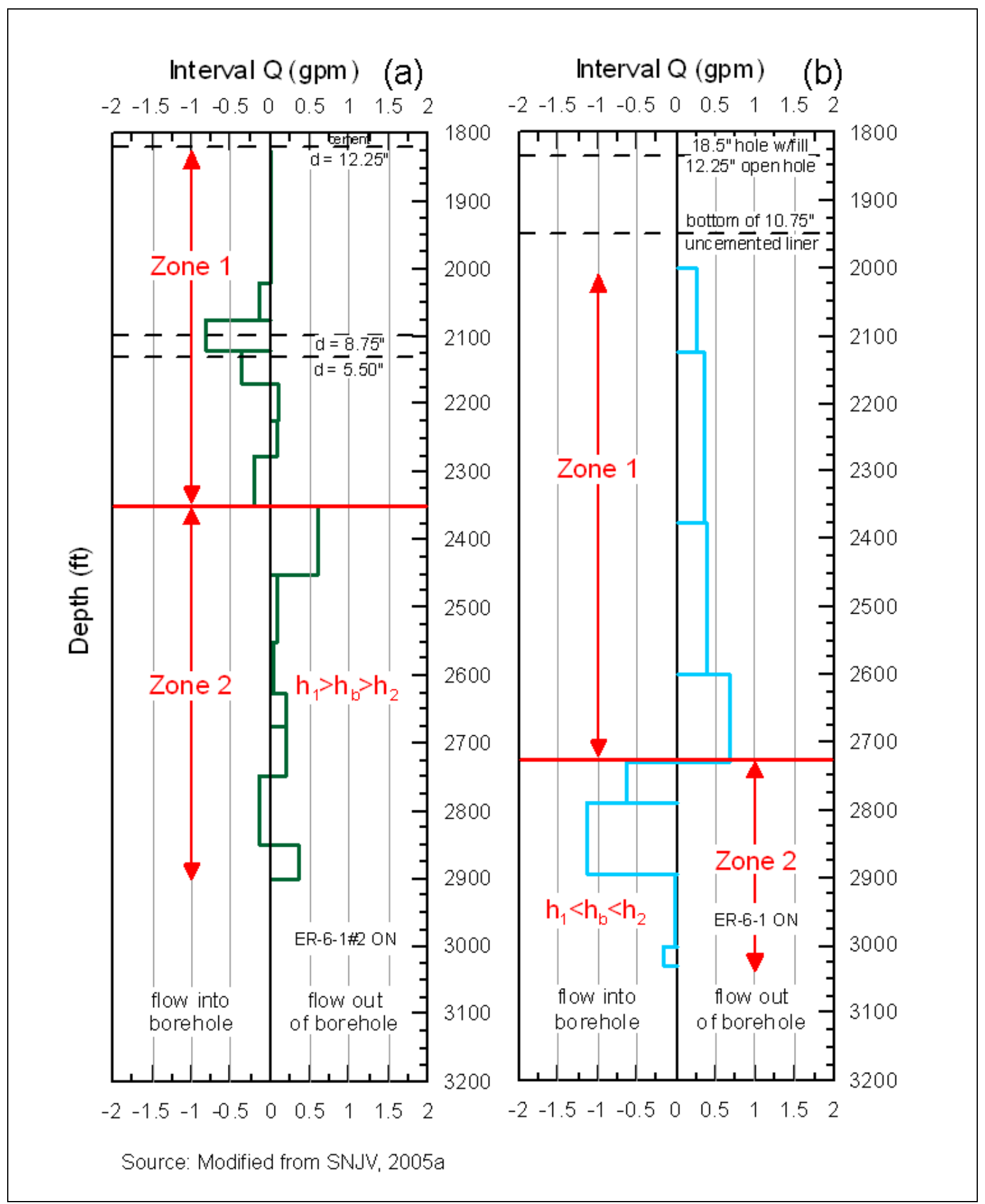

Figure 3-3

Borehole Net Interval Flows from Pumping Interference at (a) ER-6-1 and (b) ER-6-1 \#2 


\subsubsection{Tracer Breakthrough}

A subset of the exhaustive tracer data, selected to capture features of the curve, was used for quantitative comparison because it is not possible to collect numerical model output efficiently on an arbitrarily fine temporal discretization. Figures 3-4 through 3-8 show the full and subset data for 2,6-DFBA, microspheres, 2,5-DFBA, PFBA, and 2,4,5-TFBA respectively. The reduced data are 98, $63,44,75$, and 81 points out of 2,189, 234, 704, 1,507, and 1,762, for 2,6-DFBA, microspheres, 2,5-DFBA, PFBA, and 2,4,5-TFBA respectively.

\subsection{Hydraulic and Tracer Test Calibration}

\subsubsection{Model Run Sequences/Setup}

Before parameter estimation, a model-run sequence was established to unite the transient calibration data with the practical limitations of the numerical code FEHM. Continuous simulation of the complete fast-path and MWAT-TT hydraulic and tracer responses required that multiple, individual FEHM runs be completed in a specific, chronological sequence. In general, the setup was accomplished by separating flow runs from transport runs, and further by separating runs within each group in order to satisfy changing boundary and transport conditions. Figure 3-9 shows a schematic of the model run sequences.

Given the MWAT-TT field operations schedule, FEHM is limited with respect to the SPTR macro functionality. There is no capability to introduce particles with some temporal delay in a transient simulation. Therefore, the four tracers, each with a unique insertion time, required an individual simulation. Again, the first tracer was inserted for the fast-path test, and the latter three as part of the MWAT-TT. Because the complete flow simulation, with the exception of the steady-state run to define initial conditions, can be completed in a single model run (i.e., FEHM can incorporate multiple, transient boundary conditions), it was most efficient (relative to the total model run time) to interrupt this run only once for the addition of the fast-path tracer. Thus, after defining initial model conditions, two sequential model runs were completed to simulate all flow responses, as well as simulation of transport for the fast-path tracer test (concurrent with the second flow run). Afterwards, three individual model runs were completed for each of the MWAT-TT tracers, with each beginning at the corresponding tracer insertion time. 


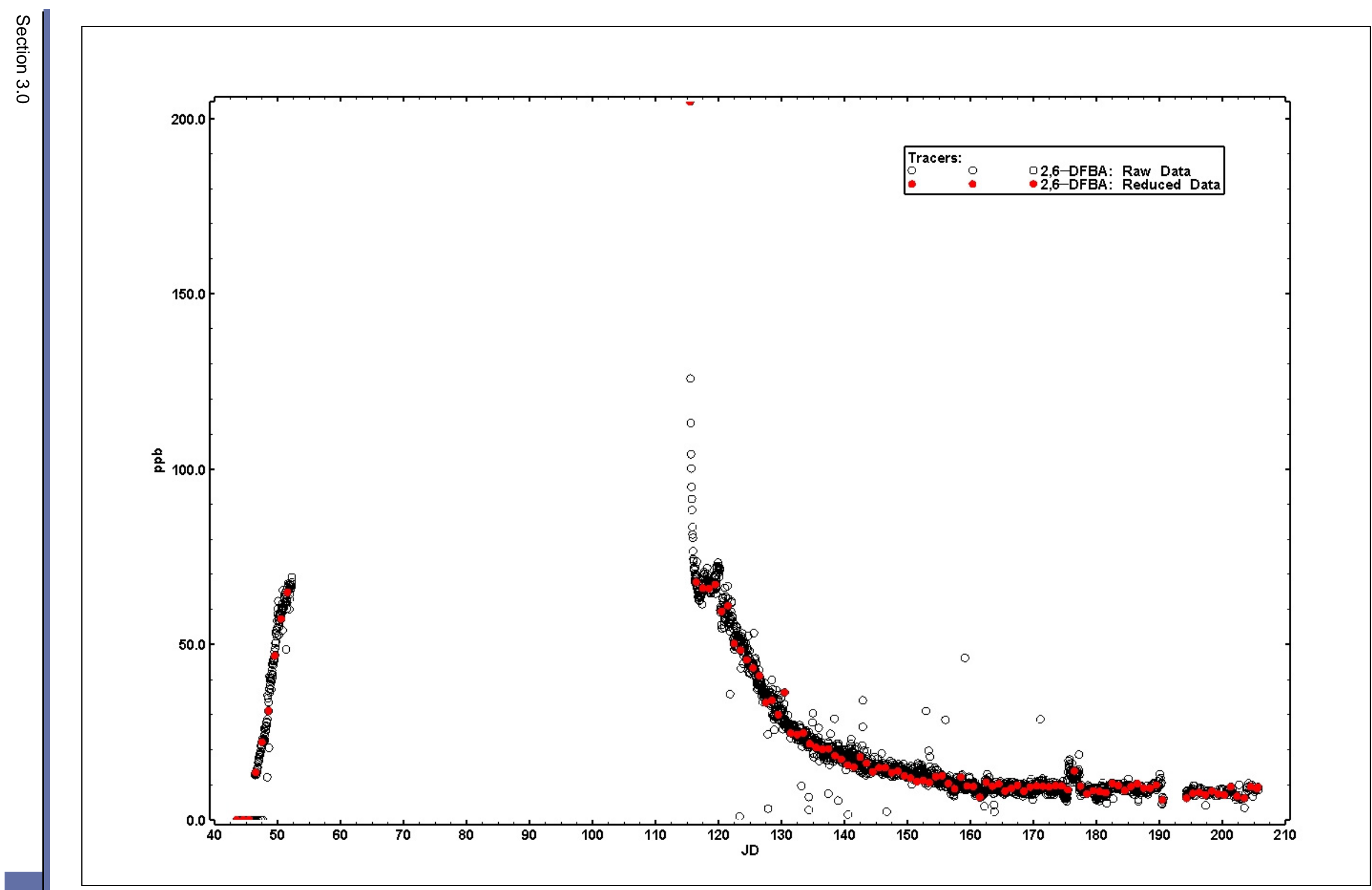

Figure 3-4

2,6-DFBA Concentration Data



Uncontrolled When Printed 


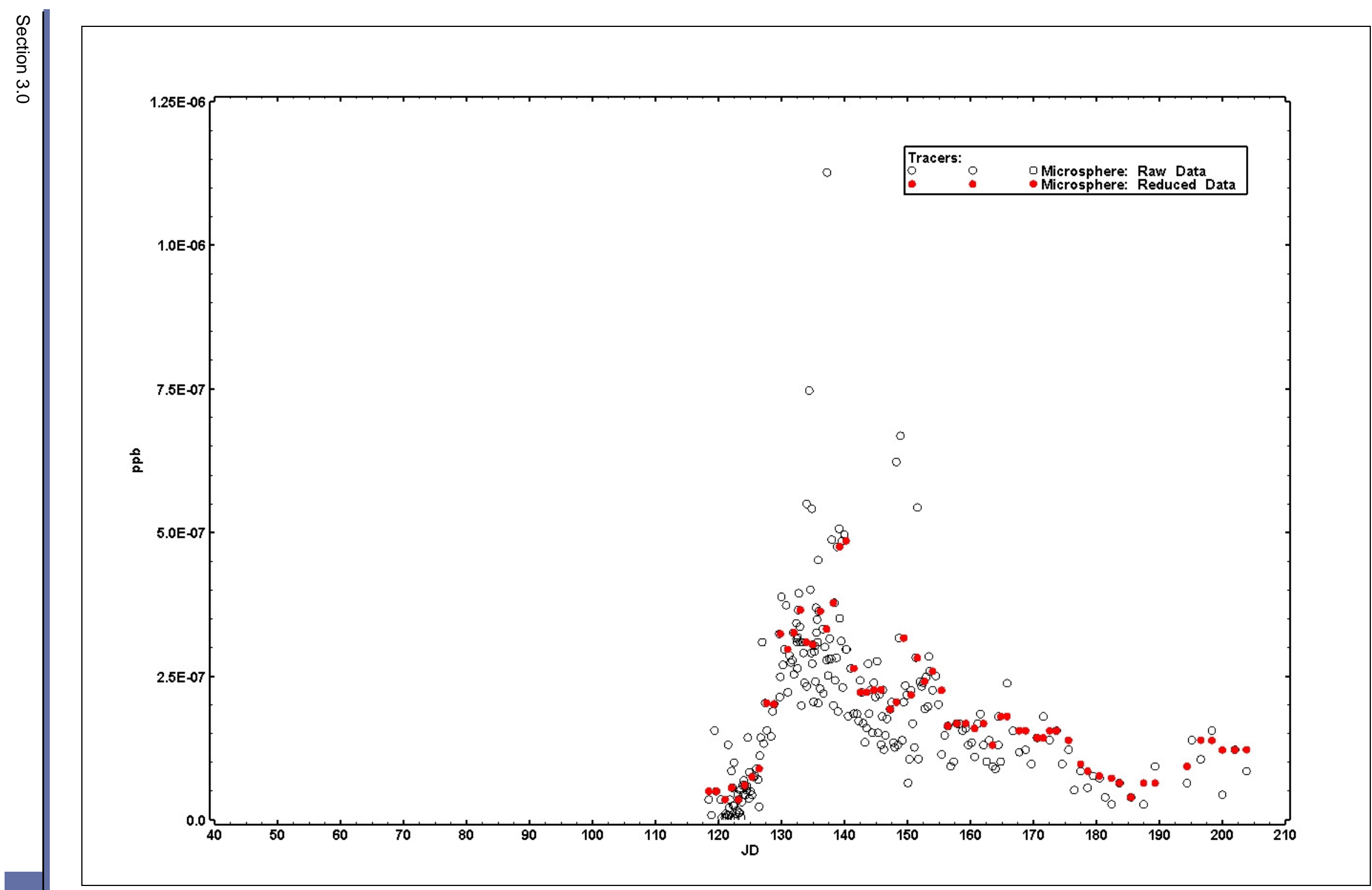

Figure 3-5

Microsphere Concentration Data 


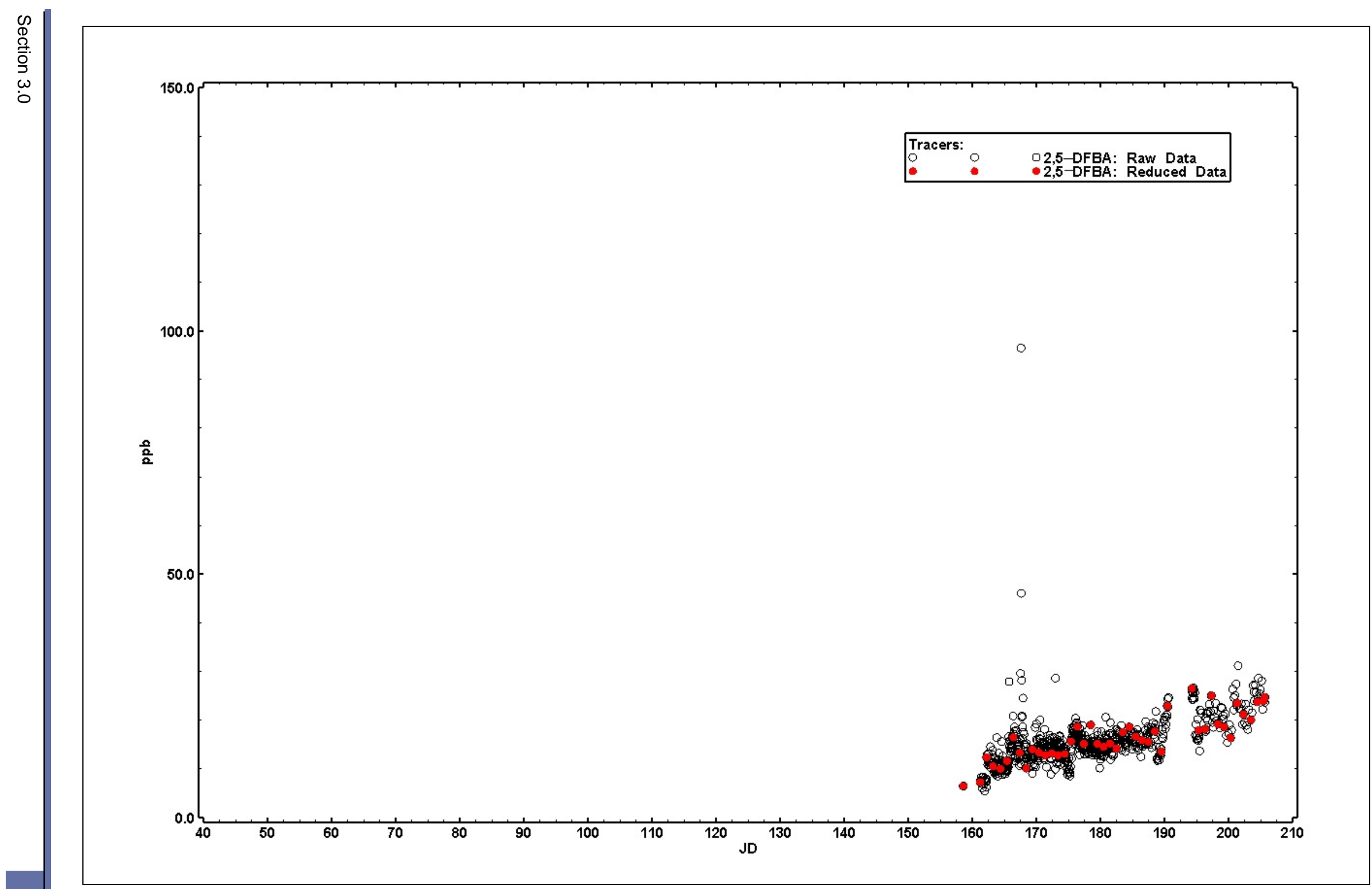

Figure 3-6

2,5-DFBA Concentration Data 


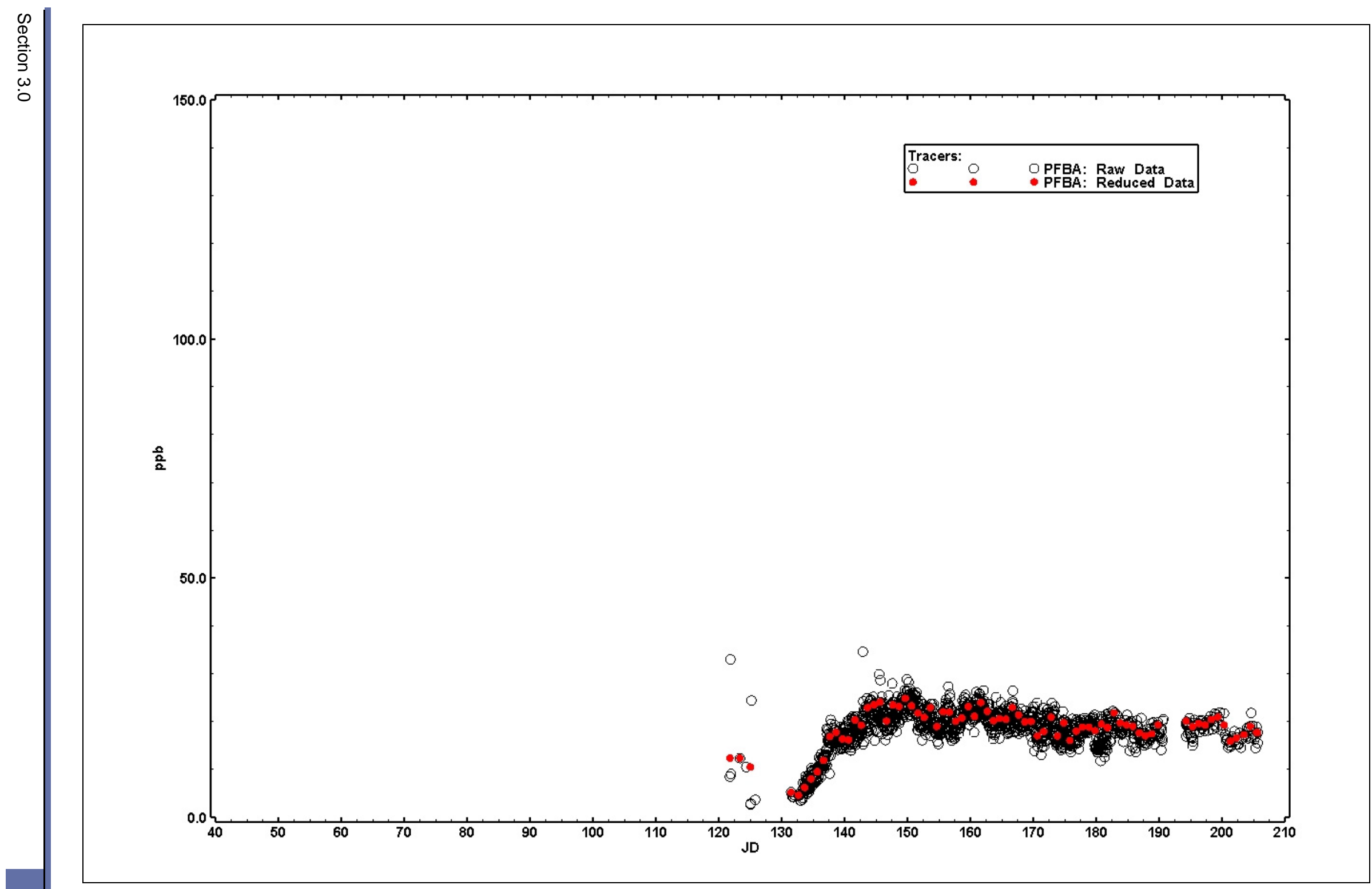

Figure 3-7

PFBA Concentration Data

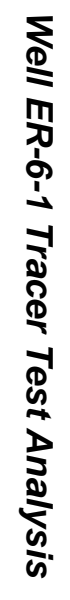

Uncontrolled When Printed 


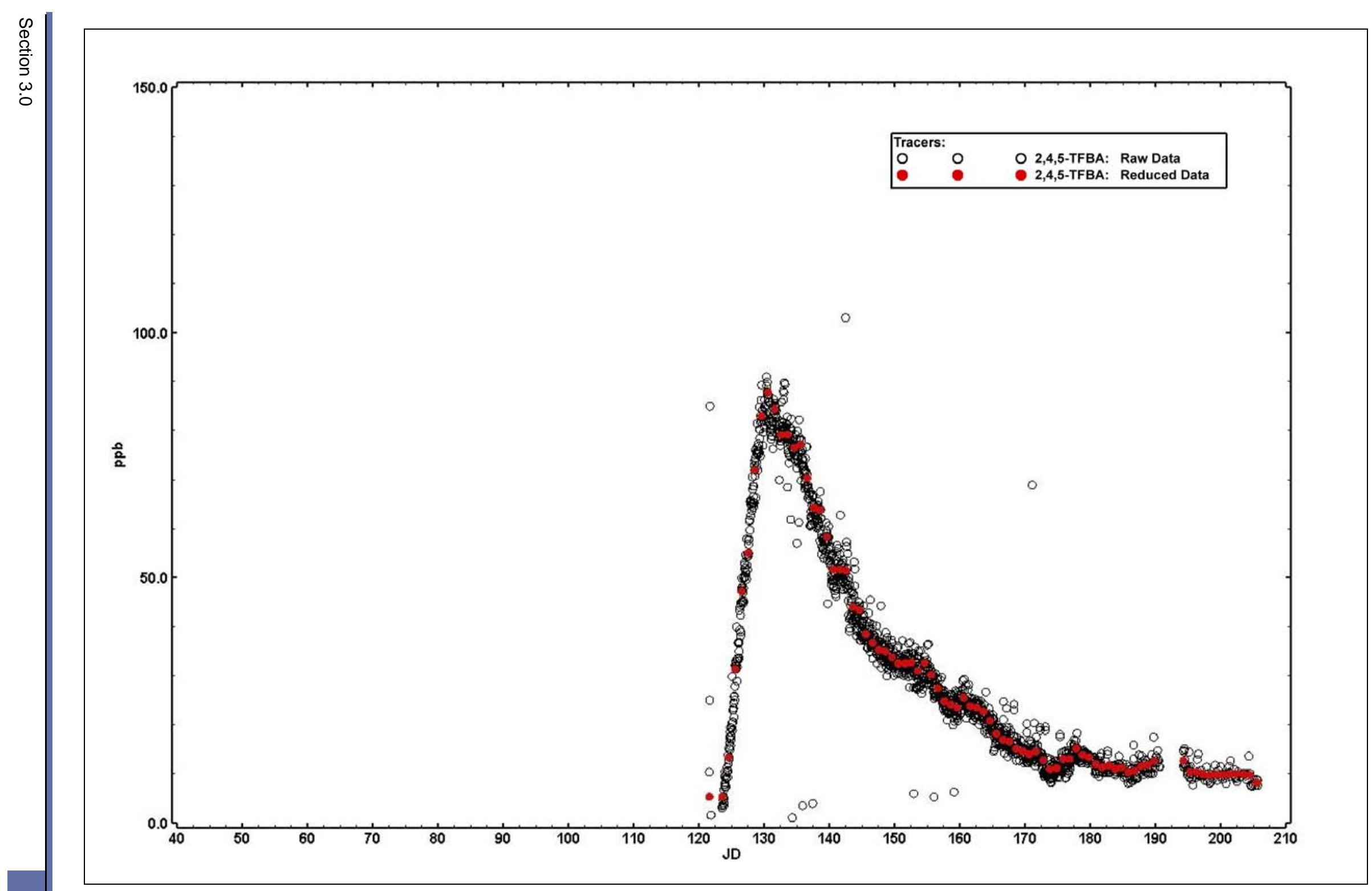

Figure 3-8 


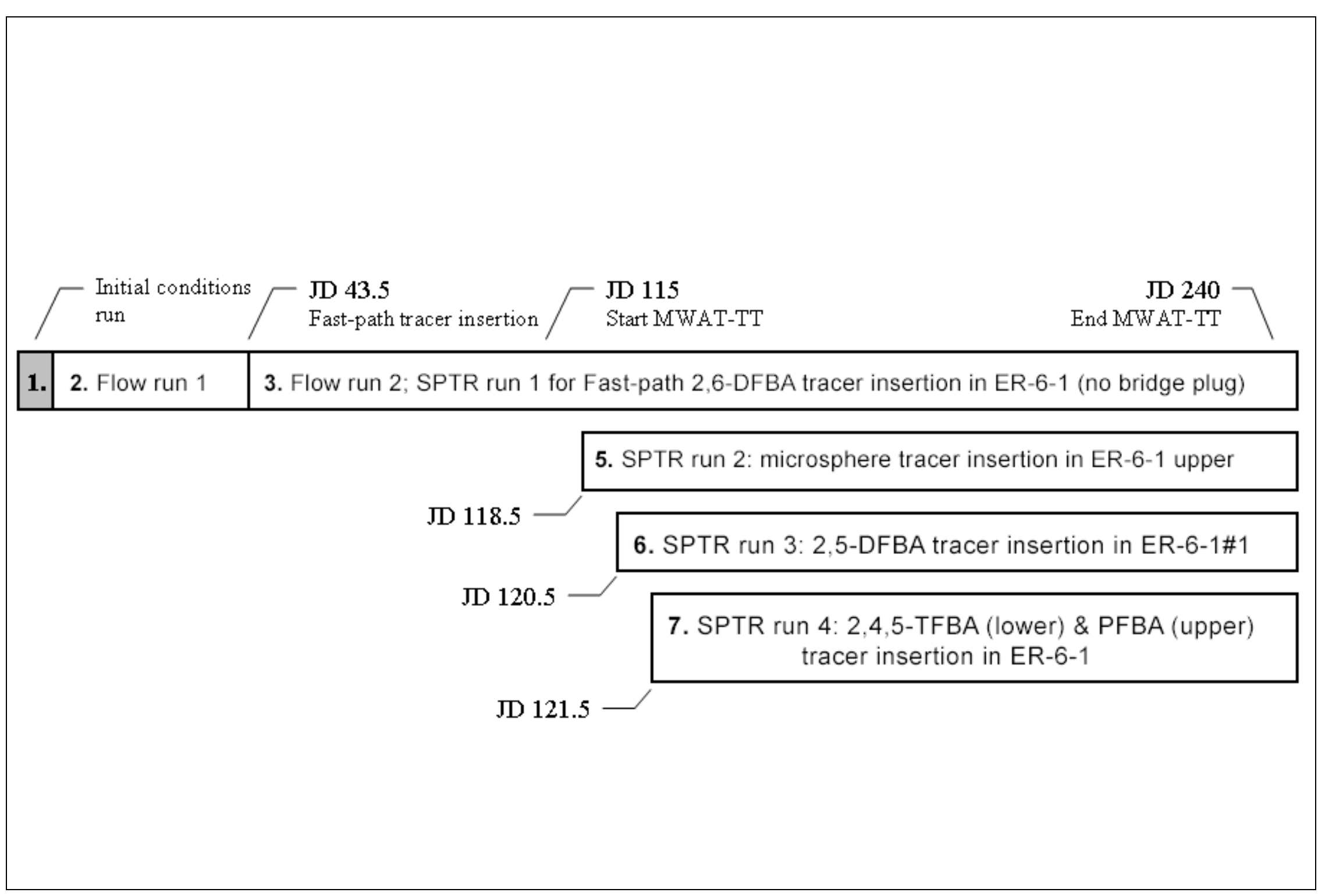

Figure 3-9

Sequence of Model Runs per Single Forward Simulation of Flow and Transport 


\subsection{Numerical Tracer Test Model Results}

\subsubsection{Flow Calibration}

Initially, the observed TFM flows and drawdown were both considered. However, the relatively small mesh scale required for high-resolution in and between the cluster wells for transport, along with the need to constrain simulation time (the flow model alone takes about $2 \mathrm{hr}$ to run), resulted in non-physical drawdown responses from the proximity of specified-head boundaries. Even though FEHM treats constant-head boundaries as a third-type boundary condition that allows specification of a boundary impedance factor to control the degree that the head is enforced adjustment of this factor was not enough to remove the effect, and as parameters changed the boundary impedance also became a sensitive model parameter. Thus, only the TFM flows were considered in later stages of flow model calibration. This is considered reasonable because the TFM data are directly related to the groundwater flow velocity that the tracer experienced in the rock. Jones et al. (1992) used a similar procedure with good results in a fractured dolomite aquifer.

Because no hydraulic head data were used to calibrate the model, the storativity could not be estimated. The FEHM code requires input of aquifer compressibility in 1/megapascals (MPa); the compressibility of water is computed internally. Touloukian and Ho (1981) present values that range from $1.32 \times 10^{-5}$ to $1.75 \times 10^{-4} 1 / \mathrm{MPa}$; a value of $1.41 \times 10^{-5} 1 / \mathrm{MPa}$ was used with a bulk density of 2,200 kilograms per cubic meter $\left(\mathrm{kg} / \mathrm{m}^{3}\right)$ (a generic estimate for dolomite) and porosity of 5 percent, giving a specific storage of about $7 \times 10^{-7} 1 / \mathrm{m}$ - similar to the value $\left(3 \times 10^{-8} 1 / \mathrm{m}\right)$ estimated from the MWAT analysis (SNJV, 2005a). As indicated previously, the analysis initially included drawdown fits, but due to the small size of the domain required for transport, the aquifer compressibility required to reproduce the discrete fracture/channel response, which was observed to strongly focus drawdown north-south along the strike of the faults, became physically non-realistic because the pressure transient in the model reached the edges too quickly when a more plausible storativity was used.

Analysis of the ER-6-1 MWAT-TT TFM and spinner flow log data in conjunction with the tracer migration suggests that the connection between ER-6-1 and ER-6-1 \#2 is in discrete fracture/breccia zones. Thus, the approach to interpretation was to use discrete features generated by the power-plane code described in Appendix B in conjunction with PEST to match the TFM flows in ER-6-1 and 
ER-6-1 \#2. This process was exploratory by its very nature. Other specific features that were included in order to evaluate their importance are as follows:

- The Sevy/Laketown Dolomite contact

- The Laketown/Ely Springs Dolomite contact

- The fault through the well cluster

- A horizontal connection between ER-6-1 and ER-6-1 \#2 at about 2,900 ft bgs

The final results of simulated and measured TFM data for ER-6-1 and ER-6-1 \#2 when the other well is pumping are shown in Figures 3-10 and 3-11. The ER-6-1 flow when ER-6-1 \#2 is pumping (the tracer test conditions) is better than the converse (Figure 3-10). The strong outflows from ER-6-1 at 2,400, 2,700, and 2,900 $\mathrm{ft}$ bgs are matched, as is the strong inflow at 2,100 $\mathrm{ft}$ bgs, but the subtleties are not. The flows in ER-6-1 \#2 when ER-6-1 is pumping are notably in error in the deepest intervals, where net flow should be out of the borehole to ER-6-1 instead of in from the formation. The connection between the wells at about 2,900 ft bgs is directly between the wells, but that connection was carried throughout the domain and is too direct to the rest of the area. This result suggests that the connection between the two wells is not the sole controlling factor; that is, heterogeneous connections to the fracture system north and south of the well cluster influence the response at the cluster.

The estimated discrete feature permeability and confidence limits are shown in Figure 3-12 along with the MWAT estimated permeability (SNJV, 2005a). The feature planes and TFM-calibrated permeability field is shown in Figure 3-13 (a), and for two of the key features in Figure 3-13 (b). None of the individual features permeability matches that from the well test, but most are within an order of magnitude of the value estimated from the MWAT hydraulic analysis.

\subsubsection{Transport Analysis}

The solute transport solution is based on a numerical technique called the convolution-based particle tracking (CBPT) method, which is similar to that utilized by Wolfsberg et al. (2002). The particle-tracking simulations are used to propagate, by convolution, the transient tracer fluxes at the injection wells. As a result, the breakthrough curves of tracer concentrations at the extraction well are obtained. The breakthrough curves are computed using particle-tracking capabilities as implemented in the SPTR macro feature of FEHM and a specially developed code for numerical convolution. 


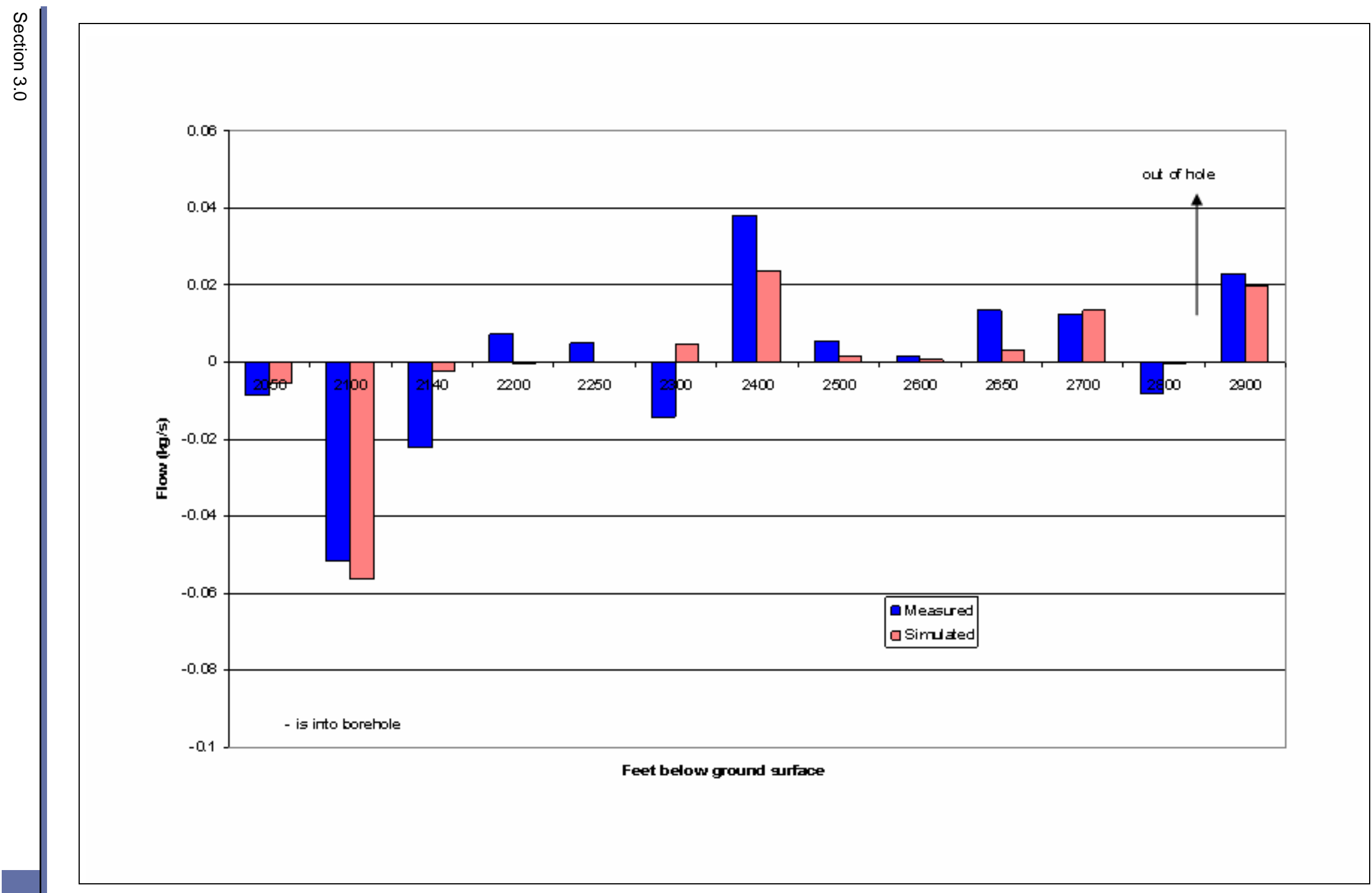

Figure 3-10

Simulated and Observed ER-6-1 MWAT-TT Drawdown Response

Uncontrolled When Printed 


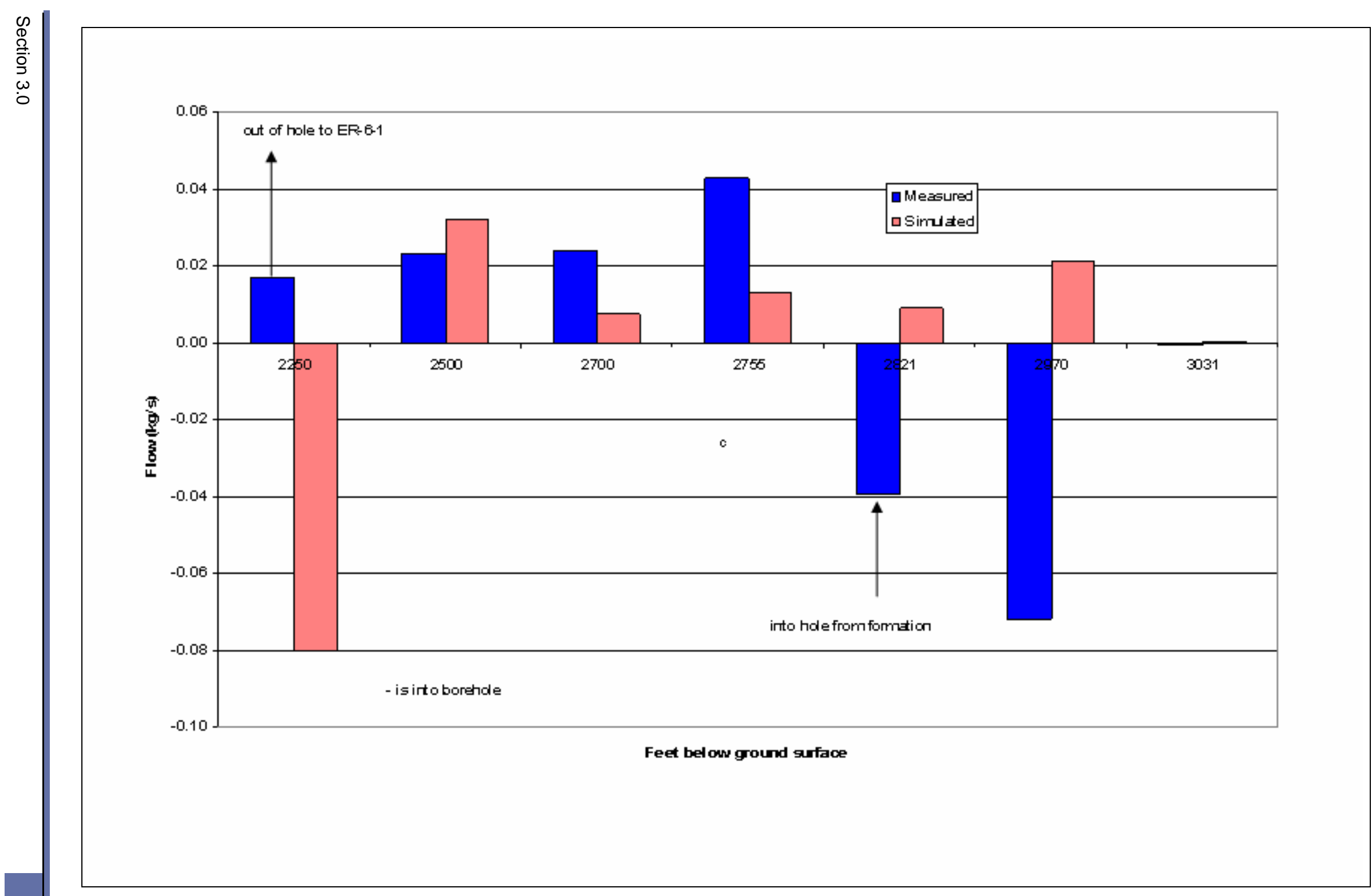

Figure 3-11

Simulated and Observed ER-6-1 \#2 MWAT-TT Drawdown Response

\section{Uncontrolled When Printed}




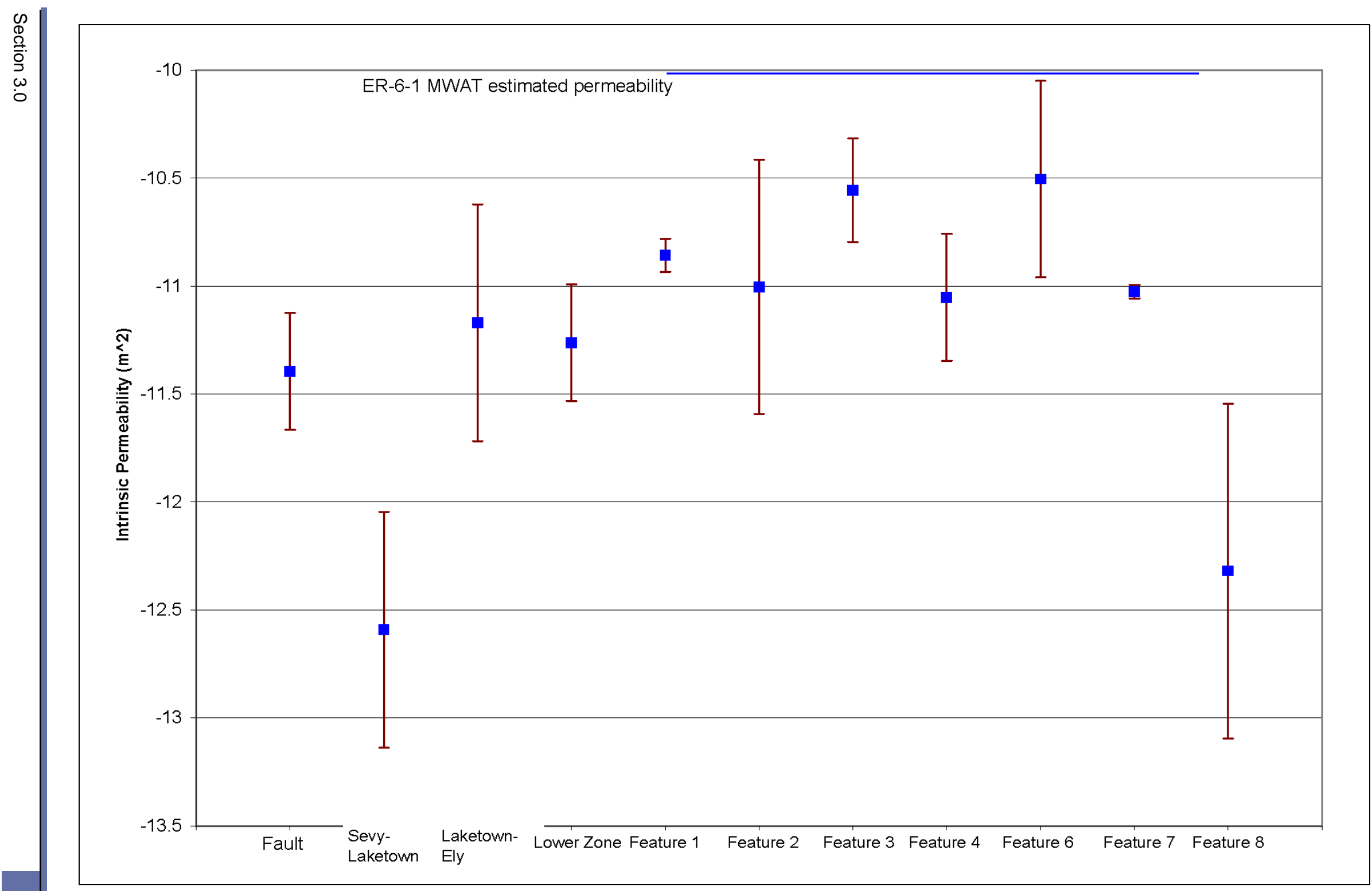

Figure 3-12

Estimated Discrete Feature Permeability and Confidence Limits 


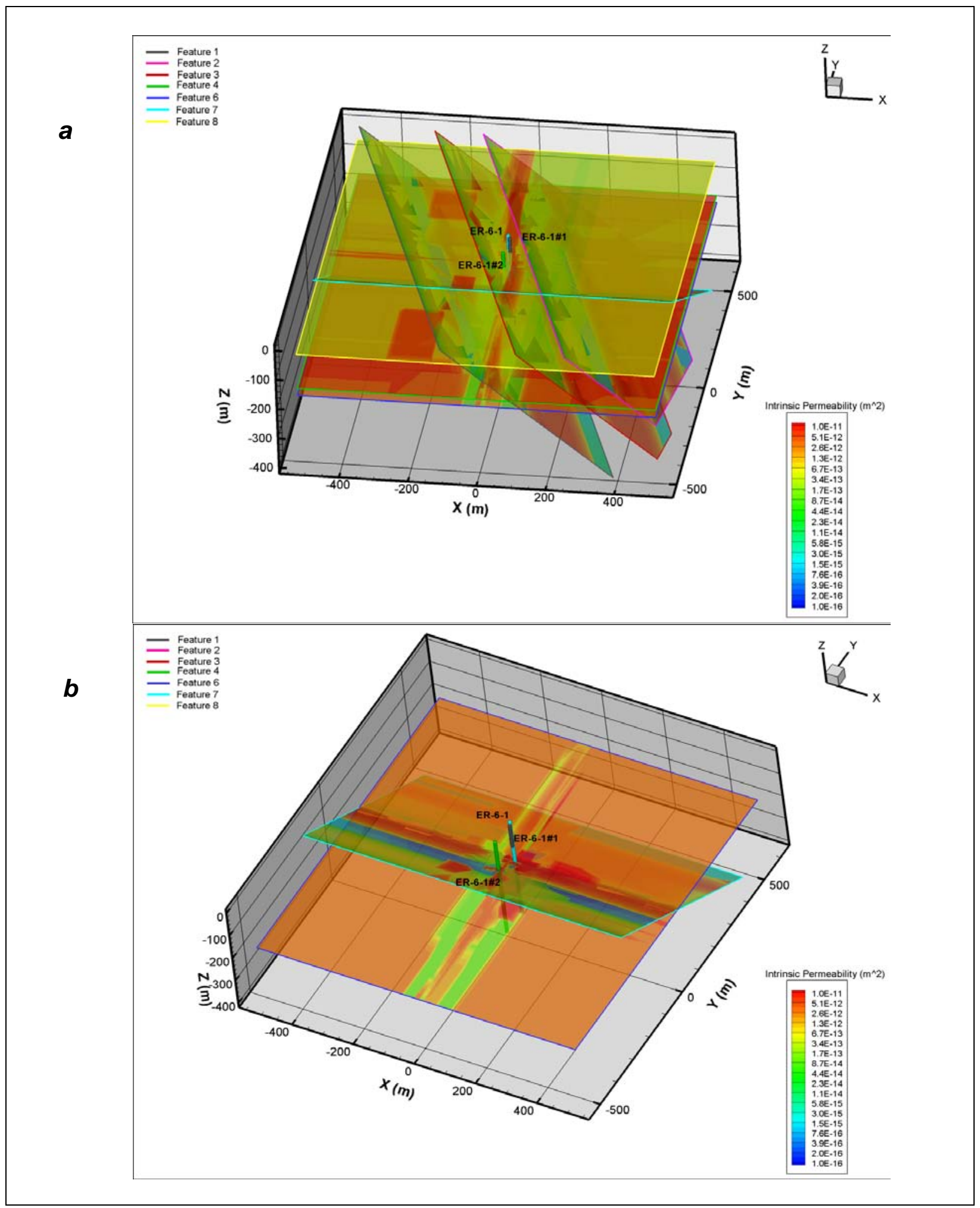

Figure 3-13

Discrete Feature and TFM-Calibrated Permeability Field for

(a) All Discrete Features and (b) Two Selected Discrete Features 
The predicted concentrations in the extraction well take into account the mixing of traced and untraced groundwater in the pumping borehole. A pulse of particles is introduced at each tracer injection location and the technique accounts for the time variation of each input source function during the course of the calculation. The CBPT method uses particle tracking to take advantage of the ability of particle-based approaches to maintain sharp fronts for advection-dominated transport problems common in groundwater modeling, and because of the flexibility of the random-walk method to simulate a wide range of possible forms of the dispersion tensor. Furthermore, the algorithm for carrying out the convolution and superposition calculation from particle-tracking results is very efficient. Drawbacks to the method are that it can be time consuming to track particles through strongly heterogeneous rock such as the LCA; the random-walk simulation of dispersion can strand particles in stagnant parts of the flow system, and sufficient particles must be used. In this analysis 10,000 particles were used for 2,6-DFBA, microspheres, and 2,5-DFBA; 5,000 particles were used for PFBA and 2,4,5-TFBA.

The analyses presented in this section are subject to a variety of assumptions and consequent limitations. The scoping estimates of dispersivity and effective porosity assume a radially convergent flow field, which given the MWAT fracture and channel interpretive hydraulic models is at least partially violated. The TFM data were used to interpret fracture zone connections; however, the data have the limitation that they were collected on discrete intervals over which the measurement was assumed to apply. Thus, there may be smaller features, or features across which in and out flows are balanced, that would not be detected resulting in interpretive, or conceptual, uncertainty. It is assumed Darcy’s Law adequately describes fluid flow in the fractured LCA.

The flow model was calibrated to the TFM data before beginning substantial transport analysis. This approach is not ideal; it was hoped to use the concept of Weiss and Smith (1993 and 1997) to better define the joint confidence region of both flow and transport parameters by performing simultaneous estimation on flow and transport parameters. However, the 16-hr forward simulation times for a single complete test flow and transport simulation along with the need to use central differencing to compute the Jacobian matrix made the desired approach impractical.

The dispersivity was defined in two zones. The first zone was in the wellbore and one element away from the wellbore, and the second was everywhere else. A value of 0 dispersivity is assigned to the 
first zone because the travel distance in the rock (which is the physical cause of dispersion) is zero in the injection wells, and with the non-scale dependent dispersion in FEHM it makes no physical sense to have up to several meters of spread at or very near the injection wells. In addition, dispersion (implemented in FEHM as a random walk) in and near the wellbore caused numerical problems with the particle tracking that were solved by removing dispersion close to the wells.

Manual adjustment and PEST was used to calibrate the tracer breakthrough curves. The results are shown in Figures 3-14 through 3-17 for 2,6-DFBA (fast-path test), 2,5-DFBA (ER-6-1 \#1), PFBA (upper ER-6-1), and 2,4,5-TFBA (lower ER-6-1), respectively. Table 3-1 summarizes the properties. The microsphere recoveries were very low and were not considered in the numerical analysis.

For 2,6-DFBA (Figure 3-14), the rising limb during the fast-path test is too steep and declines while the data are still rising. At the beginning of the MWAT-TT, the qualitative model behavior is similar to the data, with the concentration rebounding and then declining. The systematic errors could be due to either too high an effective porosity, or too direct (not tortuous enough) flow path between ER-6-1 and ER-6-1 \#2.

The ER-6-1 \#1 tracer (2,5-DFBA) response (Figure 3-15) was greatly attenuated, so much so that no peak was identified during the test. The hydraulic response and interpretative model at ER-6-1 \#1 was similar to that at ER-6-1, although the hydraulic conductivity was interpreted to be about 2/3 that at ER-6-1. These two observations suggest that while ER-6-1 \#1 lies within the fault zone, it is across strike and otherwise less well connected to the features that connect ER-6-1 and ER-6-1 \#2. Jones et al. (1992) noted qualitatively similar behavior between tracers emplaced along and across the strike of major anisotropy in a fractured dolomite in New Mexico. It is possible that this lesser connection is due to the fact that ER-6-1 \#1 does not extend as deeply into the LCA as the other wells at the cluster.

The ER-6-1 upper zone tracer (PFBA) results are shown in Figure 3-16. The nearly 30-day delay until the peak arrives is simulated at 42 days, with fair agreement between 42 and 54 days where both the data and model show a gentle decline in concentration. Thereafter the data and model depart, with the data showing a plateau and the model showing a continuing decline. This suggests that additional flow paths are present. 


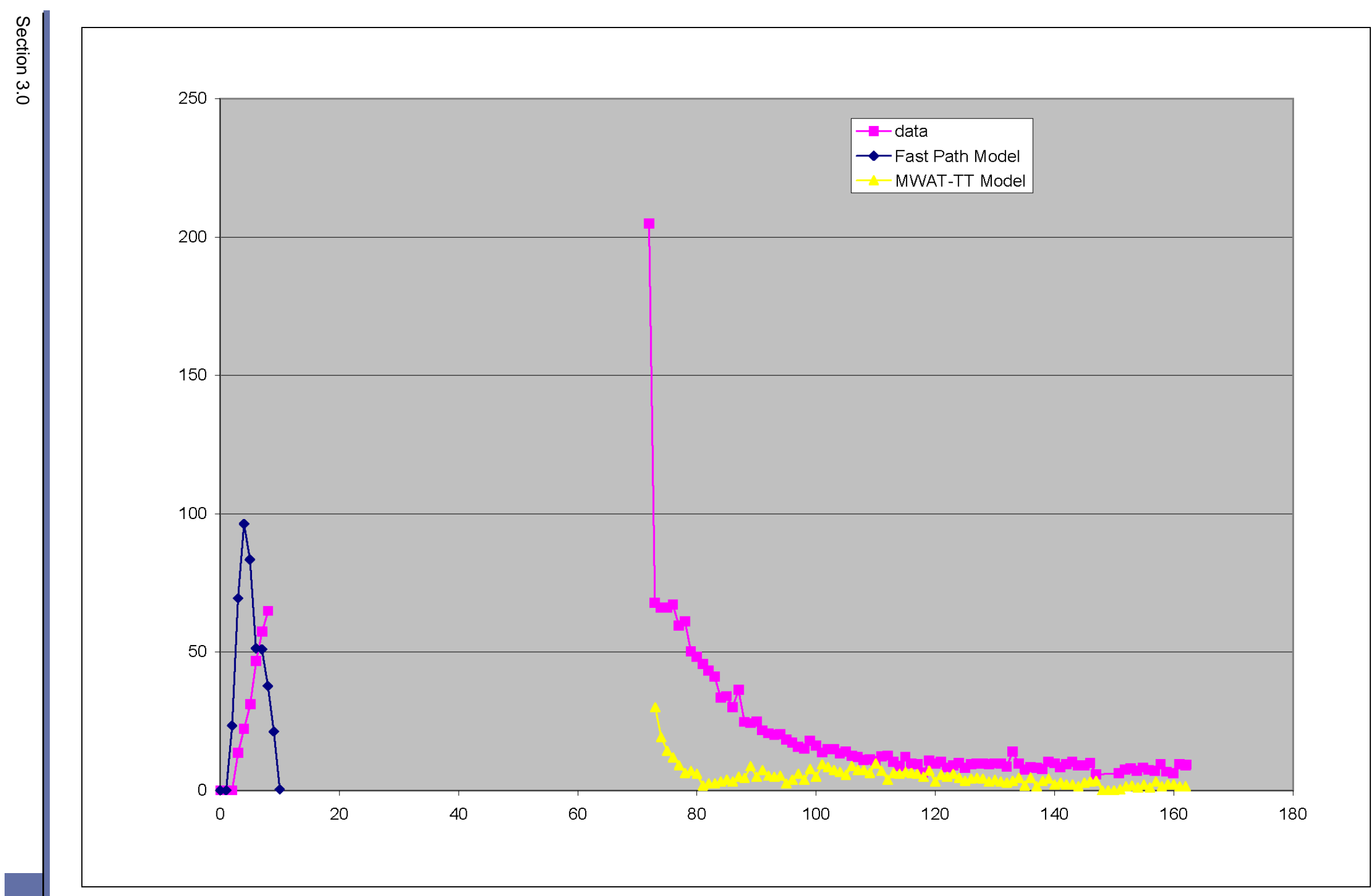

Figure 3-14 


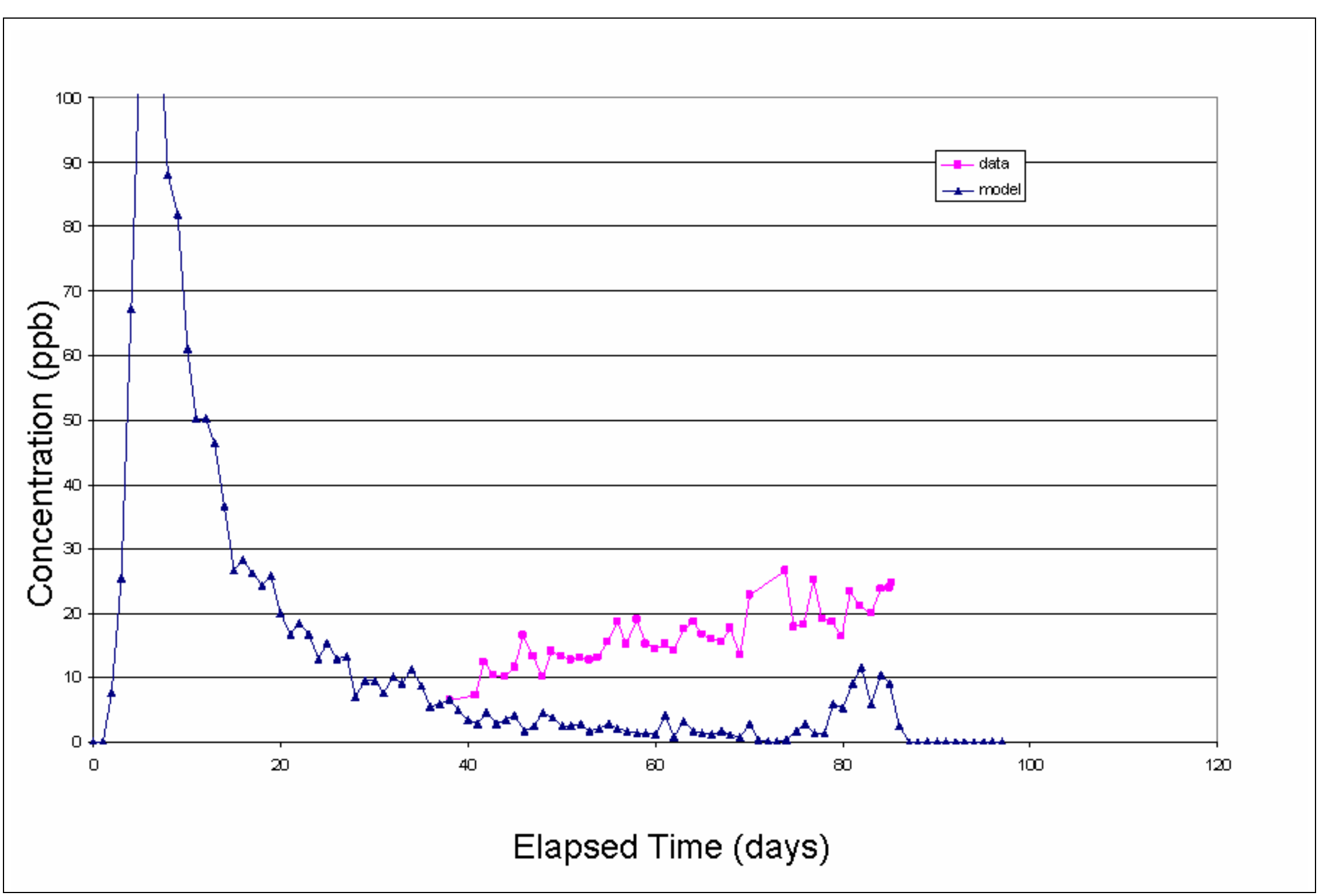

Figure 3-15

2,5-DFBA (ER-6-1 \#1) Numerical Model Results 


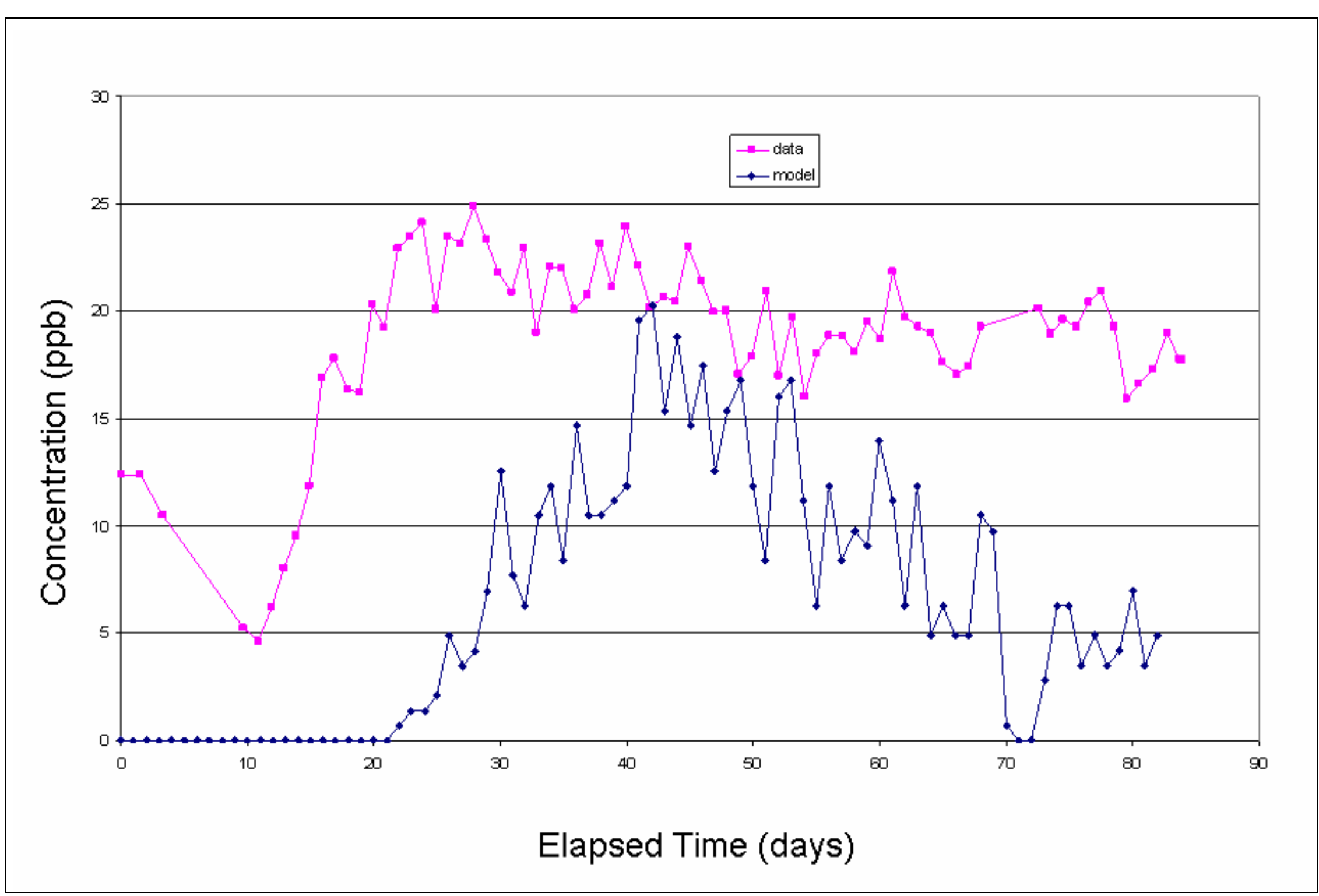

Figure 3-16

PFBA (Upper ER-6-1) Numerical Model Results 


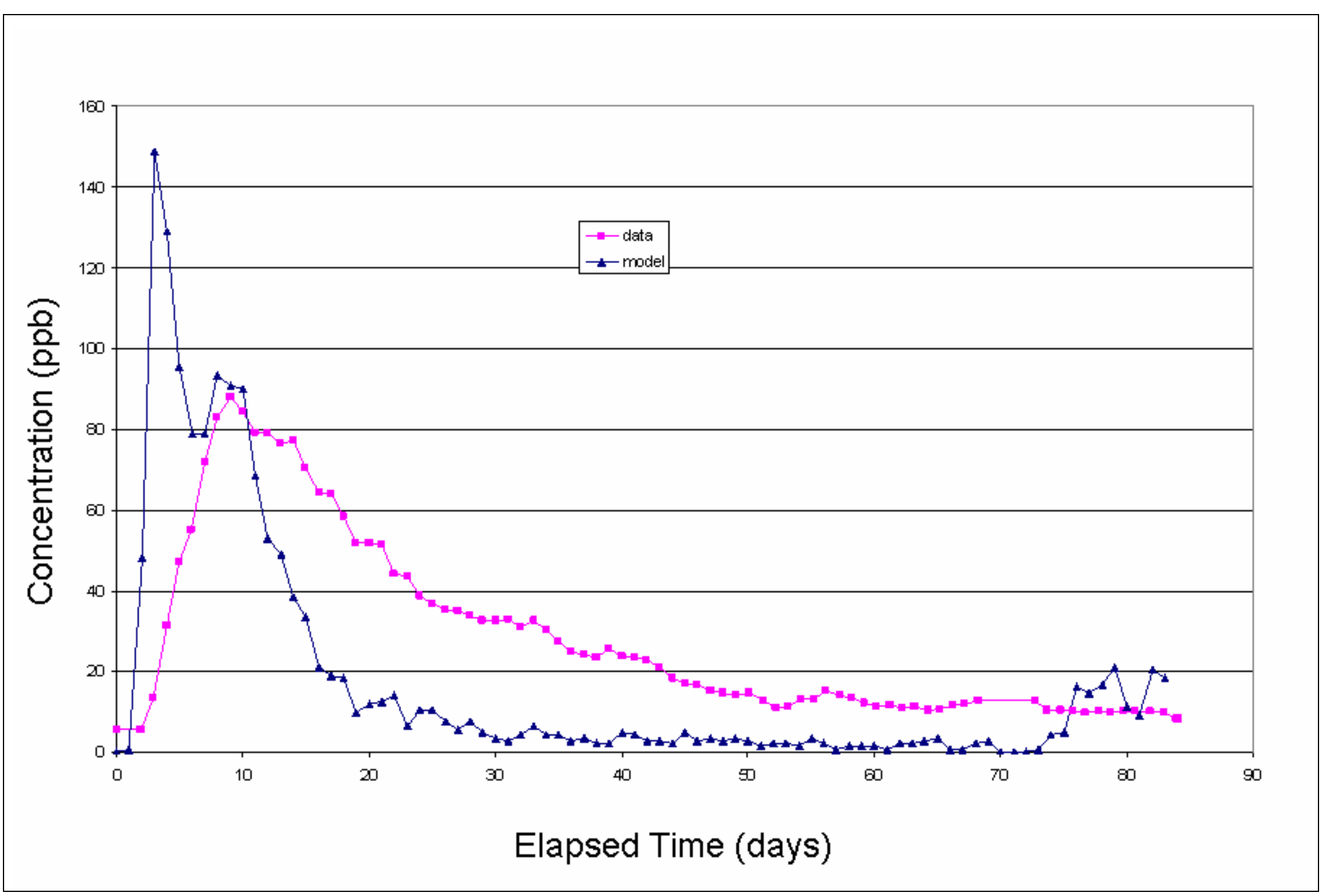

Figure 3-17

2,4,5-TFBA (Lower ER-6-1) Numerical Model Results 
Table 3-1

Summary of Transport Parameters

\begin{tabular}{|c|c|c|}
\hline Feature or Parameter & Value & Notes \\
\hline $\begin{array}{l}\text { Head change north to south across } \\
\text { domain }(\mathrm{m})\end{array}$ & 0.0618 & Very uncertain \\
\hline Laketown/Ely Contact Effective Porosity & 0.018 & \\
\hline $\begin{array}{c}\text { Sevy/Laketown Contact Effective } \\
\text { Porosity }\end{array}$ & 0.020 & \\
\hline \multicolumn{3}{|l|}{ Fault Effective Porosity } \\
\hline $\begin{array}{c}\text { Feature } 1,2,3,4,5 \text {, and } 7 \text { Effective } \\
\text { Porosity }\end{array}$ & 0.021 & Adjusted as a group \\
\hline Feature 8 Effective Porosity & 0.10 & \\
\hline Lower Zone Effective Porosity & 0.03 & \\
\hline Less Fractured LCA Effective Porosity & 0.02 & \\
\hline Longitudinal Dispersivity $\left(\alpha_{L}\right)(\mathrm{m})$ & 5 & \\
\hline $\begin{array}{c}\text { Ratio of Longitudinal:Transverse } \\
\text { Dispersivity }\end{array}$ & 10 & $\begin{array}{l}\text { Axisymmetric form of dispersion tensor used: } \\
\qquad \alpha_{T H}=\alpha_{T V}\end{array}$ \\
\hline Diffusion Coefficient $\left(\mathrm{m}^{2} / \mathrm{s}\right)$ & $\begin{array}{c}5.05 \times 10^{-7} \text { PFBA } \\
5.4 \times 10^{-7} 2,5-\text { DFBA } \\
2,4,5-\text { TFBA }\end{array}$ & Average computed from Reimus et al. (2006) \\
\hline
\end{tabular}

Finally, the ER-6-1 lower zone tracer (2,4,5-TFBA) results are shown in Figure 3-17. The connection appears to be too direct, a possibility suggested in the TFM results, with faster simulated than actual peak arrival, and more decline on the falling limb and stabilization at a lower concentration than observed.

Confidence limits were computed by PEST for the effective porosity and head difference parameters, but given the clear differences in observed and simulated behavior in some of the responses (e.g., 2,5-DFBA), they may not be meaningful and are not reported.

\subsection{Subregional Scale Lower Carbonate Aquifer Numerical MWAT Analysis}

The FEHM model constructed to analyze the tracer test has a limited spatial domain because of its need for high-resolution in conjunction with practical computational limits. It was initially thought that it might be necessary to have time-varying boundary conditions for the FEHM model, and a 2-D MODFLOW-2000 (Harbaugh et al., 2000) model was constructed and calibrated for this purpose. 
Ultimately, these results were not used in the tracer-test analysis, but they are reported for completeness and the insight they generated.

The MODFLOW family of codes (McDonald and Harbaugh, 1988; Harbaugh and McDonald, 1996; Harbaugh et al., 2000) is widely used for the simulation of saturated groundwater flow in porous media under steady-state and transient conditions. A variety of graphical pre- and postprocessors (such as Groundwater Vistas [ESI, 2004] used in this analysis) exist that greatly speed model preparation and calibration. In this analysis, it is assumed that the LCA is fractured enough to behave as an equivalent, but heterogeneous as described by the major fracture and fault systems, porous medium - a mixed discrete-continuum model. The ER-6-1 MWAT-TT analysis (SNJV, 2005e) showed linear to bilinear flow geometry near ER-6-1 associated with either discrete fracture or a strip of enhanced (from fracturing) permeability rock. However, distal observation wells eventually showed more porous-media like responses, which suggests the equivalent porous medium assumption is not completely unreasonable at some scale. The conceptual model of flow in the LCA also suggests that it is zones of fracturing, rather than a single discrete feature, which carry flow in the LCA (Winograd and Pearson, 1976; Laczniak et al., 1996; SNJV, 2005e).

The hydrologic boundary of the LCA on northeast Yucca Flat is formed where the LCCU rises in the northern part of the Halfpint Range, creating a natural hydrologic no-flow boundary (Laczniak et al., 1996). Likewise, the conjunction of Climax Stock, Halfpint Range, and Eleana Range forms a natural hydrologic boundary on the northern edge of Yucca Flat, although where this boundary ends is uncertain (Laczniak et al., 1996). To the west, thrusting associated with the Eleana Range complicates structure with the LCA present under Rainier Mesa/Shoshone Mountain (Laczniak et al., 1996). To the south, it has been postulated (Winograd and Pearson, 1976; Laczniak et al., 1996) that flow continues to Ash Meadows, about a 70-km straight-line distance southwest of ER-6-1. A major internal hydrologic boundary in the LCA exists along the Yucca and Topgallant Fault systems, where the LCA has been faulted. In particular, water is thought to leak downward along the Yucca Fault into the LCA (Laczniak et al., 1996).

Calibration of a steady-state flow model of Yucca Flat was outside the scope of this analysis; thus an “impact," or superposition, analysis was conducted. In this approach, only the change in head due to tracer test pumping is simulated, removing the need to evaluate the actual regional head and flows. 
The major assumption is that the change is only from the imposed hydrologic stress and not due to any other processes. Given the short duration of pumping, this assumption is satisfied for the ER-6-1 MWAT-TT.

The MODFLOW model domain, boundary conditions, and grid are shown in Figure 3-18. Figure 3-18 also shows wells considered in this analysis: ER-6-1 \#2, UE-7nS, U-3cn \#5, UE-1h, ER-7-1, and ER-3-1. The no-flow conditions along the northeastern and northern part of Yucca Flat were interpreted from geologic data presented by Gonzales et al. (1998), Gonzales and Drellack (1999), BN (2006), and Laczniak et al. (1996). The western edge of the model is treated as a no-flow boundary; whether or not this treatment is correct is unknown. Several factors make it unimportant relative to this analysis including:

- It is about $26 \mathrm{~km}$ to the western edge from ER-6-1 \#2; the sheer distance makes this boundary less important.

- The Carpetbag fault and the CP Thrust lies between ER-6-1 \#2 and the western model edge, and these faults are thought to act as flow barriers further reducing the impact of the western model boundary.

- $\quad$ Lack of hydraulic response at UE-1h during the MWAT-TT further suggests that proper specification of the western model boundary is not overly important.

- The overall strike of the faults in Yucca Flat is north to south, and thus the western boundary is off the direction of continuity and response in that direction will be commensurately slower.

The eastern boundary, which is not associated with the clastic confining units, was modeled as a no flow. It is possible that this should be a boundary connected to the LCA flow system to the east (as discussed by Laczniak et al., 1996). However, it is likely that the LCA becomes unconfined east of ER-6-1. If the unconfined storage coefficient increases the characteristic response time associated with the eastern boundary, it may become so long as to render its effect minor for this analysis. The entire southern edge was specified as a general head boundary because flow is thought to continue from Yucca Flat down through Frenchman Flat and on to Ash Meadows. Part of the northern boundary is also set as a general head boundary, although the character of this boundary is very uncertain because of the arrangement of rocks at the northern end of Yucca Flat. However, the clastic confining unit no-flow boundaries and the Carpetbag and Tippinip fault systems reduce the importance of the northern model edge. Given that ER-7-1 (about $10 \mathrm{~km}$ north of ER-6-1 \#2), and 


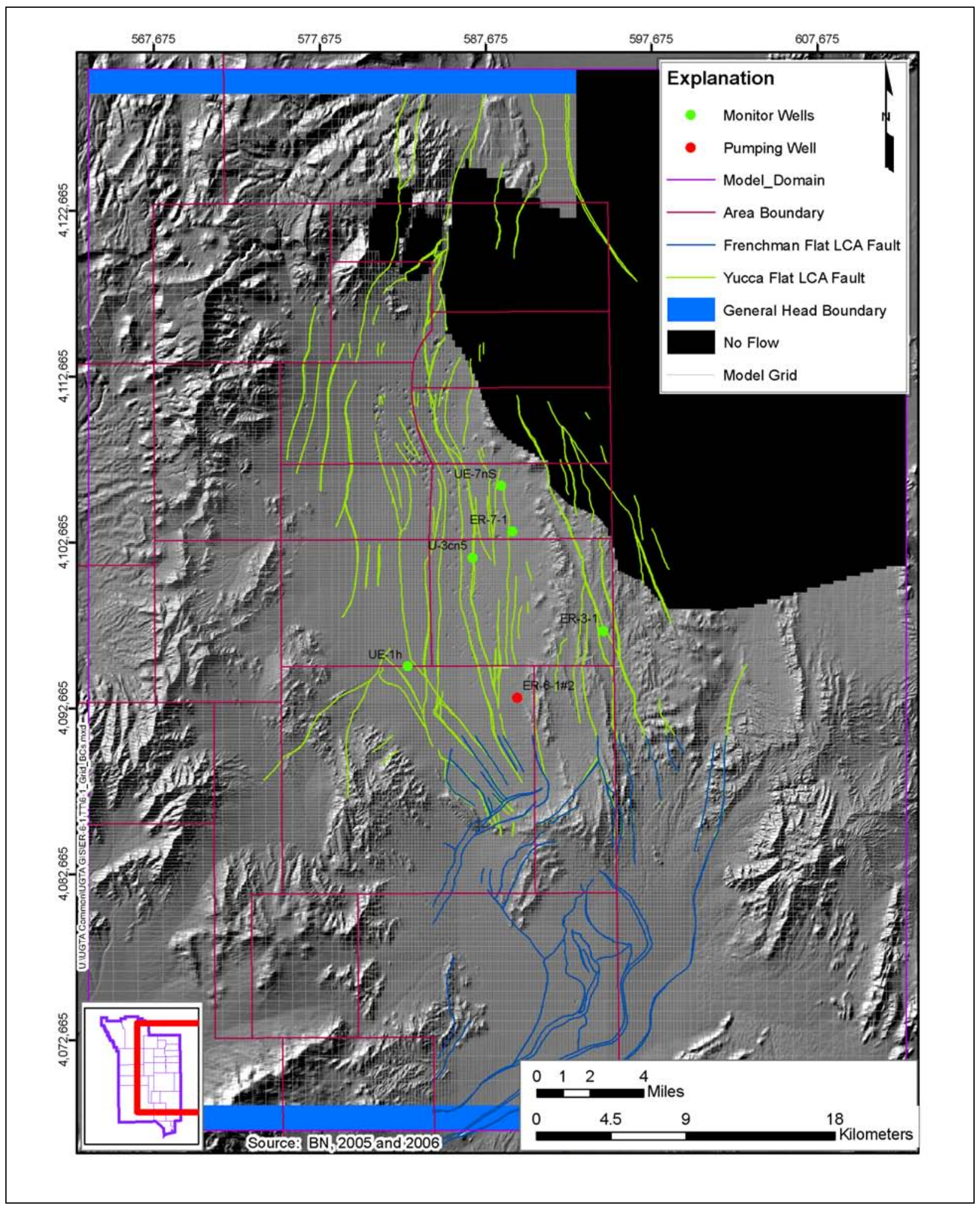

Figure 3-18

Model Grid and Boundary Conditions for Subregional Analysis 
UE-7nS (about $13 \mathrm{~km}$ north of ER-6-1 \#2) showed responses to pumping, it is clear that regional-scale influences on drawdown propagation are important, and these features are felt to be reasonably captured. The overthrust LCA (LCA3) on the western side of Yucca Flat was not included because no data were collected from any wells in it during the MWAT and it is at least partially separated from the LCA by the upper clastic confining unit. However, the major faults running through the basin appear to effectively divide the LCA making this a reasonable approximation for the intended purpose.

The grid blocks ranged in size from 100 to 1,500 $\mathrm{m}$ in the west-to-east and north-to-south directions. The fault system shown in Figure 3-18 is from the EarthVision ${ }^{\circledR}$ models of Frenchman Flat (BN, 2005) and Yucca Flat (BN, 2006). The trace at the top and bottom of the LCA was obtained, and because the model is 2-D, the approximate midpoint between the two bounding traces was used to represent the entire fault. A constant elevation of $652 \mathrm{~m}$, the top of the LCA at the ER-6-1 well cluster, was used to define the top of the model, and the section of interest was assumed to be $397 \mathrm{~m}$ thick (roughly the bottom of ER-6-1 \#2 and ER-6-1). Clearly, this is an approximation to the true structure and thickness, but the observation data do not extend any deeper. The quartzite unit at the bottom of the ER-6-1 cluster wells may act to compartmentalize the LCA flow system as described by Laczniak et al. (1996), and the uncertainty and variability in formation properties is likely much greater than the variability in transmissivity introduced by unaccounted-for structure. Four periods of pumping were used: about 75 days representing the main tracer test and MWAT, about 3.5 days of shutoff, about another 11.5 days of final pumping, and then about 24.5 days of recovery. An average rate of 524 gpm was used for the pumping periods.

The calibration data consisted of drawdown data from ER-3-1, U-3cn \#5, UE-7nS, ER-7-1, and UE-1h. The full dataset is several thousand data points for each well, which is far more detail than can reasonably be accommodated with MODFLOW, which only records drawdown at a set number of times (considerably less than the full number of data points). Data were winnowed by removing every other data point until about 1,400 data points were obtained for ER-3-1 and ER-7-1, which is still a very fine in time dataset but one which would be accurate no matter the changes made to model time stepping. Well ER-6-1 was too close to ER-6-1\# 2 to be included, and the grid is too coarse to adequately capture the pumping well response. Only four data points were collected at U-3cn \#5 and UE-7nS, and because UE-1h showed no response, only a few points assigned a high weight were used 
for brevity of input. No other weighting was considered because only one type of data was used and the clustering of the data is also desirable relative to the calibration targets to be fit.

The model was calibrated using the PEST computer code (Watermark, 2004). Initially, the faults and matrix were each assigned different, but spatially uniform, hydraulic conductivities and storage coefficients. The Carpetbag fault was assigned a very low (conceptually more from the arrangement of LCCU than that thrusted LCA forms a barrier) hydraulic conductivity $\left(1 \times 10^{-8} \mathrm{~m} / \mathrm{d}\right)$ in order to represent its conceptualization as impairment to west-east hydraulic connection in the LCA. Another possibility would be to represent this fault as a very high hydraulic conductivity feature that would route and dissipate the MWAT pressure transient along its length. Similarly, the Yucca fault (suggested by Winograd and Thordarson [1975]) may be an internal boundary condition from which the MWAT pressure transient might be able to induce flow, also attenuating the pressure transient. No attempt was made in this analysis to discriminate among these possibilities.

Initially confined, or elastic storage, conditions were assumed for the entire model. However, under confined conditions, the response at ER-3-1 was always too fast. Reconsideration of the estimated LCA potentiometric surface and the top of the LCA in boreholes showed that somewhere between ER-6-1 and ER-3-1, the LCA becomes unconfined, and an additional zone of increased storage was introduced in southeast Yucca Flat to reflect this interpretation — water table convertable cells (in MODFLOW parlance) were not used. In addition, a uniform fault hydraulic conductivity did not perform well in matching the data. Each fault was assigned its own material property so it could be adjusted individually. However, there are not enough spatially distributed data to strongly constrain the properties of 55 faults. The PEST regularization approach, designed to overcome the numerical instability that can accompany extreme parameter non-uniqueness by introducing only enough heterogeneity to fit the data (Watermark, 2004), was used for this phase of analysis.

The calibration results, after reparameterizing the storage and faults are shown in log-log diagnostic format, to allow identification of the interpretive model, in Figures 3-19 and 3-20 for ER-3-1 and ER-7-1, respectively. Wells UE-7nS, UE-1h, and U-3cn \#5 are shown in Figure 3-21. The rising limb of the simulated drawdown for ER-3-1 reasonably matches the initial delay and slope, but does not plateau soon enough although final stabilization is similar. The simulated ER-7-1 MWAT-TT response matches the data well. Wells U-3cn \#5 and UE-7nS are only matched in the sense that some 
response was observed and is predicted, the scarcity of the observation data makes further diagnosis of the response and identification of conditions near these wells infeasible. Well UE-1h did not have any observed drawdown from the MWAT-TT, but the model simulates a slight response.

The parameter fields and simulated drawdown at the end of the main pumping period are shown in Figures 3-22 and 3-23 for hydraulic conductivity and storativity, respectively. The trace of the LCA faults at the bottom of the LCA are shown; thus, the materials do not always overlay the faults. The faults have hydraulic conductivities at least 10 times more than the less-fractured rock, but too much should not be construed because of the areal scarcity of data. However, the simulated response at ER-7-1 shows the right conceptual model and rapid response to pumping at ER-6-1 \#2. The faults in between ER-6-1 \#2 and ER-7-1 tend to show lower hydraulic conductivity, presumably to the conditioning effect of fitting the drawdown at ER-7-1 which, as seen in the MWAT analysis (SNJV, 2005a) resulted in low effective hydraulic conductivity between ER-6-1 \#2 and ER-7-1. The simulated response at ER-3-1 has similar character as the data with the nearly 10-day lag between pumping and response approximately preserved, and it is interesting to note that some of the highest fault-zone hydraulic conductivities occur near ER-3-1, presumably in order to bleed off or otherwise attenuate the response from ER-6-1 \#2. Similarly, the storativity is higher in the southeastern, possibly unconfined, part of Yucca Flat with a value of about 0.0028 , and a value of $2.1 \times 10^{-3}$ in the faults and $1 \times 10^{-7}$ everywhere else. The specific yield of the LCA is unknown (Belcher et al., 2001 present no specific yield values), but as an analogue Beauheim and Ruskauff (1998) observed storativity in the fractured Culebra Dolomite of $6 \times 10^{-3}$ that they thought reflected unconfined conditions, and Fleming et al. (2001) estimated specific yields for unconfined limestones of the Floridan Aquifer at 0.001 to 0.1. Thus, relative to other similar rocks under unconfined conditions, the calibrated value does not seem unreasonable. The storage coefficient estimated from ER-7-1 responses was about $1 \times 10^{-5}$ (SNJV, 2005e). Kilroy (1992) analyzed LCA responses to earth tides throughout southern Nevada and estimated LCA specific storage. A total of 12 analyses were performed, with values ranging from $4.57 \times 10^{-8} \mathrm{ft}^{-1}\left(1.50 \times 10^{-7} \mathrm{~m}^{-1}\right)$ to $1.06 \times 10^{-7} \mathrm{ft}^{-1}\left(3.47 \times 10^{-7}\right.$ $\mathrm{m}^{-1}$ ), which for the $397 \mathrm{~m}$ of LCA thickness in the model gives storativity from $6 \times 10^{-5}$ to $1.4 \times 10^{-4}$.

Simulating the single-well test at ER-7-1 further tested the MWAT-TT response calibrated model. Obviously the detailed well response cannot be matched, but as the pressure transient reaches other blocks, the local hydraulic conductivity can be estimated using standard well test analysis methods. 


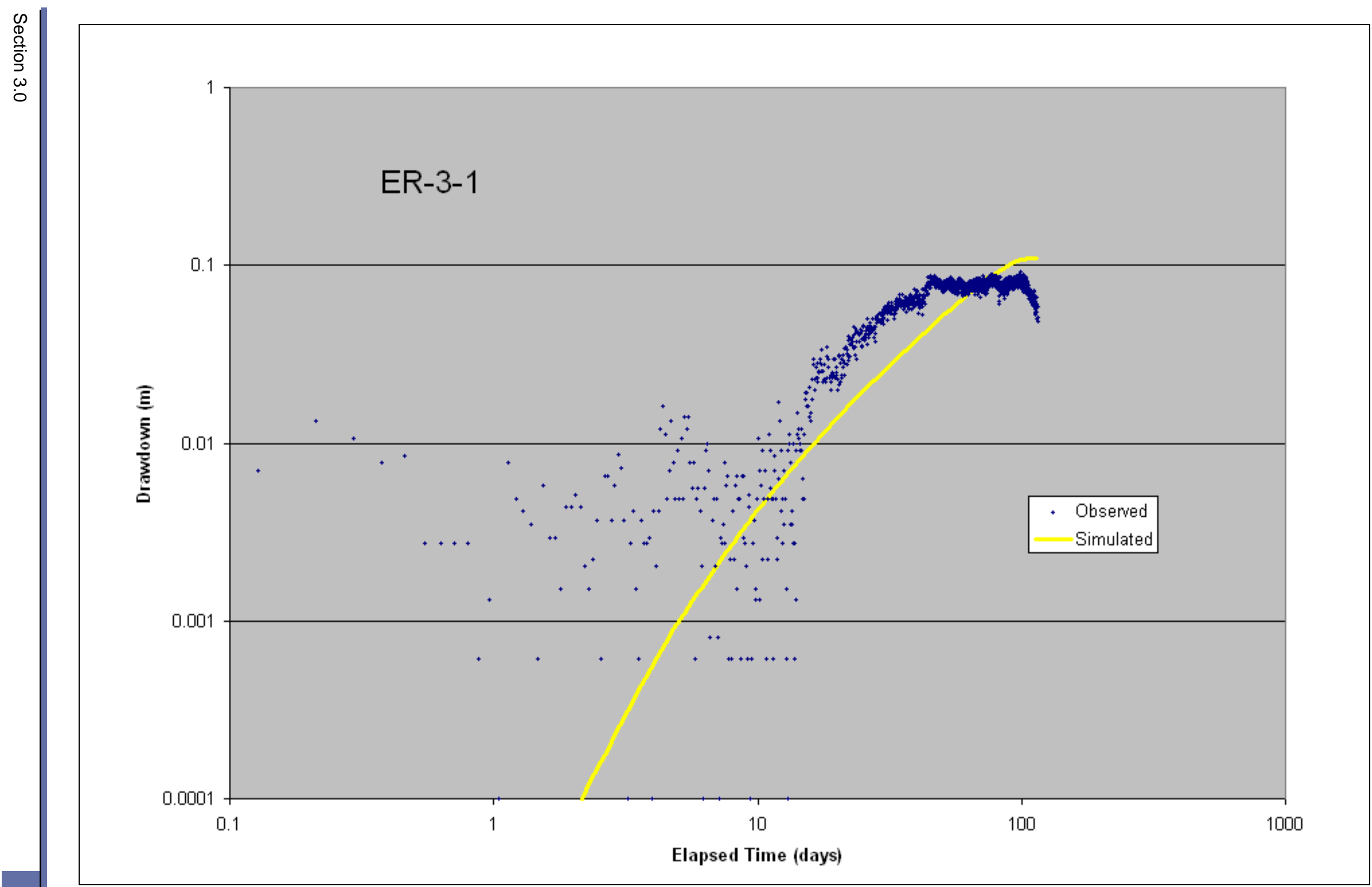

Figure 3-19

Simulated and Observed ER-3-1 MWAT-TT Drawdown Response 


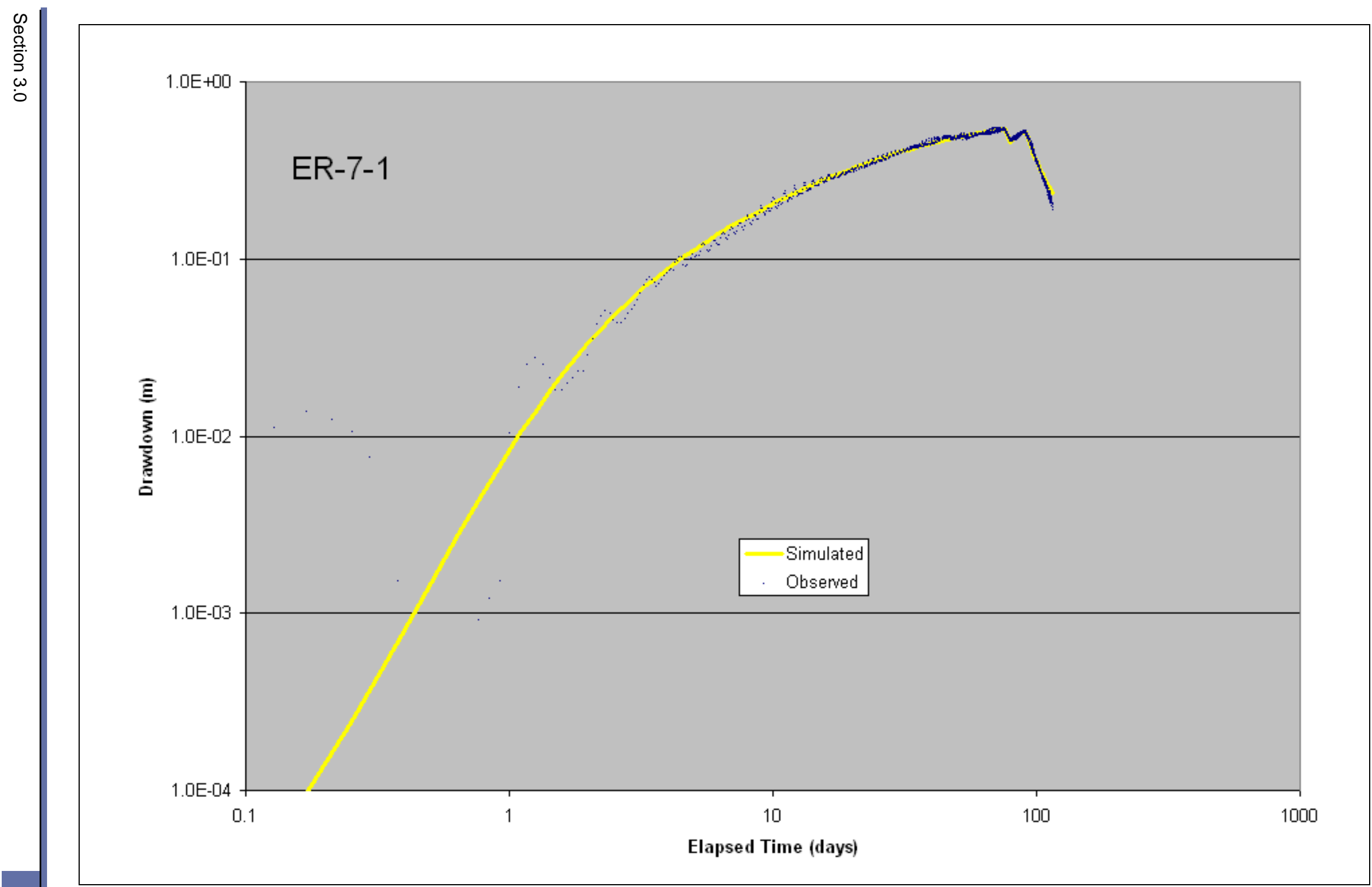

Figure 3-20 

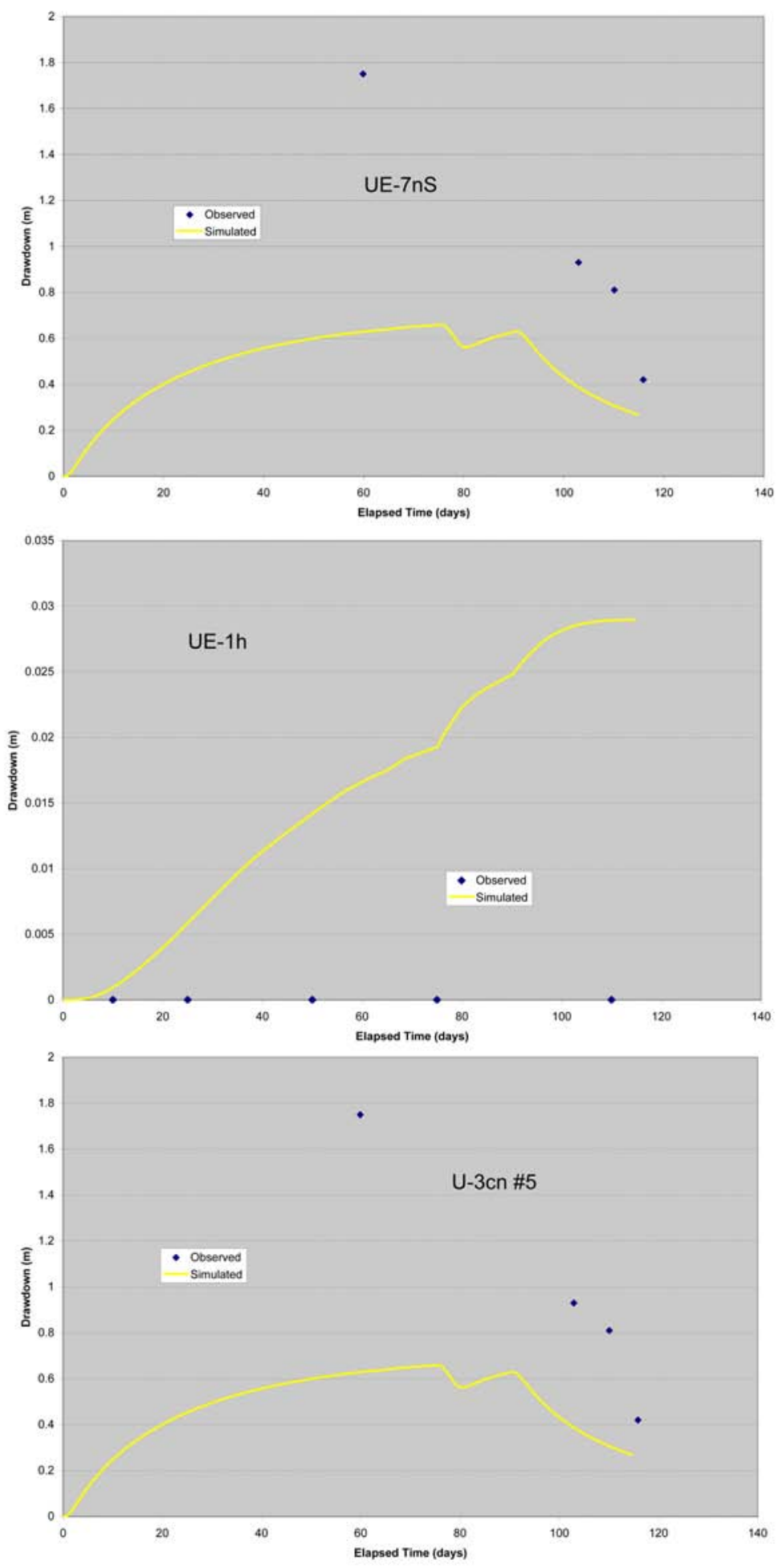

Figure 3-21

Simulated and Observed UE-7nS, UE-1h, and U-3cn \#5

MWAT-TT Drawdown Response 


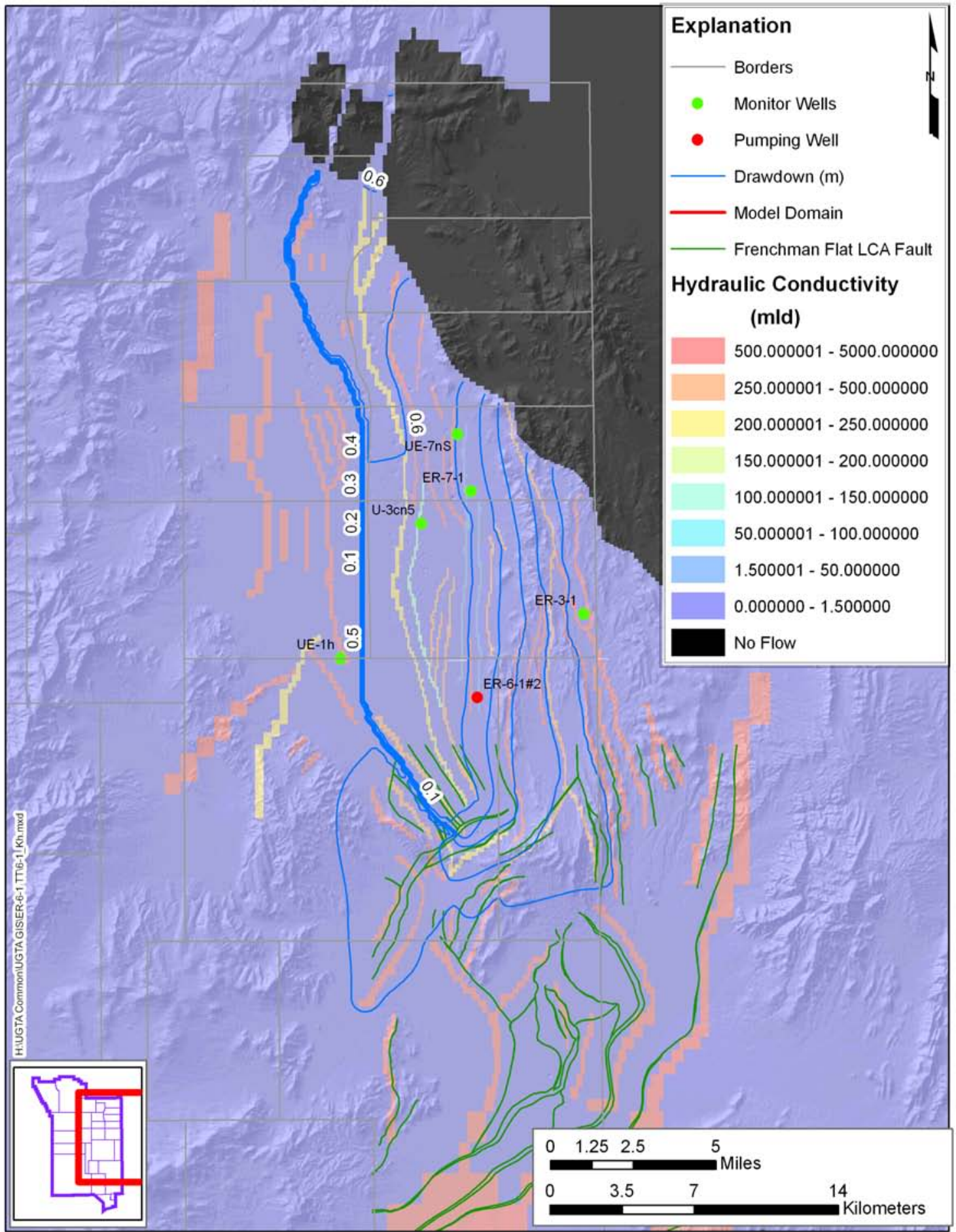

Figure 3-22

Calibrated Model Hydraulic Conductivity Distribution 


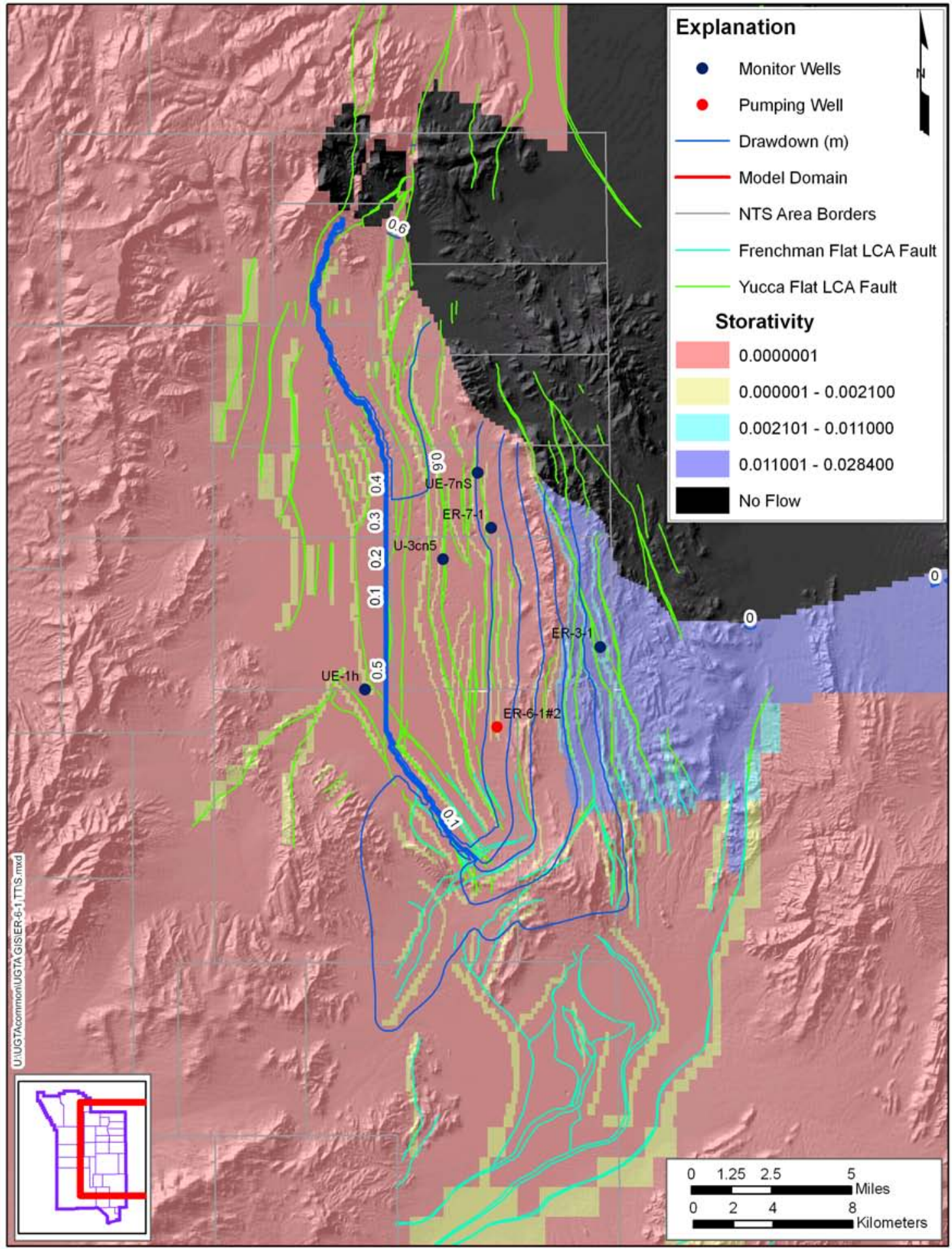

Figure 3-23

Calibrated Model Storativity Distribution 
Figure 3-24 shows the derivative of the log-log diagnostic drawdown plot for the simulated ER-7-1 test. The most important feature to notice is that the simulation results show a period of infinite acting radial flow (the period in which Theis-like model assumptions are obeyed) followed by a slight barrier effect; the field data showed a less well defined infinite acting flow period followed by a constant-head boundary effect (which has the same appearance on the log-log diagnostic as a very strong nearby increase in hydraulic properties). Thus, while the far-field response at ER-7-1 is reasonably captured by the geologic model faults and associated parameters, the local scale does not represent the single-well test conceptual model properly, a discrepancy that must be related to the approximate nature of the fault definitions in the HFM. Finally, the subarea shown in Figure 3-14 was analyzed using MODFLOW as a numerical parameter with arbitrary (but with the same hydraulic gradient) boundary conditions imposed in the north-south and then east-west directions and collecting the fluxes in each direction. The north-south flow is about five times greater than that in the east-west direction, which shows the effect of the north-south fault continuity on effective hydraulic conductivity.

\subsection{Limitations of the Analysis}

The analyses presented in this section are subject to a variety of assumptions and consequent limitations. The scoping estimates of dispersivity and effective porosity assume a radially convergent flow field, which given the MWAT fracture and channel interpretive hydraulic models is at least partially violated. The TFM data were used to interpret fracture zone connections. However the data have the limitation that they were collected on discrete intervals over which the measurement was assumed to apply. Thus, there may be smaller features, or features across which in and out flows are balanced, that would not be detected resulting in interpretive, or conceptual, uncertainty. It is also assumed Darcy’s Law adequately describes fluid flow in the fractured LCA. 


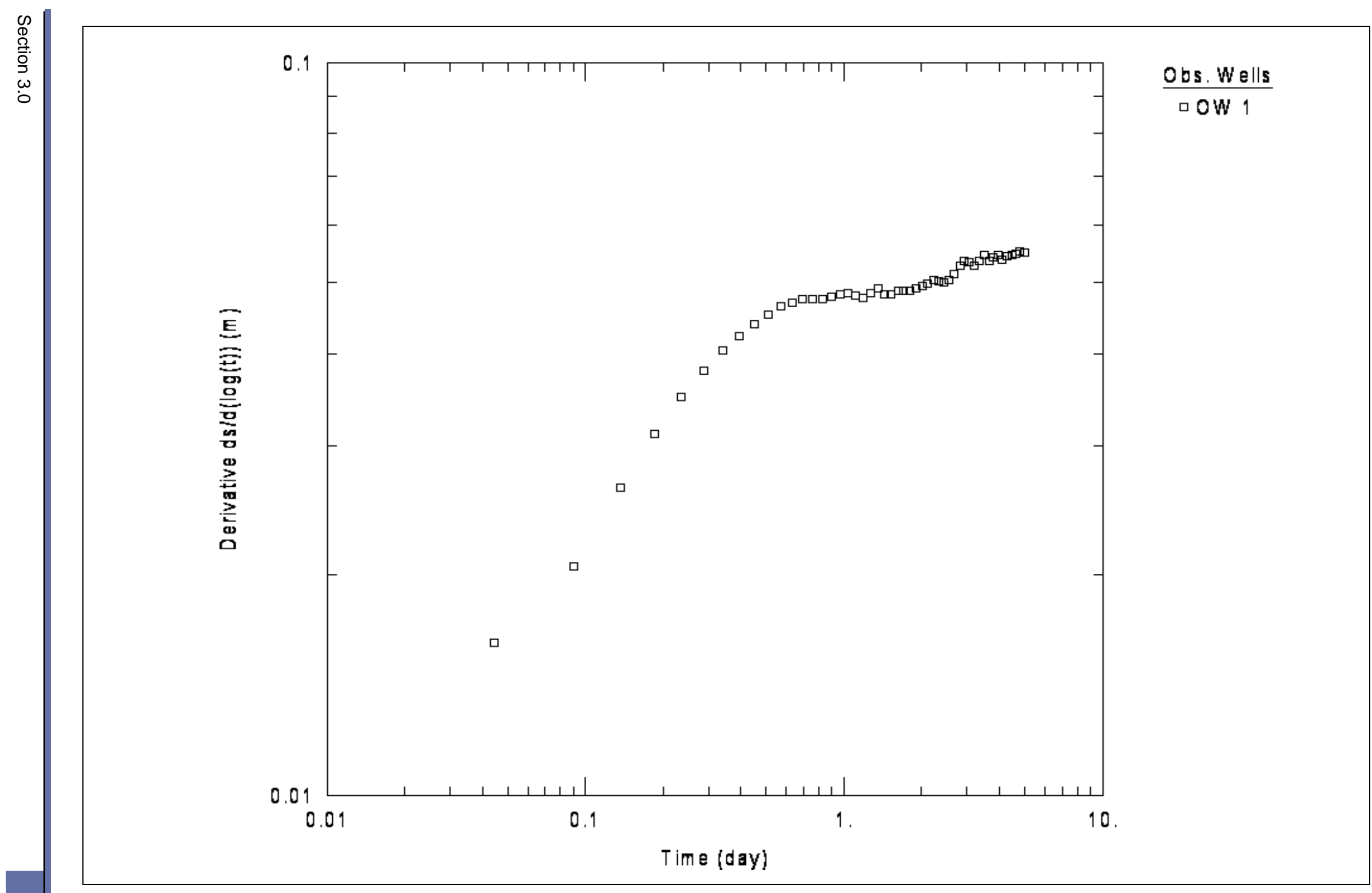

Figure 3-24

Log-Log Derivative for Simulated ER-7-1 Single-Well Test 


\subsection{Discussion and Conclusions}

\subsection{LCA Conceptual Model}

As a supplement to the SFM and TFM data analyses (SNJV, 2005e), the borehole EC logs collected by DRI in ER-6-1 during the fast-path test were analyzed by three different methods using the SFM and TFM analyses as a conceptual framework. Each method gave somewhat different results, but combining the results provides a set of constraints from which a conceptual model of borehole flow can be determined. In general, three main flow characteristics are identified. Each characteristic is unique; the measured EC logs cannot be fit without these features. These features are as follows:

1. A zone of high inflow at or near the top of the simulated borehole interval (i.e., shallower than $2,129 \mathrm{ft}$ bgs) is identified. The inflow from this area of the borehole supplies the majority of the volumetric flow that moves down the borehole.

2. Horizontal flow from and to the formation between the borehole depth interval 2,075 and 2,950 ft bgs. Within this depth interval, the simulations were sensitive to two horizontal flow zones that control most of the inflow/outflow: (1) the upper borehole inflow interval from 2,129 to 2,170 ft bgs, and (2) the (combined) outflow interval from 2,350 to 2,550 ft bgs (see Figure 2-16). These zones correlate well to larger-magnitude inflow and outflow zones identified in the TFM logs.

3. The third borehole flow feature is the large vertical flow rate directed downward and out below the 2,850 ft bgs in ER-6-1, corresponding to the interval of lowest head across the completion. It is likely that the head in this zone is reduced relative to the upper portion of the borehole as a result of pumping at ER-6-1 \#2. These results also point out the significant connectivity from the lower portion of ER-6-1 and ER-6-1 \#2.

These results are consistent with the MWAT-TT (SNJV, 2005e) interpretation that the borehole is dominated by discrete flow zones that are related to fractures and brecciated zones within the LCA and also the underlying Eureka Quartzite. Moreover, it seems unlikely that flow is uniform over the height of a fracture zone in the LCA and that the flow path through a fracture zone could be quite tortuous. 


\subsection{LCA Transport Parameters Review}

Winograd and West (1962) present preliminary results of a tracer test conducted between Water Wells $\mathrm{C}$ and $\mathrm{C}-1$ in the LCA under Yucca Flat. The report provides the transport time between the two wells, thicknesses of the LCA penetrated by the wells, pumping rates, and the distance between the two wells. The results of the test were analyzed in the UGTA Phase I Transport Parameter and Source Term Data Documentation Package (IT, 1996a) and estimated effective porosity ranged from 0.00064 to 0.005 .

Winograd and Thordarson (1975) discuss the porosity of the LCA. The pore space of the unfractured LCA was measured by mercury injection or water saturation on core samples between 0.000 to 0.090 with a mean of 0.023 and median of 0.011 for 25 samples.

Borg et al. (1976) suggested effective porosity ranges of 0.0001 to 0.01 for the LCA. IT Corporation (IT, 1996b) analyzed core from ER-6-2 and ER-6-1. In ER-6-2, only fractures interpreted to be related to extension (also with a high-angle dip between 75 and 85 degrees) had measurable apertures (typically $1 \mathrm{~mm}$ or smaller). Roughly two fractures per $1.52 \mathrm{~m}$ are seen on the log for an average apparent spacing of $0.76 \mathrm{~m}$. Using dip ranges from 75 to 85 degrees gives true spacing of 0.067 to 0.19 for effective porosity ranging from 0.01 to 0.008 . The ER-6- 1 core was too shattered to be quantitatively analyzed for fracture porosity, but it was concluded that brecciated zones rather than individual fractures were the important flow features (IT, 1996b).

The estimated effective porosities from Section 2.4.2 are 0.0024 for the lower zone and 0.0083 for the upper zone of ER-6-1. No estimate could be made for the upper part of the LCA investigated by the ER-6-1 \#1 tracers due to the lack of any identifiable peak. Semianalytic modeling of the tracer breakthroughs gave a lower zone porosity of 0.02 for single-porosity models and 0.011 for double-porosity models, and an upper zone porosity of 0.018. Thus, the data from the ER-6-1 tracer test give effective porosities that are concluded to be representative of the LCA properties in Yucca Flat. The porosities are generally low, supporting the conceptual model of flow predominantly in fractures and fracture zones.

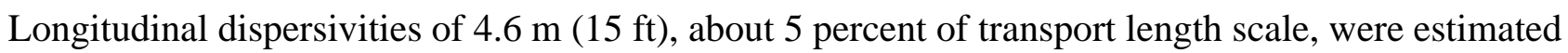
from the approach of Welty and Gelhar (1989). Semianalytic estimated values ranged from 14 to 
$29 \mathrm{~m}$ (15 to 32 percent of transport scale). These values may be larger because RELAP considers the entire breakthrough curve when fitting. The estimated values are consistent with relationships reported in the literature for dispersivity versus transport length scale by Gelhar et al. (1985) and Neuman (1990). Thus, it appears that there is nothing unique about dispersion in the saturated LCA that precludes the use of published dispersivity-scale relationships over larger scales in contaminant boundary calculations.

The peak and tail separations between tracers with different diffusion coefficients is typically used to identify double-porosity effects. However, Haggerty et al. (2000) showed that it is possible to identify double porosity and multirate diffusion from the late-time breakthrough curve behavior subject to assumptions of a single, non-channelized, flow path and Fickian dispersion. They show that slopes of $-3 / 2$ and $-5 / 2$ at late tracer test time correspond to classic single-rate double-porosity mass transfer and heterogeneous rate (e.g., from different local porosities and matrix block size) double-porosity matrix diffusion (so-called multirate diffusion), respectively. The 2,4,5-TFBA breakthrough curve has the soonest arriving peak and thus the longest tail. A log-log plot of the slightly smoothed data is shown in Figure 4-1 along with the characteristic slopes for double porosity and multirate diffusion.

It was not possible to numerically differentiate the data to obtain the slope directly because of the noise in the data, particularly on the falling limb of the curve. The increasing noise in the data after about $700 \mathrm{hr}$ is due to the data becoming close to the analytical detection limit, and there is no obvious correspondence to either of the matrix diffusion conceptual models. It is also possible that power-law type behavior with a -2 slope (Figure 4-1) can result from the superposition of the breakthroughs from many highly channelized flow paths with little or no matrix diffusion (this is akin to non-Fickian dispersion, which violates one of the assumptions of Haggerty et al. (2000), although it is certainly a possible conceptual model of LCA transport given its fractured nature and low matrix porosity) as demonstrated by Becker and Shapiro (2003). Such power-law tailing could also be the result of dispersion caused by natural-gradient flow superimposed on forced-gradient flow (resulting in stagnation or near-stagnation points in the system that give rise to non-Fickian tailing) or by a slowly-decaying source injection function caused by tracers lingering in or near the injection borehole. The noise in the data makes it difficult to determine whether there are any matrix diffusion effects or non-Fickian dispersion effects present; therefore, this aspect of the mass transport 


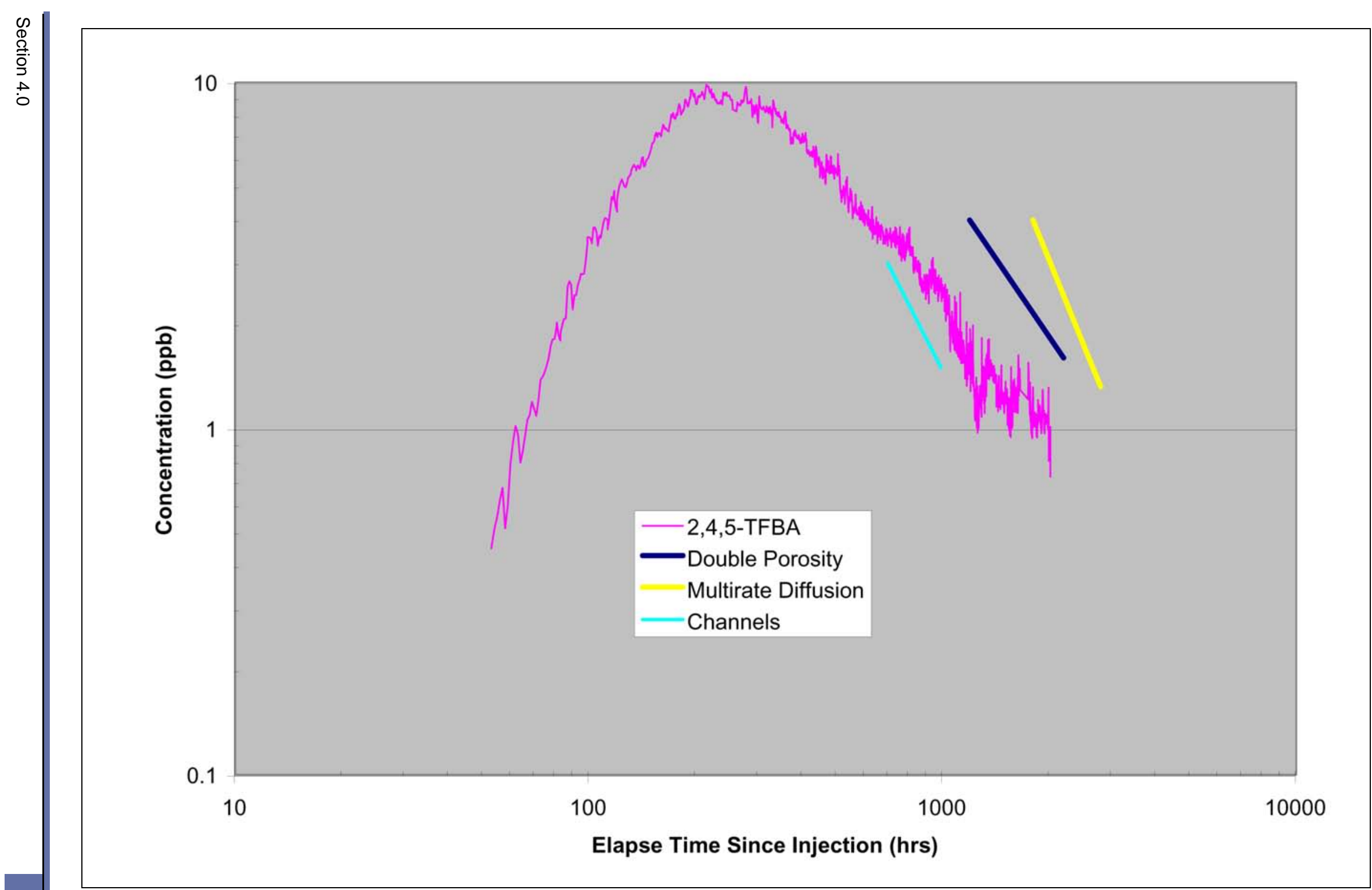

Figure 4-1

2,4,5-TFBA Breakthrough Curve Used To Identify Double Porosity and Multirate Diffusion 
conceptual model remains vague, but not unknown with respect to matrix diffusion because Hershey et al. (2003) and Reimus et al. (2006) observed matrix diffusion on a core wafer scale for dolomite of the LCA.

In summary, it appears likely that the time scales of the field tracer tests were too short to allow for unequivocal determination or parameterization of matrix diffusion because of the low matrix porosity (perhaps coupled with large fracture apertures) of the LCA. However, laboratory testing confirms the viability of matrix diffusion as a transport process that will affect transport over longer time and distance scales than the field tests. Indeed, the small LCA matrix diffusion coefficients measured in the laboratory tests are entirely consistent with the indeterminate evidence for matrix diffusion in the field tests given the time scales of the tests.

\subsection{LCA CAU Scale Processes}

Matrix diffusion was not conclusively evident in the ER-6-1 field tracer test(s), presumably because test time scales were too short in the lower interval for the effects of diffusion to be noticed in the low-porosity LCA matrix, and tracer concentrations were too low relative to Li and Br background concentrations in the upper interval to see the effects of matrix diffusion because of the noise in the tracer responses. Recall also that no hydraulic double-porosity effects were noticed in the MWAT. However, it is not axiomatic that double-porosity effects should be neglected when modeling LCA transport processes.

Reeves et al. (1987) analyzed important factors in regional double porosity flow and transport. They found the groups of factors to be relevant.

$$
\kappa=\frac{\phi_{m}+\phi_{f}}{\phi_{f}}
$$

and

$$
\tau_{c}=\frac{L^{2}}{\theta D_{m}}
$$

Where $\kappa$ is the solute storage enhancement of the fractures by the matrix; $\phi_{\mathrm{m}}$ and $\phi_{\mathrm{f}}$ are the fracture and matrix porosities. If $\kappa$ is unity, there will be no double-porosity behavior, and transport will behave as a fracture-only system. As $\kappa$ increases, there is increasing solute storage in the matrix, until as $\kappa$ becomes very large, the other limit of double-porosity behavior, that of an equivalent porous 
media with the porosity of the matrix, is reached. However, the relative porosities are not the only factor controlling the degree of fracture/matrix interaction. Where $\tau_{c}$ is the characteristic matrix diffusion time with $L$ as matrix half-block size, $\theta$ as the tortuosity, and $D$ as the free water diffusion coefficient. Physically, $\tau_{c}$ represents the time required for diffusion to penetrate from the fracture-matrix interface to the center of the matrix block, and for concentration at that point to reach about 68 percent of the value at the fracture-matrix interface (Reeves et al., 1987). When the time of solute travel in the fracture is much less than $\tau_{c}$, the rock will tend to act as a single porosity, with rapid breakthrough in the fractures (subject to constraint by $\kappa$ ). As the residence time of the solute in the fracture becomes greater than $\tau_{c}$ double-porosity effects become more pronounced, and eventually at very large $\tau_{\mathrm{c}}$ the system will act as a single-porosity system with the effective porosity of the matrix.

Laboratory experiments (Reimus et al., 2006) yielded estimates of tracer matrix diffusion coefficients in core samples from ER-6-1 as well as matrix porosities of the core samples used for diffusion testing. The measured matrix porosities and matrix diffusion coefficients are listed in Table 4-1 (note that the diffusion coefficients reported in Table 10 of Reimus et al. [2006] were one order of magnitude too high — the diffusion coefficients should be $x 10^{-7} \mathrm{~cm}^{2} / \mathrm{s}$, not $\left.\times 10^{-6} \mathrm{~cm}^{2} / \mathrm{s}\right)$. These values, measured in core samples, reflect the $\theta D_{m}$ product.

Table 4-1

Matrix Diffusion Coefficients (x 10-7 $\mathrm{cm}^{2} / \mathrm{s}$ ) from Diffusion Wafer Experiments in Core Samples from ER-6-1

\begin{tabular}{|c|c|c|c|c|c|c|}
\hline Wafer & Porosity & PFBA & $\begin{array}{l}2,5-\text { DFBA, } \\
2,4,5-T F B A\end{array}$ & $\mathrm{Br}$ & I & Halide/FBA \\
\hline $2240-A$ & 0.035 & 2.5 & 2.8 & 5.5 & 5.5 & $2.08: 1$ \\
\hline 2240-B & 0.031 & 3.2 & 3.5 & 7 & N/A & 2.09 \\
\hline $2400-A$ & 0.010 & 1.4 & 1.6 & 2 & 2.3 & 1.43 \\
\hline $2400-B$ & 0.009 & 0.85 & 1 & 1.7 & $\mathrm{~N} / \mathrm{A}$ & 1.84 \\
\hline 2944-A & 0.060 & 11 & 11 & 22 & 23 & 2.05 \\
\hline 2944-B & 0.059 & 10 & 10 & 20 & N/A & 2 \\
\hline 3048-A & 0.013 & 4 & 5 & 7 & 5.8 & 1.42 \\
\hline $3048-B$ & 0.013 & 7.5 & 8.5 & 16 & $\mathrm{~N} / \mathrm{A}$ & 2 \\
\hline
\end{tabular}

Source: Reimus et al., 2006 
Using LCA representative matrix and fracture porosities of 0.031 and 0.002 gives a $\kappa$ of 16.5 . The time constant $\tau_{\mathrm{c}}$ is more difficult to estimate because matrix block size is typically a parameter estimated from tracer tests that could not be determined for the LCA. However, if the half-block size is considered to be half the fracture spacing estimated at $0.76 \mathrm{~m}$ from ER-6-2 core analysis (see previous discussion), $\tau_{\mathrm{c}}$ is (using matrix diffusion of $3.2 \times 10^{-7} \mathrm{~cm}^{2} / \mathrm{s}$ ) about 143 years. The 2,4,5-TFBA breakthrough occurred in about $220 \mathrm{hr}$ (0.025 years); thus, the tracer test time scale is about $2 \times 10^{-4}$ of that required for substantial diffusion into the matrix blocks, and coupled with the low solute storage capacity, one might not expect significant matrix diffusion effects during the tracer test.

In contrast, consider that the $\tau_{c}$ and $\kappa$ for the volcanic Benham Aquifer on Pahute Mesa are 40,000 years and 200, using mean matrix and fracture porosities of 0.20 and 0.001 (Shaw, 2003), matrix diffusion of $0.555 \times 10^{-8} \mathrm{~cm}^{2} / \mathrm{s}$ for FBA (Reimus and Haga, 1999), and fracture spacing of $1.68 \mathrm{~m}$ giving a half-block size of $0.84 \mathrm{~m}$ (Shaw, 2003). Thus, the Benham Aquifer will store roughly an order of magnitude more radionuclides in a given volume than the LCA and show matrix diffusion effects 200 times longer.

Another set of dimensionless parameters can also be defined ( $P 1, P 2, P 3)$ :

$P 2=\left(\frac{\phi}{b}\right)^{2} D_{m} \tau$ is the ratio of advection to matrix diffusion time scales. Recognize that, excluding $\tau$, the group is the square of the characteristic mass transfer coefficient for matrix diffusion used in RELAP.

$P 2=\frac{\sqrt{D_{m} \tau}}{(L / 2)}$ is the ratio of characteristic tracer diffusion distance in matrix to half the characteristic distance between flowing fractures $(L)$, which is similar to the $\tau_{\mathrm{c}}$ parameter of Reeves et al. (1987). For fixed $D_{m}$ and $\tau$, as $P 2$ becomes smaller, the characteristic distance increases.

$P 3=1+\frac{\phi(L / 2-b)}{b}$, which is 1 plus the ratio of stagnant water volume to flowing water volume in the system. $P 3$ is essentially an effective retardation factor that nonsorbing solutes will experience as a result of matrix diffusion. Note that these parameters assume that the transport system can be conceptualized as a series of parallel plate fractures of aperture $2 b$ embedded in a matrix of porosity $\phi$, with the fractures being separated by the characteristic distance $L$. 
In the case of the 2,4,5-TFBA and I responses in the ER-6-1 tracer test, the value of $\left(\frac{\phi}{b}\right)^{2} D_{m} \tau$ is approximately 0.02 (assuming the mean tracer residence time under radial flow conditions is the advective time scale). This value suggests that the time scale of the tracer test was very short relative to the time scale required to observe matrix diffusion in the LCA. Unique values cannot be readily assigned to $P 2$ and $P 3$ for the ER-6-1 tracer test because there are no good independent estimates of L. $P 1$ highlights the time (via velocity) dependent nature of interaction between fracture and matrix mass transfer.

The influence of the three dimensionless parameters on matrix diffusion can be illustrated by a series of RELAP simulations in which a solution of tracer concentration $\mathrm{C}_{\mathrm{o}}$ is assumed to be injected into the flow system at time 0 and is continued to be injected for the remainder of the simulation (i.e., a constant concentration source term). In Figure 4-2, the value of $P 3$ was held constant at approximately 2.0 in a set of simulations by setting $f=0.01, b=0.1 \mathrm{~cm}$, and $\mathrm{L} / 2=10 \mathrm{~cm}$ (values that may be quite reasonable for the LCA). A constant $P 3$ fixes the fracture spacing, aperture, and matrix porosity. The effects of $P 1$ and $P 2$ were tested by varying t from a minimum of 2,000 hr (about 0.23 years) to a maximum of 500 years (note that it is not possible to vary all three dimensionless parameters independently - when one is varied, one of the other two will also vary). The effects of varying the parameters $P 1$ and $P 2$ are explained directly in Figure 4-2.

Figure 4-3 shows the effect of varying the parameter $P 2$ by varying $L / 2$, and hence also varying $P 3$ while holding $P 1$ constant. The breakthrough curves in Figure 4-3 are identical for all values of $P 2$ less than about 0.25 .

If $\frac{\sqrt{D_{m} \tau}}{(L / 2)}$ is less than 0.25 , the matrix will behave as if the distance between flowing fractures is essentially infinite (because the tracers from adjacent fractures will not encounter each other, which would lower the concentration gradient in the matrix and thus suppress matrix diffusion).

Although relatively small values of $1+\frac{\phi(L / 2-b)}{b}$ were used in Figures 4-2 and 4-3, the relationships illustrated in these figures will hold for any values of $1+\frac{\phi(L / 2-b)}{b}$. When larger values of $1+\frac{\phi(L / 2-b)}{b}$ are used (corresponding to fractured rocks with much larger matrix porosities or to much larger flowing fracture spacings than assumed here), the retarding effects of matrix diffusion will be significantly greater than that shown in Figures 4-2 and 4-3. 


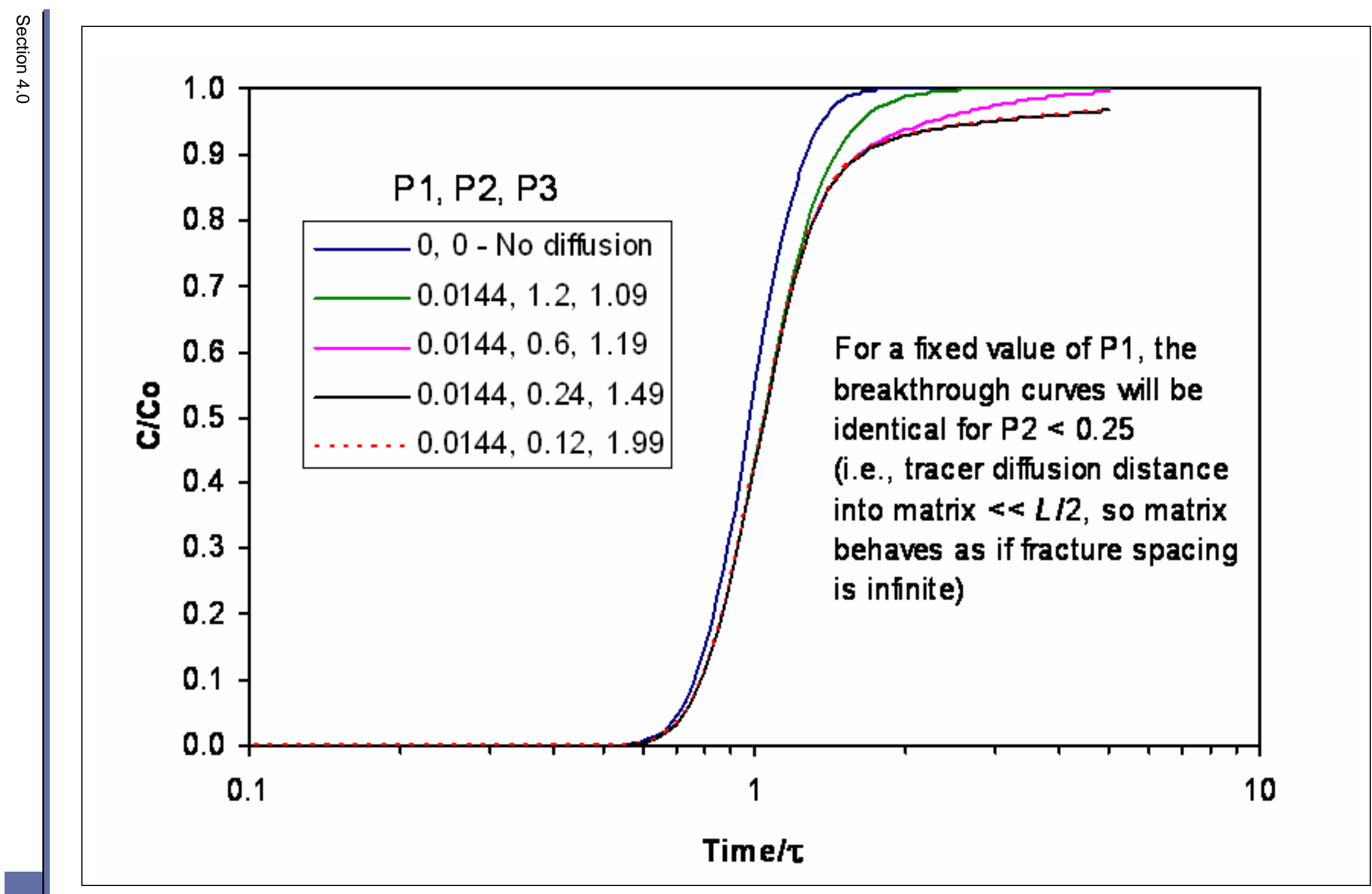

Figure 4-3

Effects of Varying P2 and P3 While Holding P1 Constant 
In SNJV (2006), the travel time between ER-6-1 \#2 and ER-7-1 is estimated on the order of 6,500 years, with an average linear velocity of 1.7 meters per year $(0.0046 \mathrm{~m} / \mathrm{d})$. Estimates of groundwater velocity made from the tracer test results range from 0.036 to $0.066 \mathrm{~m} / \mathrm{d}$, roughly an order of magnitude greater, resulting in travel times from 400 to 700 years from ER-7-1 to ER-6-1 \#2. Considering these velocities and the above discussion, it is evident that matrix diffusion may be an important physical process at the CAU scale even though it was not significant at the scale of the ER-6-1 tracer test. 


\subsection{REFERENCES}

BN, see Bechtel Nevada.

Beauheim, R.L., and G.J. Ruskauff. 1998. Analysis of Hydraulic Test of the Culebra and Magenta Dolomites and Dewey Lake Redbeds Conducted at the Waste Isolation Pilot Plant Site, SAND98-0049. Albuquerque, NM: Sandia National Laboratories.

Bechtel Nevada. 2003. Updated Coordinates and Ground Elevations for the ER-6-1 Wells, 26 October. Las Vegas, NV.

Bechtel Nevada. 2005. A Hydrostratigraphic Model and Alternatives for the Groundwater Flow and Contaminant Transport Model of Corrective Action Unit 98: Frenchman Flat, Clark, Lincoln and Nye Counties, Nevada, DOE/NV/11718--1064. Las Vegas, NV.

Bechtel Nevada. 2006. A Hydrostratigraphic Model and Alternatives for the Groundwater Flow and Contaminant Transport Model of Corrective Action Unit 97: Yucca Flat-Climax Mine, Lincoln and Nye Counties, Nevada, DOE/NV/11718--1119. Las Vegas, NV.

Becker, M.W., and A.M. Shapiro. 2003. "Interpreting Tracer Breakthrough Tailing from Different Forced Gradient Tracer Experiment Configurations in Fractured Bedrock.” In Water Resources Research, v. 39 (1): 1024.

Belcher, W.R., P.E. Elliott, and A.L. Geldon. 2001. Hydraulic-Property Estimates for Use With a Transient Ground-Water Flow Model of the Death Valley Regional Ground-Water Flow System, Nevada and California, Water-Resources Investigations Report 01-4210. Carson City, NV: U.S. Geological Survey.

Borg, I.Y., R. Stone, H.B. Levy, and L.D. Ramspott. 1976. Information Pertinent to the Migration of Radionuclides in Ground Water at the Nevada Test Site, UCRL-52078. Livermore, CA: Lawrence Livermore National Laboratory.

Butler, J.J., Jr. 1990. "The Role of Pumping Tests in Site Characterization: Some Theoretical Considerations.” In Ground Water, v. 28(3): 394-403.

Byers, F.M., Jr., W.J. Carr, P.P. Orkild, W.D. Quinlivan, and K.A. Sargent. 1976. Volcanic Suites and Related Cauldrons of Timber Mountain-Oasis Valley Caldera Complex, Southern Nevada, Professional Paper 919. Denver, CO: U.S. Geological Survey. 
Carrera, J., and L. Martinez-Landa. 2000. "Mixed Discrete-Continuum Models: A Summary of Experiences in Test Interpretation and Model Prediction.” In Dynamics of Fluids in Fractured Rock, Geophysical Monograph Series, v. 122: 400.

Chen, C., and J.J. Jiao. 1999. "Numerical Simulation of Pumping Tests in Multilayer Wells with Non-Darcian Flow in the Wellbore.” In Ground Water, v. 37(3): 465-474.

Dash, Z.V. 2000. Validation Test Report (VTR) for the FEHM Application Version 2.10, Yucca Mountain Project Identification Numbers SAN: LANL-1999-046; STN: 10086-2.10-00. Los Alamos, NM: Los Alamos National Laboratory.

Dash, Z.V. 2001. Validation Test Report (VTR) for the FEHM Application Version 2.12, Yucca Mountain Project Identification Numbers SAN: LANL-2001-133; STN: 10086-2.12-00. Los Alamos, NM: Los Alamos National Laboratory.

Dash, Z.V., B.A. Robinson, and G.A. Zyvoloski. 1997. Software Requirements, Design, and Verification and Validation for the FEHM Application - A Finite-Element Heat- and Mass-Transfer Code, LA-13305-MS. Los Alamos, NM: Los Alamos National Laboratory.

Doughty, C., and C.-F. Tsang. 2000. BORE-II - A Code to Compute Dynamic Wellbore Electrical Conductivity Logs with Multiple Inflow/Outflow Points Including the Effects of Horizontal Flow Across the Well, LBNL-46833. Berkeley, CA: Lawrence Berkeley National Laboratory.

Drellack, S.L., Jr., L.B. Prothro, R.L. McCall, and P.H. Thompson. 1992. Preliminary Geology and Drill Hole Data Report for Groundwater Characterization Well ER-6-1, Nevada Test Site, Nye County, Nevada. Las Vegas, NV: Raytheon Services Nevada.

ESI, see Environmental Simulations, Inc.

Environmental Simulations, Inc. 2004. Groundwater Vistas. Reinholds, PA.

Finsterle, A.L., and P. Persoff. 1997. "Determining Permeability of Tight Rock Samples Using Inverse Modeling.” In Water Resources Research, v. 33(8): 1803-1811.

Fleming, S., G. Ruskauff, and A. Adams. 2001. “Local-Scale Wellfield Analysis for Improving a Numerical Water Resource Management Model.” In Proceedings of the MODFLOW 2001 Conference, September 11-14, 2001. Golden, CO.

Freeze, R.A., and J.A. Cherry. 1979. Groundwater. Englewood Cliffs, NJ: Prentice Hall.

Garber, M.S., and W. Thordarson. 1962. Ground Water Test Well C, Nevada Test Site, Nye County, Nevada, A Summary of Lithologic Data, Aquifer Tests, and Well Construction, Trace Elements Investigations-818. Denver, CO: U.S. Geological Survey. 
Gelhar, L.W., A. Mantoglou, C. Welty, and K.R. Rehfeldt. 1985. A Review of Field-Scale Physical Solute Transport Processes in Saturated and Unsaturated Porous Media, EPRI EA-4190.

Palo Alto, CA: Electric Power Research Institute.

Gonzales, J.L., and S.L. Drellack. 1999. Addendum to the Descriptive Narrative for the Hydrogeologic Model of the Yucca Flat Corrective Action Unit: Northern Extension. Las Vegas, NV: Bechtel Nevada.

Gonzales, J.L., S.L. Drellack, and M.J. Townsend. 1998. Descriptive Narrative for the Hydrogeologic Model at the Yucca Flat Corrective Action Unit: An Interim Report. Las Vegas, NV: Bechtel Nevada.

Haggerty, R., S.A. McKenna, and L.C. Meigs. 2000. "On the Late-Time Behavior of Tracer Test Breakthrough Curves.” In Water Resources Research, v. 36(12): 3467-3479.

Harbaugh, A.W., and M.G. McDonald. 1996. User's Documentation for MODFLOW-96, an Update to the U.S. Geological Survey Modular Finite-Difference Groundwater-Water Flow Model, Open-File Report 96-485. Denver, CO: U.S. Geological Survey.

Harbaugh, A.W., E.R. Banta, M.C. Hill, and M.G. McDonald. 2000. MODFLOW-2000, the U.S. Geological Survey Modular Ground-Water Model -- User Guide to Modularization Concepts and the Ground-Water Flow Process, Open-File Report 00-92. Reston, VA: U.S. Geological Survey.

Hershey, R.L., W. Howcroft, and P.W. Reimus. 2003. Laboratory Experiments to Evaluate Diffusion of ${ }^{14}$ C into Nevada Test Site Carbonate Aquifer Matrix, DOE/NV/11508-55. Las Vegas, NV.

IT, see IT Corporation.

IT Corporation. 1996a. Transport Parameter and Source Term Data Documentation Package (Phase I Data Analysis Documentation, Volume V), ITLV/10972--181. Las Vegas, NV.

IT Corporation. 1996b. Wells ER-6-1 and ER-6-2 Core Fracture Analyses and Geophysical Log Comparisons, ITLV/10972/171. Las Vegas, NV.

IT Corporation. 2003. Written communication. Subject: Yucca Flat ER-6-1 \#2 Well Data Report, Rev. 0. Las Vegas, NV.

Jones, T.L., V.A. Kelley, J.F. Pickens, D.T. Upton, R.L. Beauheim, and P.B. Davies. 1992. Integration of Interpretation Results of Tracer Tests Performed in the Culebra Dolomite at the Waste Isolation Pilot Plant (WIPP) Site, SAND92-1579. Albuquerque, NM: Sandia National Laboratories. 
Kilroy, K.C. 1992. Aquifer Storage Characteristics of Paleozoic Carbonate Rocks in Southeastern Nevada Estimated from Harmonic Analysis of Water-Level Fluctuations. University of Nevada at Reno, Ph.D. dissertation.

Krabbenhoft, D., and M.P. Anderson. 1986. "Use of a Groundwater Model for Hypothesis Testing." In Ground Water, v. 24(1): 49-55.

Laczniak, R.J., J.C. Cole, D.A. Sawyer, and D.A. Trudeau. 1996. Summary of Hydrogeologic Controls on Ground-Water Flow at the Nevada Test Site, Nye County, Nevada, Water-Resources Investigations Report 96-4109. Carson City, NV: U.S. Geological Survey.

Lerman, A. 1979. Geochemical Processes: Water and Sediment Environments. New York: John Wiley \& Sons.

McDonald, M.G., and A.W. Harbaugh. 1988. Techniques of Water-Resources Investigations of the United States Geological Survey, A Modular Three-Dimensional Finite-Difference Ground-Water Flow Model, Book 6, Chapter A1. Washington, DC: U.S. Geological Survey.

NNSA/NSO, see U.S. Department of Energy, National Nuclear Security Administration Nevada Site Office.

Neuman, S.P. 1990. "Universal Scaling of Hydraulic Conductivities and Dispersivities in Geologic Media.” In Water Resources Research, v. 26(8): 1749-1758.

Oberlander, P.L., and C.E. Russell. 2004. Letter Report: Horizontal Hydraulic Conductivity Profile with Depth for Wells ER-6-1 and ER-6-1 \#2, DOE/NV/13609-LTR2004-02. Las Vegas, NV: Desert Research Institute.

Reeves, M., V.A. Kelley, and J.F. Pickens. 1987. Regional Double-Porosity Solute Transport in the Culebra Dolomite: An Analysis of Parameter Sensitivity and Importance at the Waste Isolation Pilot Plant (WIPP) Site, SAND-87-7105. Albuquerque, NM: Sandia National Laboratories.

Reimus, P.W. 2005. Personal communication from P. Reimus to G. Ruskauff, J. Wurtz, and B. Fryer (SNJV), and Andrew Wolfsberg (LANL) regarding an update of "Semi-Analytical Interpretations of ER-6-1 Multiple-Well Tracer Test Results,” 23 March. Los Alamos, NM: Los Alamos National Laboratory.

Reimus, P.W., and M.J. Haga. 1999. Analysis of Tracer Responses in the BULLION Forced-Gradient Experiment at Pahute Mesa, Nevada, LA-13615-MS. Los Alamos, NM: Los Alamos National Laboratory.

Reimus, P.W., R.L. Hershey, D.L. Decker, S.D. Ware, C. Papelis, S. Earman, A. Abdel-Fattah, M. Haga, D. Counce, S. Chipera, and C. Sedlacek. 2006. Tracer Transport Properties in the Lower Carbonate Aquifer of Yucca Flat, LA-UR-06-0486. Los Alamos, NM: Los Alamos National Laboratory. 
Rojstaczer, S. 1987. “The Local Effects of Groundwater Pumpage Within a Fault-Influenced Groundwater Basin, Ash Meadows, Nye County, Nevada, U.S.A.” In Journal of Hydrology, v. 91: 319-337.

Shaw, see Shaw Environmental Inc.

SNJV, see Stoller-Navarro Joint Venture.

Shaw Environmental, Inc. 2003. Contaminant Transport Parameters for the Groundwater Flow and Contaminant Transport Model of Corrective Action Units 101 and 102: Central and Western Pahute Mesa, Nye County, Nevada, Rev. 0, Shaw/13052-201-CD. Las Vegas, NV.

Stoller-Navarro Joint Venture. 2004a. Analysis of Well ER-7-1 Testing, Yucca Flat FY 2003 Testing Program, Nevada Test Site, Nevada, Rev. 0, S-N/99205--021. Las Vegas, NV.

Stoller-Navarro Joint Venture. 2004b. Underground Test Area Project, ER-6-1 Multi-Well Aquifer Test - Tracer Test Plan, Rev. 0, S-N/99205--013. Las Vegas, NV.

Stoller-Navarro Joint Venture. 2005a. Analysis of Hydraulic Responses from the ER-6-1 Multiple-Well Aquifer Test, Yucca Flat FY 2004 Testing Program, Nevada Test Site, Nye County, Nevada, Rev. 0, S-N/99205--051. Las Vegas, NV.

Stoller-Navarro Joint Venture. 2005b. Analysis of Well ER-6-2 Testing, Yucca Flat FY 2004 Testing Program, Nevada Test Site, Nye County, Nevada, Rev. 0, S-N/99205--053. Las Vegas, NV.

Stoller-Navarro Joint Venture. 2005c. Phase II Contaminant Transport Parameters for the Groundwater Flow and Contaminant Transport Model of Corrective Action Unit 98: Frenchman Flat, Nye County, Nevada, Rev. 0, S-N/99205--043. Las Vegas, NV.

Stoller-Navarro Joint Venture. 2005d. Underground Test Area Fracture Analysis Report for Yucca Flat Wells ER-2-1, ER-6-1 \#2, ER-7-1, and ER-12-2 Nevada Test Site, Rev. 0, S-N/99205--040. Las Vegas, NV.

Stoller-Navarro Joint Venture. 2005e. Written communication. Subject: ER-6-1 Well Cluster Multiple Well Aquifer Test - Tracer Test Data Report, Volumes I, II, and III, Rev. 0. Las Vegas, NV.

Stoller-Navarro Joint Venture. 2006. Geochemical and Isotopic Evaluation of Groundwater Movement in Corrective Action Unit 97: Yucca Flat/Climax Mine, Nevada Test Site, Nevada, Rev. 0, S-N/99205--070. Las Vegas, NV.

Touloukian, Y.S., and C.Y. Ho. 1981. "McGraw Hill/Cindas Data Series on Material Properties.” In Physical Properties of Rocks and Minerals, v. II-2. New York, NY: McGraw Hill Book Co. 
Tucker, W.A., and L.H. Nelken. 1982. “Diffusion Coefficients in Air and Water.” In Handbook of Chemical Property Estimation Methods: Environmental Behavior of Organic Compounds, 17-1 - 17-25 pp. Washington, DC: American Chemical Society.

U.S. Department of Energy, National Nuclear Security Administration Nevada Site Office. 2004a. Completion Report for Well ER-7-1, DOE/NV/11718-865. Las Vegas, NV.

U.S. Department of Energy, National Nuclear Security Administration Nevada Site Office. 2004b. Completion Report for Well Cluster ER-6-1, DOE/NV/11718-862. Las Vegas, NV.

Watermark, see Watermark Numerical Computing.

Watermark Numerical Computing. 2004. PEST Model-Independent Parameter Estimation Software. Brisbane, Australia.

Weiss, R., and L. Smith. 1993. "Parameter Estimation using Hydraulic Head and Environmental Tracer Data.” In Proc. of the Groundwater Modeling Conference, June 9-12, 1993. Golden, CO.

Weiss, R., and L. Smith. 1997. "Efficient and Responsible Use of Prior Information in Inverse Methods.” In Groundwater, v. 36(1): 151.

Welty, C., and L.W. Gelhar. 1989. Evaluation of Longitudinal Dispersivity from Tracer Test Data, R-89-05. Prepared for the U.S. Environmental Protection Agency and National Science Foundation. Cambridge, MA: Massachusetts Institute of Technology.

Winograd, I.J., and L.R.West. 1962. Preliminary Tracer Experiment to Demonstrate Hydraulic Continuity Between Water Wells C and C-1, Yucca Flat, Nevada Test Site, Technical Letter, NTS-20. U.S. Geological Survey.

Winograd, I.J., and W. Thordarson. 1975. Hydrogeologic and Hydrochemical Framework, South-Central Great Basin, Nevada-California, with Special Reference to the Nevada Test Site, Professional Paper-712-C. Denver, CO: U.S. Geological Survey.

Winograd, I.J. and F.J. Pearson, Jr. 1976. “Major Carbon-14 Anomaly in a Regional Carbonate Aquifer: Possible Evidence for Megascale Channeling, South Central Great Basin.” In Water Resources Research, v. 12: 1125-1143. Washington, DC: American Geophysical Union.

Wolfsberg, A., L. Glascoe, G. Lu, A. Olson, P. Lichtner, M. McGraw, T. Cherry, and G. Roemer. 2002. TYBO/BENHAM: Model Analysis of Groundwater Flow and Radionuclide Migration from Underground Nuclear Tests in Southwestern Pahute Mesa, Nevada, LA-13977. Los Alamos, NM: Los Alamos National Laboratory.

Zyvoloski, G.A., B.A. Robinson, Z.V. Dash, and L.L. Trease. 1997a. Summary of Models and Methods for the FEHM Application - A Finite-Element Heat- and Mass-Transfer Code, LA-13307-MS. Los Alamos, NM: Los Alamos National Laboratory. 
Zyvoloski, G.A., B.A. Robinson, Z.V. Dash, and L.L. Trease. 1997b. User's Manual for the FEHM Application - A Finite-Element Heat- and Mass-Transfer Code, LA-13306-M. Los Alamos, NM: Los Alamos National Laboratory. 
Appendix A

Sampling Analysis Review 


\section{A.1.0 sampling analysis ReView}

The following describes the depth-discrete and wellhead sampling results reported in ER-6-1 Well Cluster Multiple Well Aquifer Test - Tracer Test Data Report, Volumes I, II, and III (SNJV, 2005). An evaluation of the hard copies of raw data (chromatograms) for the FBAs and the laboratory notebook was performed. In general, stringent quality control criteria were satisfied for the analyses performed by SNJV in the field and by UNLV-HRC in the laboratory. A large number of samples were analyzed and, with the large amount of data present, certain details in the data often may be overlooked. In addition, HPLC analysis of organics can be less than straightforward when concentrations are at low ppb levels. This technique is not very selective, and other compounds or ions may show peaks in the chromatograms, which often may be mistakenly identified as the tracer analyte. This response documents the results of the evaluation.

\section{A.1.1 Depth-Discrete Sampling}

Depth-discrete samples were collected from ER-6-1 \#2, ER-6-1, and ER-6-1 \#1 at different time intervals throughout the period of the tracer test. A number of the positive hits from the depth-discrete samples reported were unexpected and thought unlikely to be representative of actual transport behavior. Chromatograms for the tracer samples with concentrations above the detection limit reported in the report (Table B.1-2, SNJV, 2005) were evaluated and discussed below.

\section{A.1.1.1 2,5-DFBA Well ER-6-1 \#2}

Depth-discrete samples were collected from ER-6-1 \#2 on May 6, 9, and 11, 2004, and a peak was present in the chromatograms with a similar retention time as 2,5-DFBA. To confirm the presence of 2,5-DFBA in these samples, a small quantity of the $200 \mathrm{ppb}$ calibration standard was added to the sample vial. This "spiked" sample was then analyzed using the same HPLC method as was used for the "unspiked" sample. The chromatograms were compared, and the presence of two clearly separated peaks in the "spiked" sample and only a single peak in the "unspiked" sample confirmed 
that 2,5-DFBA was not present in the groundwater samples; instead, another unknown component was present. This unknown peak eluted approximately 1 minute before that of 2,5-DFBA in the chromatograms. This is also the case for the sample collected on May 6, 2004, from a depth of 3,050 ft. Although a concentration of $216 \mathrm{ppb}$ is reported for 2,5-DFBA in this sample, no 2,5-DFBA is present. These spiking experiments are reported in the scientific notebook. Many components that are typically present in groundwater are detectable using the HPLC with ultraviolet absorbance detection. The presence of a peak with a similar retention time as any of the tracers is not unexpected. It is apparent from this evaluation that 2,5-DFBA is not present in the depth-discrete samples collected in May 2004 from ER-6-1 \#2.

Depth-discrete samples were again collected from ER-6-1 \#2 on June 13 and 14, 2004. Measured concentrations ranging from 13 to 26 ppb were reported for the samples collected on June 13, 2004. Although spikes were not performed on these samples, a comparison between the retention time of the peak observed in depth-discrete samples (approximately 9.7 minutes) and those observed for the wellhead samples (10.1 to 10.2 minutes) and the calibration check standard (10.6 minutes) suggests that the reported values were incorrectly reported. The peak identified as 2,5-DFBA in the depth-discrete samples is probably associated with the same component as present in the samples collected in May 2004. It is apparent from this evaluation that 2,5-DFBA is not present in the depth-discrete samples collected in June 2004 from ER-6-1 \#2.

Another set of depth-discrete samples was collected from ER-6-1 \#2 on August 10, 11, 27, and 30, 2004. Relatively high concentrations of 2,5-DFBA (16 to $642 \mathrm{ppb}$ ) were measured in most of these samples. The retention times for the peaks identified as 2,5-DFBA in these samples closely match those of the standards. In addition, a second peak to the left of the 2,5-DFBA peak is observed in several of the samples. These analyses cannot be explained in a similar manner as the May and June 2004 samples. The measured concentrations reported for these samples could accurately describe the levels of 2,5-DFBA actually present. It is likely that the small peak identified in the rinsate sample that is quantified as $14 \mathrm{ppb} 2,5$-DFBA is not 2,5-DFBA but is instead the unknown component present in these discrete samples. The retention time for this peak is 8.4 minutes compared to retention times greater than 9 minutes observed for 2,5-DFBA in the standards and groundwater samples. 


\section{A.1.1.2 2,5-DFBA Well ER-6-1}

The first set of depth-discrete samples from ER-6-1 was collected on May 14 and 15, 2004. Similar to the spiked samples described earlier, two peaks with similar retention times as 2,5-DFBA are observed in the chromatograms for these samples, suggesting that the concentrations for 2,5-DFBA may be correctly reported (25 to 55 ppb). Samples collected on May 21, 2004, were analyzed on May 22, 2004, for 2,5-DFBA. The first sample analyzed was collected from a depth of 2,950 ft and also shows two peaks in the chromatograms again, suggesting accurate quantitation of 2,5-DFBA (192 ppb). The samples analyzed following this sample are different. A large broad peak with a similar retention time as 2,5-DFBA is present in the resulting chromatograms. It appears that this peak may be “carry-over” from the previous analyses. This cannot be verified, but broader peaks are typically observed as the compound is retained on the chromatographic column, and these broad peaks are therefore often attributed to a chromatographic run time that is too short to elute all of the compounds from a given sample. The reported concentrations of 2,5-DFBA for samples from depths of 2,650 and 2,850 ft as well as the rinsate sample reflect this interference peak and are not accurate. This is confirmed by the nondetects observed for the diluted samples. If the reported concentrations were accurate, the concentrations in the diluted samples should have been significantly above the detection limits. These samples were not re-analyzed. The presence of 2,5-DFBA in these samples cannot be verified. Data for samples from depths of 2,650 and 2,850 ft do not reflect actual concentrations. Depth-discrete samples from ER-6-1 were collected again on June 18, 2004. The 2,5-DFBA may be present at levels closer to $21 \mathrm{ppb}$ in the samples collected from 2,850 and 2,950 ft (performed on June 19, 2004). The peaks corresponding to the originally reported concentrations (39 and 8 ppb) may have been inaccurately defined. The last depth-discrete samples from ER-6-1 were collected on September 1 and 2, 2004. Only two concentrations above the detection limit were reported. One of these samples was the bailer rinse sample. Although, a concentration of 21.06 is reported for 2,5-DFBA in the rinsate sample, from viewing the chromatogram it appears that this was not 2,5-DFBA. The 2,5-DFBA may be accurately identified in the sample collected at a depth of $2,850 \mathrm{ft}$.

\section{A.1.1.3 2,5-DFBA Well ER-6-1 \#1}

Depth-discrete samples from ER-6-1 \#1 were collected on May 16 and 22, 2004, and high concentrations of 2,5-DFBA (greater than 80,000 ppb) were measured in all groundwater samples. 
Although some of the samples were not diluted so that the concentration of 2,5-DFBA was within the calibration range (10 ppb to $200 \mathrm{ppb}$ ), the order of magnitude of the reported concentrations is probably accurate. The elevated concentrations of 2,5-DFBA in the depth-discrete samples collected from ER-6-1 \#1 in June and September 2004 appear accurate.

\section{A.1.2 PFBA Well ER-6-1 \#2}

The reported PFBA concentrations in the depth-discrete samples from ER-6-1 \#2 are consistent with the chromatograms. Low levels of PFBA appeared to be present in the samples collected from 2,000 to $2,550 \mathrm{ft}$.

\section{A.1.2.1 PFBA Well ER-6-1}

The reported positive hits for PFBA in the depth-discrete samples from ER-6-1 may be inaccurate. The retention times for the peaks identified as PFBA in the chromatograms for most of the samples were significantly different than those observed for the wellhead samples and the standards. This is the case for samples collected on May 14, June 18, and September 1, 2004. A low concentration of PFBA may be present in the samples collected on May 21, 2004. The high value reported for PFBA in the sample from 2,750 $\mathrm{ft}(1,783 \mathrm{ppb})$ does not accurately reflect the actual levels. If present, the PFBA concentration in this sample is approximately $13 \mathrm{ppb}$.

\section{A.1.2.2 PFBA Well ER-6-1 \#1}

The presence of PFBA in the depth-discrete samples collected from ER-6-1 \#1 cannot be verified. The reported concentrations are near the detection limit for PFBA and other peaks are present in some of the chromatograms, making identification of PFBA unclear. No spiking experiments were performed, and therefore a high uncertainty is associated with the reported values.

\section{A.1.2.3 2,4,5-TFBA Well ER-6-1 \#2}

The reported 2,4,5-TFBA concentrations in the depth-discrete samples from ER-6-1 \#2 are consistent with the chromatograms. Detectable quantities of 2,4,5-TFBA were reported for most samples. A spike was performed for one sample collected on May 11, 2004 (2,400 ft). Unlike the results for the 
2,5-DFBA spikes, a single peak was observed in the chromatograms for both the spiked and unspiked samples. This indicates that 2,4,5-TFBA was accurately identified in these samples.

\section{A.1.2.4 2,4,5-TFBA Well ER-6-1}

The reported 2,4,5-TFBA concentrations in the depth-discrete samples from ER-6-1 are consistent with the chromatograms.

\section{A.1.2.5 2,4,5-TFBA Well ER-6-1 \#1}

The low levels reported for 2,4,5-TFBA in the depth-discrete samples from ER-6-1 \#1 are difficult to assess. The reported levels are typically very close to the detection limit for 2,4,5-TFBA. In addition, there are interfering chromatographic peaks present in most of the analyses. The approximate $100 \mathrm{ppb}$ levels reported in the samples collected on September 2, 2004, from ER-6-1 \#1 at the depth of $1,880 \mathrm{ft}$ are consistent with the chromatograms. The retention times for these peaks are very similar to those of the standards. Poor integration of the 2,4,5-TFBA peak in the chromatogram for the sample collected on the same day from a depth of 2,000 ft resulted in a greater than actual concentration (52 ppb). The concentration of 2,4,5-TFBA is closer to $10 \mathrm{ppb}$. No spikes were performed for these samples.

\section{A.1.3 Summary}

\section{Comment:}

Positive tracer hits are reported from depth-discrete samples along full depth of ER-6-1 \#2 either during or after the tracer test. Positive hits along full borehole length are not expected.

\section{Response:}

All levels of 2,5-DFBA reported above detection in samples collected from ER-6-1 \#2 before the completion of the tracer test were probably incorrectly reported. An interference peak was present in the chromatograms, and in some cases this peak was mistakenly identified as 2,5-DFBA. It appears that 2,5-DFBA was not present in these samples. Low levels of PFBA appeared to be present in the samples collected from 2,000 to 2,550 ft. The 2,4,5-TFBA appears to be present in most depth-discrete samples collected from ER-6-1 \#2. 


\section{Comment:}

Comment: For samples collected after the tracer test pumping stopped, positive hits in samples collected deep in the borehole (ER-6-1 \#2) could result from flow within the borehole.

\section{Response:}

The 2,5-DFBA and 2,4,5-TFBA were measured in most of the depth-discrete samples from ER-6-1 \#2 following the completion of the tracer test; concentrations range from 16 to $642 \mathrm{ppb}$. This was not the case for PFBA.

\section{Comment:}

Positive tracer hits of organic tracers injected in upper and lower zones of ER-6-1 are reported from depth-discrete samples taken in ER-6-1 \#1 either during or after the tracer test. Positive hits are not expected from tracers (I and 2,4,5-TFBA) injected in the lower zone of ER-6-1.

\section{Response:}

A high uncertainty is associated with the reported concentrations of 2,4,5-TFBA in the depth-discrete samples from ER-6-1 \#1. The values are close to the detection limit, and interfering chromatographic peaks are present in most of the analyses. This is not the case for the approximate $100 \mathrm{ppb}$ levels reported in the samples collected on September 2, 2004, from ER-6-1 \#1 at the depth of 1,880 ft.

\section{A.1.4 Wellhead Sampling}

As described in the report, a subset of samples was collected and sent to UNLV-HRC for analysis of the FBA tracers. A comparison between the UNLV-HRC results and those of the field analyses for this subset of samples is shown in the following plots.

\section{2,4,5-TFBA}

The field results are quite consistent with those of the UNLV-HRC laboratory for 2,4,5-TFBA as shown in Figure A.1-1. 


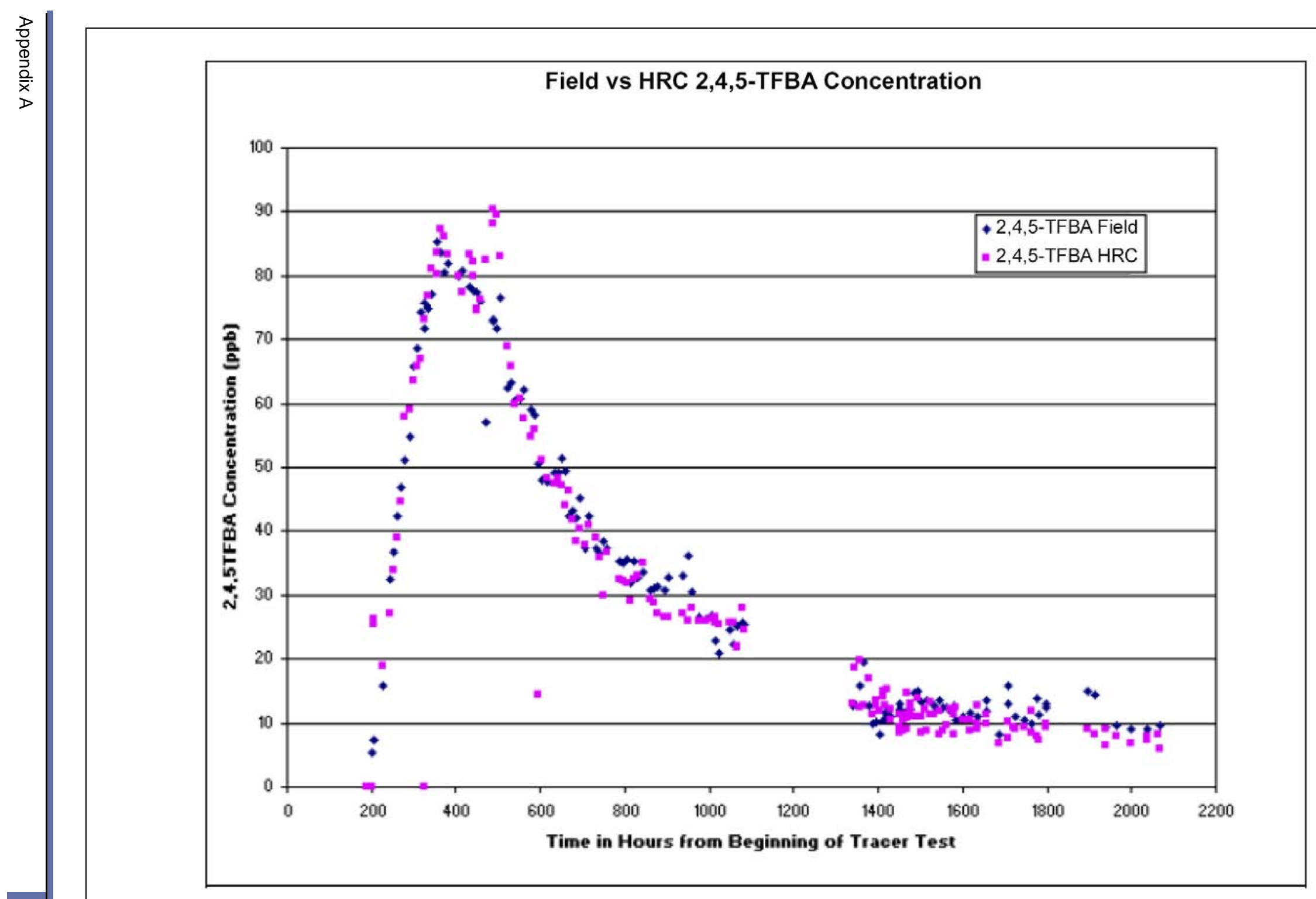

Figure A.1-1

2,4,5-TFBA 


\section{2,5-DFBA}

The concentrations or 2,5-DFBA along with a trend line calculated as the moving average of 20 samples is shown in Figure A.1-2. Although the field results tend to be greater than those of the UNLV-HRC laboratory for 2,5-DFBA, the trend is rather similar. The differences observed are likely due to two factors. First, the range of calibration standards used by UNLV-HRC (10, 25, 50, and $100 \mathrm{ppb}$ ) was different that for the field analyses (10, 25, 50, 100 and $200 \mathrm{ppb})$. The concentrations of 2,5-DFBA in the samples tend to be between the two lowest standards (10 and $25 \mathrm{ppb})$. The greater concentration standard used for the field analyses may result in a slight shift in the slope of the least square regression line (calibration curve) compared to that of UNLV-HRC and thus result in slightly greater overall measured concentrations. Next, the measured concentrations in these samples are relatively close to the analytical detection limit of approximately $5 \mathrm{ppb}$. The greater variability observed in these data likely reflect the close to detection limit analyses. The comparison of the two breakthrough curves likely reflects the actual uncertainties in the measured concentration of 2,5-DFBA.

\section{PFBA}

The concentrations of PFBA along with a trend line calculated as the moving average of 20 samples are shown in Figure A.1-3 for the UNLV-HRC and field analytical results. Similar to the results of 2,5-DFBA, the PFBA concentrations measured in the field tend to be greater than those of the UNLV-HRC laboratory and again the trend is rather similar. This can be attributed to the same factors as described above for 2,5-DFBA. Although the detection limits for PFBA and 2,5-DFBA are quite similar (approximately 5 ppb), the chromatographic peak for PFBA is more symmetrical.

Quantitation based on the more symmetrical peak is more reproducible and therefore results in less variability in the measured concentrations. 


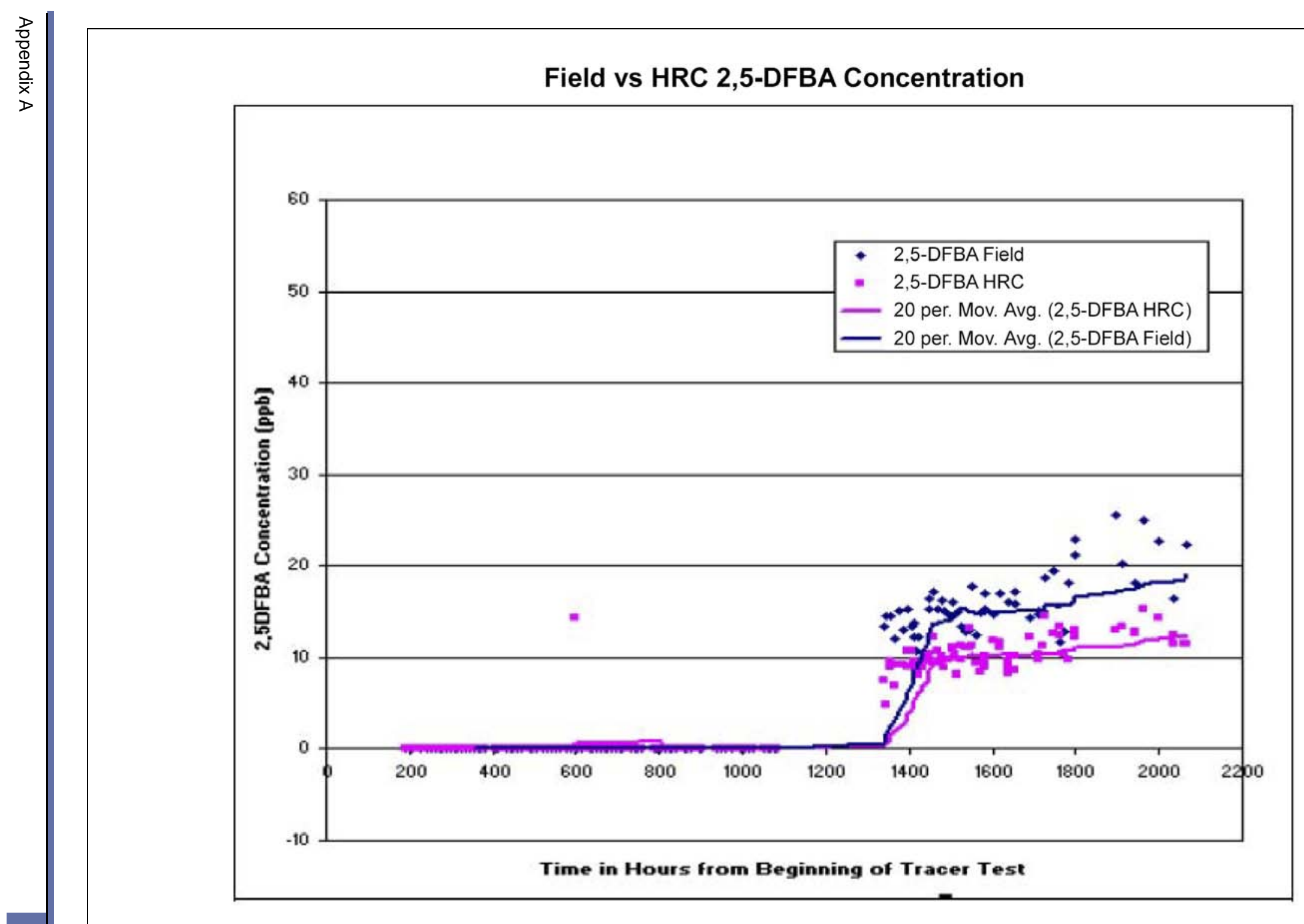

Figure A.1-2 2,5-DFBA 


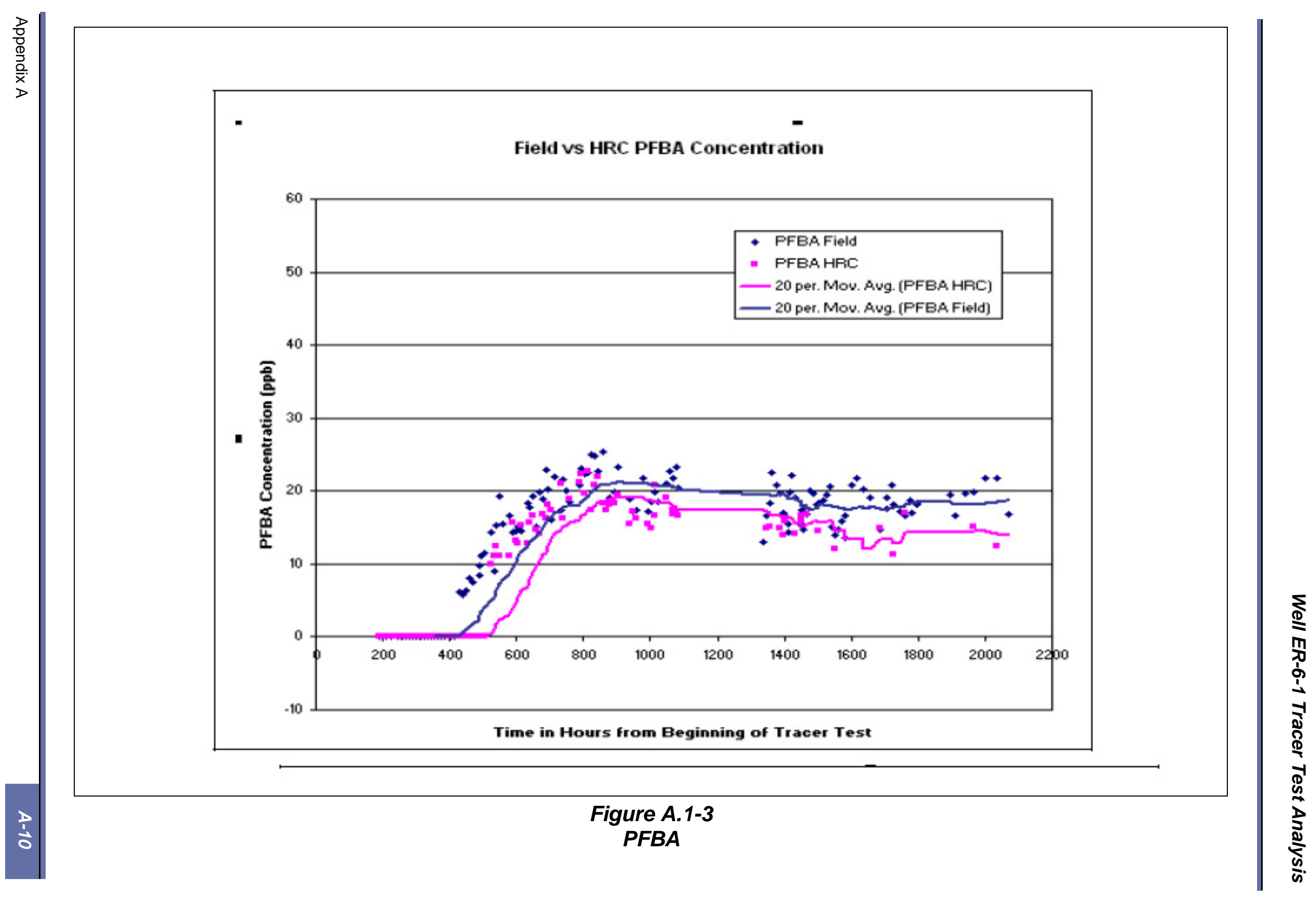

Uncontrolled When Printed 


\section{A.2.0 REFERENES}

Stoller-Navarro Joint Venture. 2005. Written communication. Subject: ER-6-1 Well Cluster Multiple Well Aquifer Test - Tracer Test Data Report, Volumes I, II, and III, Rev. 0. Las Vegas, NV. 
Appendix B

Power-Plane Code 


\section{B.1.0 DEscription of POWER-PLANe TECHNIQUe AND THE C CODE X-POWER}

The pilot-point technique is widely used in hydrogeological practice to characterize medium heterogeneity (e.g., Lavenue et al., 1995). However, it has limited capability to define pronounced linear features such as faults and fractures within a simulated domain. An extension of the method that incorporates additional structural features is presented here called "power planes."

Power planes are 3-D surfaces within the domain that define zones of different medium properties. The planes can be defined either as deterministic features, or as a series of power points distributed along the plane and are included in the kriging process similar to the regular power points. Spatial distribution of the pilot points along the plane should by at a resolution comparable with the resolution at which medium heterogeneity is resolved in the applied stochastic process. In the current work, the first approach (deterministic features) was applied, which is computationally simpler and generally produces similar results.

A definition of the power planes within the medium is performed using the $\mathrm{C}$ code $\mathrm{X}$-power (Section B.2.0). The code also allows definition of deterministic power lines (2-D equivalent of power planes) as well deterministic power points. The power planes are defined by 3-D coordinates of three arbitrary points located along each plane.

The code reads as input the FEHM coordinate file and a respective kriged field associated with each node of the FEHM grid. The Gstat code (Utrech University, 2006) is used to krige the permeability field before the execution of X-Power. X-Power produces as an output a new output file that has similar structure to the input kriged field. However, the kriged field is modified based on a series of user-defined deterministic features (points, lines, planes). The code can also modify the kriged field using spatial trends of different orders (0th, 1st or 2nd); however, this feature was not used in the current work. 
In addition of the spatial location, each of the power planes are characterized with four additional attributes. These attributes define how the medium properties are modified in the vicinity of each power plane. In the order they are read by the code, the attributes are defined as: (1) power exponent, (2) range, (3) magnitude, and (4) distance scale. "Range” defines the thickness of the power plane. "Magnitude" defines the medium properties within the power plane strip, which takes into account the plane thickness. If needed, smooth transition outside the power plane range. Thus, the distance scale defines a scaling factor of distances outside the power plane. "Power" defines an exponent at which the transition decays reversely proportional with the distance. In the current work, transition regions have not been incorporated, and these parameters are set equal to zero. 


\section{B.2.0 C CODE X-POWER}

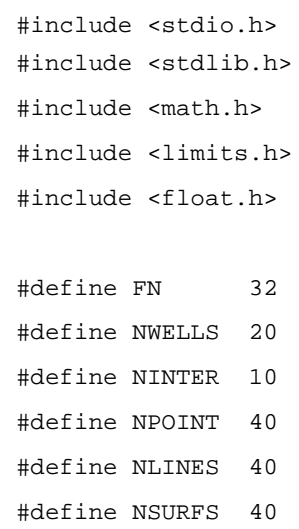


if $(\operatorname{nDim}>=1)\{\operatorname{printf}(" \operatorname{order} 1: ")$; $\operatorname{scanf}(" \% f \% f \% f ", \& b[0], \& b[1], \& b[2]) ;\}$

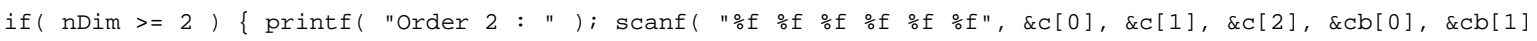
$\& c b[2]) ;\}$

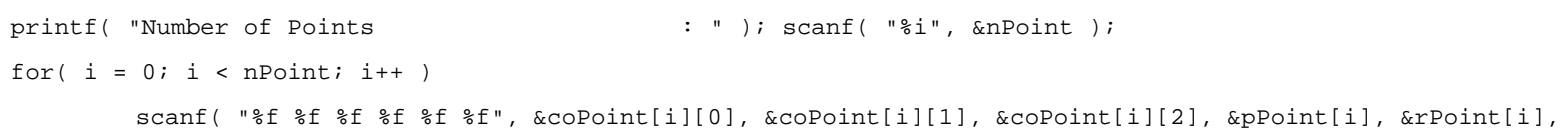




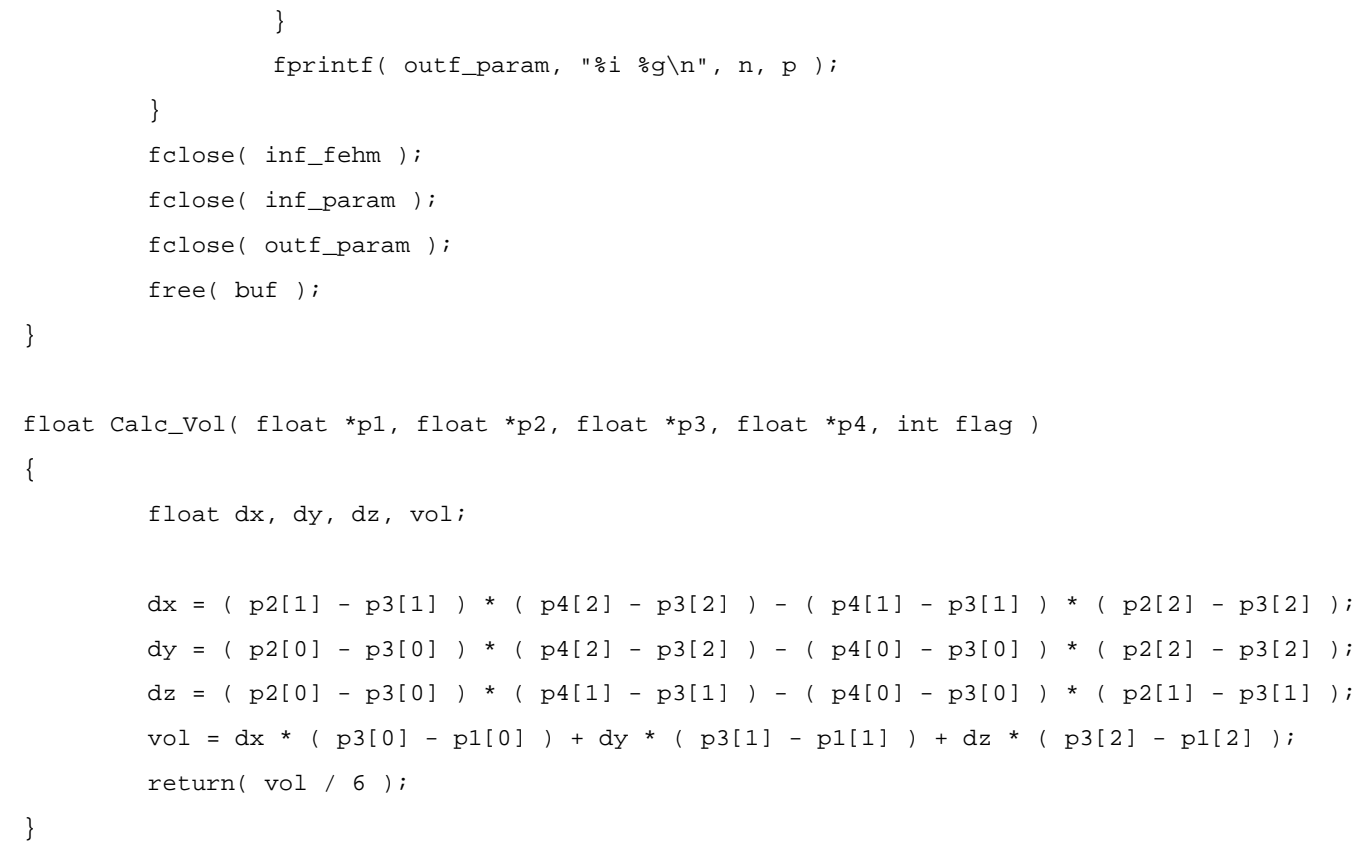




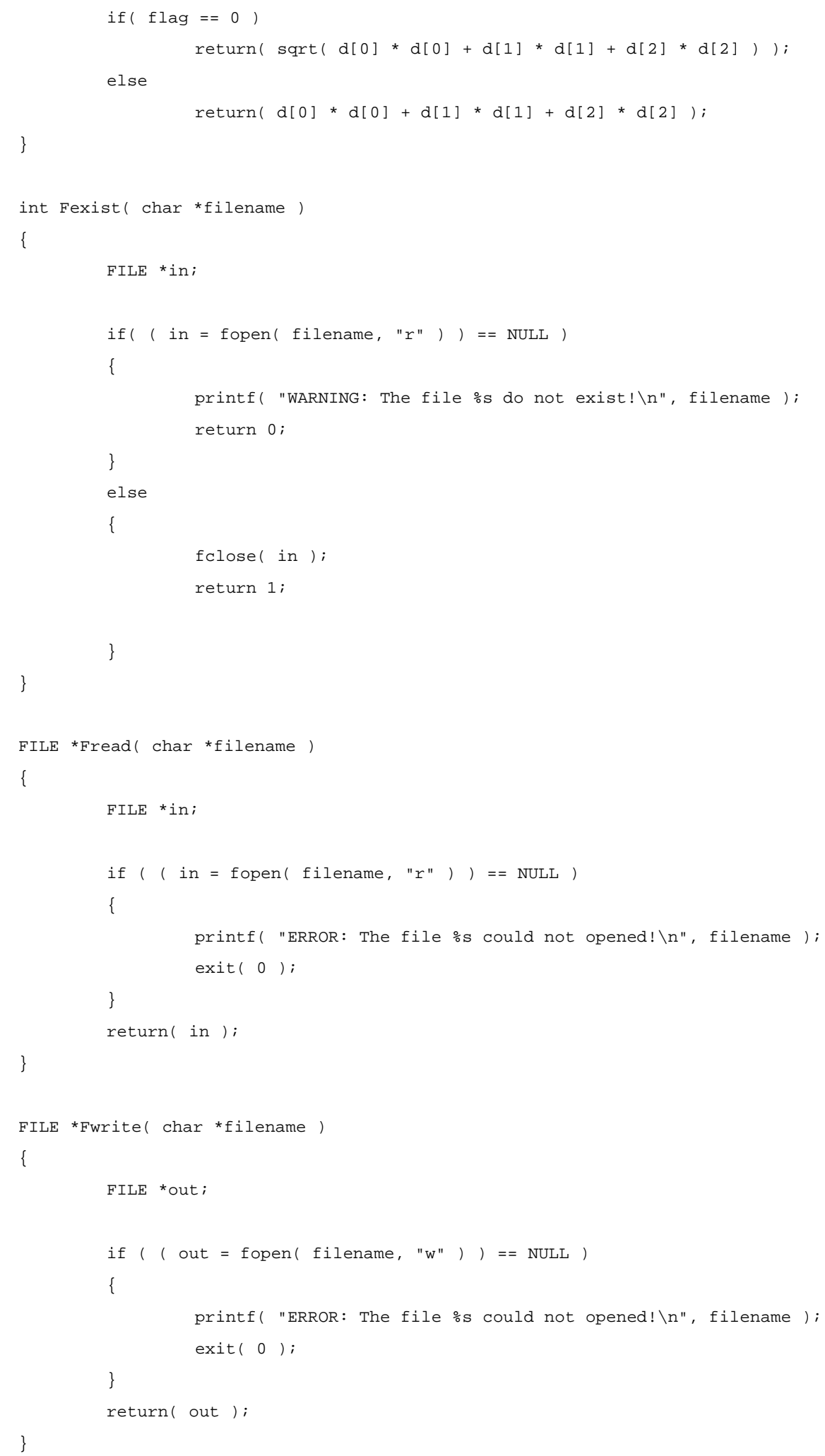




\section{B.3.0 REFERENCES}

LaVenue, A.M., B.S. RamaRao, and G. de Marsily. 1995. "Pilot Point Methodology for Automated Calibration of Condionally Simulated Transmissivity Fields." In Water Resources Research, v. 31(3): 495-516.

Utrech University. 2006. Gstat Code. As accessed at "http//:www.gstat.org” on 6 June. The Netherlands. 


\section{DISTRIBUTION}

Bill R. Wilborn

Environmental Restoration Division

U.S. Department of Energy

National Nuclear Security Administration

Nevada Site Office

P.O. Box 98518, MS/505

Las Vegas, NV 89193-8518

Alicia Tauber

Environmental Management Records

U.S. Department of Energy

National Nuclear Security Administration

Nevada Site Office

P.O. Box 98518, MS/505

Las Vegas, NV 89193-8518

U.S. Department of Energy

National Nuclear Security Administration

Nevada Site Office

Technical Library

P.O. Box 98518, M/S 505

Las Vegas, NV 89193-8518

Naomi Becker

Los Alamos National Laboratory, M/S F665

Bikini Atoll Rd., SM30

Los Alamos, NM 87545

P. W. Reimus

Los Alamos National Laboratory, M/S J534

Bikini Atoll Rd., SM30

Los Alamos, NM 87545

Gayle Pawloski

Lawrence Livermore National Laboratory

7000 East Avenue, L-221

Livermore, CA 94550-9234

Mavrik Zavarin

$1 \mathrm{CD}$
$2 \mathrm{HC} / 2 \mathrm{CD}$

$1 \mathrm{HC} / 1 \mathrm{CD}$

Lawrence Livermore National Laboratory

7000 East Avenue, L-221

Livermore, CA 94550-9234 
R. M. Maxwell

$1 \mathrm{CD}$

Lawrence Livermore National Laboratory

7000 East Avenue, L-208

Livermore, CA 94550-9234

Bonnie Thompson

$1 \mathrm{CD}$

U. S. Geological Survey

160 North Stephanie Street

Henderson, NV 89074

R. P. Graves

$1 \mathrm{CD}$

U. S. Geological Survey

160 North Stephanie Street

Henderson, NV 89074

Chuck E. Russell

$1 \mathrm{CD}$

Desert Research Institute

755 E. Flamingo

Las Vegas, NV 89119

Ken Ortego

$1 \mathrm{CD}$

National Security Technologies

P.O. Box 98521, M/S NLV 082

Las Vegas, NV 89193-8521

Sig Drellack

$1 \mathrm{HC}$

Bechtel Nevada

P.O. Box 98521, M/SNLV082

Las Vegas, Nevada 89193-8521

John P. McCord

$1 \mathrm{HC}$

Stoller-Navarro Joint Venture

7710 W. Cheyenne, Bldg. 3

Las Vegas, NV 89129

Irene Farnham

$1 \mathrm{HC}$

Stoller-Navarro Joint Venture

7710 W. Cheyenne, Bldg. 3

Las Vegas, NV 89129

Greg Pohll

$1 \mathrm{HC}$

Desert Research Institute

2215 Raggio Parkway

Reno, NV 89512 
Paul Reimus

Los Alamos National Laboratory

Bikini Atoll Rd., SM30

Drop Pt. 48 RC1015

Los, Alamos, NM 87545

Greg Ruskauff

Stoller-Navarro Joint Venture

7710 W. Cheyenne, Bldg. 3

Las Vegas, NV 89129

Stoller-Navarro Joint Venture

Central Files

7710 W. Cheyenne, Bldg. 3

Las Vegas, NV 89129
$1 \mathrm{HC}$

$1 \mathrm{HC}$

$1 \mathrm{HC}$ 